\title{
ARCHITECTURE OF THE ATHLETE
}

By

Jared Zivkovic

A 120-point thesis

Submitted to the Victoria University of Wellington

in partial fulfillment of the requirements for the

degree of Master of Architecture (Professional)

Victoria University of Wellington

School of Architecture

2017 

Thank you to all that have supported me on this journey.

A Special Thanks to:

My Parents, Jessica Hunter-Wilson, Tane Moleta, and the team at Capital Sports Performance 


\section{ABSTRACT}

Designers of sports facilities focus on physical aspects, like walls and tile angles to improve an athlete's performance. However, from experience, the mental components of an athlete's performance are overlooked; which is believed to have a greater impact on their overall performance.

Using my experiences to produce a unique body of research, this thesis focusses on using the athlete's perspective to design. This thesis investigates Sporting Facilities and Natatoriums are the focus. Using the skill of architects to create space and affect emotion, the thesis will investigate how they can be used to create an atmosphere that will allow an athlete to enter the optima emotional state to achieve a successful sporting performance.

The research will look the emotion and atmosphere of architecture, and the knowledge of sports psychology to understand how atmosphere can be used to challenge current design conventions.

The approach will look at the relationship of facilities with and without local community involvement when they are not being used for competitions. This allows the needs of the community which has an effect upon the design, to be controlled. Which allows for an athlete's perspective to drive the design.

Using Natatoriums as the focus of the thesis, a series of design investigations will be conducted looking at how these spaces can be developed and arranged to optimise athlete performance. Objectives are to understand the arrangement of program and atmosphere required at each stage of an athlete's precompetition process, so a facility can be developed that is biased towards an athlete's mental state versus other design factors. 


\section{CONTENTS}

\begin{tabular}{|c|c|c|}
\hline Abstract & vii & Project 2 Design Conclusions \\
\hline Contents & ix & Project 3 The HIGH Performance Centre \\
\hline My Motivation & xi & Project 3 Introduction \\
\hline Introduction & 1 & Motivation Re-evaluation \\
\hline Research Question & 6 & Design Response \\
\hline Scope of Research & 7 & Project 3 Design Conclusions \\
\hline Research & 11 & Final Conclusion \\
\hline The Mechanics of a Natatorium & 17 & Bibliography \\
\hline The components & 19 & List of Figures \\
\hline Survey Results & 30 & Appendices \\
\hline Conclusion Of precedents & 31 & Appendix 1 \\
\hline Project 1 The ATHLETE & 33 & Appendix 2 \\
\hline Project 1 Introduction & 35 & Appendix 3 \\
\hline Project 1 Design Conclusions & 71 & \\
\hline Project 2 THE SPECTATOR AND PUBLIC & 73 & \\
\hline Project 2 Introduction & 75 & \\
\hline The Site & 77 & \\
\hline Design Response & 85 & \\
\hline
\end{tabular}





\section{MY MOTIVATION}

My desire to undertake this thesis came from two areas. I have a professional involvement at a major Aquatic Facility in New Zealand and secondly, my active interest in competing at a national and international level of triathlon.

While completing this thesis, I represented New Zealand at the Triathlon Age Group World Championships in Chicago. Additionally, I worked as a Senior Lifeguard at the Wellington Regional Aquatic Centre. I am passionate about, and have been involved in a number of sports from a young age.

I am driven to pursue this line of research because of my passion for architecture. I want to learn what it takes for an elite or professional level athlete to strive for, and reach their 'peak performance'. Therefore, I am not looking at sport through architecture which the majority of international facilities appear to do, but rather and perhaps more importantly, pursuing what architecture is, through the lens of sport.

Looking at architecture through a lens of sport, will allow me to see new insights on how sporting facilities operate and allow new design opportunities to be investigated. 



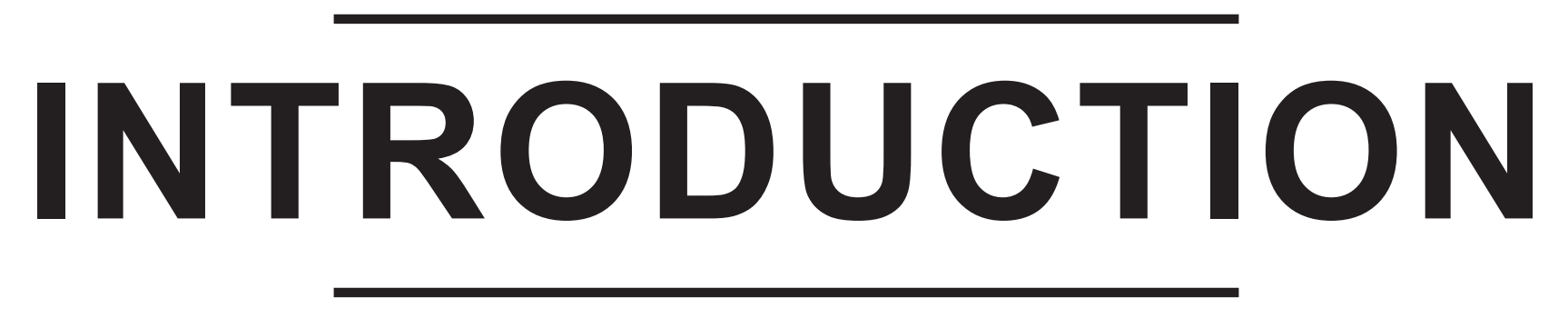


"When you reach that elite level, 90 percent is mental and 10 percent is physical.

You are competing against yourself.

Not against the other athlete."

Dick Fosbury (Michael, 2006) 


\section{SPORTS AND ARCHITECTURE}

The Olympic Games and other significant sporting events around the world; like the Football World Cup, all play big roles in showing us how sport and architecture have a combined role to inspire people to achieve great things. Many great sporting events are held indoors, and sport and architecture have worked alongside each other for many generations. This has resulted in the development of unique and interesting structures that form training facilities and stadiums. I propose that these have a role in facilitating peak performance in athletes.

Facilities to develop sport are becoming key social elements within communities at both an urban and local scale. Integration of sport and architecture has stemmed from a need for facilities that allow players, and even more so, allow spectators to experience a match or competition with incredible (or increasing) participation. "At present, and with increasing frequency, sporting activities are giving rise to a multiplicity of infrastructure designed for practicing and enjoying sports, many directly related to the increasing professionalism." (Broto, 2005)

Architecture and sport are not confined to the dreamy heights of the professional realm; the amateur realm of sport should be considered as well. "The increasing visibility of sport in society is creating a more 'domestic' need for the various small-scale sports spaces that can respond to the leisure needs of its citizens of all ages and descriptions" (Broto, 2005). From a small sporting field, to a community swimming pool; facilities in the local community have a fundamental role of allowing people to keep fit and enjoy an activity, sport, or competition that they love. 


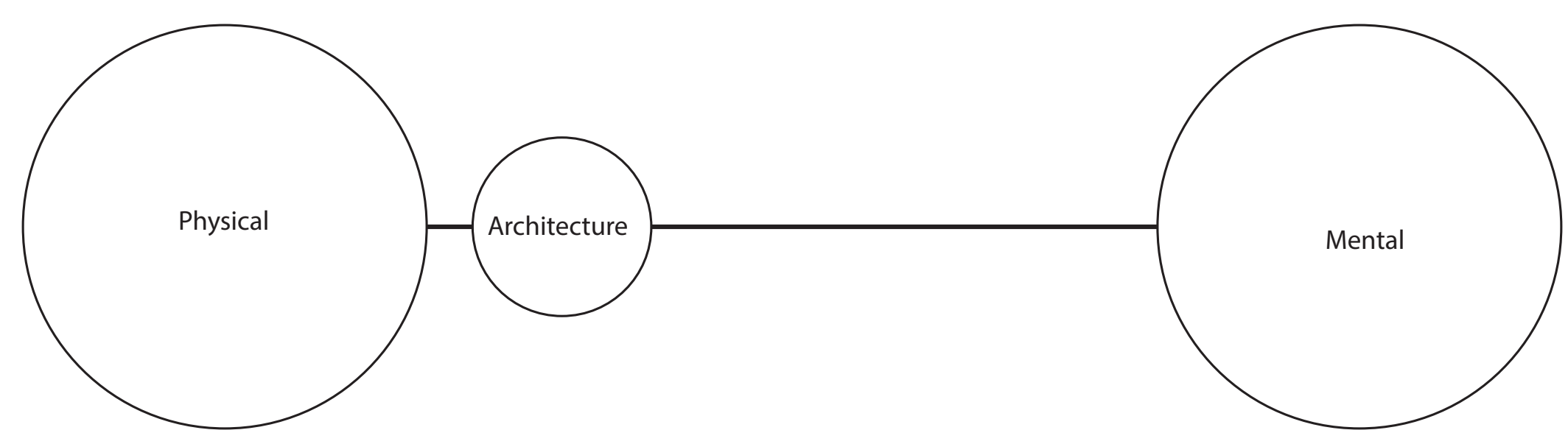

Fig. 6 : Current Facilities, diagram of Physical focus vs Mental Focus of a facility

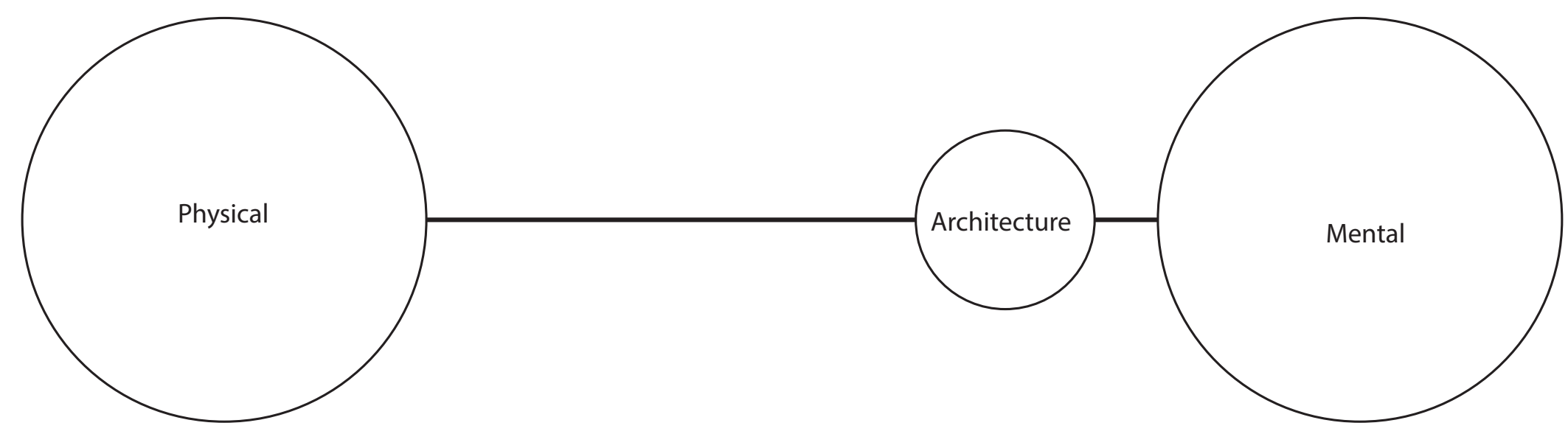

Fig. 7 : Intended Design Result, diagram of Physical focus vs Mental Focus of a facility 


\title{
PROBLEM STATEMENT
}

\author{
Reaching an Olympic Level of any sport is the pinnacle. It is the \\ dream of the highest performing athletes to represent their \\ country at the highest level. In relation to high-level sporting \\ events, some of the most avant-garde architecture is also purpose \\ built for these events. \\ The idea being explored in this thesis is not how or what make \\ these areas of design in architecture what they are, but how the \\ architecture impacts on the athlete him or herself. \\ When a high performance facility is designed, physical aspects \\ are analysed; for example, the pool depth and angle of the \\ pool wall tiles; or what will benefit the community they plan to \\ provide for. What designers fail to look at are the mental aspects \\ of sports. Despite this, it is believed that the mental aspects of \\ sport have a greater impact on an athlete's overall performance. \\ The difference between the top elite athlete's is not generally \\ about physical ability, but how 'in tune' mentally they are.
}




\section{RESEARCH QUESTION}

The aim of this research is to understand how a high-performance sports facility can be designed in a way that best supports an athlete's mental experience and ultimately inform the way that they perform as an athlete.

I propose in this research that the way an athlete experiences a building as they approach a situation, event, or training activity, may result in different outcomes. Placing an emphasis on the athlete as the priority in design situations, should yield results that are more in favour of higher athletic performances.

Using my professional experience in guiding and marshalling international sporting events, as well as my personal experiences competing as an athlete, I wish to design from this perspective and explore the corresponding architectural outcomes.

As designers, the emotive qualities of what we design play a significant role in the way people interpret or experience a building or piece of architecture.

The fundamental question this research asks is: can the emotive quality of architecture and the experience of an architecturally designed building, be reflected in how an athlete experiences the space and therefore, improve their performance? 


\section{SCOPE OF RESEARCH}

The project will delve deeper into the emotive qualities of architecture and how they can improve an athlete's performance.

The idea of the "High-Performance Aquatic Facility" will be analysed. I have chosen swimming as a way of narrowing the scope of my project. For an aquatic facility to be deemed appropriate to host top-level events, there is a vast criterion of requirements that must be met, in order. But these requirements and traditional design aspects of a facility focus on three main factors: spectators, pool requirements, and a physical aspect, to make an athlete perform at a high level.

By looking at an aquatic facility, the series of events that an athlete goes through in the build up to a training session or event can be narrowed down to a specific moment or experience that influences a result or performance. 
My Motivation

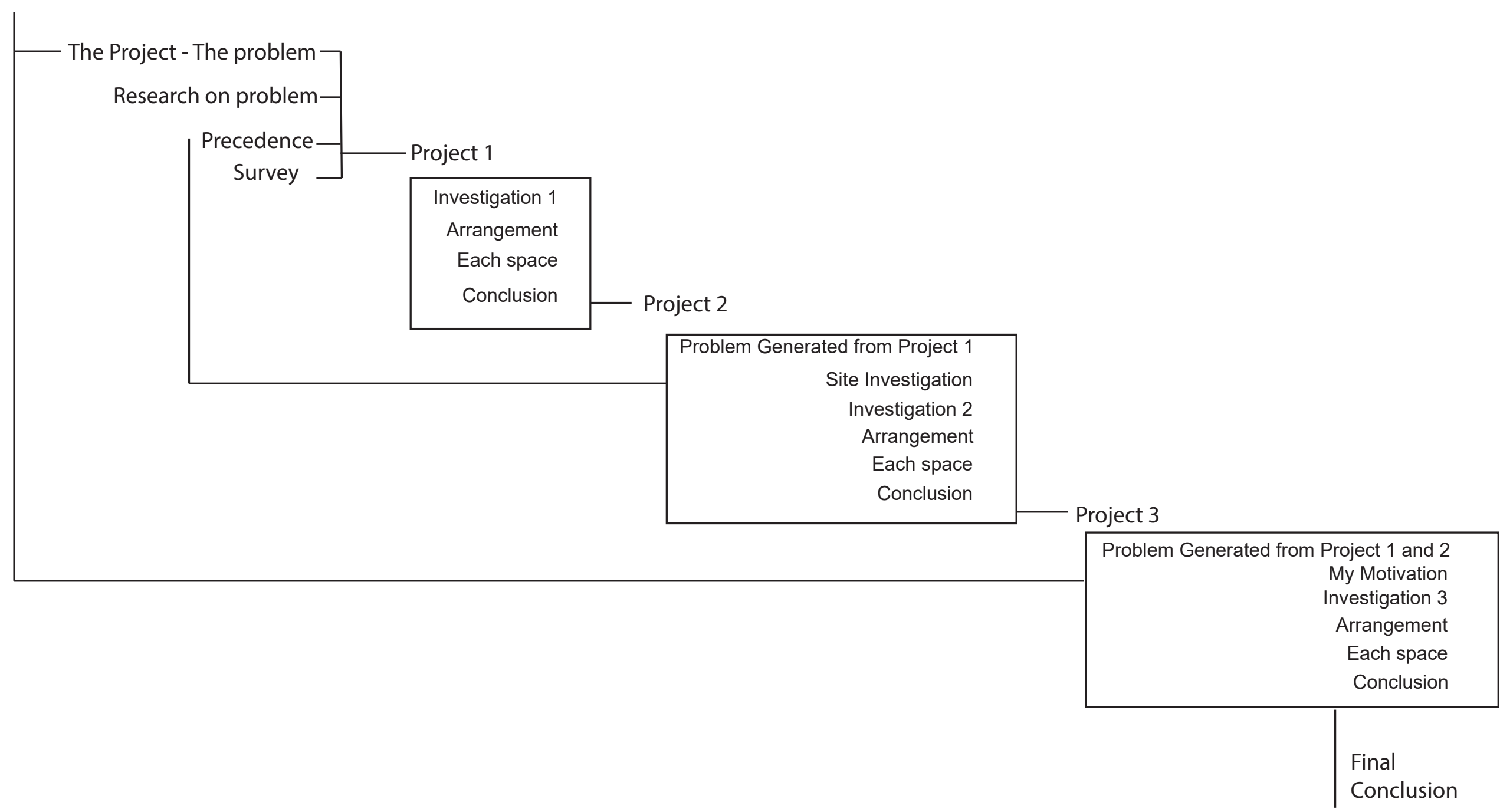




\section{DESIGN PROCESS}

Design Methods and Process

My method/ process

1. Looked at sports facilities

2. Select a sport - Swimming

3. Research the swimming facilities - How do they work/ move the Athlete's through the space vs spectators

4. Looked at ways in which design hand books suggest to design facilities

5. Look at the meaning of how space can affect a body

6. How does the emotive state of an athlete affect them.

7. What do athlete's see when competing?

8. Design to understand this process - Project One

9. Reflect on Design

10. Incorporate into a site and add the effects of spectators and their needs to the building, grass roots and general operations

11. Design and reflect - Project Two

12. Reflect and build a new brief

13. Project 3 focuses on how a true high performance facility does not just focus purely on one sport, but allows multiple sports to learn and adapt from each other Therefore, how do they all work together. 


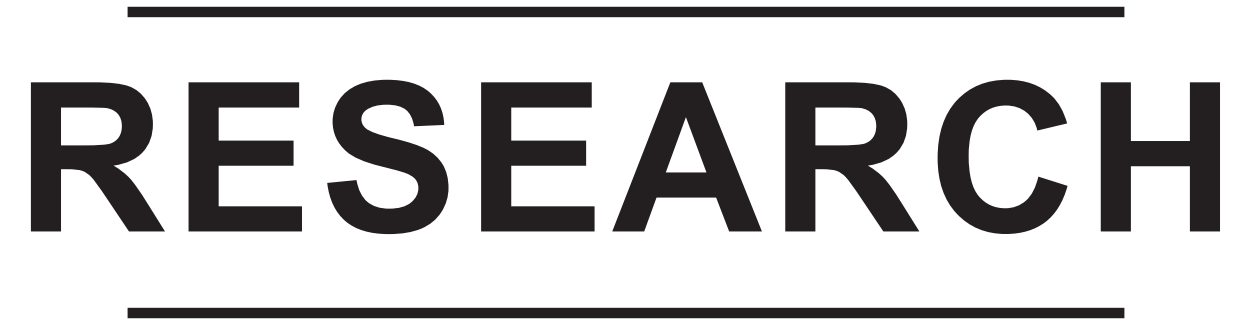


Fig. 9 : Crematorium Baumschulenweg by Shultes Frank Architeckten. Mattias Hamren
Fig. 10 Bath De Vaals by Peter Zumthor. Helene Binet 
Sport and Architecture have been combined to create some impressive structures. Although these structures have hosted and created some defining moments in sporting history, they are commonly focused on how a spectator perceives or experiences the event or their overall view of the stadium.

Discussion in this research does not consider how the spectator experiences the atmosphere of a sporting complex, but consider how the same architectural methods to create a spectator's experience, can be used to create a spectacular atmosphere that will improve an athlete's performance by taking the focus off the spectator.

In architecture, emotion is related to, or discussed when considering a space, project, or a moment. Architects use atmosphere and space to generate emotion in the body. (PALLASMAA, 2014) There are various discussions on atmosphere and how it relates to the body.

In the article 'Affective Atmosphere', by Ben Anderson, he discusses the word 'atmosphere'. He states that "the word atmosphere is used interchangeably with mood, feeling ambiance, tone and other ways of naming collective affects" (Anderson, 2009). Atmosphere is described as "ambiguous."

Anderson begins the article by discussing Karl Marx' address in London on the 14th April 1856. The speech, as described by Anderson; "invokes a certain 'revolutionary atmosphere' of crisis, danger and hope." He highlights a certain passage that Marx stated about atmosphere, "...the atmosphere in which we live, weighs upon everyone with a 20,000-pound force, but do you feel it?" Anderson uses this statement to help him describe atmosphere and the effect it has on people.

"Marx's comments hint to the ambivalent status of atmosphere. On one hand, atmospheres are real phenomena. They envelop and thus press on society from all sides with a certain, but unknown force. On the other, they are not necessarily sensible phenomena... Nevertheless, atmosphere still effect with a certain force - albeit in a way that maybe only tangentially relates to the subject." (Anderson, 2009)

Anderson points out that although atmosphere surrounds us, the person or subject entering the space is affected by atmosphere in their own personal way Therefore "Atmospheres are the shared ground from which subjective states and their attendant feelings and emotions emerge" (Anderson, 2009)

Using this understanding of atmosphere, lends itself well to understanding how sports complexes can use these ideas to create space that allow different emotions to emerge through an athlete's journey. Although the athlete is not there to admire the space created (i.e. they do not watch the event), the space needs to subconsciously impact the athlete. This leads back to Anderson's first comment on Karl Marx's speech about atmosphere. It is described as "pushing down" on the person and that this approach is needed, so that there is an effect on an athlete's specific emotions.

Material, light, and form are used to generate an architectura atmosphere. Two examplesaretheCrematorium Baumschulenweg by Shultes Frank Architeckten (fig. 9) and Bath De Vals by Pete Zumthor (fig. 10). Both spaces use material and light to create emotion. One is peace and describing life and death, and the other creates a meditative and relaxing environment.

It has been discussed that emotion is used in architecture through atmosphere to generate an experience of the space.

The emotional state of an athlete before, during, and after an event will determine their performance output. An athlete's mental space is something that is personal to them, and their state of emotion will influence their performance output. This is called the Individual Zone of Optimal Functioning (IZOF). (Hanin, 2007)

Understanding of the IZOF is continually developing and is based on emotional intensities.

The theory that levels of anxiety affect an athletic performance, is becoming redundant as the "prediction of athletic performance should be based on multiple pleasant and unpleasant emotions rather than only on pre-competition anxiety" (Hanin, 2007). Sport psychologists and athletes are able to understand how anxiety can affect performance and that an increase in self-confidence can help to overcome anxiety. (Lynette L. Craft, 2003) 


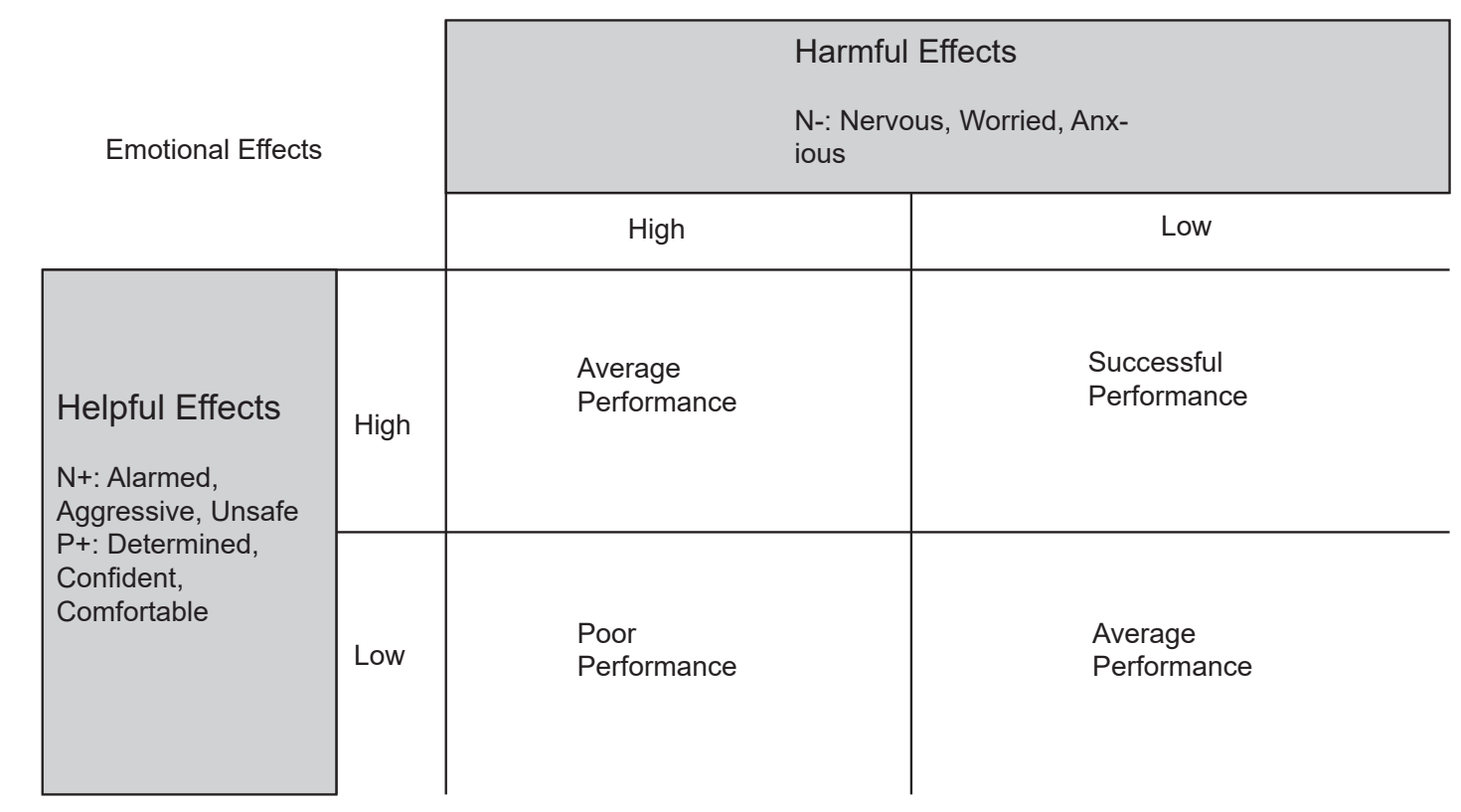

Fig. 11 : Interactive effects of enhancing and harmful emotions. Adapted from: Hanin, Y. L. (2007). Emotions in Sport. In R. C. Gershon Tenenbaum, Handbook of Sport Psycology (pp. 38-57). Hoboken: John Wiley and Son Inc. 
The developed approach by sport psychologists now look at the impact of two emotional states; the type of emotion, and the intensity of emotion that an athlete has pre-event and how these are predictors of performance.

These emotional states not only come from the sport themselves, but also from outside influences. Studies carried out with elite athletes in various sports describe three characteristics; successful or unsuccessful performance, what emotions were felt, and the intensity of each emotion.

First, the studies asked the athletes to rate their performance based on their past performances, to determine whether their performance was successful or not. A successful performance was determined by the outcome: winning or achieving the goals that they set was deemed a successful performance. (Hanin 2007)

Secondly, the athletes described all the emotions they felt before, during and after an event. They were asked to write down emotions as metaphors so that the researchers could better understand what the athlete was feeling at the time. It was found that pleasant emotions were detrimental to an athlete's performance, however, some unpleasant emotions had a surprisingly positive effect on their performance. (Hanin, 2007)

The third part, based on the athlete's metaphors, was to describe the intensity of their emotive feelings. It was found that an athlete experiences multiple feelings in the lead up to an event. This can be a result of situations and occurrences outside of the event, their underlying motivation to win also had an effect. Each of these feelings were recorded and assigned a different intensity; this allowed researchers and athletes to understand the intensity of different emotional experiences. (Hanin, 2007)

The researchers could categorise each emotion which allowed them to predict the athlete's performance. The following four categories were established to represent the pleasant and unpleasant emotions experienced. They were further broken down to describe whether these emotions are functionally optimal or dysfunctional:

Pleasant-functional $(\mathrm{P}+)$

Pleasant-dysfunctional (P-)
Unpleasant-functional $(\mathrm{N}+)$

Unpleasant-dysfunctional ( $\mathrm{N}-$ )

The level of the emotion in each category will relate to the performance of the athlete, as shown in figure 11. Greater intensity of emotion in a functional emotion meant a more successful performance.

Emotion in sport varies between individual athletes; how they control their emotions largely contributes to their overal performance. To perform optimally, most athletes have their own methods, rituals and/or routines. Therefore, the pre-event processes they go through to achieve the right emotional balance for their IZOP are different. A study looking at self-regulation and athletic performance showed that the athletes who consciously used methods to enter the IZOP pre-competition improved their performance. (Claudio Robazza, 2004)

This is where I believe the skill set of an architect can improve an athlete's performance; by understanding how an atmosphere can impact an individual's emotion and therefore, affect thei overall performance. It should be reinforced that each athlete is different and each person is affected by atmosphere differently. An architect can use their knowledge base and skill set not to create an emotionally neutral space, but a space that can allow each individual athlete to optimise their emotions to have improved overall performance. 


\section{THE MECHANICS OF A NATATORIUM}




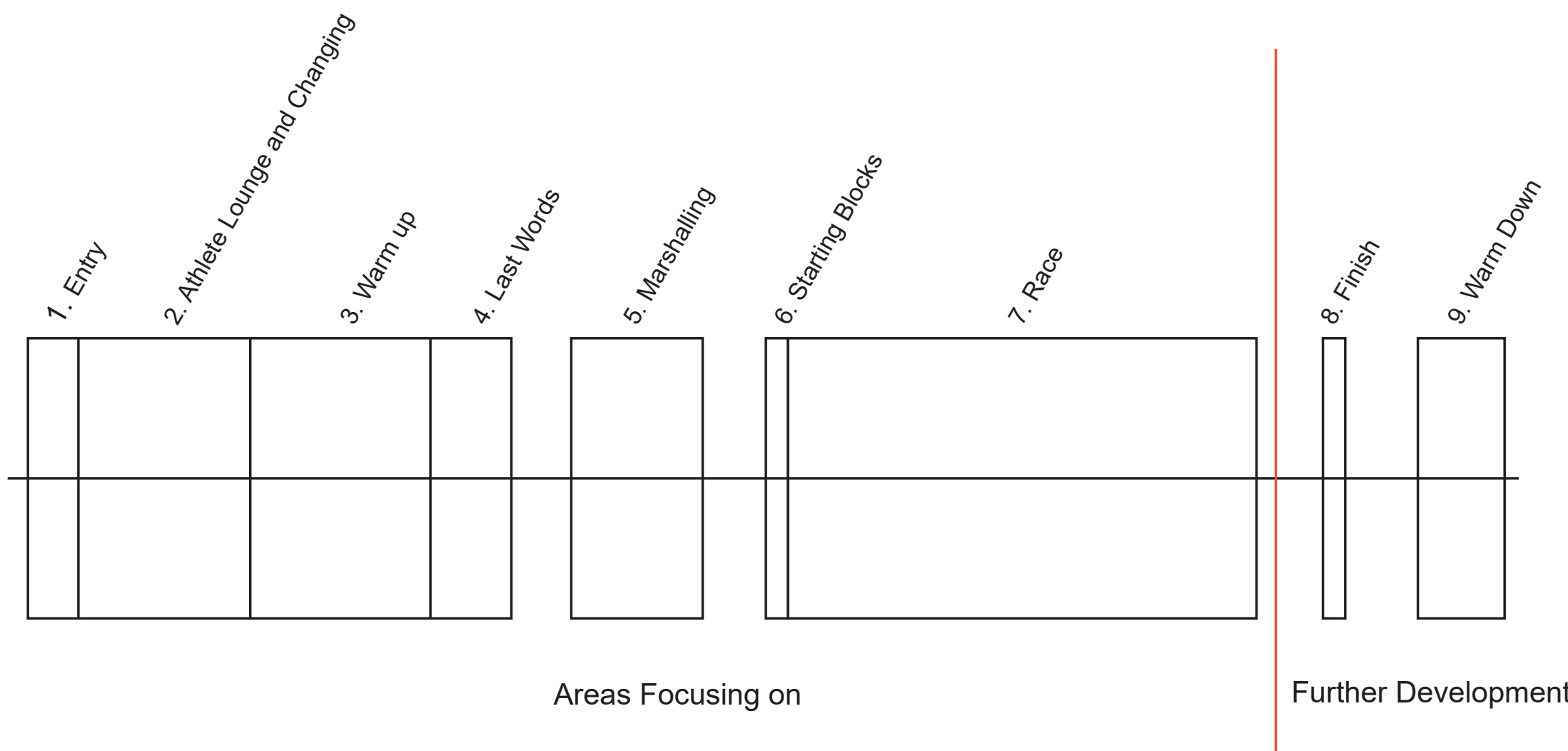

Fig. 12 Athlete's Process Timeline 


\section{THE COMPONENTS}

The natatorium or aquatics facility is made up of various components that come together to provide an experience. In order to focus on the athlete, we need to learn how they would prepare for a race; including key moments and spaces they encounter, rather than focussing on the main $50 \mathrm{~m}$ pool that they do the race in.

\section{Approaching and entering a building}

Depending on the scale of the event and how the event is run at most regional and national swim competitions the athlete would enter through the same main door as the spectators. At World Championships and Olympic Level events, the entry point is separate for the athletes. This is private and excluded from the public but still accessible by vehicle. They can enter the building straight from the vehicle.

\section{Athlete's Lounge and changing}

Although regional events and some national events do not have an Athlete's Lounge or changing area, for international events this area allows the athletes to relax between races or events. It also allows for dry-land warm-ups and the athletes can remain separate from the public.

This area needs easy access to the Changing Rooms, Warm Up Pool, Main Competition Pool, Hall, and Stands. This allows them to easily watch races and be involved with the crowd if they want

\section{Warm up/down pool area}

The warm-up and cool-down area is one of the most important areas in the whole facility as this is where the athletes 'warm-up' their muscles and body for the race. This pool is generally shorter and not as deep as the Main Competition Pool. They can practice their stroke one last time and start feeling mentally comfortable. Without this part of the process, an athlete can damage their body and not race to their 'peak performance'.

There should be plenty of space around the outside edge for dryland exercises.

\section{Marshalling}

This room is where the athletes go just before they race. This is where they are organised by a 'marshal' into their 'swim heats'. It is also a calm area where the athletes do their final mental preparation for the race. There tends to be a lot of 'waiting' in this room.

\section{Competition Pool Hall}

The Competition Pool is housed within the Main Pool Hall; this is where the race happens. This area will generally be the main part of the swimming complex. The Pool Hall is generally large and rectangular in shape, as well as being tall, bright and full of people, light and equipment.

The Olympic Swimming Pool is a 50 metre $(\mathrm{m})$ by $25 \mathrm{~m}$ pool and is at an optimal depth of $3 \mathrm{~m}$ to reduce under currents that may affect swimmers times. The pool can sometimes be a few metres longer and a pool divider can then be used to shorten the pools to create a $25 \mathrm{~m}$ pool or Dive Pool for specific events. This component of the facility design is regulated by the Swimming's Governing Body FINA (Federation Internationale De Natation) and these regulations and dimensions are consistent 


\section{PRECEDENTS}

The role of precedents allows me to compare and contrast my designs against a standard set. The pools I have considered are pools that have held national and international events in Australia and New Zealand.

I have judged them on some chosen factors and used them throughout the design phases to refer to and critique my own work.

The factors are:

- $\quad$ Role of the facility

- The layout of the program

- The overall design of the facility

- Elements of interest 


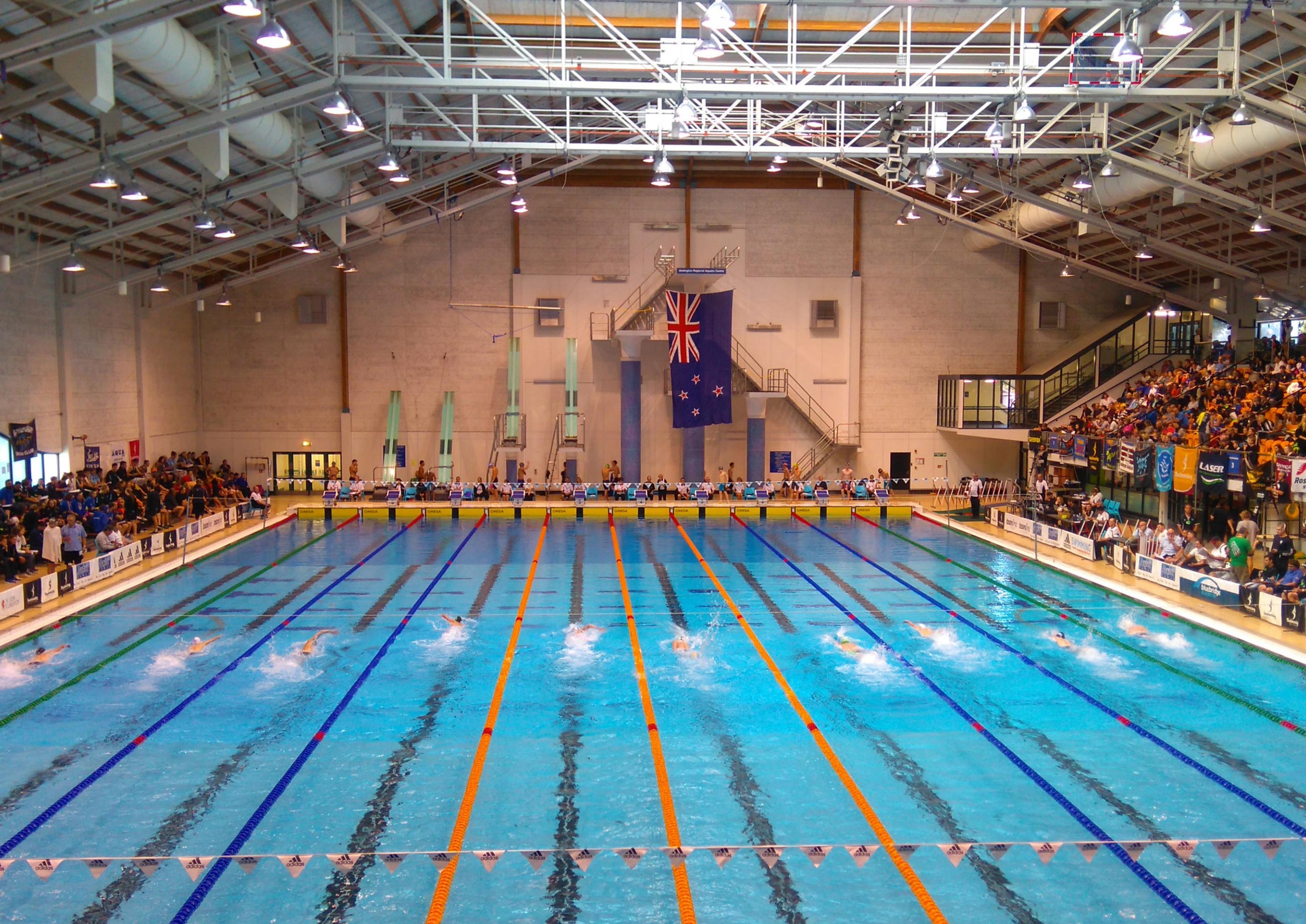




\section{Wellington Regional Aquatic Centre}

Wellington Regional Aquatic Centre (WRAC) is Wellington's largest swimming facility that hosts local, national and international swimming and diving events. At the heart of the building is the Main Pool; a $50 \mathrm{~m}$ by $25 \mathrm{~m}$ pool designed for swimming events. It is split into three depths; $1.2 \mathrm{~m}, 2 \mathrm{~m}$, and $5 \mathrm{~m}$ for dive competitions and community programs as well.

The facility is also for community use; it has a Children's Recreational Pool; Learn to Swim Pool (which is also the Warm-Up Pool); Hydrotherapy Pool (also used by the local District Health Board); a Spa and Sauna; as well as a Gym.

The design of the facility is a simple design based on a structure to house the required facilities on the inside. The design of the building has features that make the building more interesting but result in the design not being the best quality. The most successful is the Hydro-therapy Pool environment. Designed to be a relaxing and tranquil space, it uses materiality of the painted concrete walls and wooden acoustic panels to achieve this.

The layout of the facility is not practical for big swim competitions, but it appears to be designed well for community use. There is no separation between public and athlete movement; although this is good for local events, it does not work well when national events are held. The amount seating for large numbers of spectators, athlete warm-up areas, and layout of event equipment means that space is limited. The athletes enter through the main entrance along with spectators and then move to the main pool area through a set of automatic doors. They enter the grandstands through one-person-wide stairs.

The Warm-Up and Cool-Down Area are limited. They are located on the opposite side of the facility to the seating areas for the athletes, interrupting races. aesthetically. meaning they pass through the Technical Official's Area and Starting Areas to access it,

The major thing I have gathered from studying this facility is that 'space' is a crucial component in terms of large and important events, as well as every day running of the facility. I believe that the ability to have more space would allow for a cleaner and more efficient facility both operationally and

Fig. 15 Top: WRAC Ground Floor Plan Fig. 16 Left top: WRAC Entrance Fig. 17 Right Top: WRAC Main Pool Fig. 18 Left Bottom: Rear Entrance
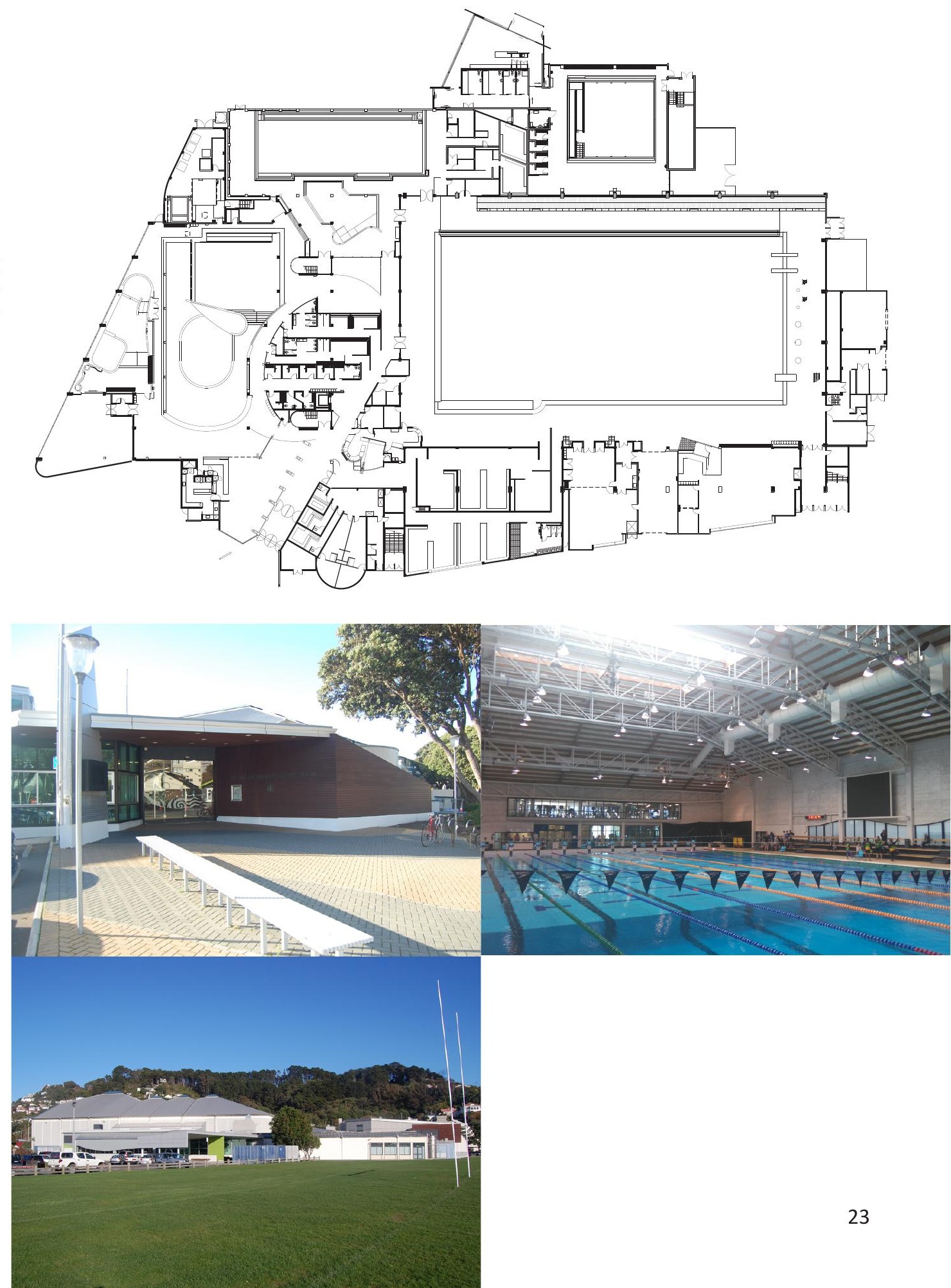


\section{London Aquatic Centre}

The London Aquatic Centre is an important building in design of aquatic centres. It is one of the most iconic and recognisable buildings in swimming worldwide. The design of the build was carried out by Zaha Hadid Architects and it explores various forms associated with swimming and water.

This pool was originally designed for the 2012 London Olympic Games, and hosted the diving and swimming events. It has hosted multiple high-level international events since. The most significant development that occurred for designing Olympic Sporting Facilities like this, was the idea of 'the legacy design'. The facility was initially built with temporary seating that was used and provided specifically for the Olympic Games. After the Games the equipment and facilities were taken away or converted so the building could operate for the community as well as larger sporting events as required. (Tom Dyckhoff, 2012)

This initiative has been the key success of the design and has allowed more people to access the facility without losing its character or heritage.

The design was established from the fluiddynamics of water. The body of the building flows and lifts well to allow for an uninterrupted line-of-sight for spectators. It also splits the Competition Pool Main Pool Hall into two zones; the Diving Pool, and the Competition Pool. The building is encompassed under one roof volume.

In my opinion, the architecture is conducive for swimming fast. The shapes and fluidity of the building encourage speed through aesthetic qualities. The Warm-Up Pool has a calm and soothing aspect to it. The low celling with the exposed concrete and focused light allow athletes to get 'in the zone'.
The building during both Olympic and legacy arrangements, there is a separation of both athletes and spectators. The building has several entrances that allow for congregation as well as separation when required. The main entrance is from the ground floor; this is where the building sits next to the river. The other entrance is from the northern end of the site. This allows for separation, as athletes can arrive below and walk around the facility without entering the Main Pool Hall. Spectators can enter from Northern Plaza through the welcome zone and straight to their seats.

Inspirations to explore the atmosphere qualities of the Warm-Up Pool and the layout of athlete pathways.
Fig. 21 Top: Ground Floor Plan(Zaha Hadid Architects)

Fig. 22 Left Top: Outside South (Red Dater) Fig. 23 Right Top: Under Diving Boards (Hélène Binet)

Fig. 24 Left Bottom: Noth Plaza (Red Dater) Fig. 25 Right Bottom: Warm Up Poo (Hélène Binet) 


\section{Sleeman's Brisbane Aquatic Centre}

The Sleeman's Brisbane Aquatic Centre is built in the eastern suburbs of Brisbane and some distance from much of the city itself. This complex is Brisbane's main Competition Pool and holds the regions national and international competitions. The pool was initially built for hosting the Commonwealth Games in 1982 (Queensland Government: Department of Housing and Public Works, 2014)

The complex is part of a greater sporting facility that hosts competition and training for many other developing sports, such as Track Cycling.

The aquatic facility has a main indoor $50 \mathrm{~m}$ pool housed with a 4500-seating arena. Adjacent to the main $50 \mathrm{~m}$ pool is the main diving complex. This is a $25 \mathrm{~m}$ pool and $5 \mathrm{~m}$ in depth. The Warm-Up Pool is located slightly away from the main arena, but still easily accessible. Outside, is another $50 \mathrm{~m}$ pool that has an area that is $4 \mathrm{~m}$ in depth, which accommodates for four diving boards.

The facilities form and materiality appear unconsidered from the outside. It is not designed with a high level of aesthetic rigour, but it does meet the functional purpose of housing a swimming facility. The design of the building is a programmatic design that is suited to holding events well. The qualities of the building include high roofs and an interesting ceiling pattern that is designed to reduce noise. The dive board offers another aspect of design relief, but again, this area is dated. There is limited natural light entering the building.

The athlete and spectator movements

Fig. 26 Left: Sleemans Brisbane Aquatic Centre (Sleeman Sports Complex) through the building are separated through different entrances. The Main Entrance can become the athlete's entrance, while there is design for spectator access on the outside of the main building through a separation in the grandstand.

There is a functional flow between Marshalling and the Changing Rooms but the Warm-Up Pool is unfortunately very separate.

As I move forward, the layout and the simple back access routes behind changing and marshalling are areas to consider because they keep athletes, officials, and spectators separate.

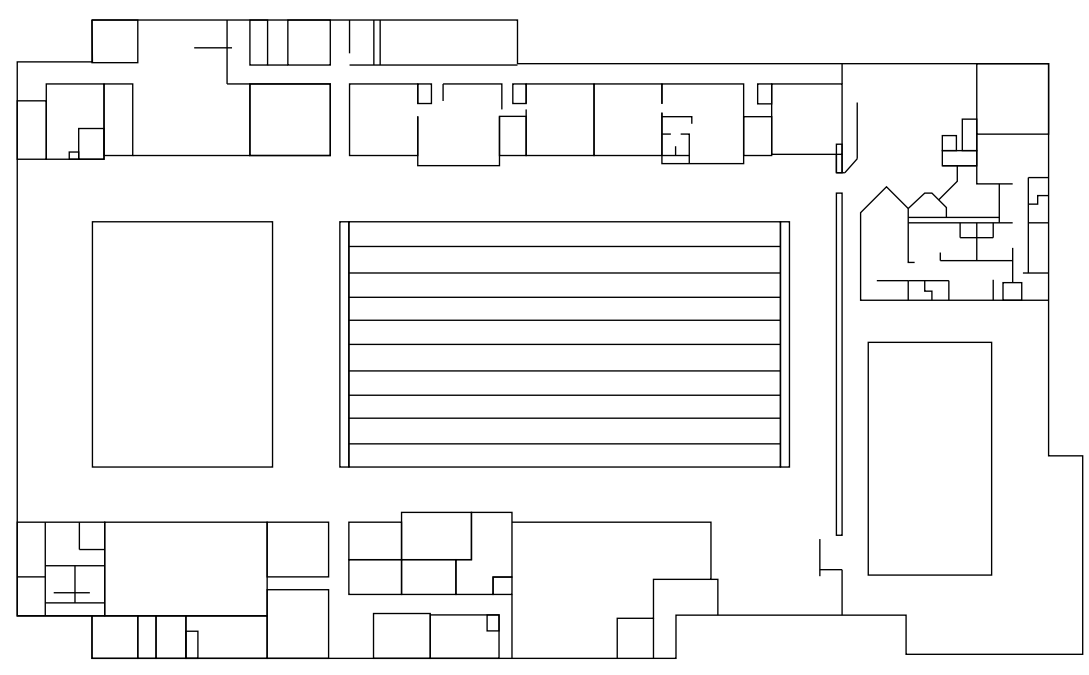

Fig. 27 Top: Ground Floor Plan (adapted from CaSSSA Diagram)

Fig. 28 Left Top: Main Entry

Fig. 29 Right Top: External Main Approach

Fig. 30 Left Bottom: Warm Up Pool

Fig. 31 Right Bottom: Main Pool Hall

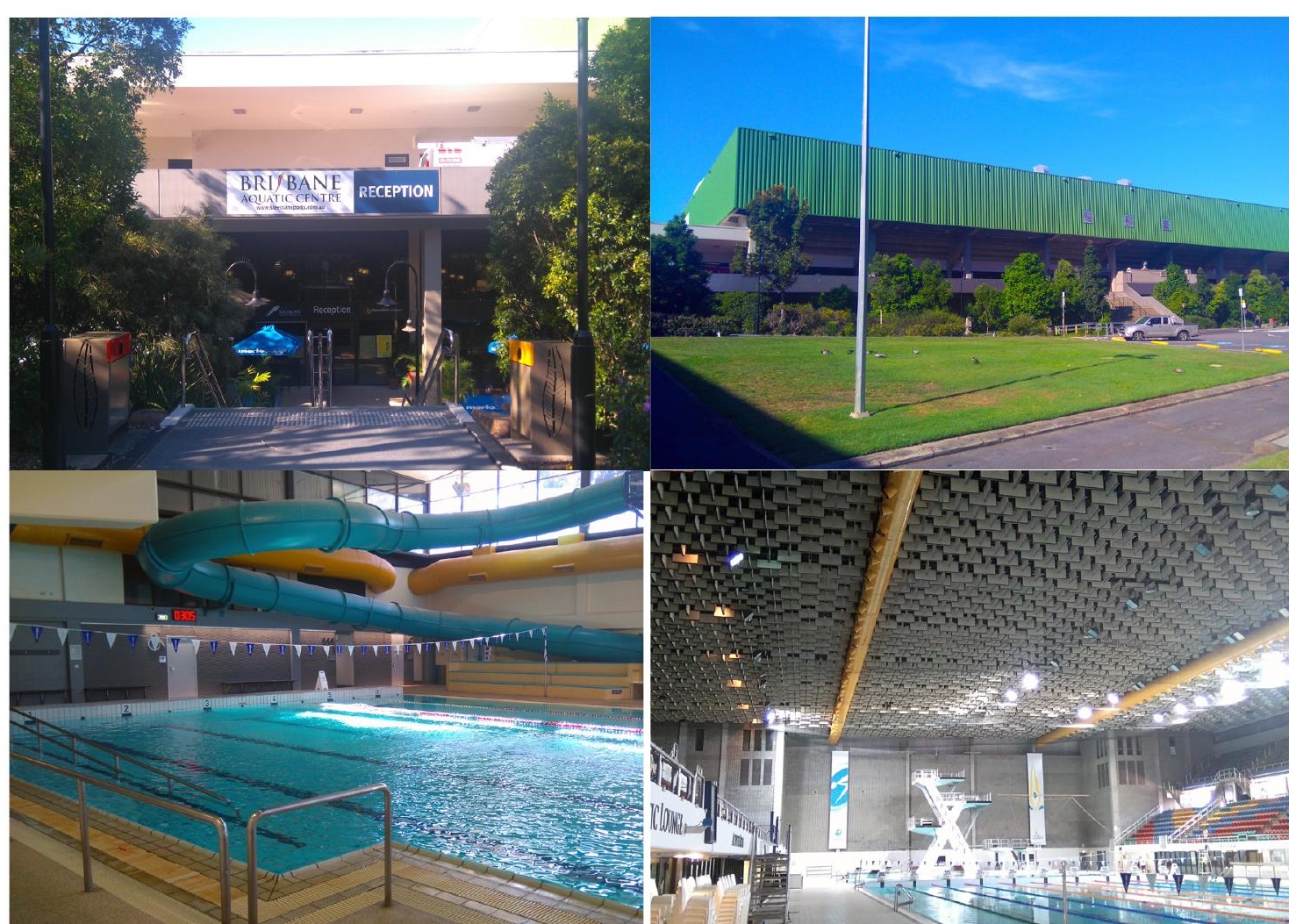




\section{Gold Coast Aquatic Centre}

This is an outdoor complex located in Southport on the Gold Coast in Australia. This facility will host the Aquatic Events at the 2018 Commonwealth Games. The facility is open-planned and designed very well, with a community feel and 'the Games' in mind.

The facility offers many swimming facilities, including a Competition Pool (50m), a second 50m Training Pool, a $25 \mathrm{~m}$ Dive Pool, as well as another $25 \mathrm{~m}$ Lap Pool. Offering a range of activities for both community and completive users, the complex also offers an indoor Learn to Swim Pool that can open out and be part of the rest of the facility. (COX Architecture, 2014)

The pool offers support to events happening within the complex, but also offers support to events hosted in ANZAC Park, adjacent to the complex. For example, the World Triathlon event in April 2016. For these external events, the facility could offer training, corporate, and other important athlete areas. (COX Architecture, 2014)

The competition area is relatively small but it has flexibility to increase seating numbers when required. The roofs of the surrounding buildings are designed so that temporary seating can be installed, thus potential for increasing the number of spectators.

The buildings' architecture is contemporary as it was built within the last 5 years. It is open-plan, with good public access for each pool. The layout is based on a single main axis that is intercepted by the orientation of the pools.

Due to the open-plan and simplicity of the building, it allows for easy navigation between facilities and allows for flexibility when required, for example, when an important event is on. 


\section{FINA and Design Guides}

Swimming complexes are designed through a series of guidelines laid out by local or national authorities on optimal ways to design sport facilities.

FINA is the governing body of international swimming. They set the standards for different world class events for swimming, diving, water polo and synchronised swimming. All international standard pools need to follow the design specifications to allow events to be registered as "sanctioned events." They "are intended to provide the best possible environment for competitive use and training." (Federation Internationale De Natation, 2015)

They produce and provide a facilities rule book to ensure that facilities are up to standard and are safe. These guides are useful when designing to ensure your design fits within the standards.

Design Guides -are a useful tool when designing a natatorium. They use previous design experiences to summarise the optimal pool space required for each activity. The amount of space required for each activity based on expected numbers of pool attendants is described, as well as specific functions that will occur in the facility being outlined.

A critique of sports hall design standards by Henning Eichberg is "Society acting practically - and then produced a mythological 'rationality' to legitimate (and enforce) the process of human streamlining and rectangurlarizing." (Eichberg, 1993) to describe how standards of design do not allow new formal responses facility design. She later states that the "sensibility for body experience rather than the demand of standardisation" is a better approach to designing. (Eichberg, 1993) This critique of sports hall design reinforces that these standards need to be challenged. 


\section{SURVEY RESULTS}

To understand what swimmers, perceive as being a good, fast facility based on experiences and emotive qualities, I conducted a survey that asked participants about key moments leading up to and during the race. The survey was anonymous and swimmers who raced at national events or higher were asked to complete this survey.

The results can be found in appendix 1 . It was concluded and reaffirmed that the atmospheric factors considered in my research and the way that an athlete wants a facility to work for them were important in designing a building.

Summary of Findings that are key to my research:

- Warm up and support areas are to be team focused

- The ability to go to a quiet space to warm up before racing

- The marshalling area is where swimmers want peace to allow them to get into their 'zone'

- Start blocks are loud areas to hype them and motivate them

- Ceiling should be interesting but simple

- Pool same depth but changes in design

- A quality designed facility that allows athletes and spectators to move freely 


\section{CONCLUSION OF PRECEDENTS}

Each of these case studies has an important part to play in how I will design my facilities. Though the majority don't use the emotive qualities talked about previously, they do provide moments that will influence my design.

Where this thesis looks to fill the gap, is what different, better, more focused role the architect can have when designing a space. The space being developed is not only the Main Competition Pool Hall but the journey of an athlete goes through until they reach the start blocks.

As expressed in the survey results, the athletes want a welldesigned space that allows them to focus or inspire their swim.

The response can happen programmatically and emotionally. Just like a spectator's journey up to the stands, the athlete's journey to the competition area or pool is just as important. Each space is unique and needs to have the right atmosphere and allow an athlete to perform at their best. 


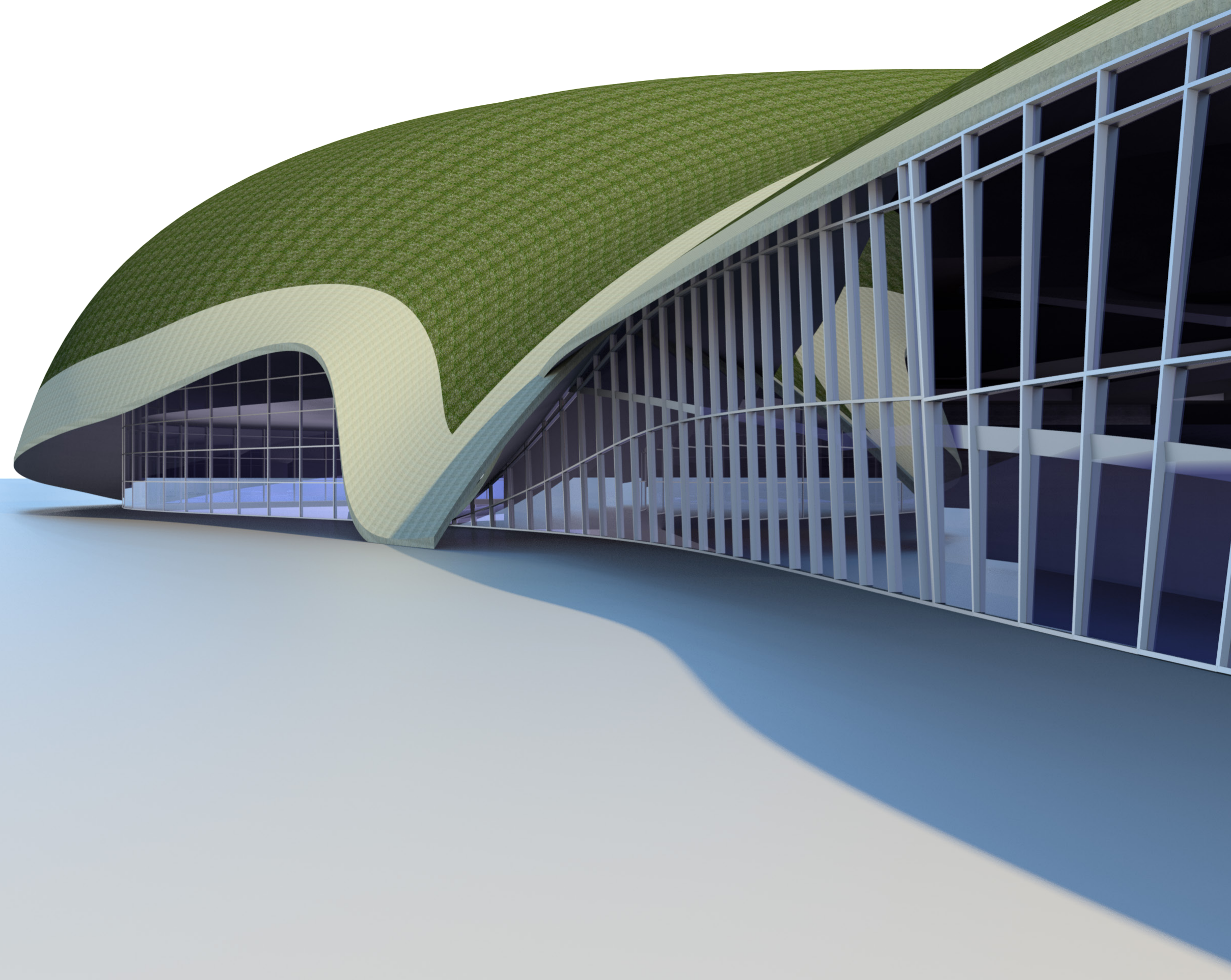




\section{PROJECT 1 THE ATHLETE}




\section{My Motivation}

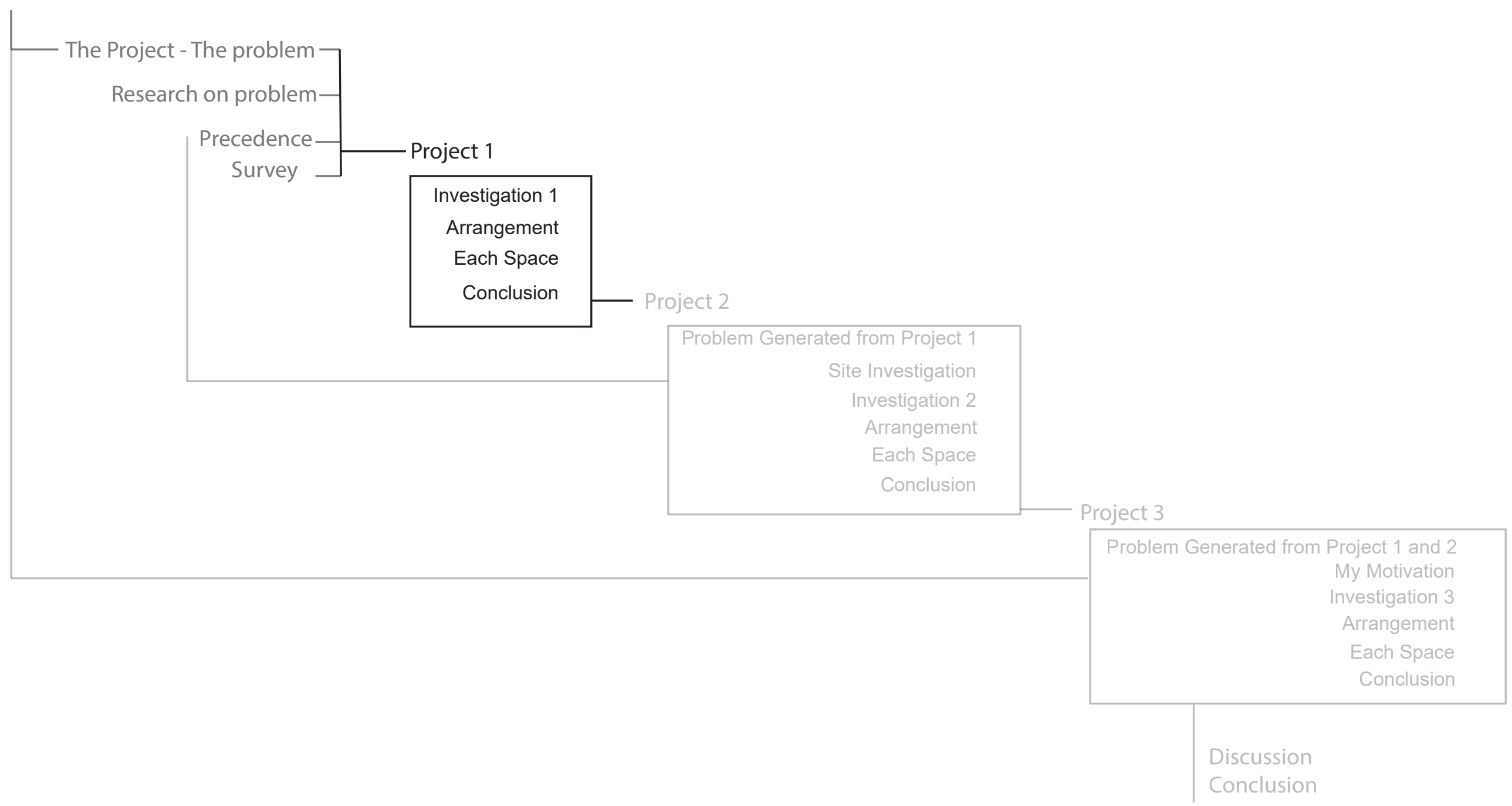




\section{PROJECT 1 INTRODUCTION}

This first project explores the High Performance Aquatic Facility from the point of view of an athlete.

The objective is to find out how the process of an athlete can be used to create architecture that is from their point of view. To do this, the focus is based around mapping and exploring information gathered in the first sections of this thesis to find out how each stage of an athlete's mental build up can be developed into space. Each space needs to operate individually as its own component of the building but also interact with the space. The goal is to design a facility that allows an athlete to enter their IZOP more easily.

Aim: To design based on the needs of each stage of the athlete's process

Method:

- To map out the athlete's process

- Develop form based around each stage of the process

- Propose the atmosphere needed for each space

- Design outcome 

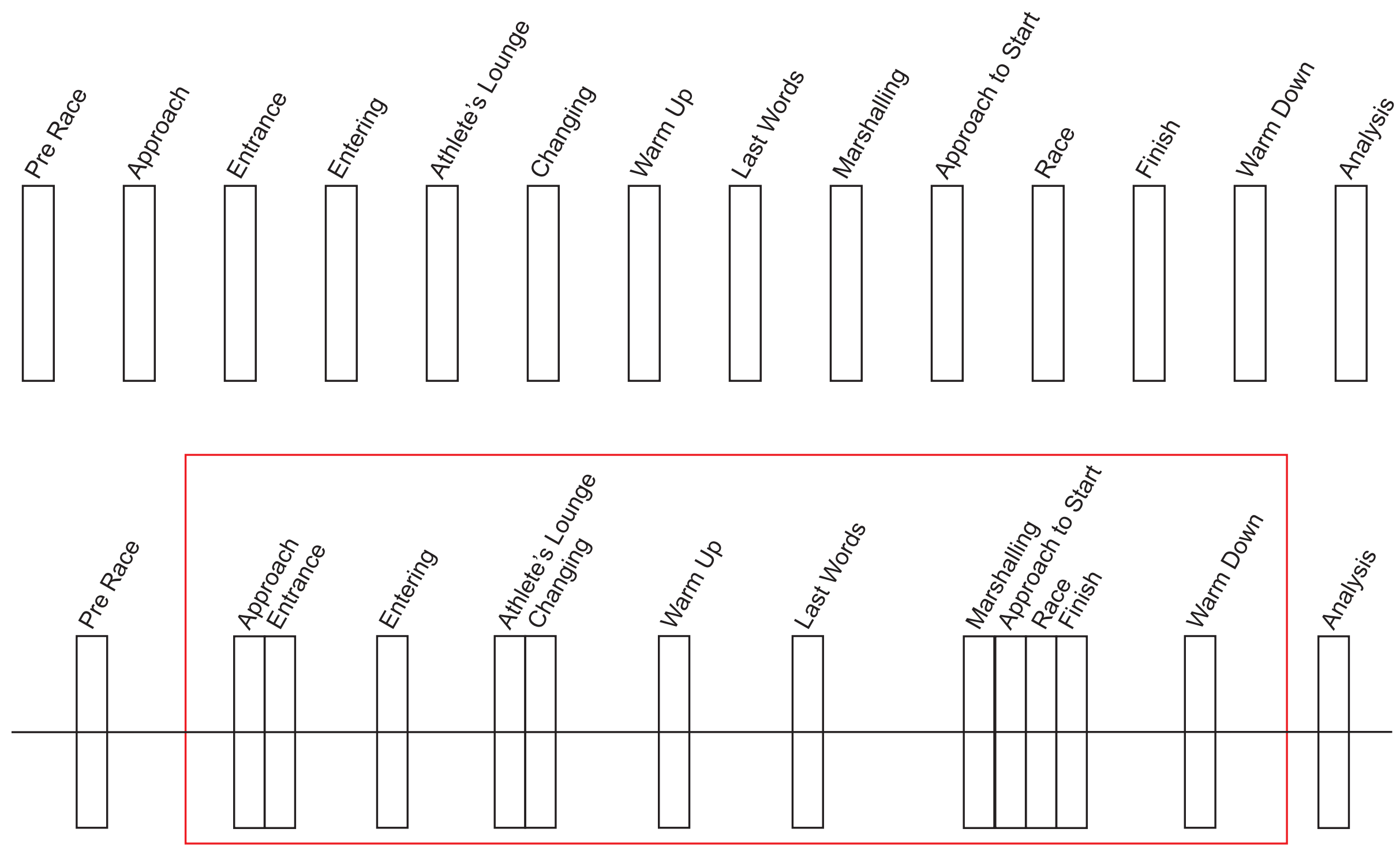

Main Focus for Project 1 


\section{ATHLETE'S PROCESS}

Taking the analysis from the first sections, you can breakdown the way an athlete builds for a race into a process. Though each athlete is an individual, the process can be broken down into common points of significance where at some point in their journey they will pass through these spaces.

To do this I will explore the overall process. As the athlete, will begin preparing for the event well before they get to the facility, I will consider the parts of the process highlighted in figure 38 in my design investigation.

Each of these parts can be developed as an individual space. Some of these spaces have stronger connections to each other than others, therefore, there can be greater gaps depending on the stage of the process that the athlete is in.

For Project One the focus will be the stage approach to the building to the warm down. 
1- Approach to facility

2- Entrance to the facility

3- Athlete's lounge/changing

4- Warm up/ Warm down

5- Last words (Coaches area)

6- Marshalling

7- Approach to start blocks

8- Race

10-Analysis

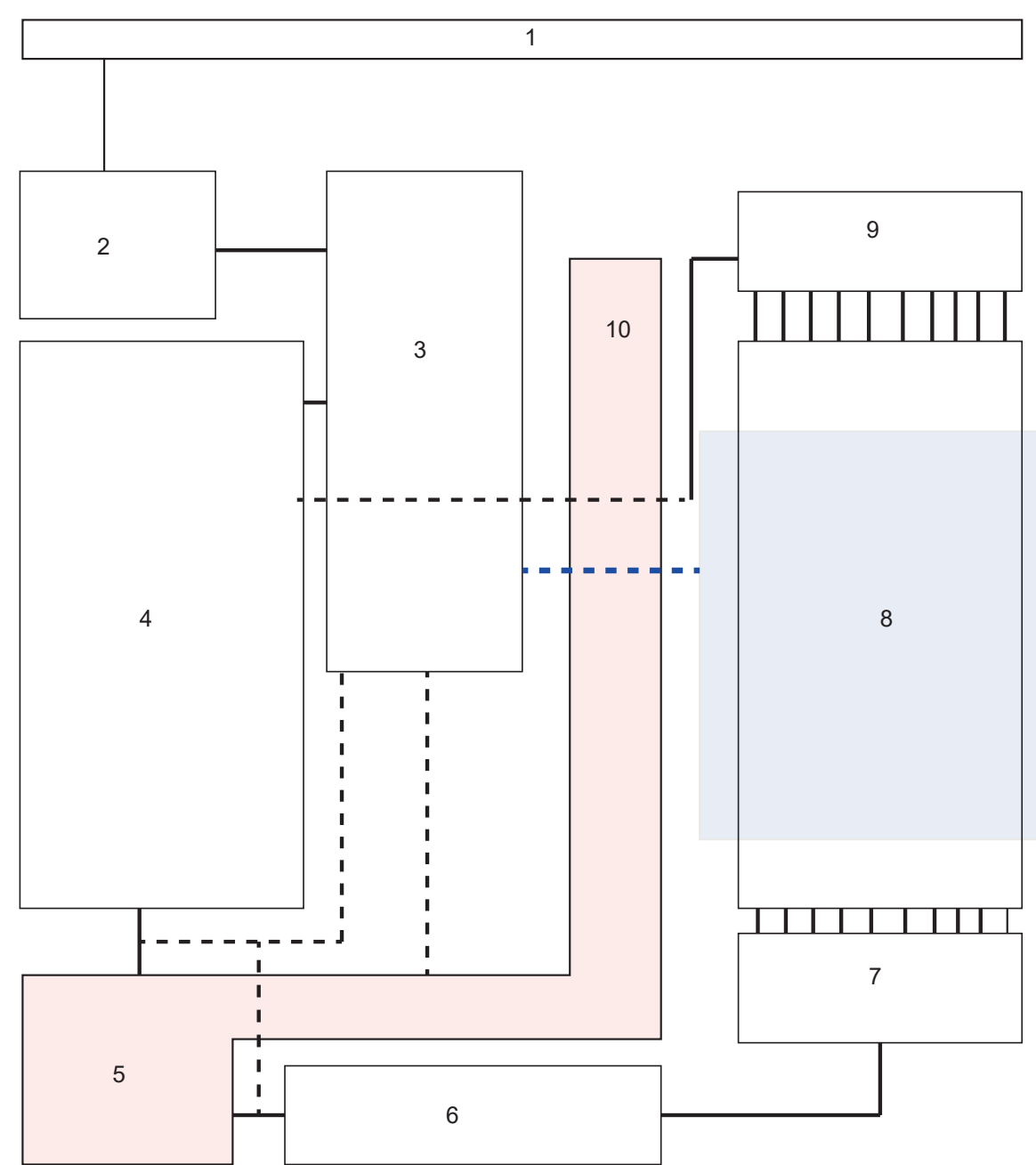

Fig. 39 : Connections of space through the athlete movements 


\section{Mapping the Process}

Taking the diagrams of the process developed on the previous page, each space can now start to be mapped based on connections, athlete's processes and relative need of space. What this creates is a map that is starting to architecturally describe the athlete's process.

The connections can be created not only by the athlete, but by the coaches and spectators. Though this section is only focusing on the athlete, they do influence the layout of the facility. The objective is to allow the athlete to flow through the building, allowing each space to help them in their preparations. The figure 39 starts to describe this flow through a building.

As we can see, spaces are used twice and connections are not definite as described above. To allow for the individual athlete, spaces need to allow for variables in their preparations. The diagram starts to describe movement that occurs during an event for an athlete.

The main flow of the athlete described in the process has been described in a solid line. The dashed lines start to describe supplementary connections. The red describe areas that the athlete are with coaches and blue is were athletes and spectators mix.

Note: athletes watch other events while waiting for their race or after they have warmed down. 


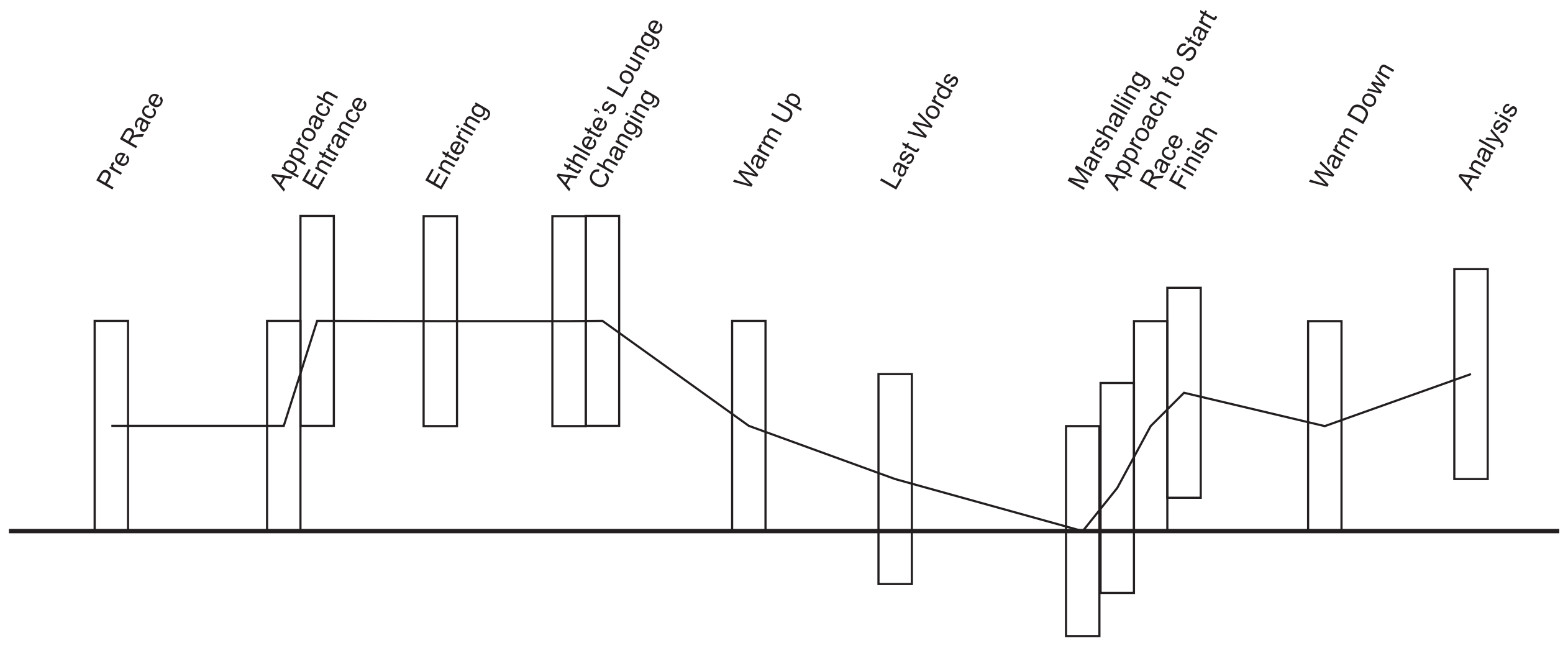

Fig. 40 : Athlete's progression through facility mapped against intensity of emotions 


\section{Mapping the Process Vertically}

Exploring the process architecturally means that it can be explored through emotion and architecture. The athlete's emotions can be used to arrange space vertically. By dropping them down physically and picking them up at the right moments, allow the separation of space and the atmosphere of each space to be enhanced.

Initially, when the athlete enters the facility they will experience increased anxiety from the anticipation of the race ahead and being in the presence of the other athletes. Ideally, on entering, the athlete will immediately feel calm.

As they progress through the facility, each 'drop' and 'pick up' will be influenced by the atmosphere required. Going from the Athlete Lounge to the Warm-Up Area will be a drop, as the athlete needs to focus on the event in a relaxed environment. They will feel calm from after the hype of entering the facility, being around other athletes and the race ahead. There will be another drop to the Marshalling Area through the Last Words Area. After Marshalling, they are to be picked up to the start block, where they should be fully focused and in their IZOP. The athletes then naturally drop down from the start block to the pool for the race where again they are focused. When they finish, they should be picked up again as they have just exhausted themselves and need to feel proud of what they have achieved.

This up and down and up movement can relate well to spacing out these areas within the building. By physically dropping them and picking them up creates zones and anticipation for what happens next. 


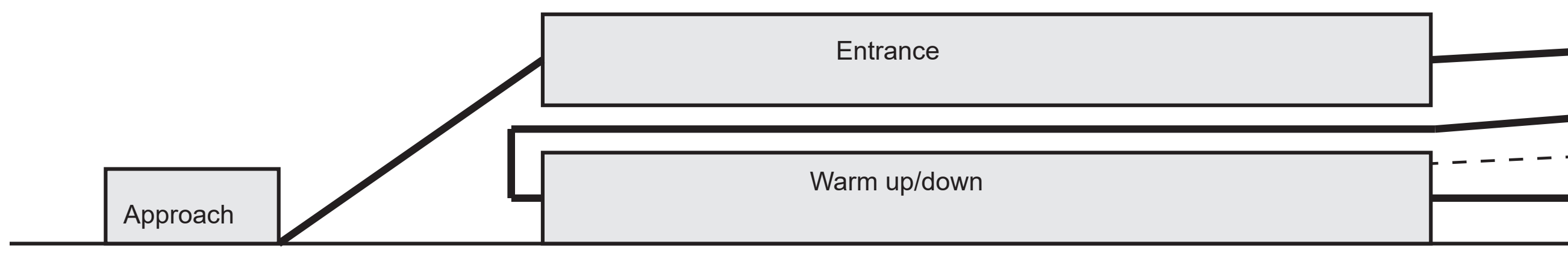




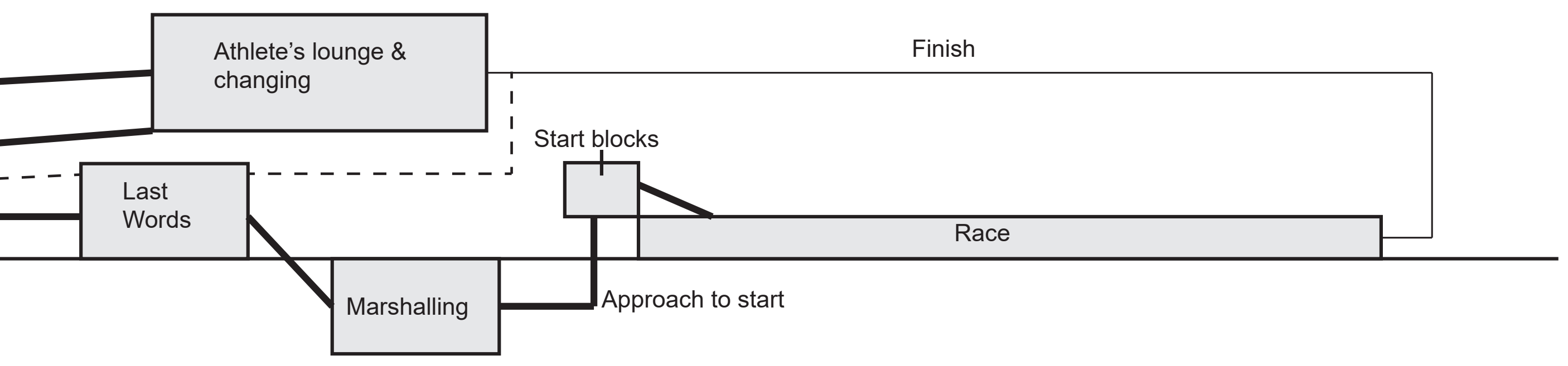

Fig. 41 : An exploration of an athlete's progression mapped vertically and spatially. 

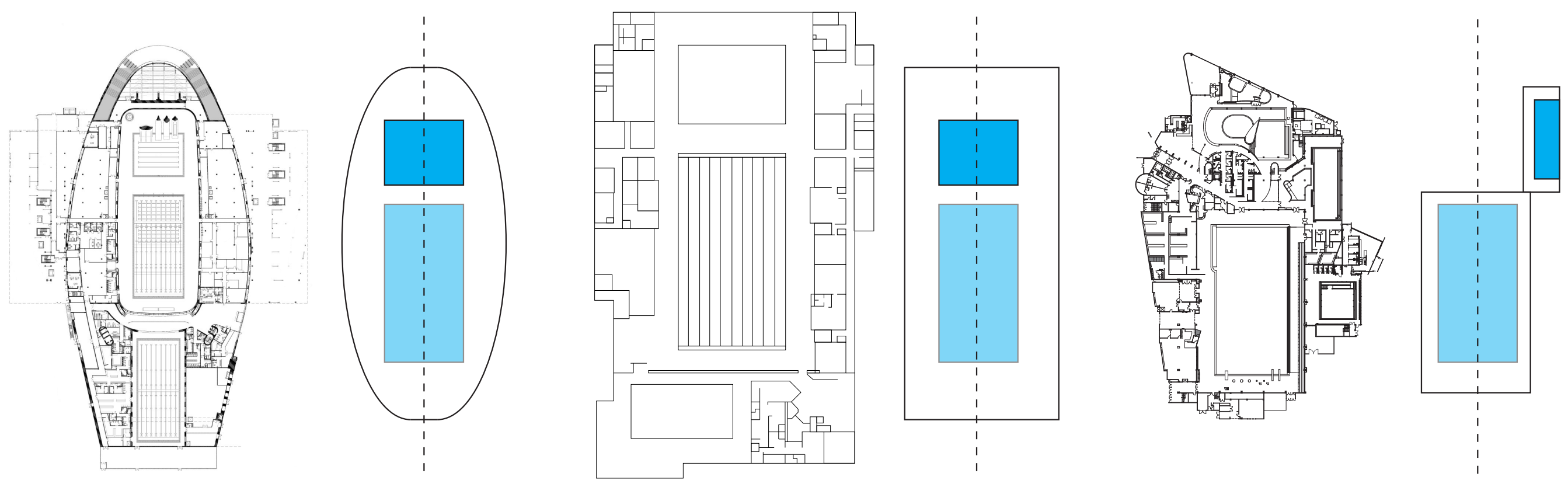

Fig. 43 : Axis analysis of precedents, from Left: London Aquatic Centre, Brisbane Aquatic Centre, WRAC
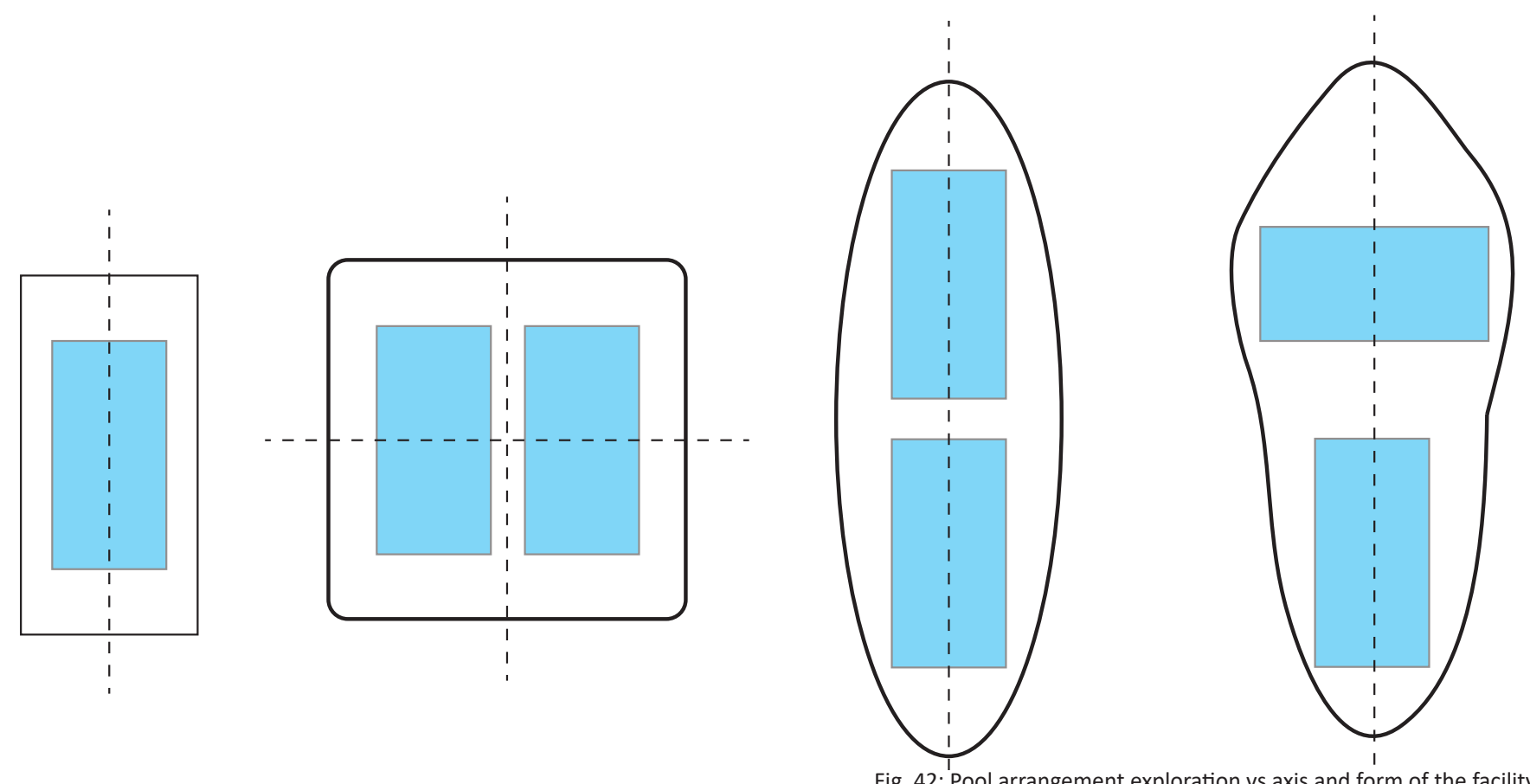


\section{Axis Exploration}

Before discussing the approach, the design of the form of the facility will be investigated, as this will influence how you approach the building. For this I am also playing on two aspects of preconceived notions that come from pre-existing facilities and the ideas of speed.

Firstly, the traditional arrangement of the pools within in a facility tends to be down the long axis of the building. Looking at the London Olympic, Brisbane and WRAC, the direction of the axis of the building dictates the orientation of the pool. Because of the length of the Competition Pool (50m), it can fit easier into the building structure and therefore highlights the length of the pool. For this design, the pools will be arranged in a " $\mathrm{T}$ " with the main Competition Pool going across and against the main axis. This rotation makes the pool seem shorter because the athlete will swim the width of the form rather than length. To do this though, the form of the building may look chunky and un-streamlined. 

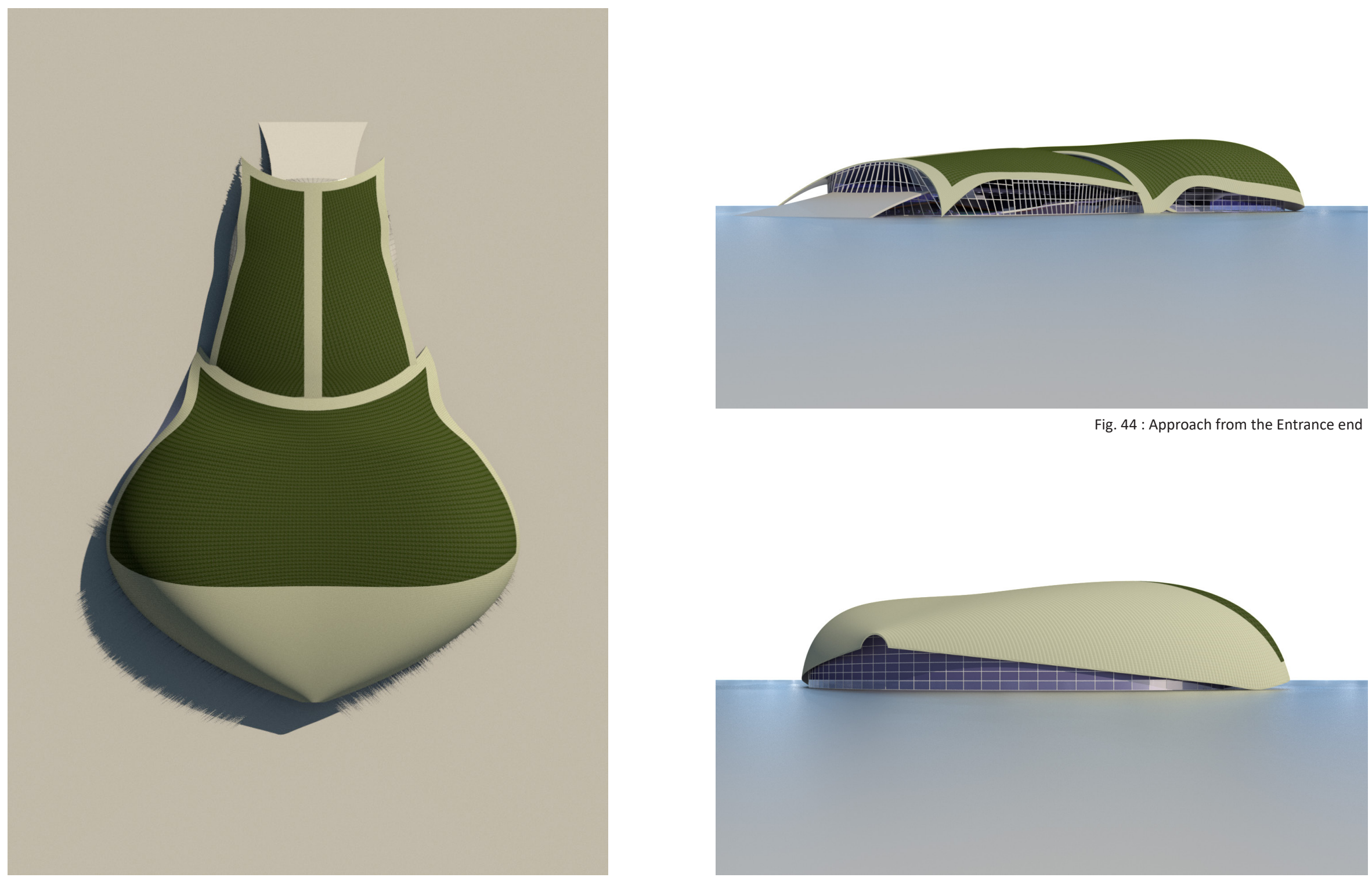

Fig. 44 : Approach from the Entrance end

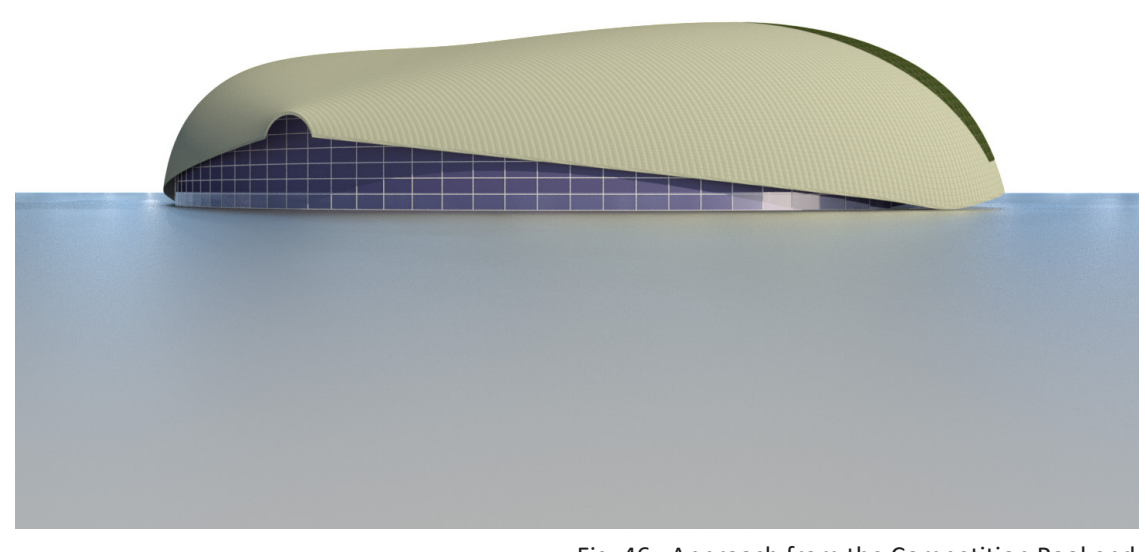

Fig. 46 : Approach from the Competition Pool end 
The second aspect investigates pre-conceived notions of speed. Henning Eichberg states "the streamline body moves on a straight line in a universe of right angles." (Eichberg, 1993) This helps to explain that long, slender, 'streamlined' forms have preconceived assumptions of being quick, like the London Olympic Aquatic Centre. Investigating other streamlined bodies, like boats; similar ideas were repeated. The bigger and chunkier the boat, the slower we perceive it to go. The more streamlined and lightweight the boat appears, the quicker we presume it will go. To allow the ' $T$ ' arrangement of the pools, the Wally Power Boat is used as a design precedent. Although it looks heavy and wide in the water, its overlapping panels and stretched-out body allow it to look quick.

The overall form of the building uses this language, allowing the streamline appearance to be achieved. The form also touches the ground lightly to reduce its appearance of weight, so the building appears quick.

Having the athlete approach the building with full view of the buildings' length, enables the design features of the building to be emphasised and the effects of these design ideas begin to influence the athlete. 


\section{Entrance}

The entrance to the building should be different for the athlete and the general public, as the separation allows the athlete to focus on the race/event ahead. This is especially important at the higher, more competitive levels of the sport.

The athletes are lifted up to enter the facility. They then experience the length of the building and are allowed a glimpse of what is to come before entering the Athlete's Lounge.

Fig. 49 Left: Entrance render with view towards the Competition Pool Fig. 50 Right: Axo of Entrance pathway

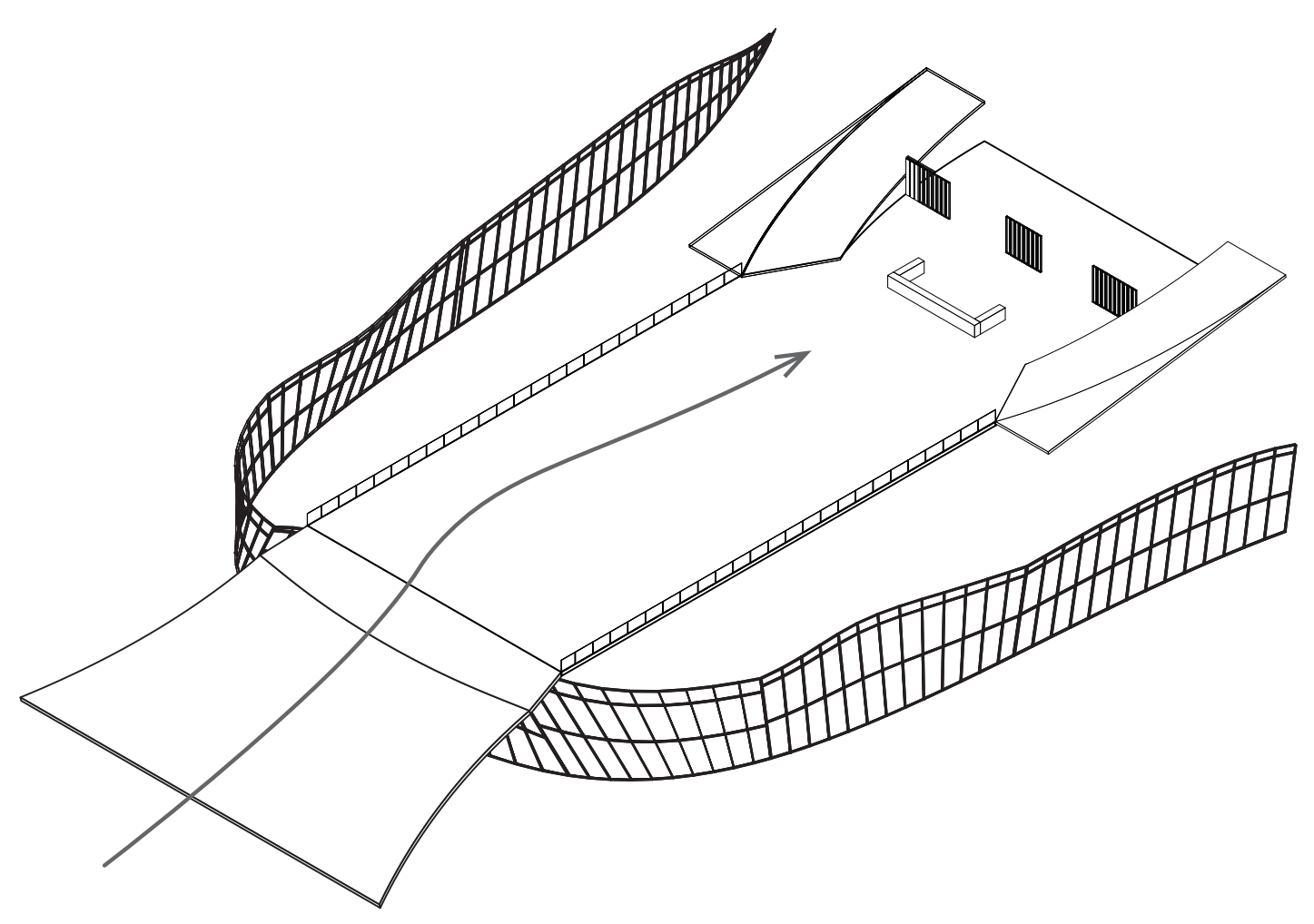



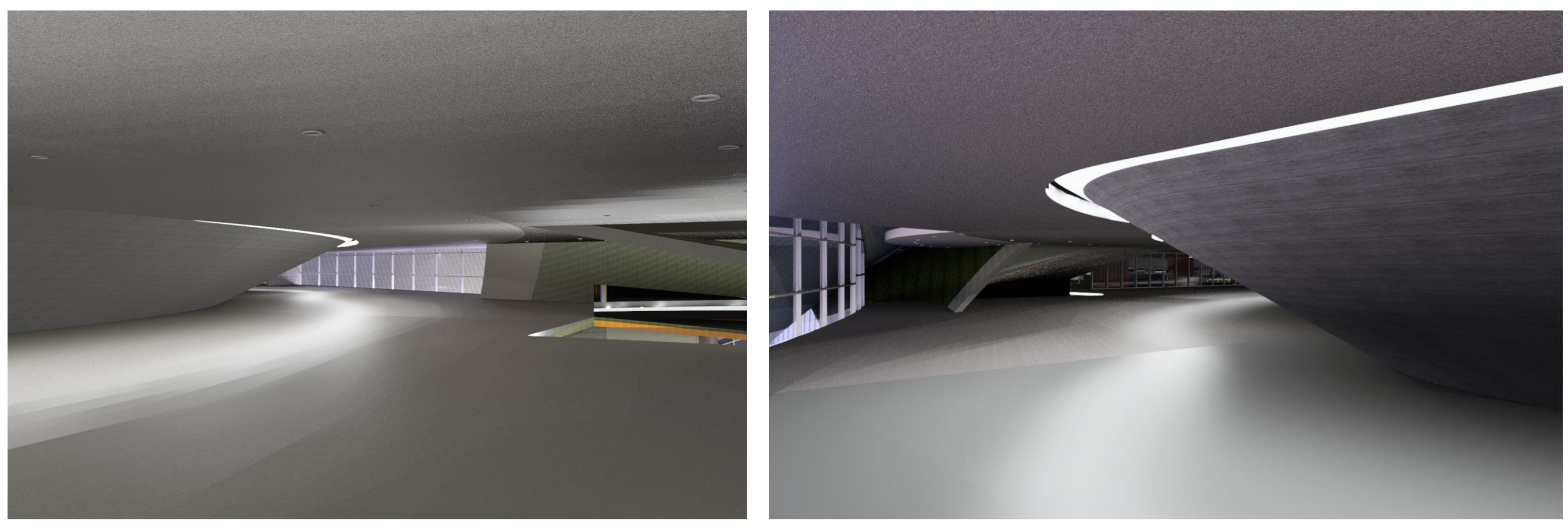

Fig. 51 Left: Athlete's Lounge looking from Entrance

Fig. 52 Right: Athlete's Lounge looking towards Warm Up Pool. 


\section{Athlete's Lounge}

This area has been designed to be neutral as it is a space that mediates the athlete entering the facility, waiting for a race and being present before they go to warm up. This is designed to be a calm but vibrant space for athletes to pass through or 'hang out'. To accommodate for this, the space has been designed with light but uses earthy materials, such as concrete and timber. It is open to allow room to stretch and lie down. This space allows athletes to hide away from the pressure of competition as an area that has little views of the Competition and Warm Up Pool.

Fig. 53 : Axo of Athlete's Lounge. Arrows show the flow of entry into the space and then down into the Warm Up Pool area.

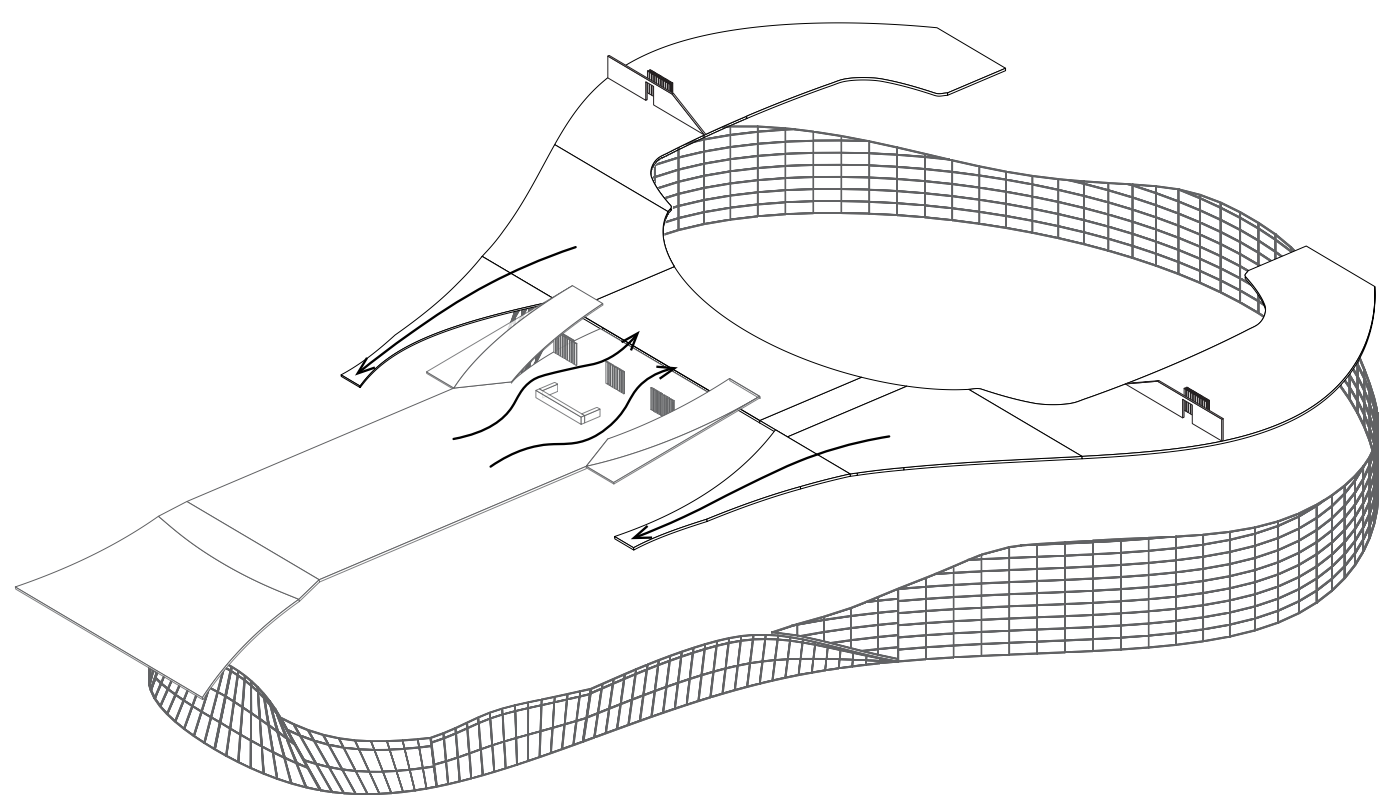




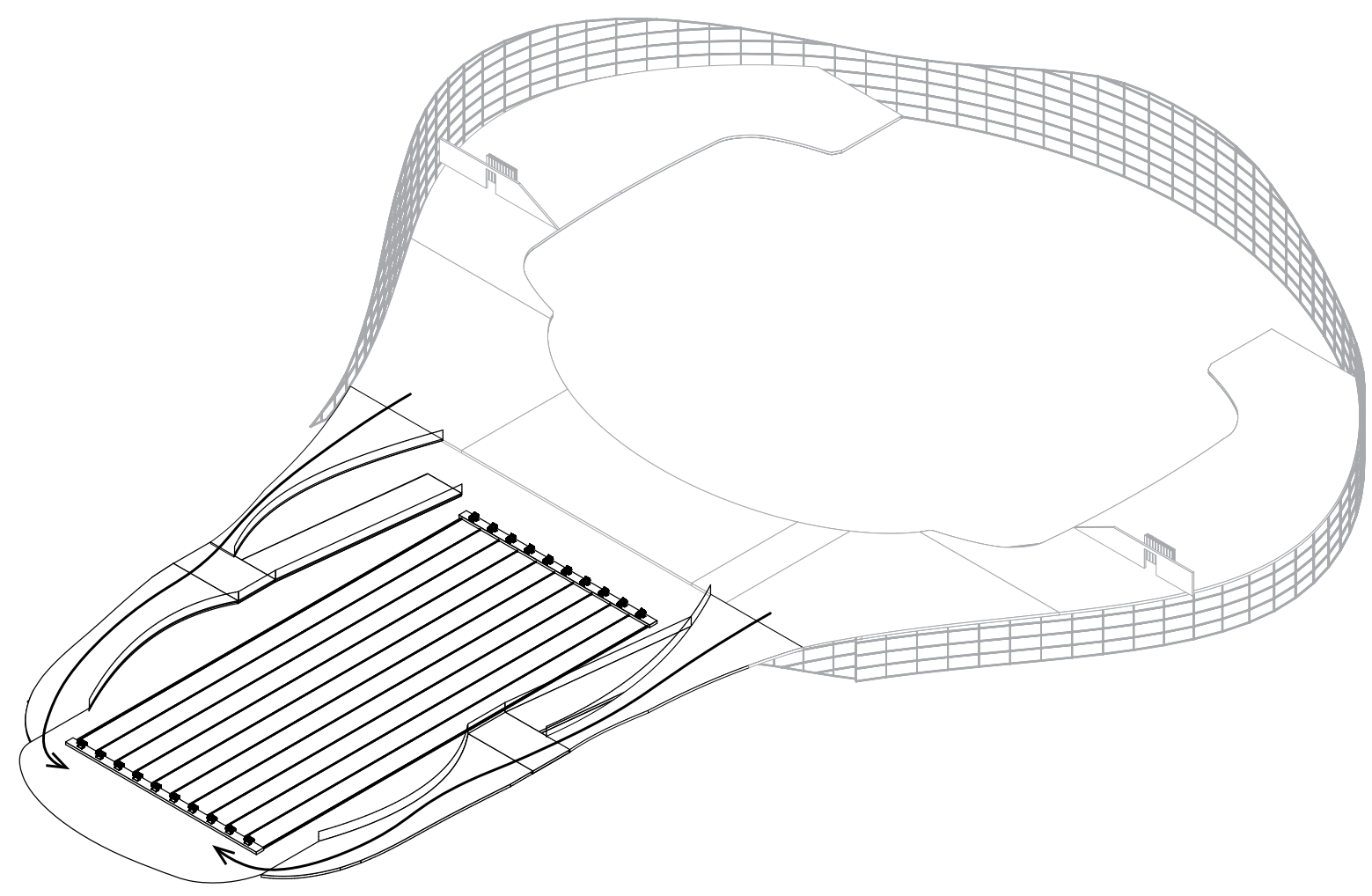

\section{Warm up/Cool Down Pool}

The warm up area is important; it needs to start to focus the athlete for their race. Taking the London Olympic Aquatic Centre

Warm Up Pool as precedents, the space is light but has broken heavy materials that impose a calming influence upon the body. The current project intends to use similar methods to create an ideal atmosphere.

By having the pool below the Athlete's Lounge, a separation is created from the outside world which allows the athlete to physically enter their IZOP through the drop.

I have chosen to use a $50 \mathrm{~m}$ pool for a warm up space because the larger pool provides athletes with space to warm up and get into their own 'zone' without interruption from others.

Fig. 54 Left: Axo of the Warm Up Pool, arrows describing the athlete's path

Fig. 55 Right: Warm Up Pool render looking towards back in the direction of the Athlete's Lounge 


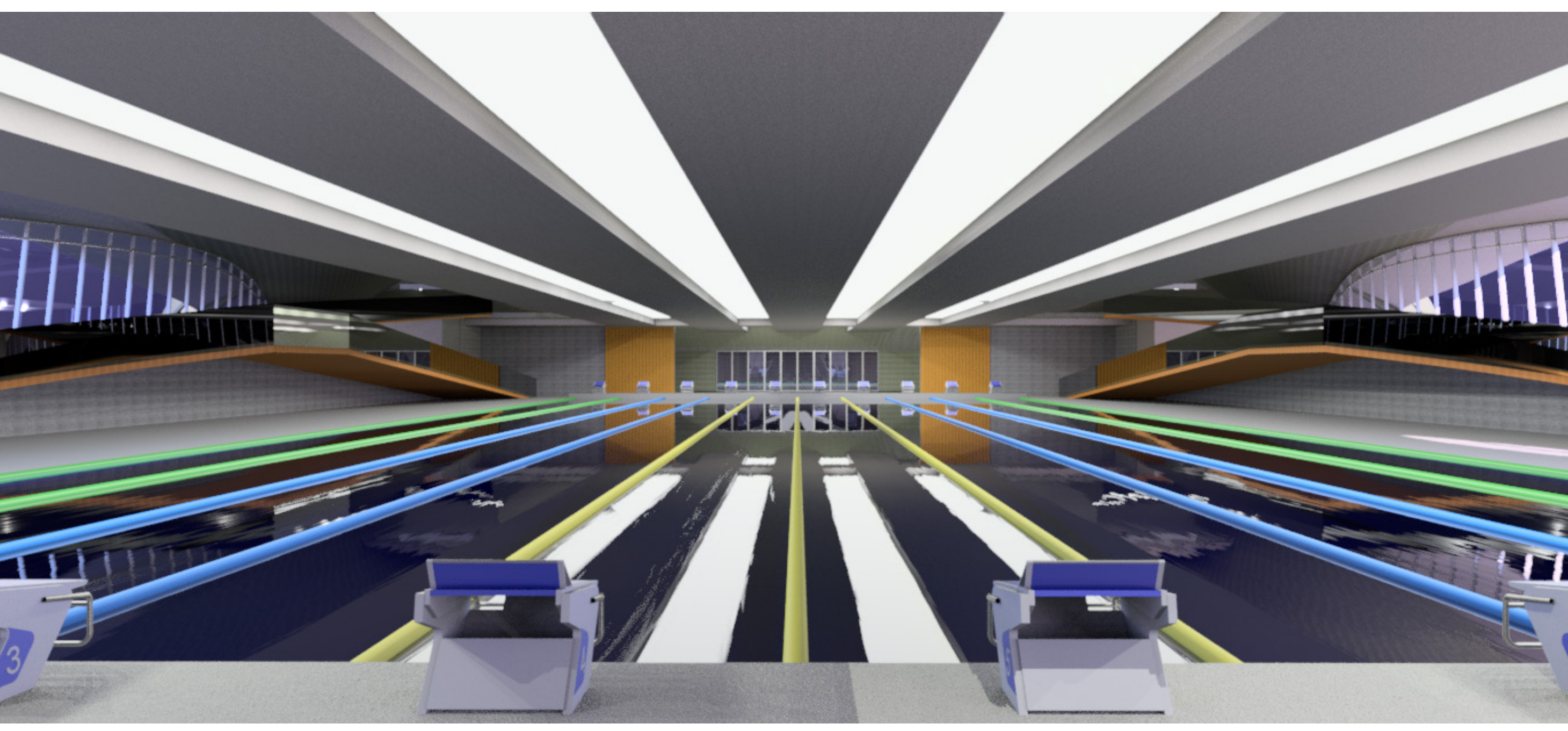




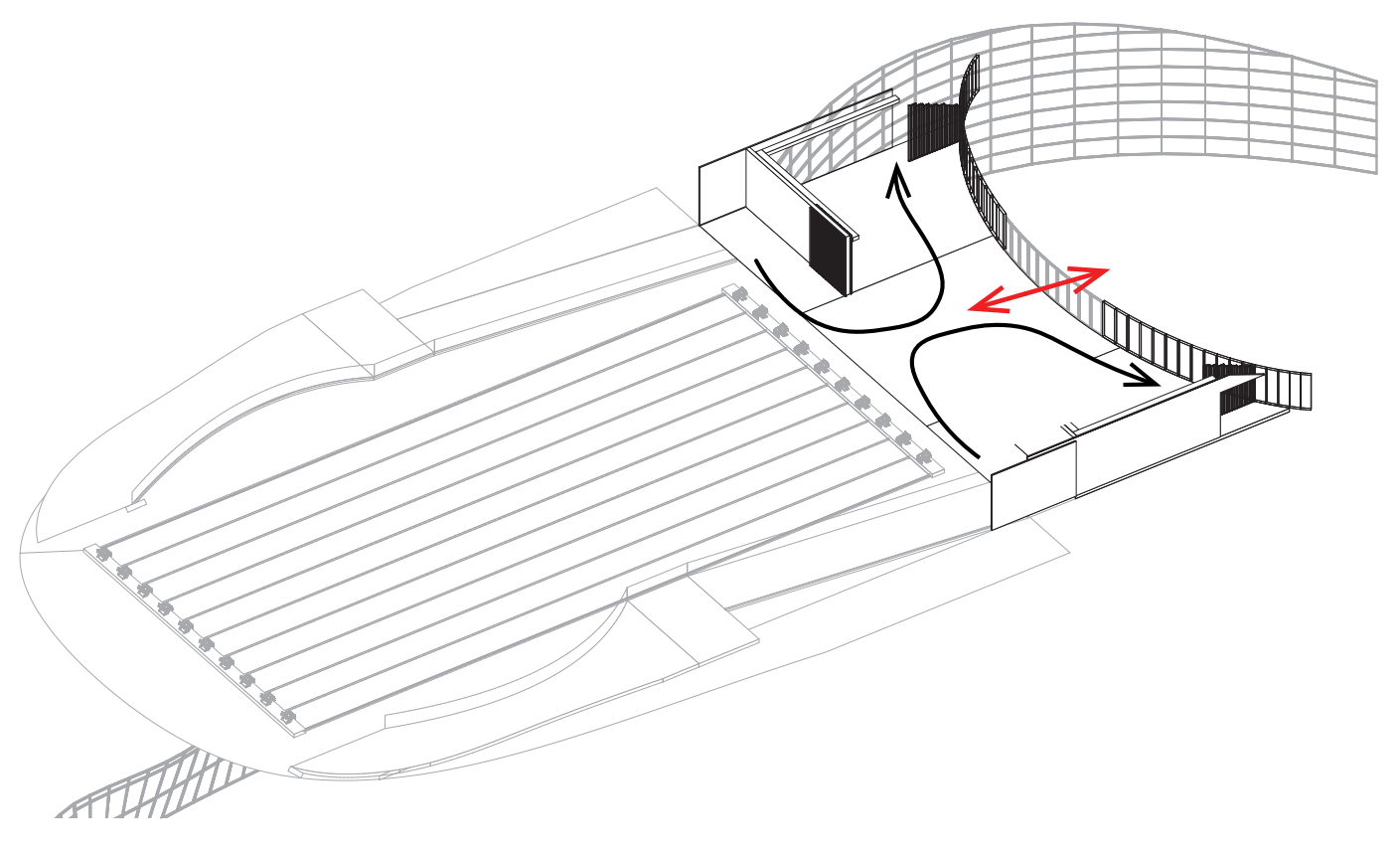

\section{Last Words (Coaches' Area)}

Last words, or coaches' area is an important space. It is the interception point between the Warm Up Pool, and Marshalling where coaches can congregate and inspire their athletes. This space has easy access to the Competition Pool and allows them to watch their athlete(s) warm up, and get any final last words in before entering marshalling to watch them race. The coach is an important figure in an athlete's life. The coach knows more about the athlete than the athlete knows about themselves. Therefore, this is an optimal point for coaches to gather. Last words provide a darker space in comparison to the Warm Up Pool or the Athlete's Lounge and allows the athlete to start to fully focus on the race ahead.

Fig. 56 Left: Axo of the Last Words area, black arrows describing athlete's path and red describing the coaches.

Fig. 57 Right: Warm Up Pool render looking towards the direction of the Athlete's Lounge 


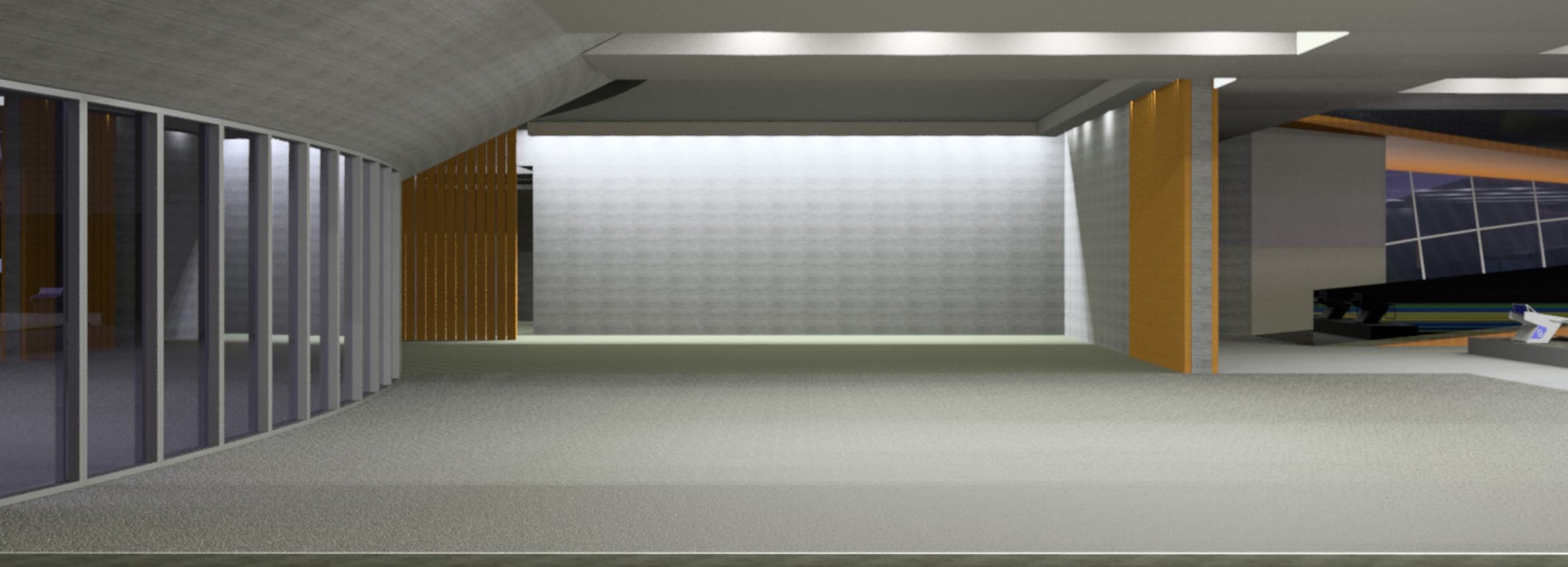




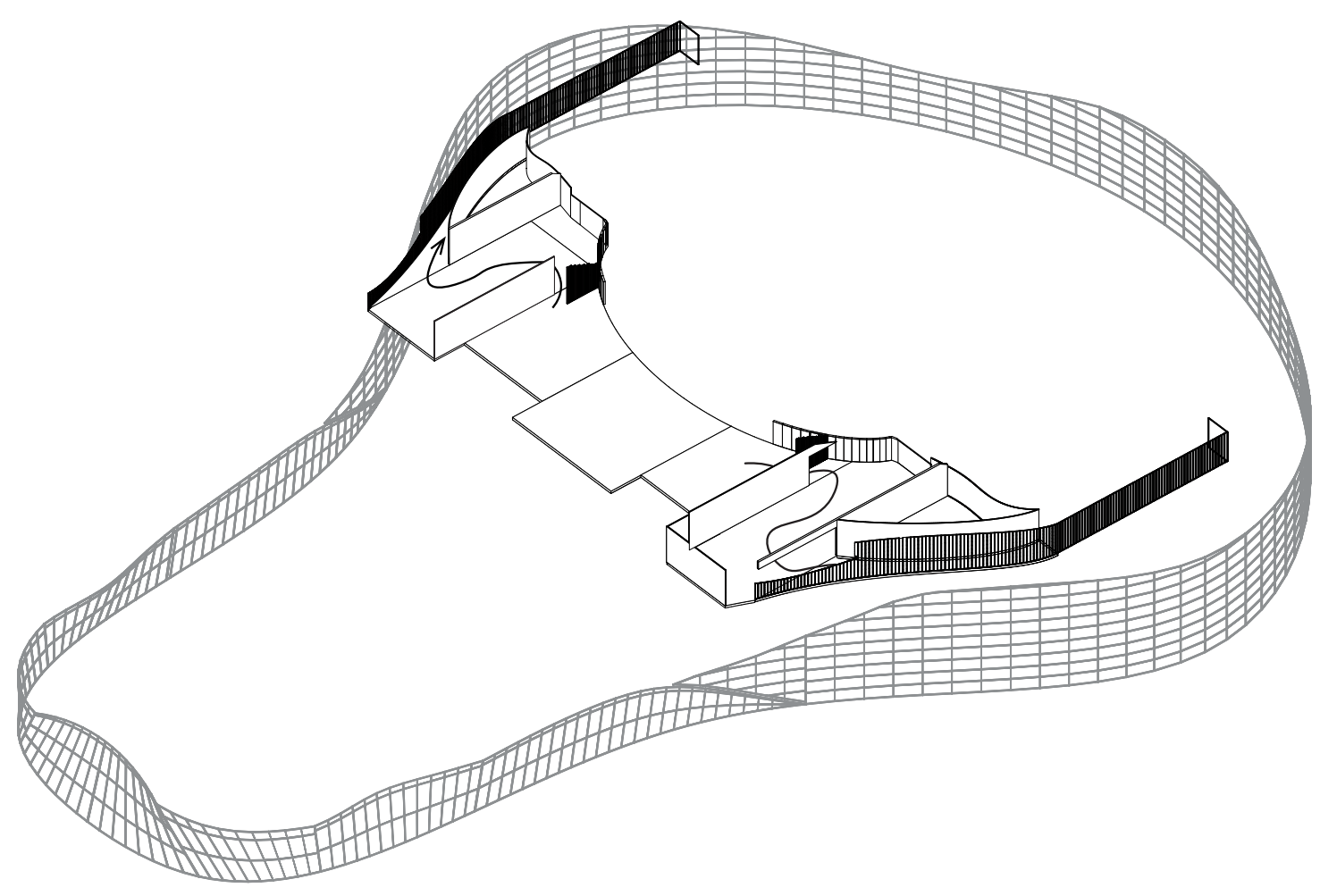

\section{Marshalling}

Marshalling is the area where the athletes wait to race. Athletes are organised in their event heat. They sit next to their opponents and are each in their own mental space preparing for the race.

The athlete is deep in concentration running through their race plan; visualising their stroke, dive starts, and turns. This is the most important space in the building for the athlete's build up. This is race time. The trick is how the athlete can enter their IZOP and maintain optimal anxiety levels.

The space is designed to be dark and heavy with earthy materials, with little visual access to the outside world or the Competition Pool. This is to emulate them going deep into concentration, it's like they are looking deep into their mind. 


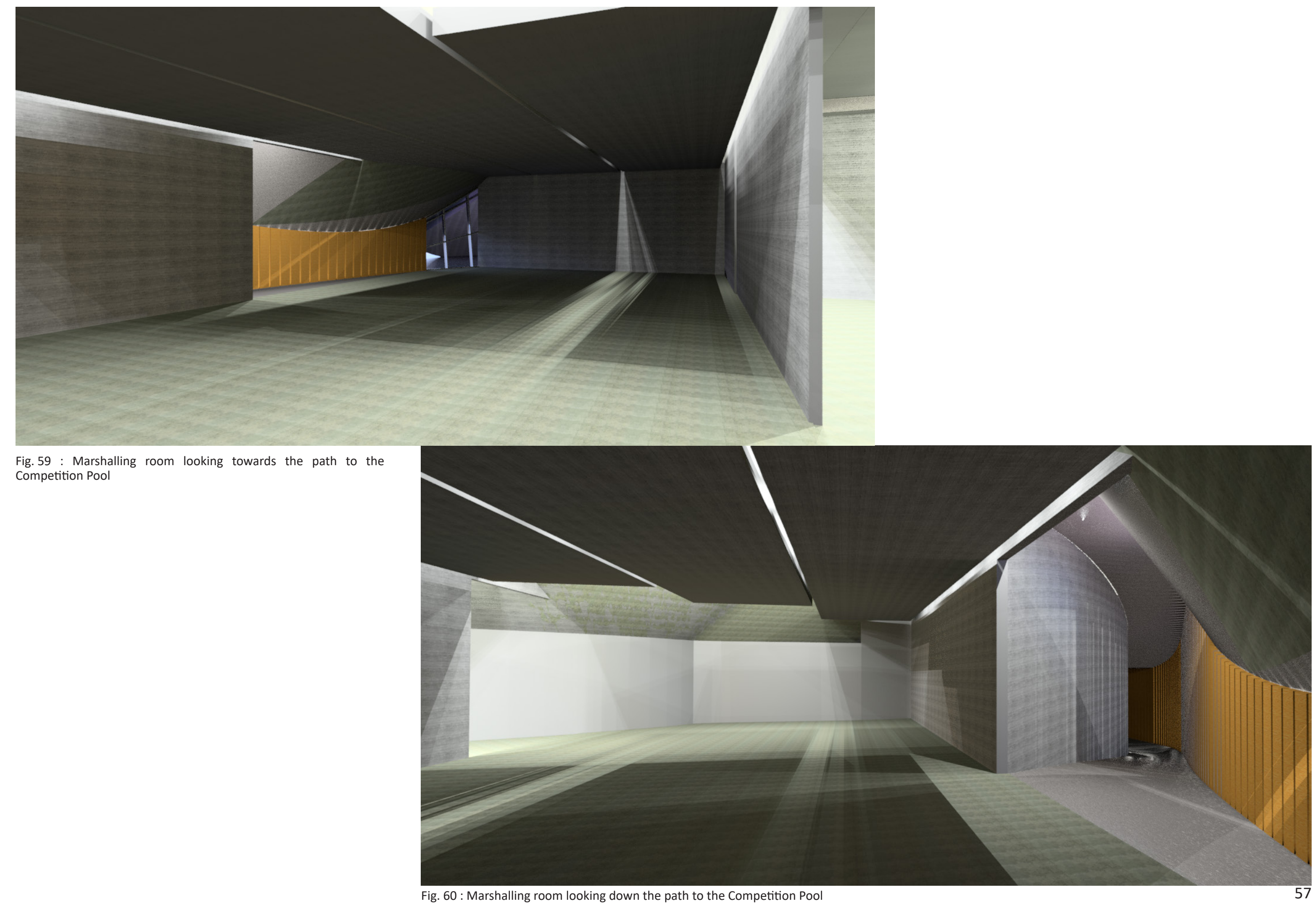




\section{Approach to Start Blocks}

The approach to the start blocks is the next important thing; there are three aspects influencing my design.

The first aspect is the tunnel down to behind the Start Blocks; this is to literally drop them into concentration. It is designed to block out all other distractions and the tunnel vision they can achieve when fully focused on the race.

Secondly, is the approach to the Competition Pool. In the survey, I created, there were many responses which reflected a need for athletes to approach the pool from behind the Start Blocks. In the majority of pool designs explored, athlete's approach the pool from the side. As shown in the Gold Coast Aquatic Centre, where the athletes enter the arena from the rear of the pool, allows them to better focus on the event ahead and limit distractions from other athletes.

The final aspect is to block the athletes from the crowd and bright lights for as long as possible. If the athlete can approach the race from the back and under the stands before rising up into the open and bright lights, this will create an adrenaline rush at an optimal time for helping the athlete perform to his or her best. The rise up to the start blocks is a symbolic move because it can be attributed to rising up to the challenge and being the best you can be.

Fig. 61 Top: Tunnel from Marshalling to behind Start Blocks

Fig. 62 Bottom: Diagram of precedents

Fig. 63 Right: Approach to Start Block 


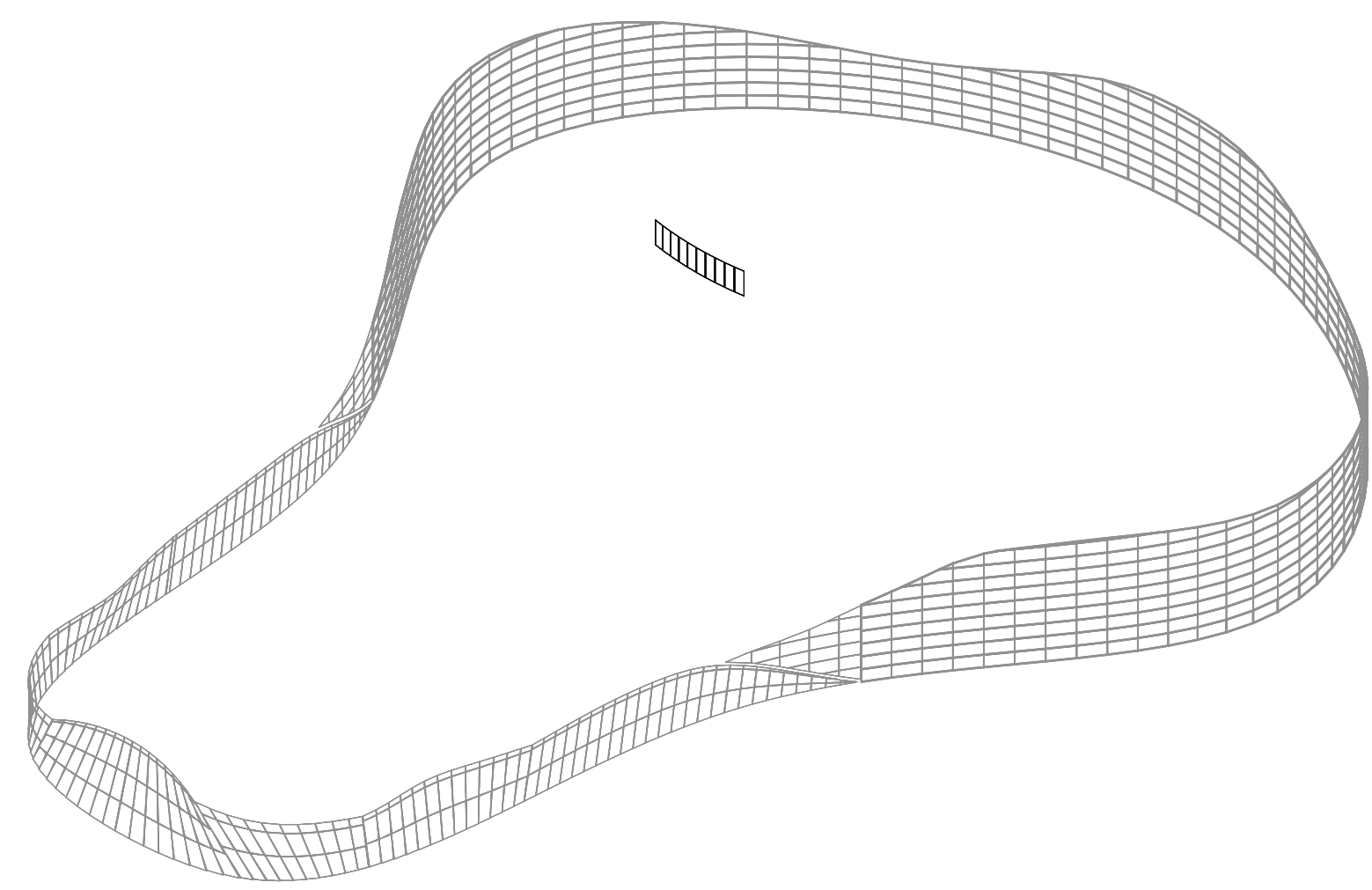

Based on feedback from the survey, the Competition Pool is designed to make the pool look short. If the athlete perceives the pool as being short, they will have more confidence to swim the visual length faster. Therefore,

I have tried to incorporate as many lines going across the pool as possible and by experimenting with curved poolside walls that come to a point at the end of the pool to shorten the visual length of the space. 


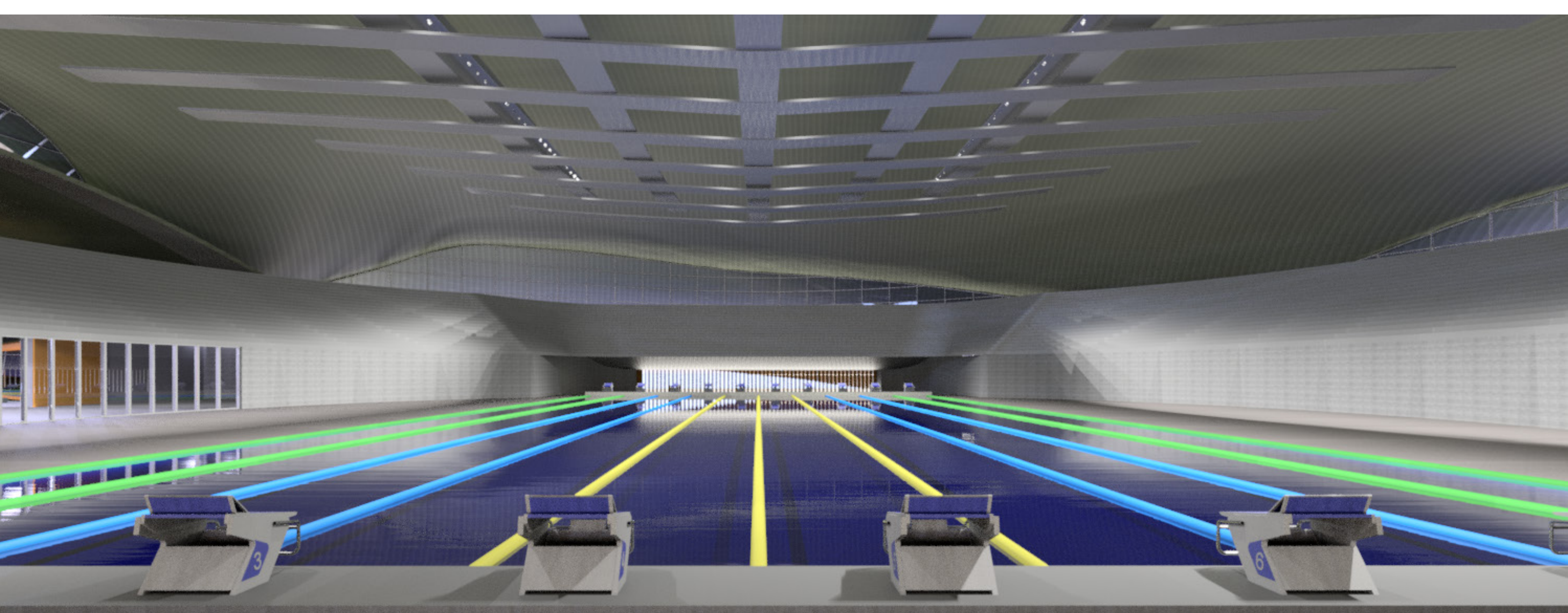




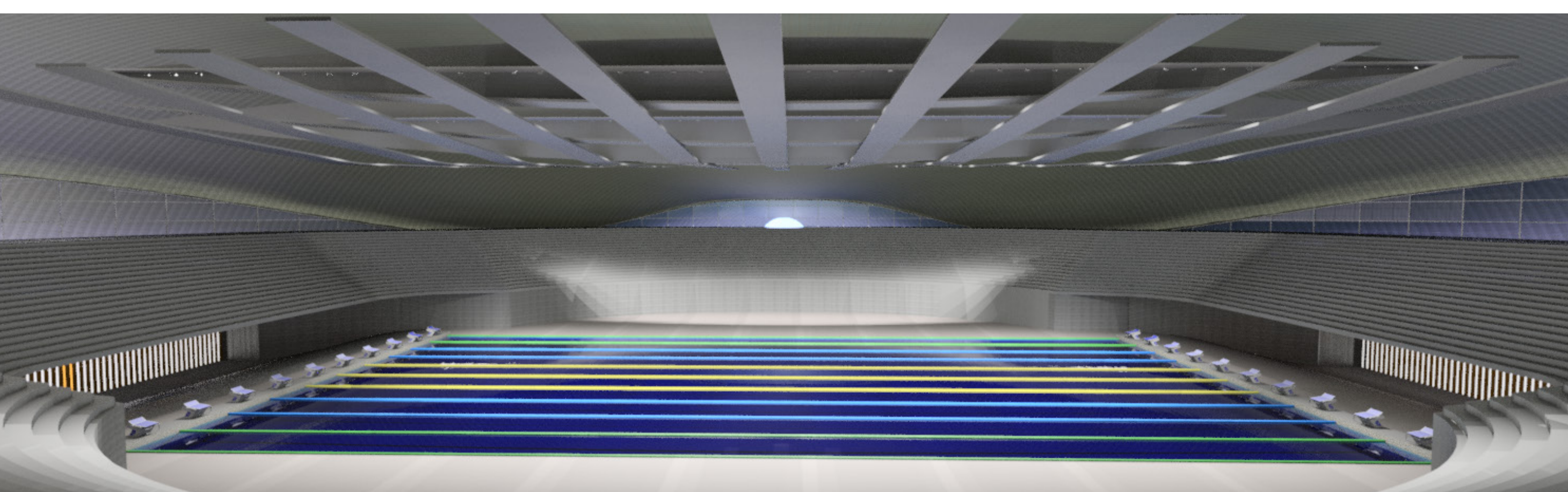



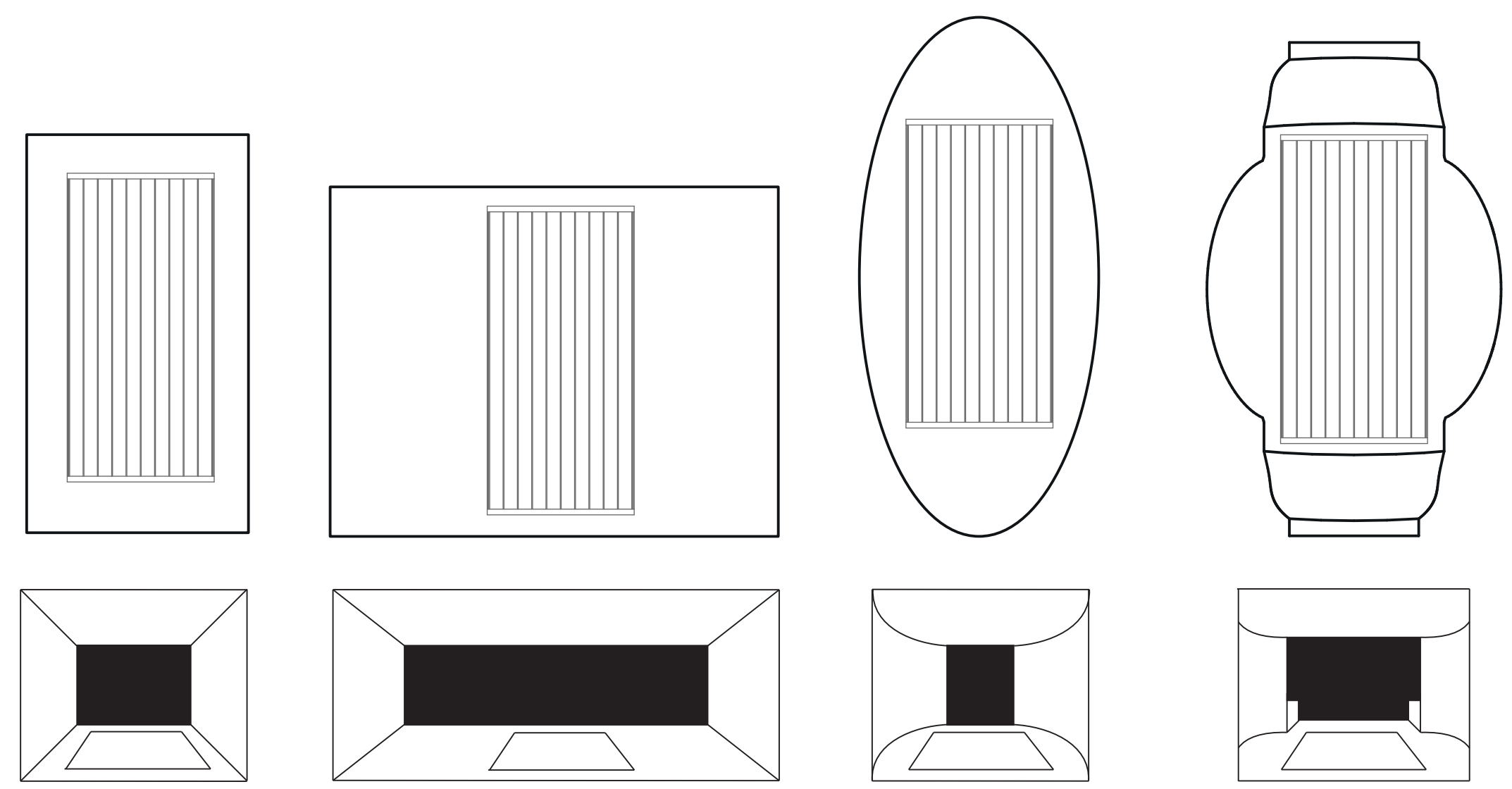

Fig. 66 Left: Rendered image of Competition Pool Hall from spectator's view

Fig. 67 Right: Experimentation with pool hall forms 
1- Entrance ramp

2- Warm up/Warm down Pool

3- Last Words (Coaches area)

4- Marshalling

5- Approach to Start Blocks

6-Competition Pool

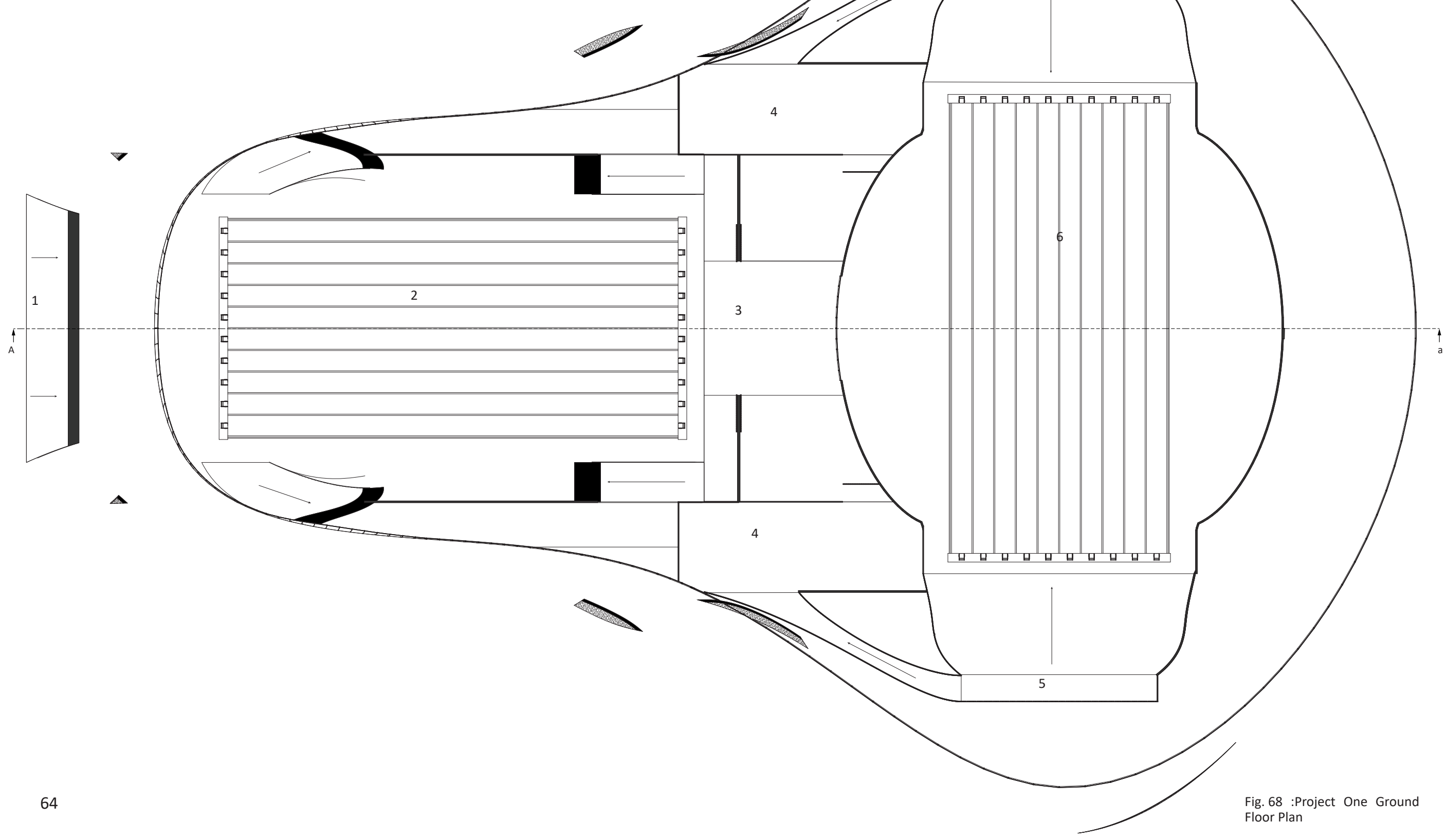


2- Entry

3- Athlete's Lounge

4- Changing Room

6 - Up to spectator seating

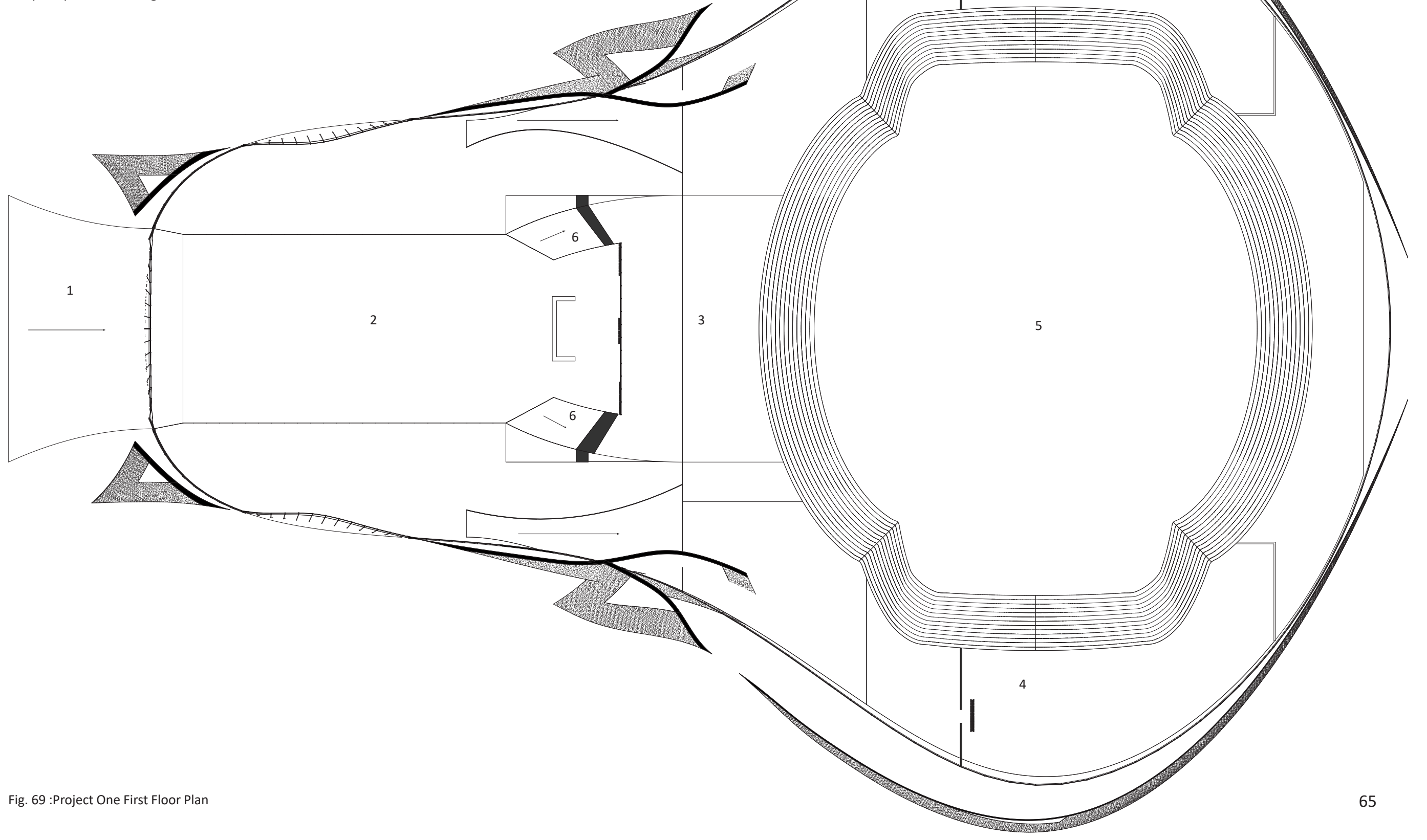




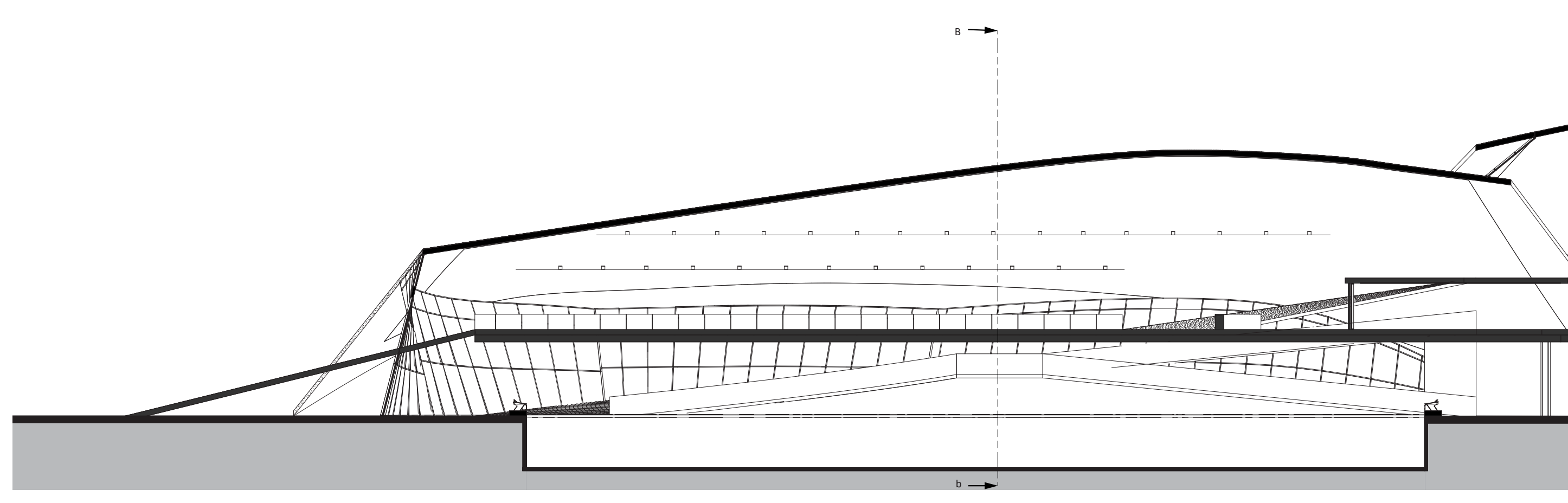




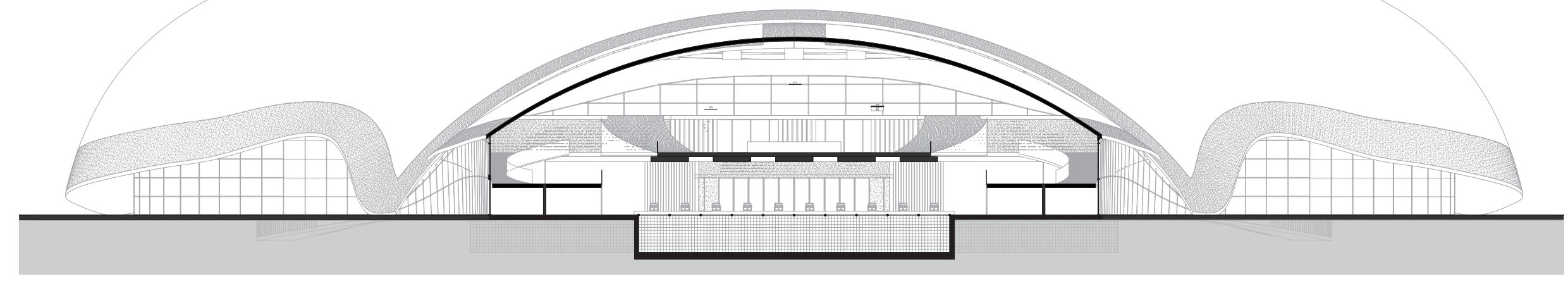

Fig. 71 : Section B-b - Warm Up Pool 


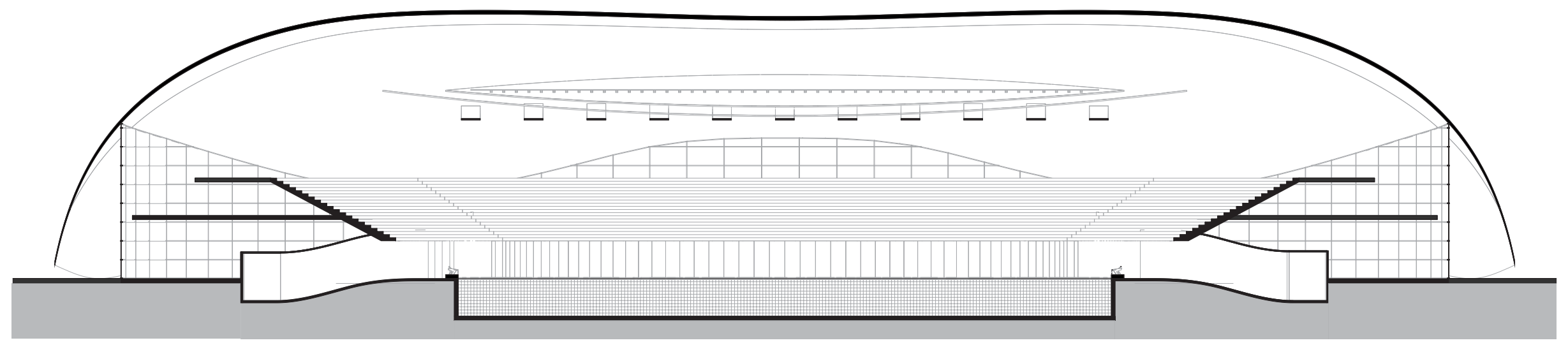

Fig. 72 : Section C-c - Competition Pool 


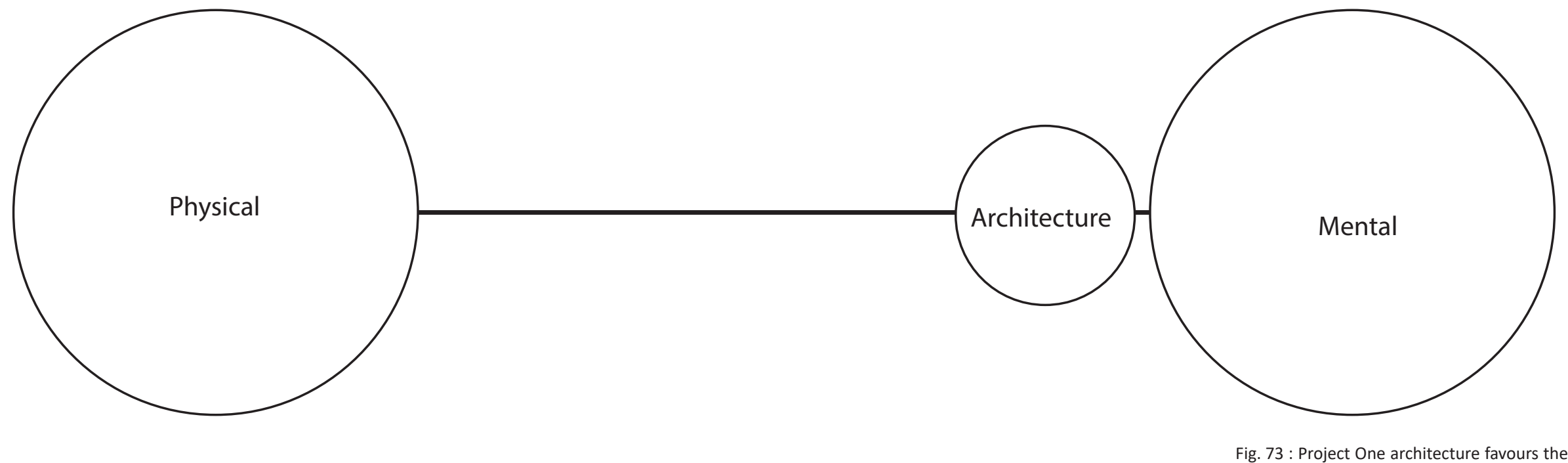

Fig. 73 : Project One architecture favours th mental qualities rather than the physical 


\section{PROJECT 1 DESIGN CONCLUSIONS}

The building is designed with the intentions of the athlete in mind. By doing this, it has created spaces with the right atmosphere to allow the athlete to enter the IZOP.

The building does not consider the influence of spectators on site. These factors have an influence on how the building operates, user experiences, and the athlete's progression through the building.

The facility overall, celebrates the athlete and prioritises them. It has a strong bias towards the architecture affecting the mental aspects of an athlete's performance. 


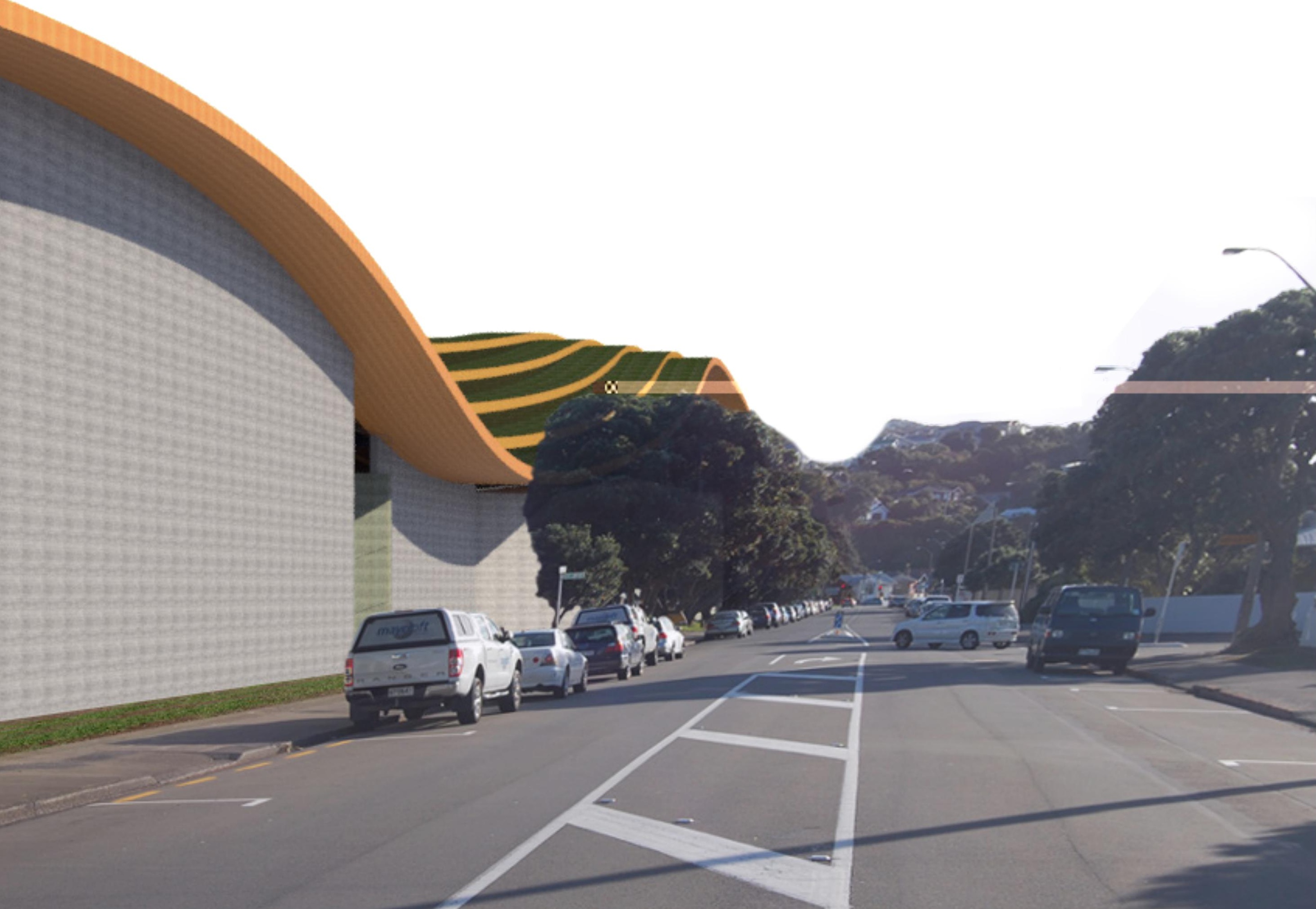




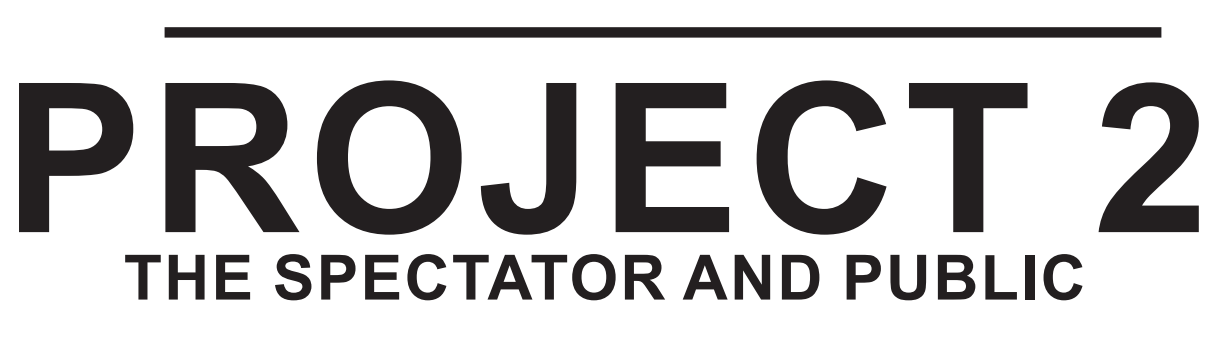


My Motivation

The Project - The problem Research on problem-

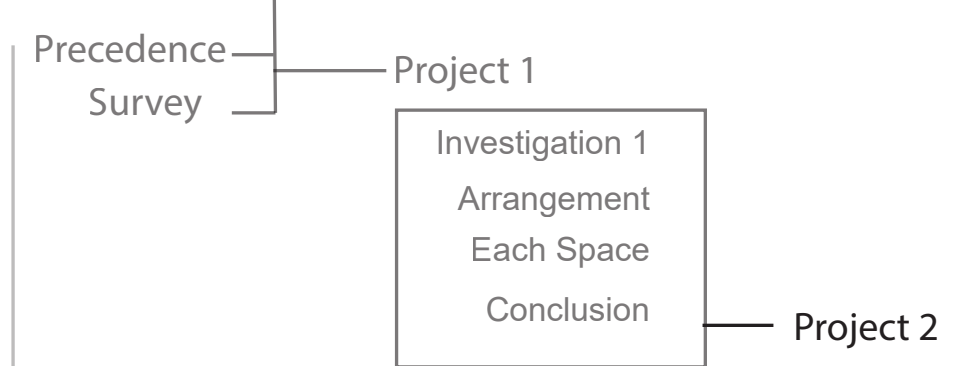

Problem Generated from Project 1

Site Investigation

Investigation 2

Arrangement

Each Space

Conclusion

\begin{tabular}{|r|}
\hline Problem Generated from $\begin{array}{l}\text { Project } 1 \text { and } 2 \\
\text { My Motivation } \\
\text { Investigation 3 } \\
\text { Arrangement } \\
\text { Each Space } \\
\text { Conclusion }\end{array}$ \\
\hline $\begin{array}{l}\text { Final } \\
\text { Conclusion }\end{array}$ \\
\hline
\end{tabular}




\section{PROJECT 2 INTRODUCTION}

Project Two will be investigating what influence a site has on the Aquatic Centre. This will continue from the themes of Project One, but explore how the new factors like community programs and public usability influence the design.

The main conclusion from Project One, is the need for a specific site or community to respond to and for the facility to take advantage of

With the introduction of the site, brings the need to influence spectators and public use. Rather than just focusing on a competition, the facility will need to handle day-today use between competitions.

The London Olympic Aquatic Centre was designed twice for during and after the games. They are called 'The Games Configuration" and the "Legacy Configuration.' This allowed for the Games events to be held in an athlete focused facility, then easily altered to a community based facility that operated both for competitions and community programs. (Tom Dyckhoff, 2012)
Aim - to apply findings from Project One and apply them to a site and community to investigate how the two programs affect each other.

\section{Method of design}

- Influences from Project One

- Influences from the site

- How the building has the design of the facility response?

- Overall design outcome 


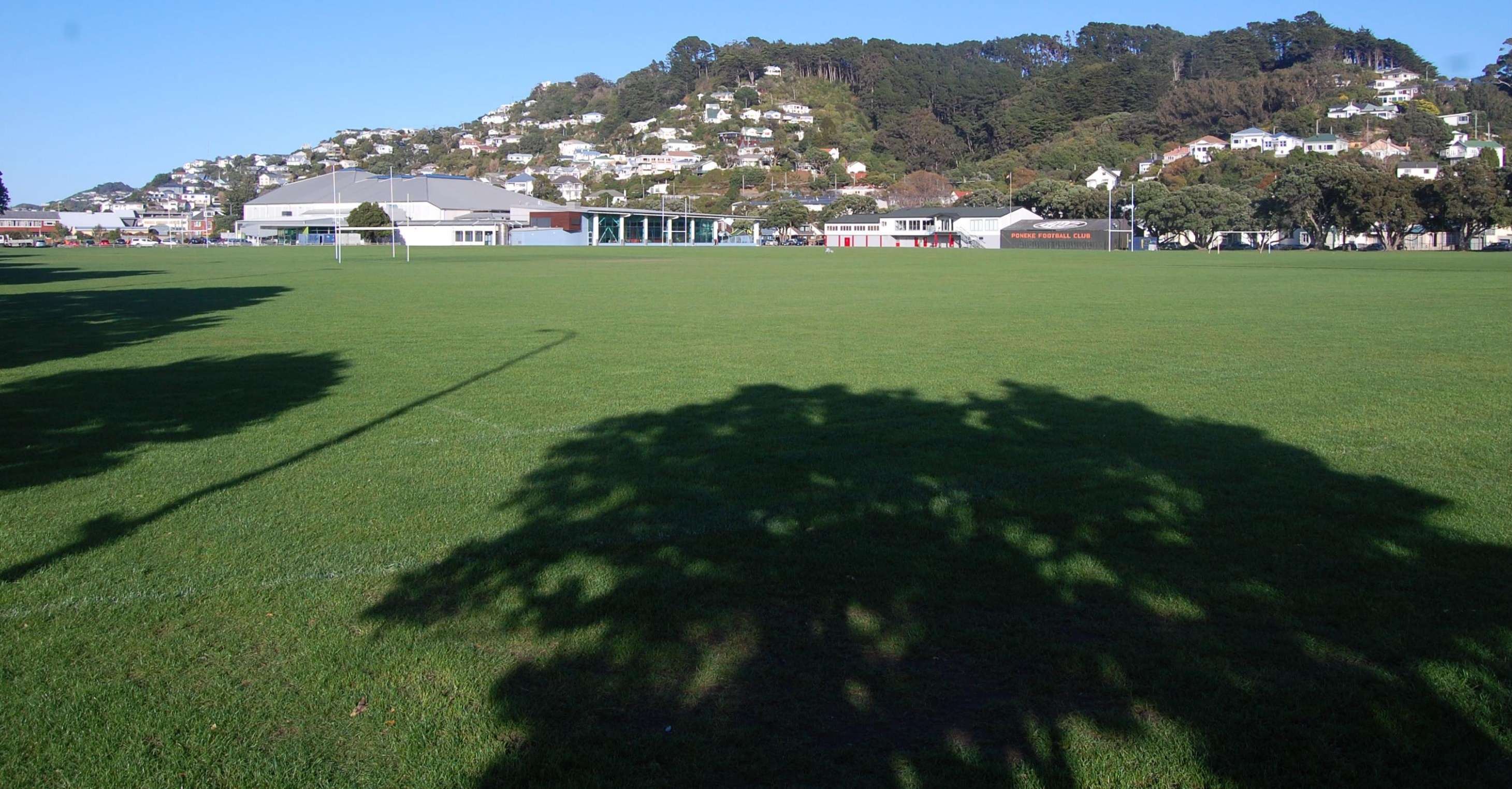




\section{THE SITE Kilbirnie Park}

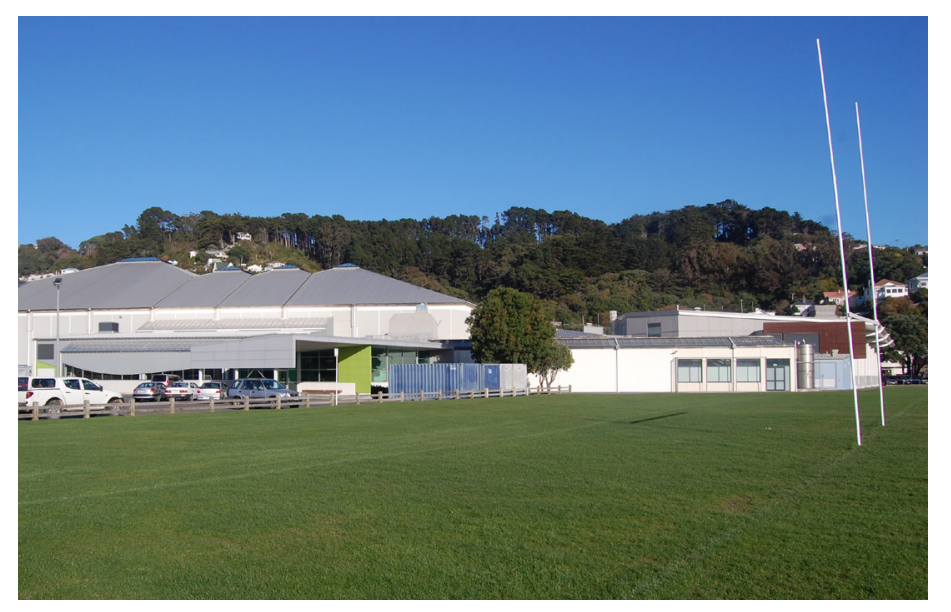

The site for the project is Kilbirnie park. The park is located in the eastern suburbs of Wellington. The park is used for sports like Cricket, Rugby, Football and numerous other community sporting events. At the southern end is the Wellington Regional Aquatic Centre, Bowls Club, Rec-centre and Library. All of them have large community connections. The ground is home to several sports clubs and social clubs.

This site is perfect for a new facility, as it can include the old pools. It is close to several local schools and colleges that use the onsite facilities. The capitals biggest indoor sports facility, ASB Sports Centre is $2 \mathrm{~km}$ down the road. The building will be placed on major bus routes therefore easy access for all. State High way one that links the airport to the central city runs on the northern edge of the park and major cycling route that links the park to oriental bay touches the park in the northeast corner.

The biggest advantage for this Centre is how close it is to the airport and the city. This allows for easy access for national and international competition. This is important as they can arrive, compete, stay and fly back the next day. This is compared with the new Sir Owen Glenn National Aquatic Centre in Auckland where it takes over an hour to reach the facility from the airport.

Fig. 76 Left: View across Kilbirnie Park to WRAC and Poneke Rugby Club Rooms.

Fig. 77 Top Right: WRAC rear entrance

Fig. 78 Right: Rec-centre and Library

Fig. 79 Bottom Right: View of access to Kilbirnie township
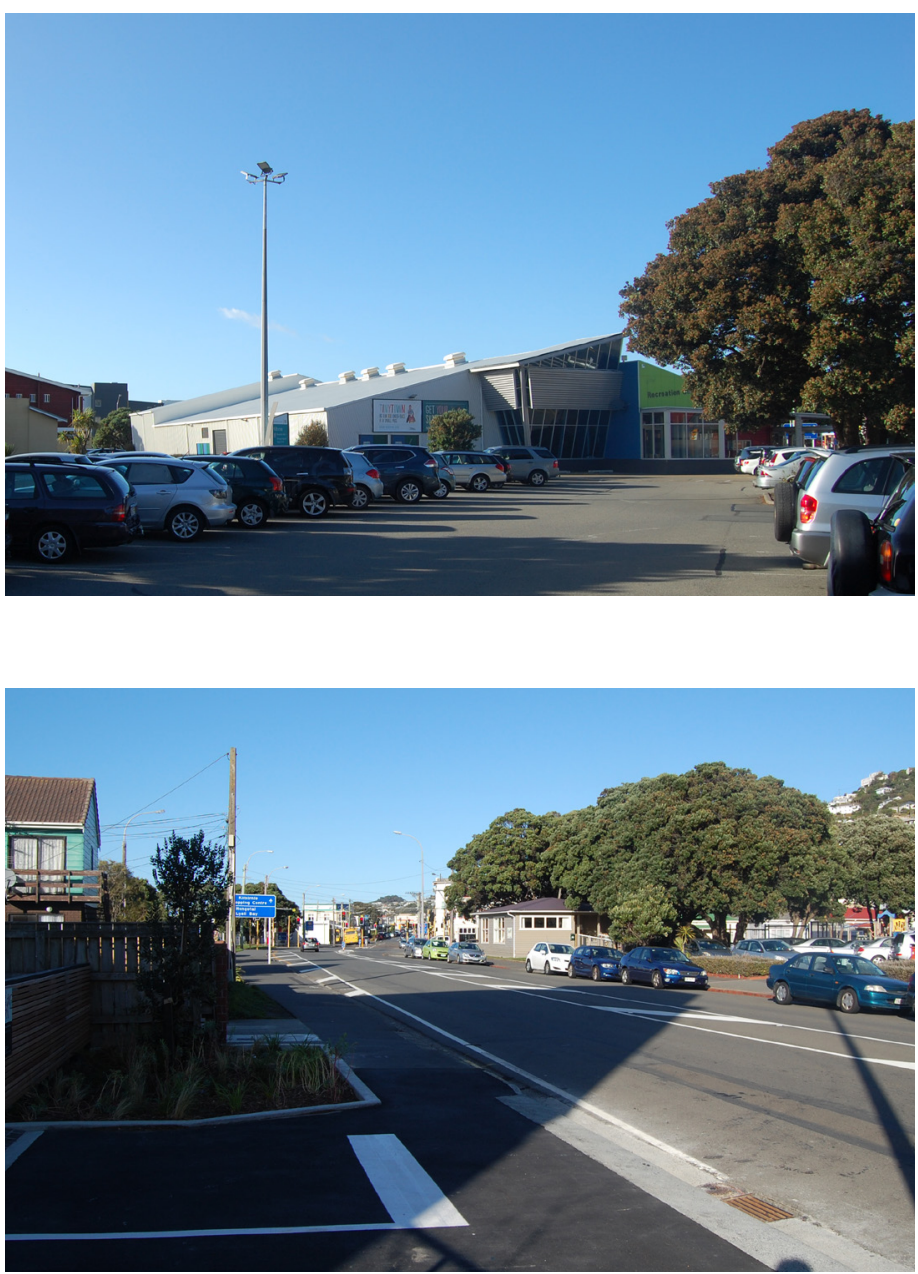


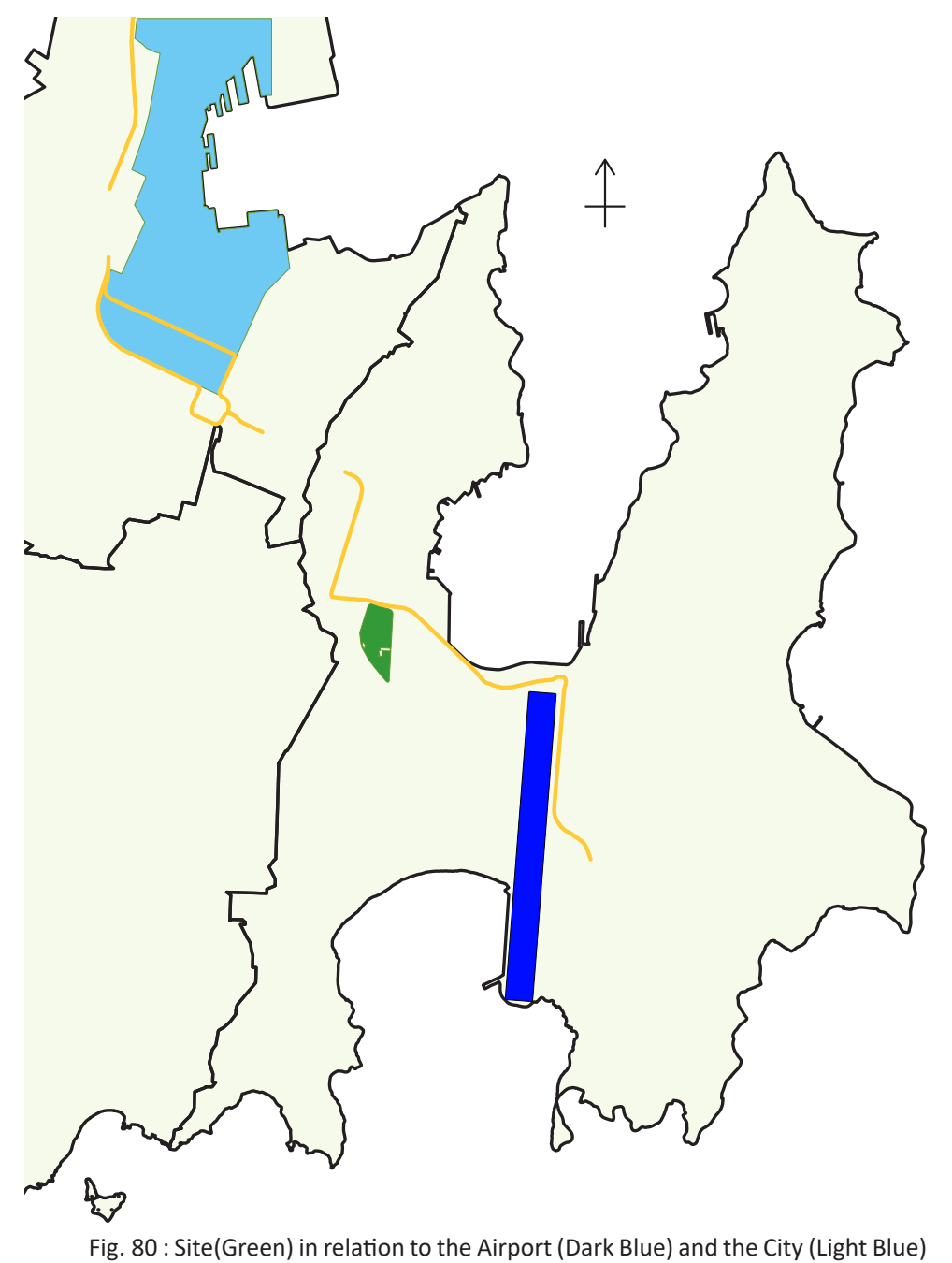



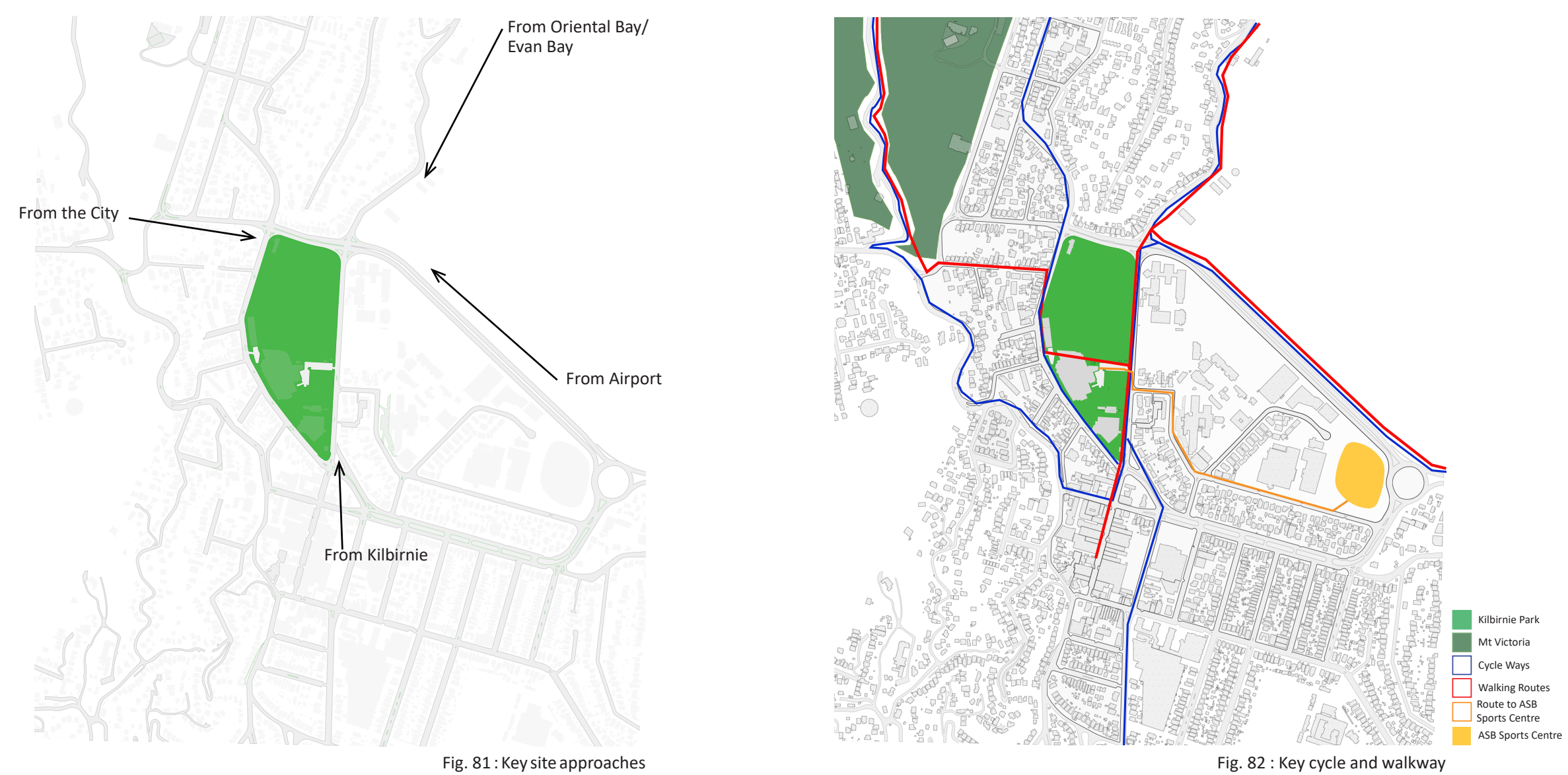

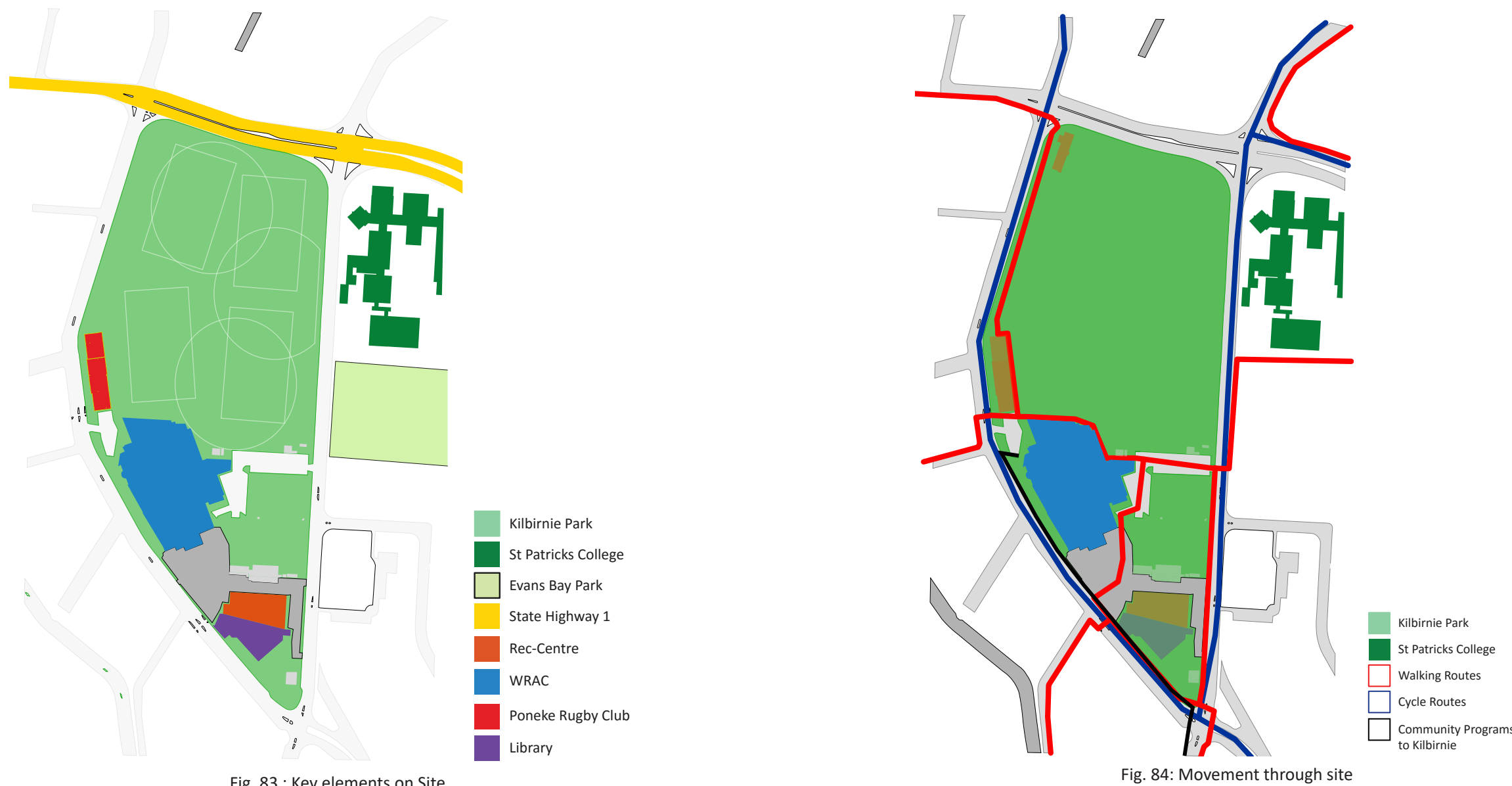


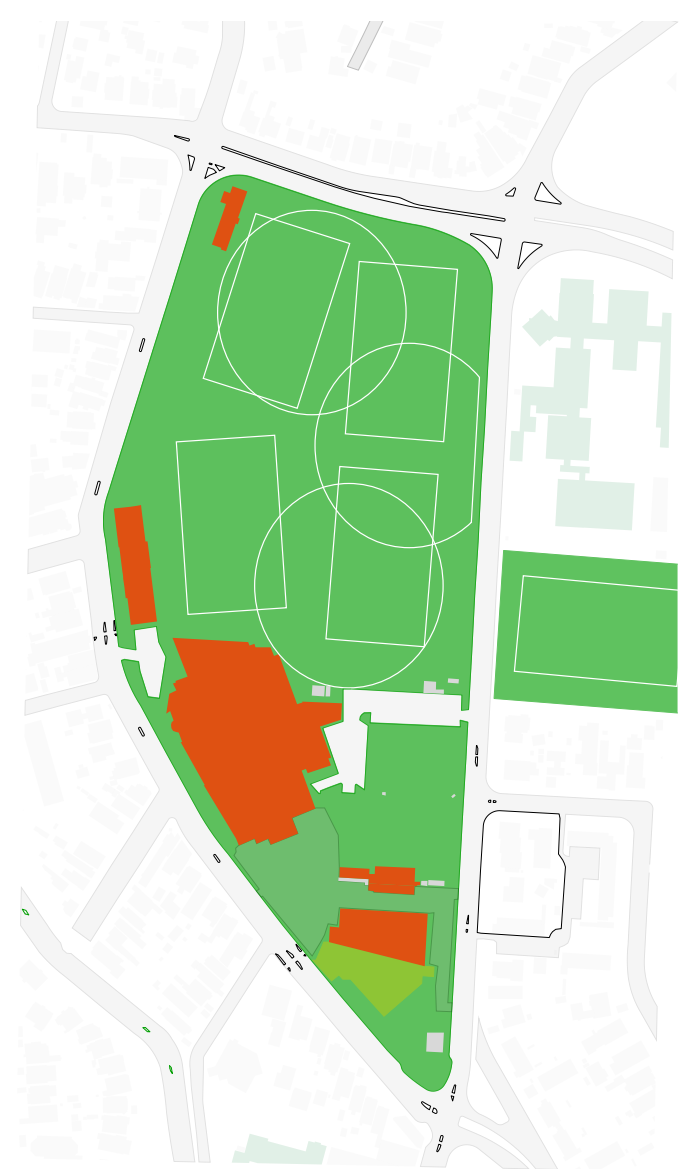

Fig. 85 : Sports facilities (Orange), Sports fields(Green)

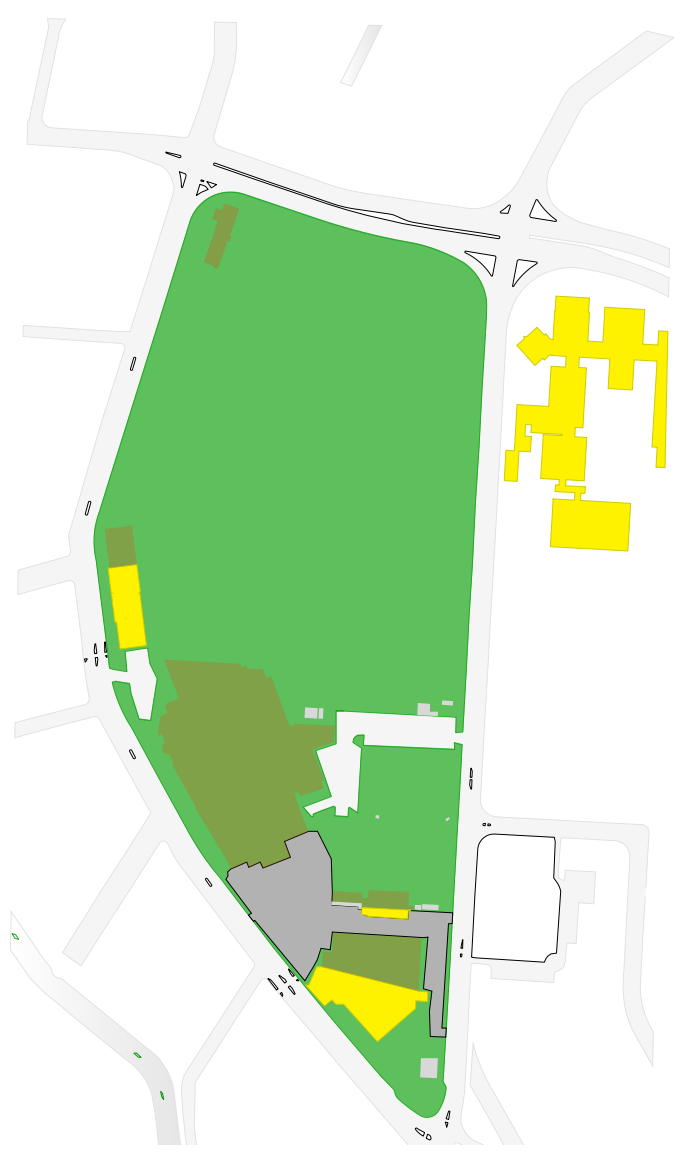

Fig. 86 : Community Facilities-Yellow 


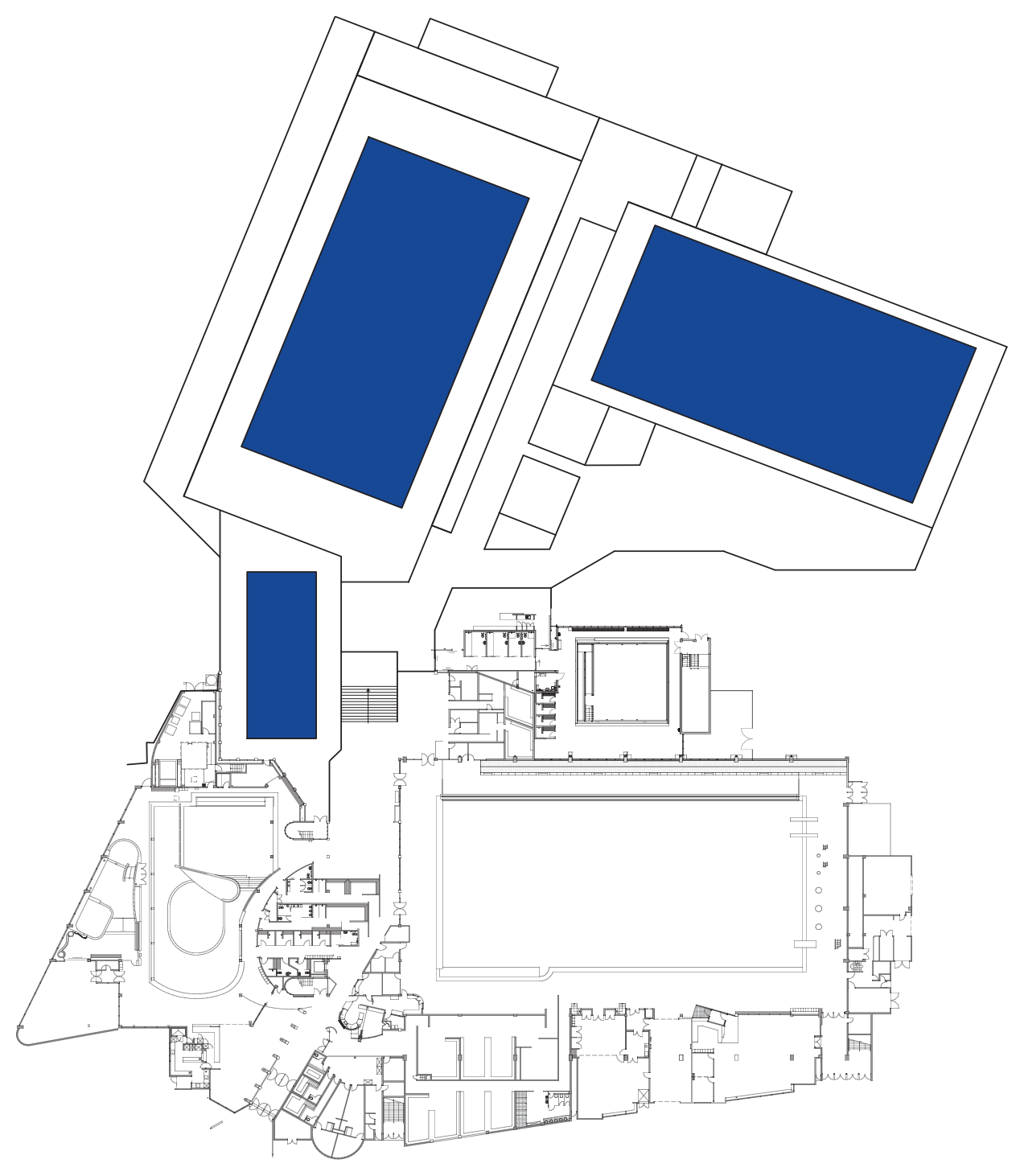

Fig. 87 :First floor plan of the initial response 


\section{The Initial Design Response}

The initial design response was to use the existing building and add an extension. This has been proposed by the Wellington City Council and other parties but has been put on hold. (DUFF, 2011)

The response would use the land the bowls club currently use. A rotation of the current Learn to Swim Pool ninety degrees to allow for the continuation of the main circulation route from the main entrance though to the new building. The new building wil have a dedicated $50 \mathrm{~m}$ Competition Pool and another $50 \mathrm{~m}$ Warm Up Pool. The T arrangement of project one will dictate the layout of the pools.

Upon starting this response, the findings allowed me to quickly realise this line of investigation will limit the introduction of new ideas based on Project One and understand how new influences, like community facilities, will interact with each other. Therefore, to get the best results I will design a new facility that includes current programs on site.

Fig. 88 Top: Initial design building foot prin

Fig. 89 Bottom: Space the addition would take up

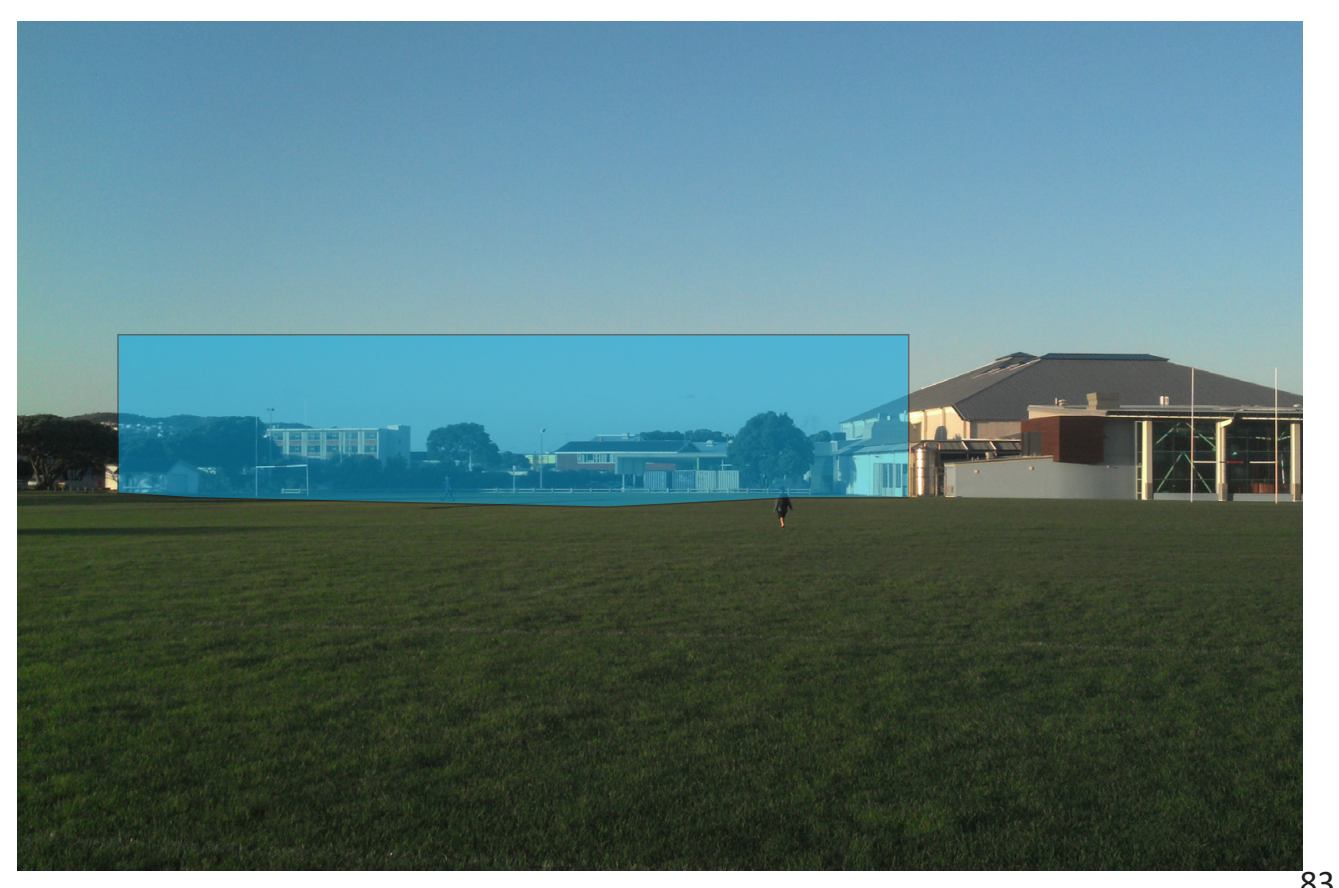


Fig. 90 Above: Cayton Community Centre (Jackson Architecture)

Fig. 91 Top Left: Exterior View (Archiphoto Pty Ltd)

Fig. 92 Left: Library (Archiphoto Pty Ltd)

Fig. 93 Bottom Left: Fitness club over looking the swimming

facilities (Archiphoto Pty Ltd) 


\section{DESIGN RESPONSE}

The design response needed a solution that used the existing same as Project One and follow the athlete's processes. The programs on site. To do this, the response has been broken up influence of these new programs will be explored in relation to into several moves that have been influenced by logic derived the effect it will have on an athlete focused facility.

from conditions on site and program requirements.

After looking at the site, the form and precedence's, the building As a precedence, I looked at the Clayton Community Centre by needs to respond to three key features:

Jackson Architecture and how they approached the key task of incorporating all aspects of the community into one building.

- The local community's access to the building and recreation

The building is separated into different community programs.

They did this to create a community hub that "encourages exploration so that users of one facility may be attracted to others on offer." (ArchDaily, 2012) Though all the programs are

under one roof, they are still separated and many have their own To do this I created a series of moves in which influenced the entrances. This precedence is still a good standard to analyses my form and shape of the building

response against when incorporating community programs into

my design.

A Library, Rec-Centre and Community Pools (Hydrotherapy, Children Play and Learn to Swim Pool, Spa and Saunas, Gym and

Café) are added to the design. The athlete program will be the 


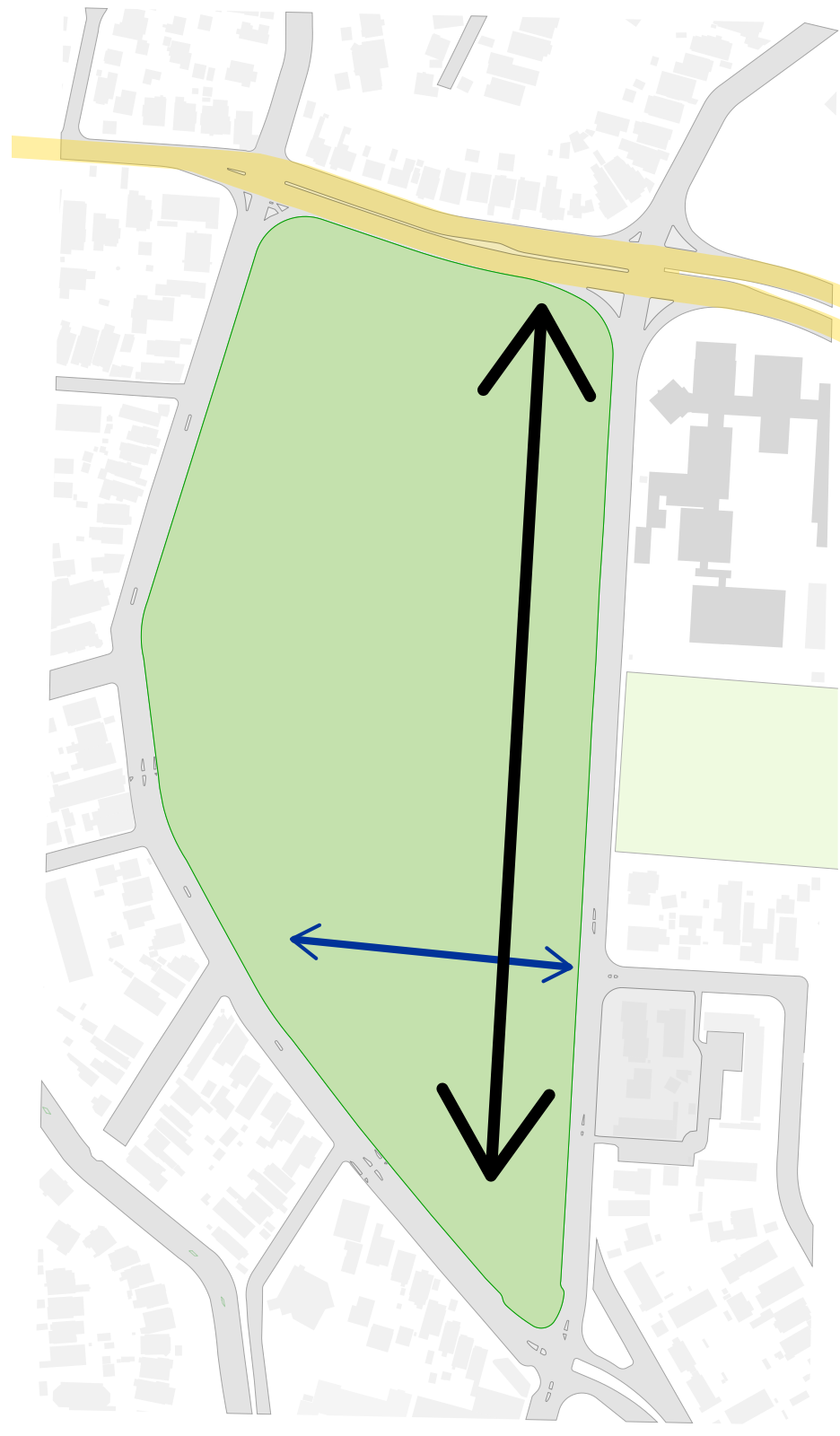

Fig. 94 : Finding the axis

The first move was to find an axis that existed on the site. The main axis is North

to South, from SH1 to the township of Kilbirnie. The second less pronounced axis is, East to west; St Patricks College to St Catherine's College, where they share school facilities. Also by developing a stronger link to the ASB Sports Centre along this axis, will help to create a hub for sport in Wellington. 


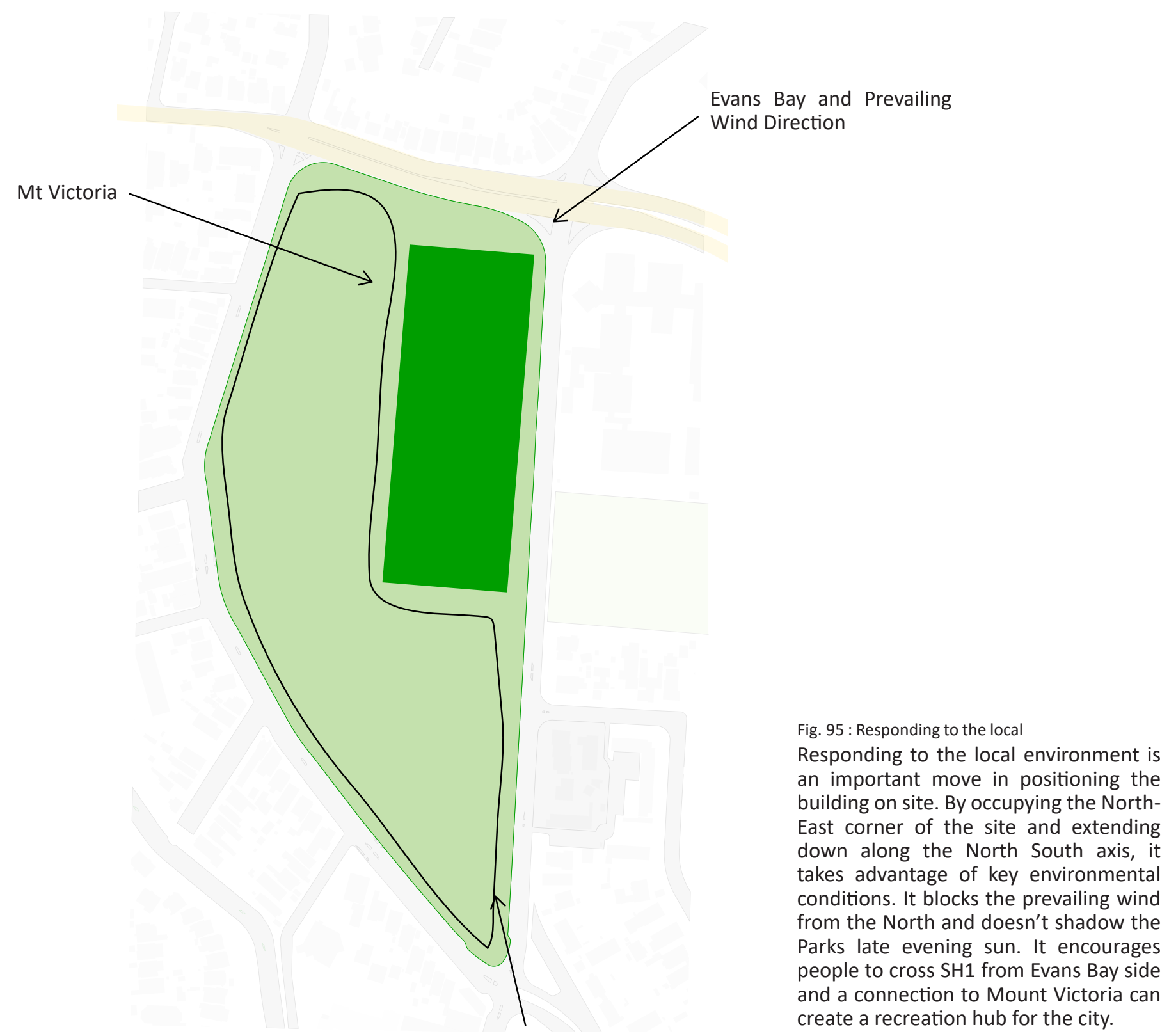

Kilbirnie Township 


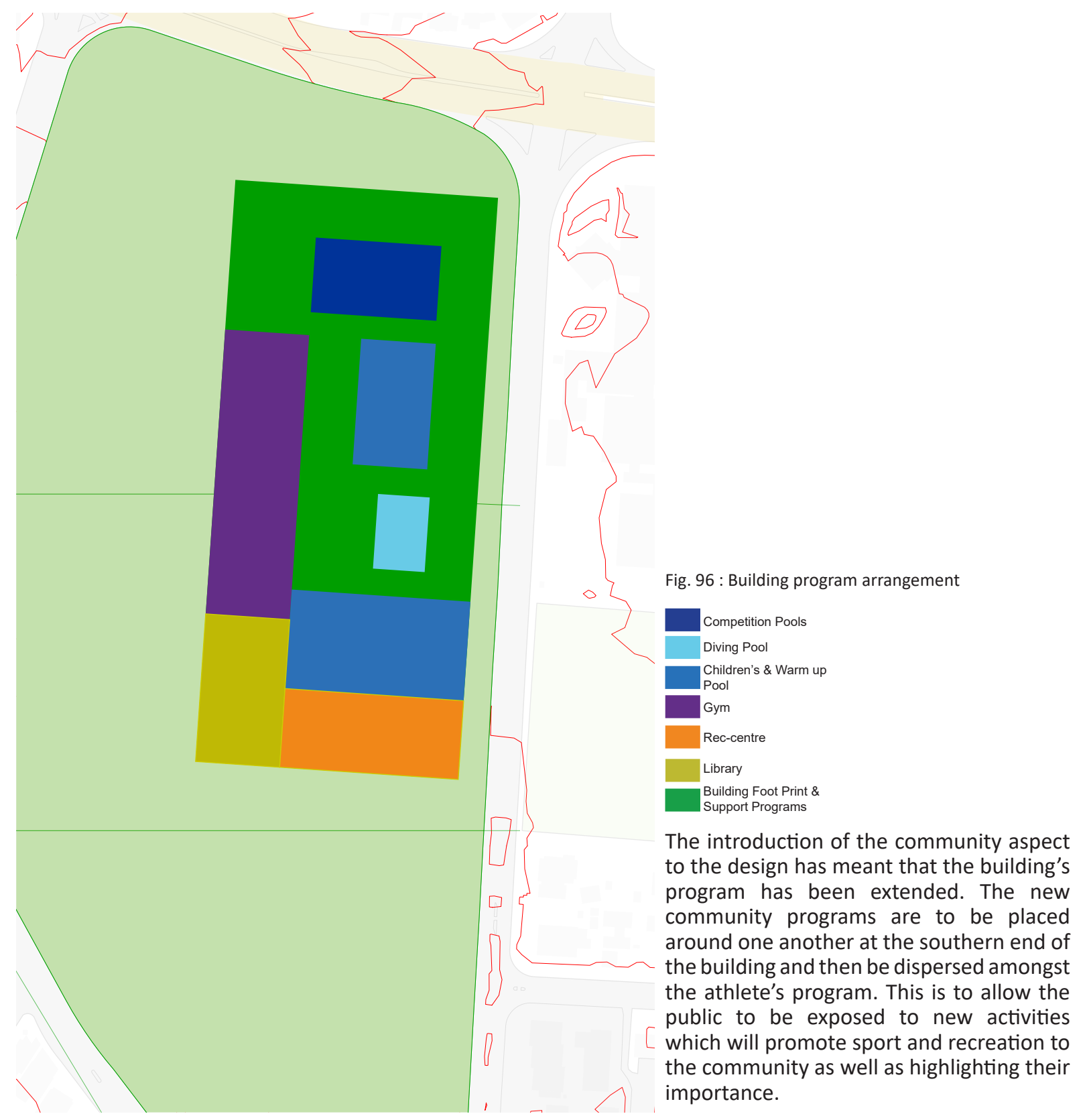




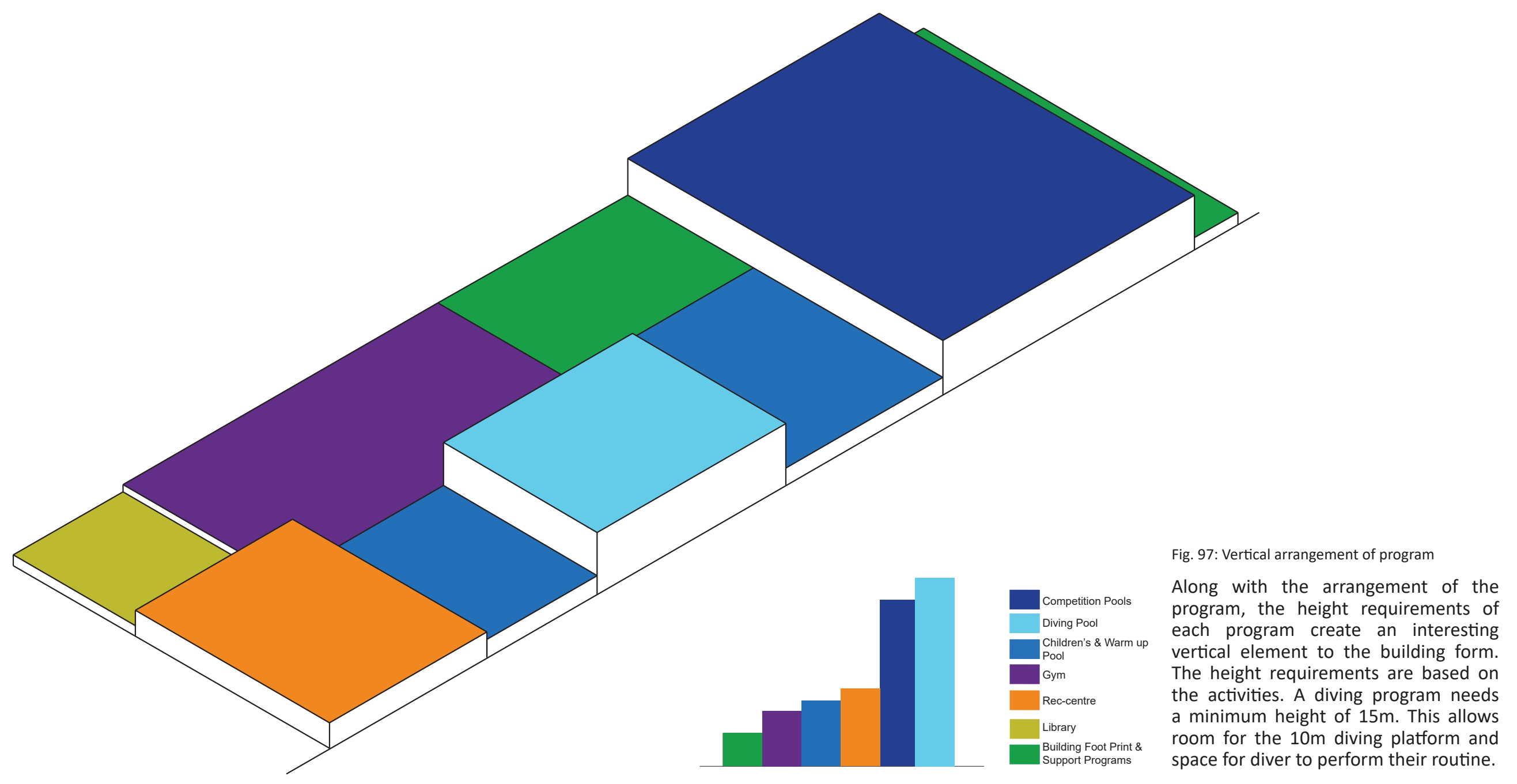




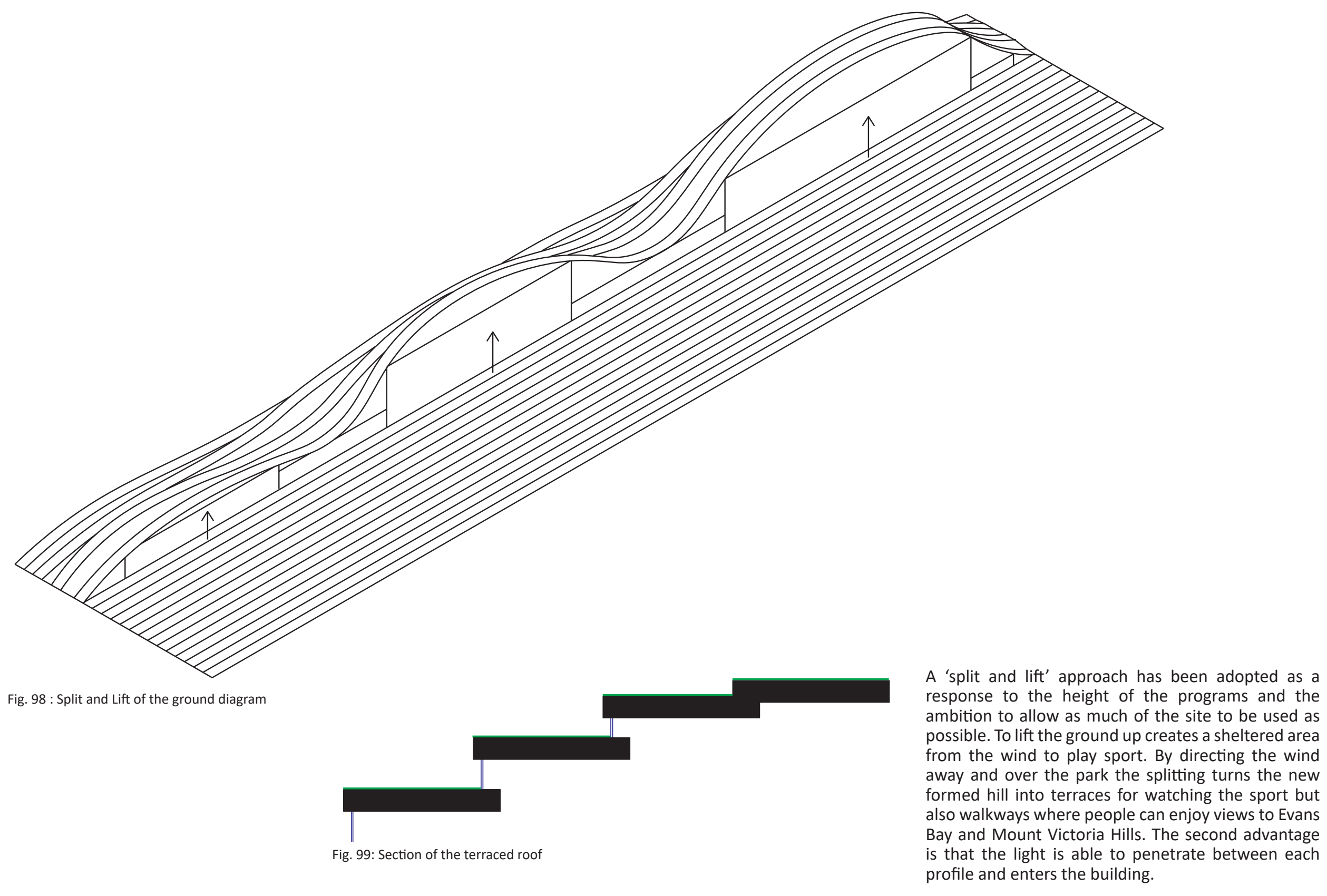


Three precedents have inspired the 'split and lift' action

Yokohama Ferry Terminal (Fig:102) Designed by Foreign Office Architects inspired the use of the roof as an extension of the park. The materiality of this building has influenced the design.

Navy Pier Chicago (Fig:101) by nARCHITECTS inspired the splitting of the roof which allows light into the building but also allows the roof to be used as well.

Church of Saint Francis of Assisi (Fig:103) by Oscar Namimer inspired the lifting of the ground and the profile created by this action.

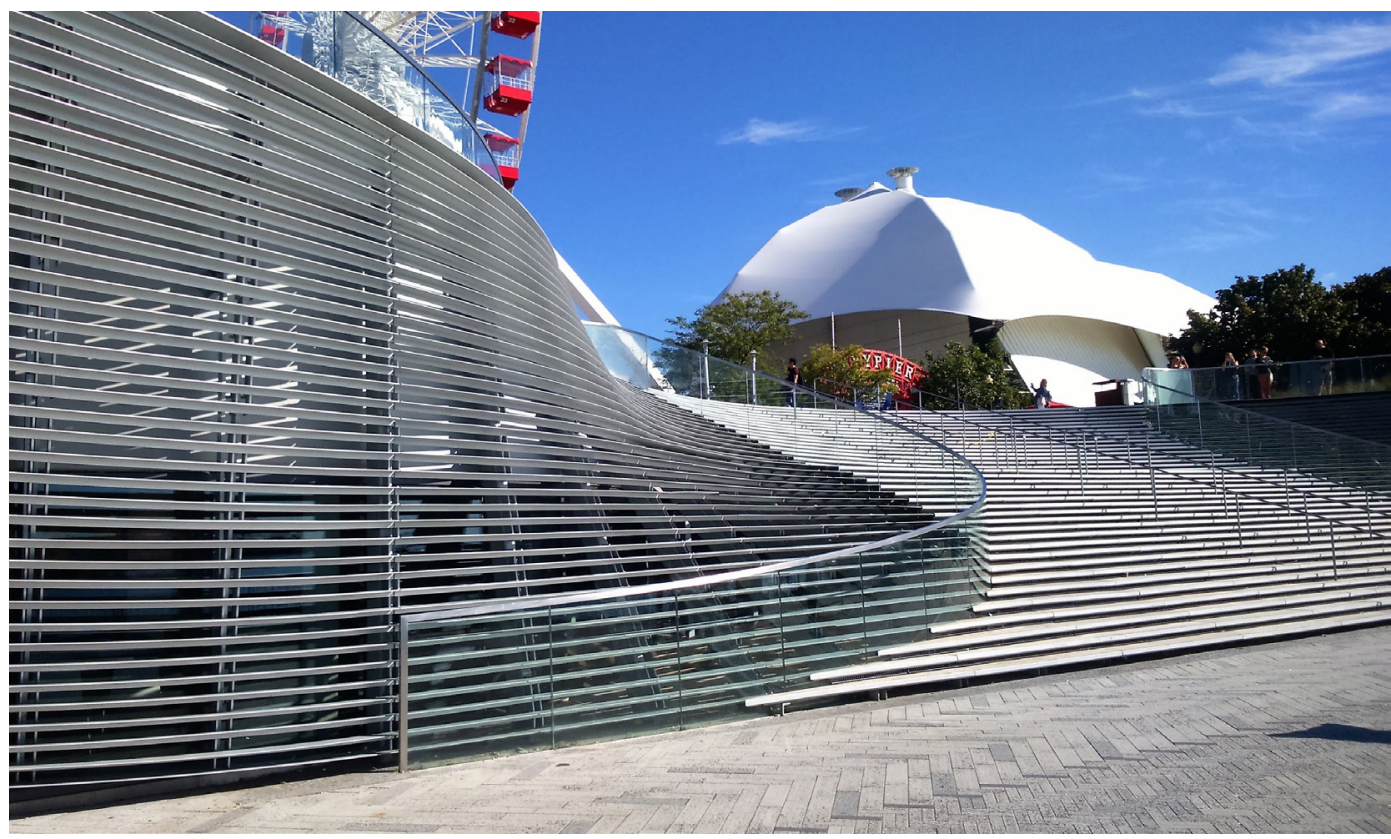

Fig. 100 : (Author 2015) 


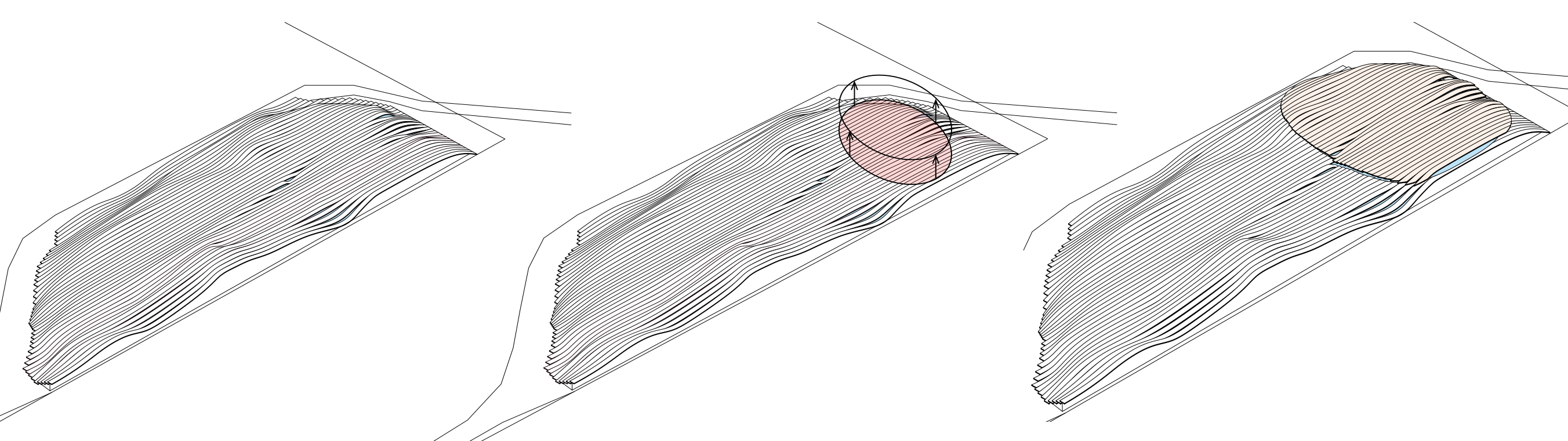

Fig. 103 : Roof Cut Out Diagram

The roof of the competition pool has been cut out and raised to highlight it from the exterior. It also lets the public view the top athletes while they train and compete,

Fig. 104 : Section of the roof cut out which also helps to help inspire the next generation of swimmers. 


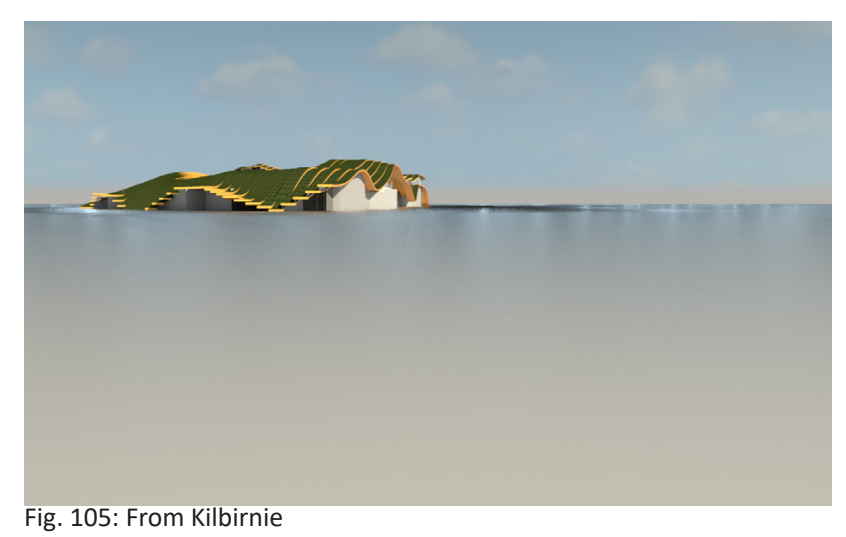

From Evans Bay

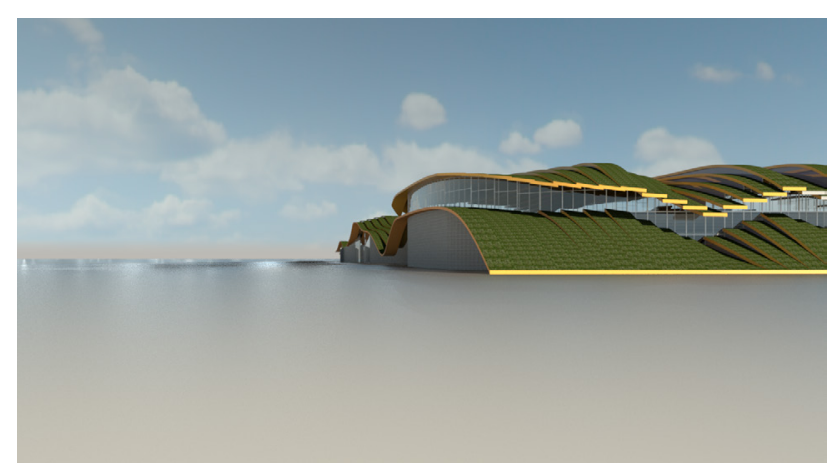

Fig. 106: From Evans Bay

From the City

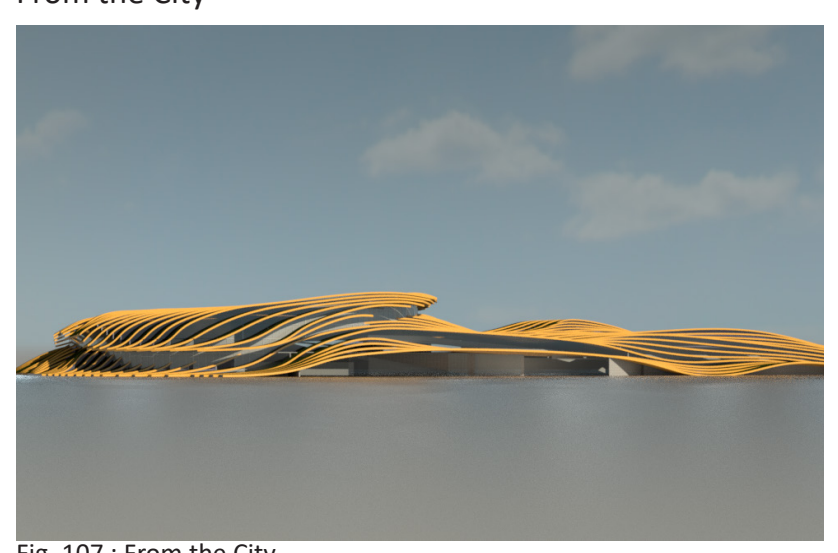

\section{Approaching the Facility}

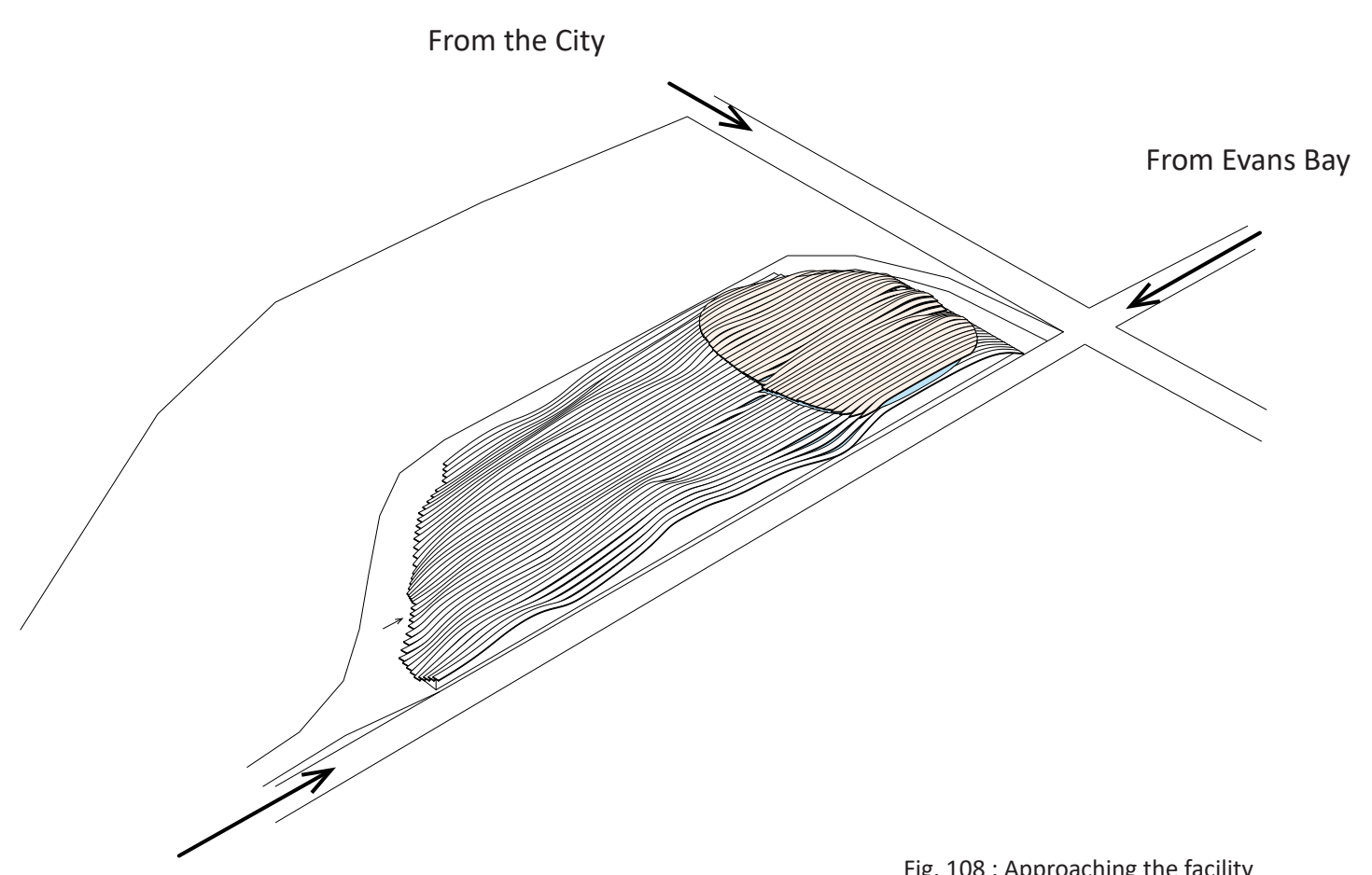

From Kilbirnie

Fig. 108 : Approaching the facility

Approaching the facility, a good visual of the length of the building is achieved. Influenced by the first project, the building is long and thin at each end, which makes the building look even longer. This has created an opportunity for a path to be added through the site, from Evans Bay towards Kilbirnie, which activates both edges of the building. 


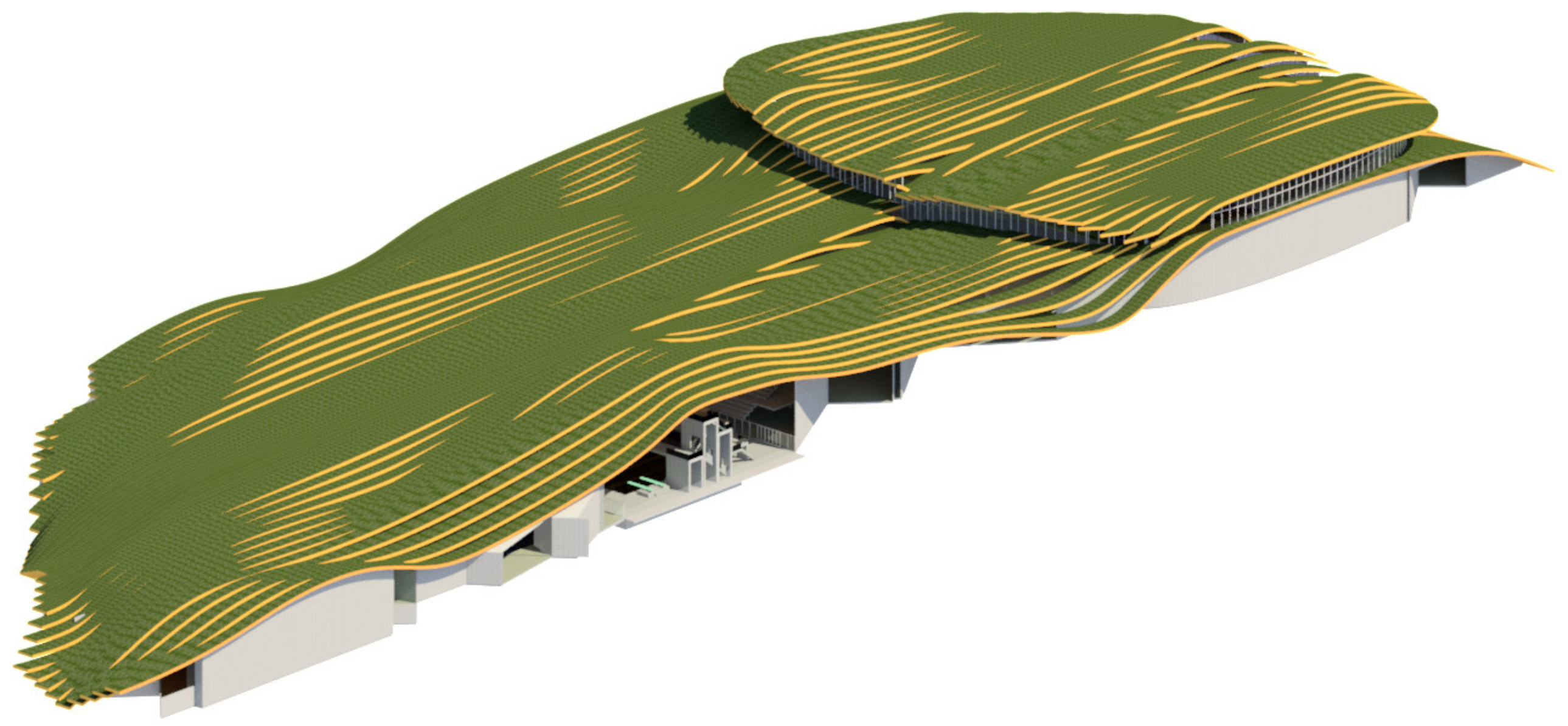




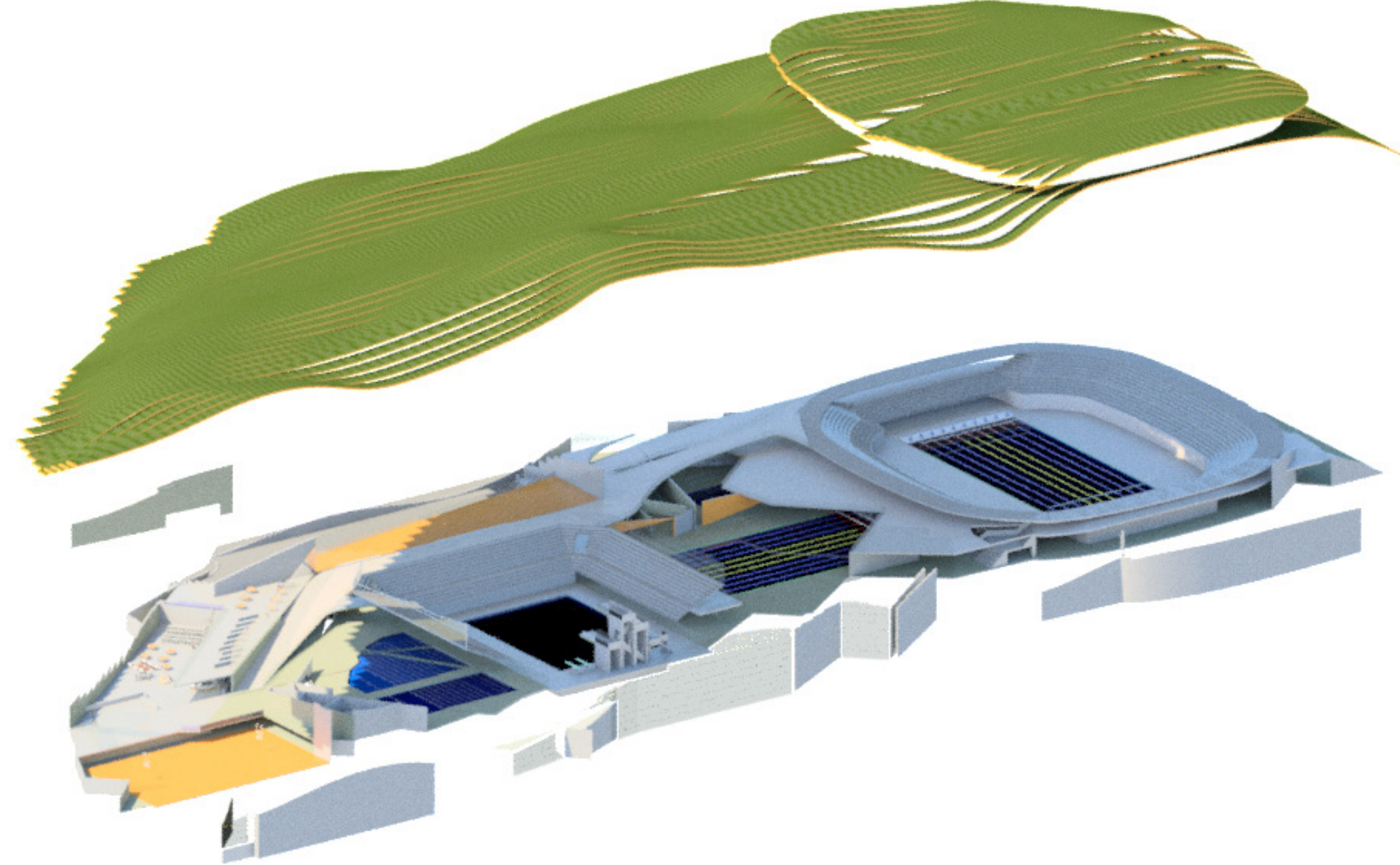

Fig. 110: Exploded Axo of the design showing the interior layout. 


\section{Layout of Facility}

1 - Entry

2 - Children's pool

3 - Library

4 - Rec-centre

- Gym

7 - Warm Up Pool

- Warm Up Pool

8- Hydrotherapy

10- Up to the Athlete's Lounge

10- Up to the Athletes

(1)

13- Marshalling

4- Main pool entry

- Changing rooms

7-

ort Program

18- Ramp for spectators to Dive and Competition Pools

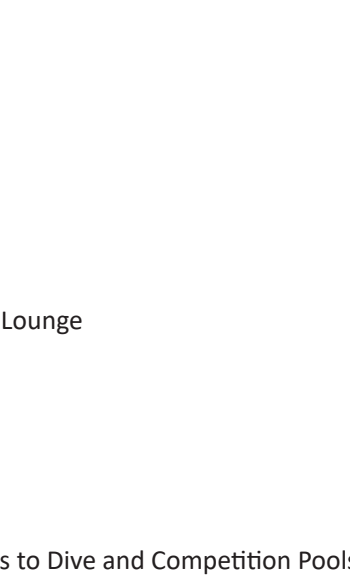

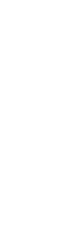

to Dive and Competition Pools
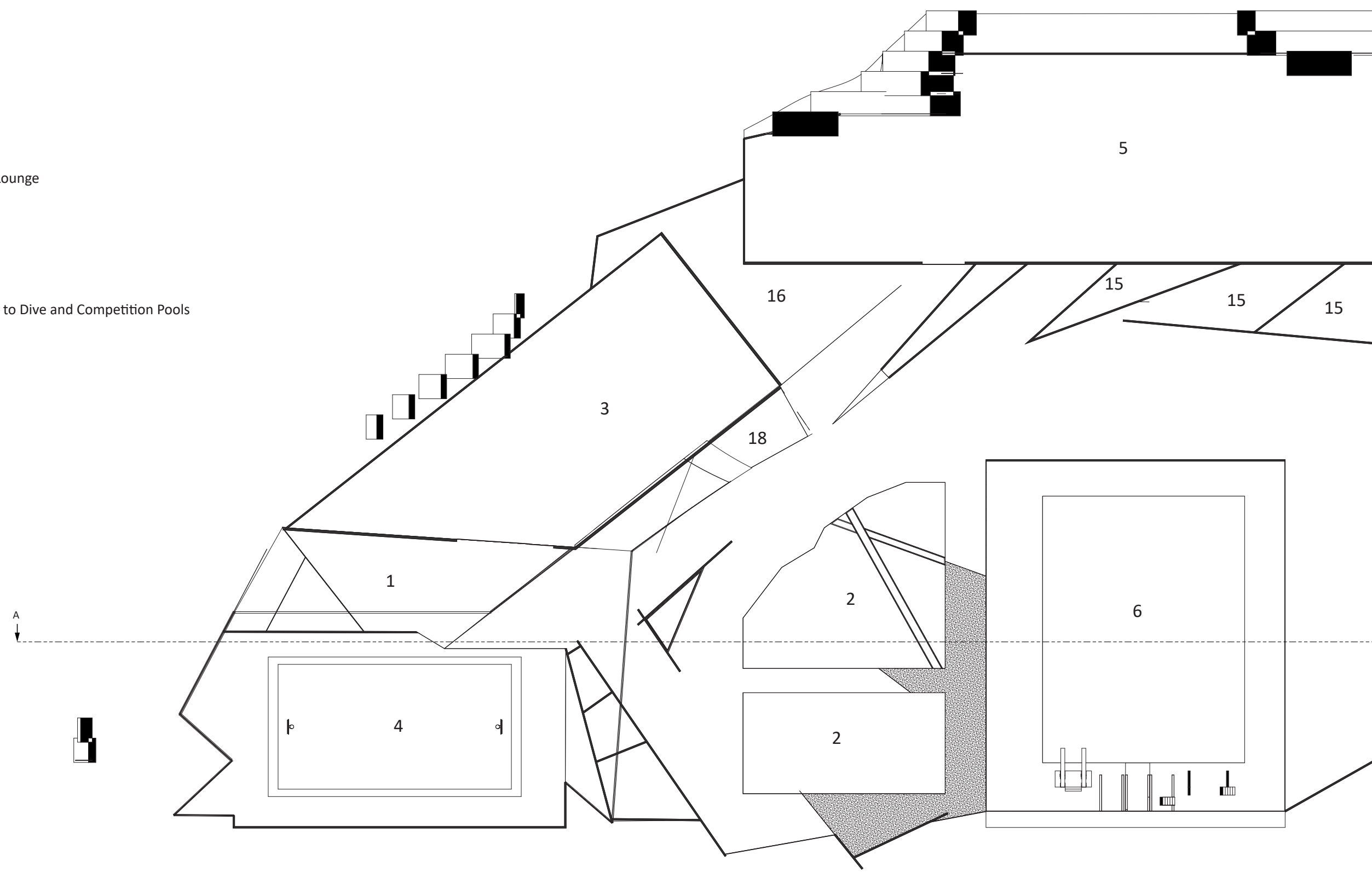

- 


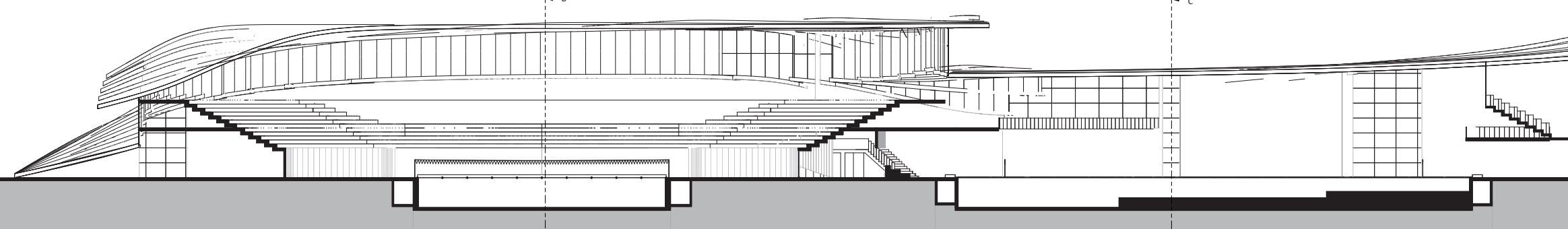




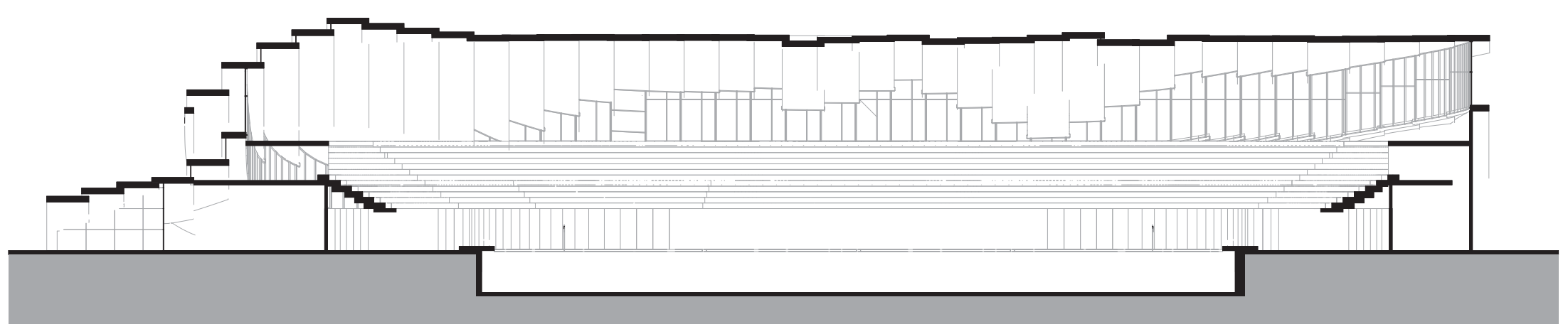

Fig. 113: Section B-b-Competition Pool

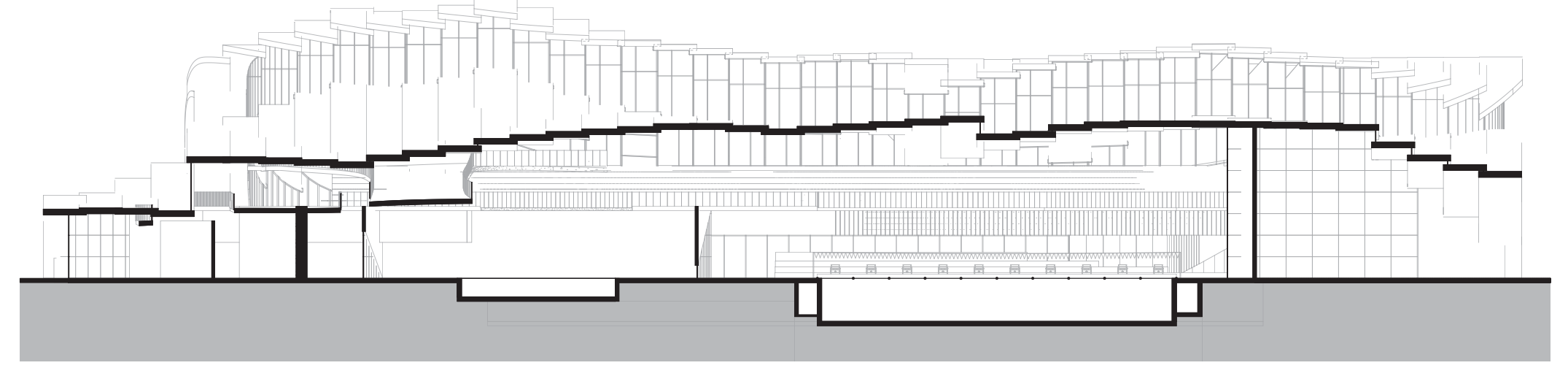

Fig. 114: Section C-c- Warm Up Pool 


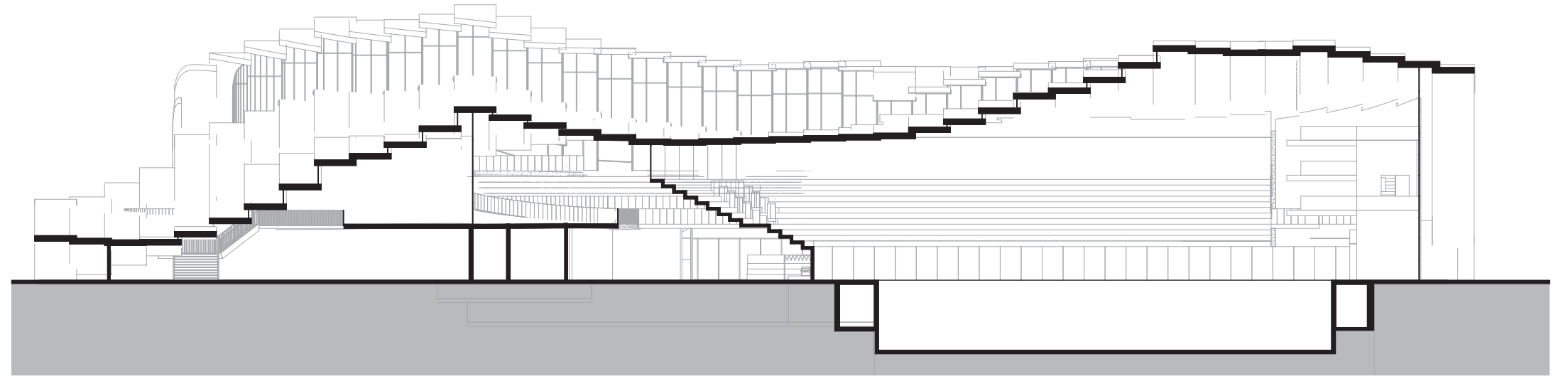

Fig. 115: Section D-d- Dive Pool

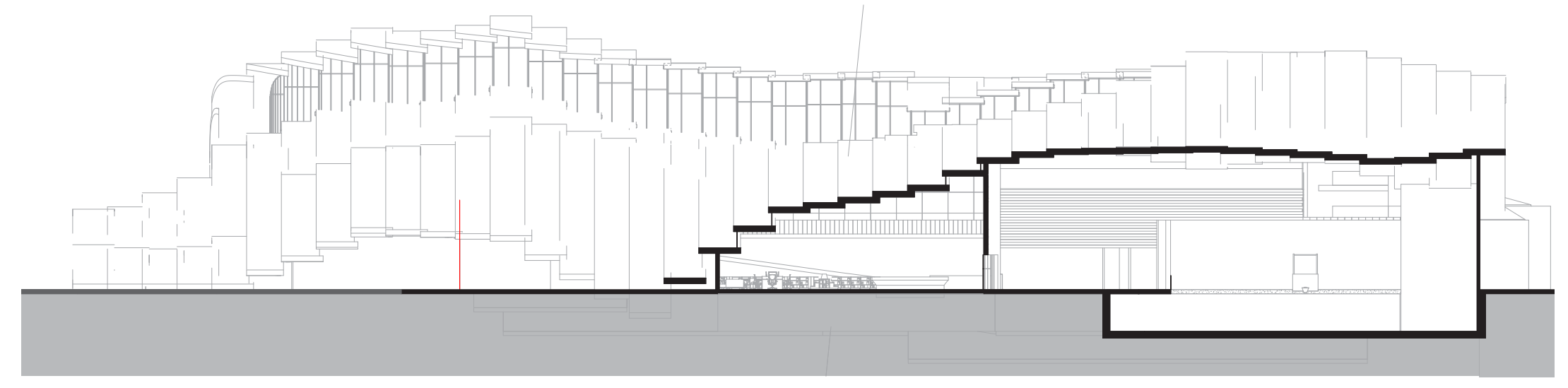

Fig. 116: Section E-e - Rec-Centre and Library 


\section{Community Programs}

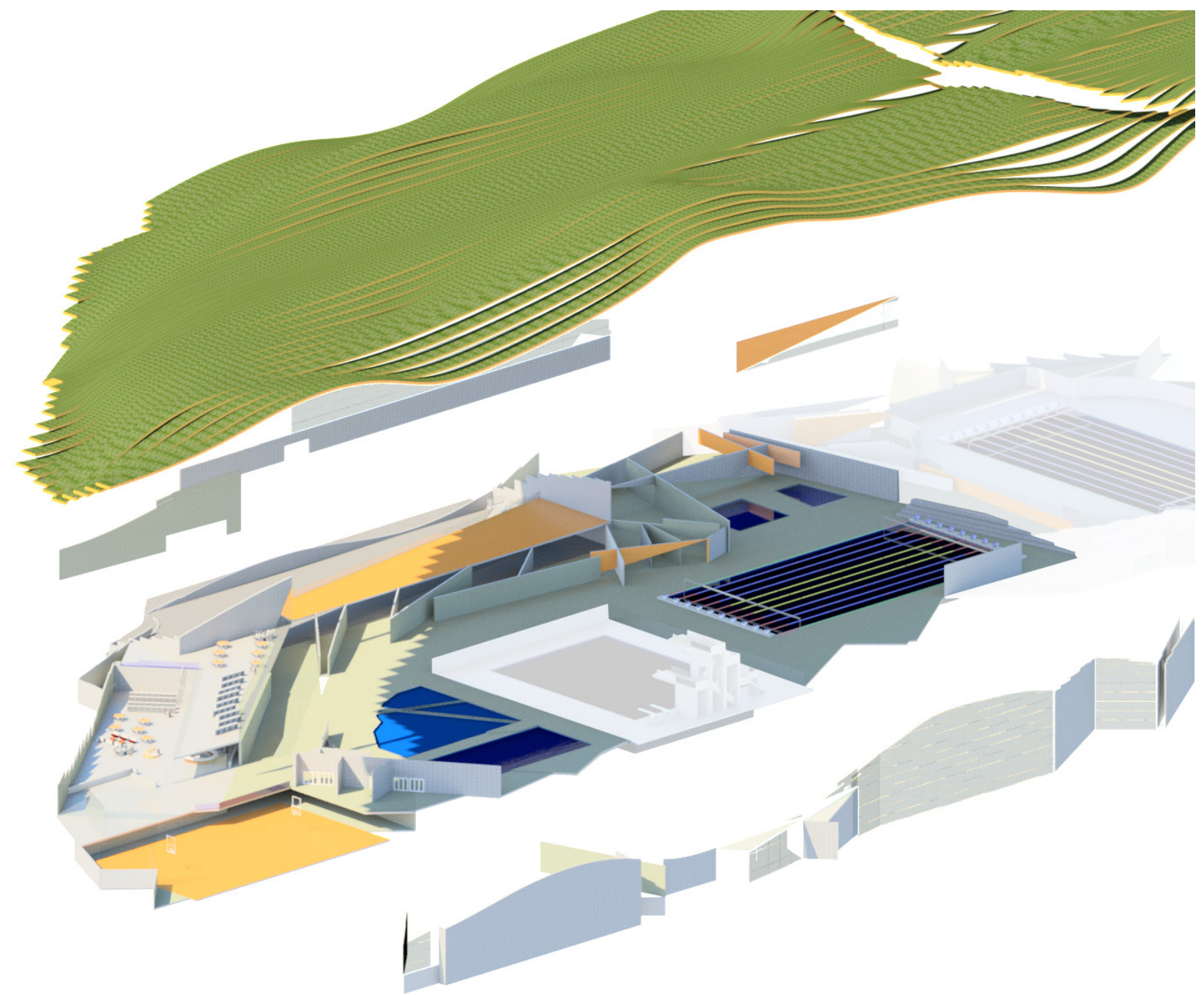

Fig. 117 : Exploded Axo - Community Programs 


\section{Building Entry}
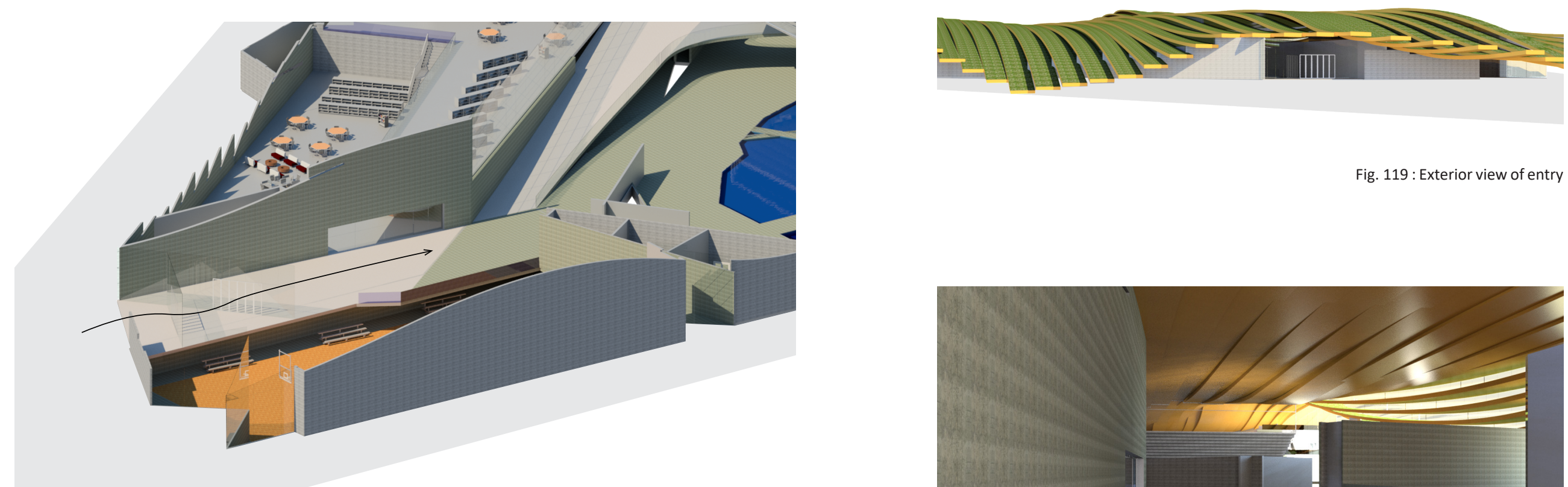

Fig. 119 : Exterior view of entry

Fig. 118 :Entry Axo

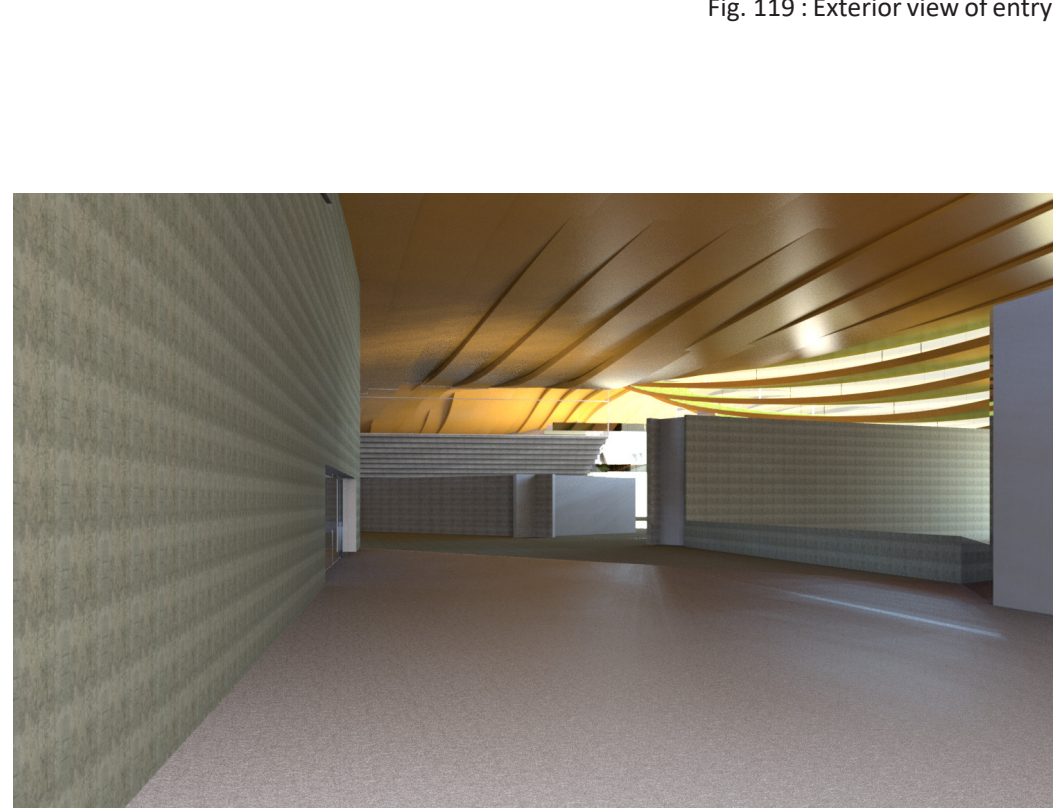

Fig. 120 : Interior view of entry looking toward Children's Pool 


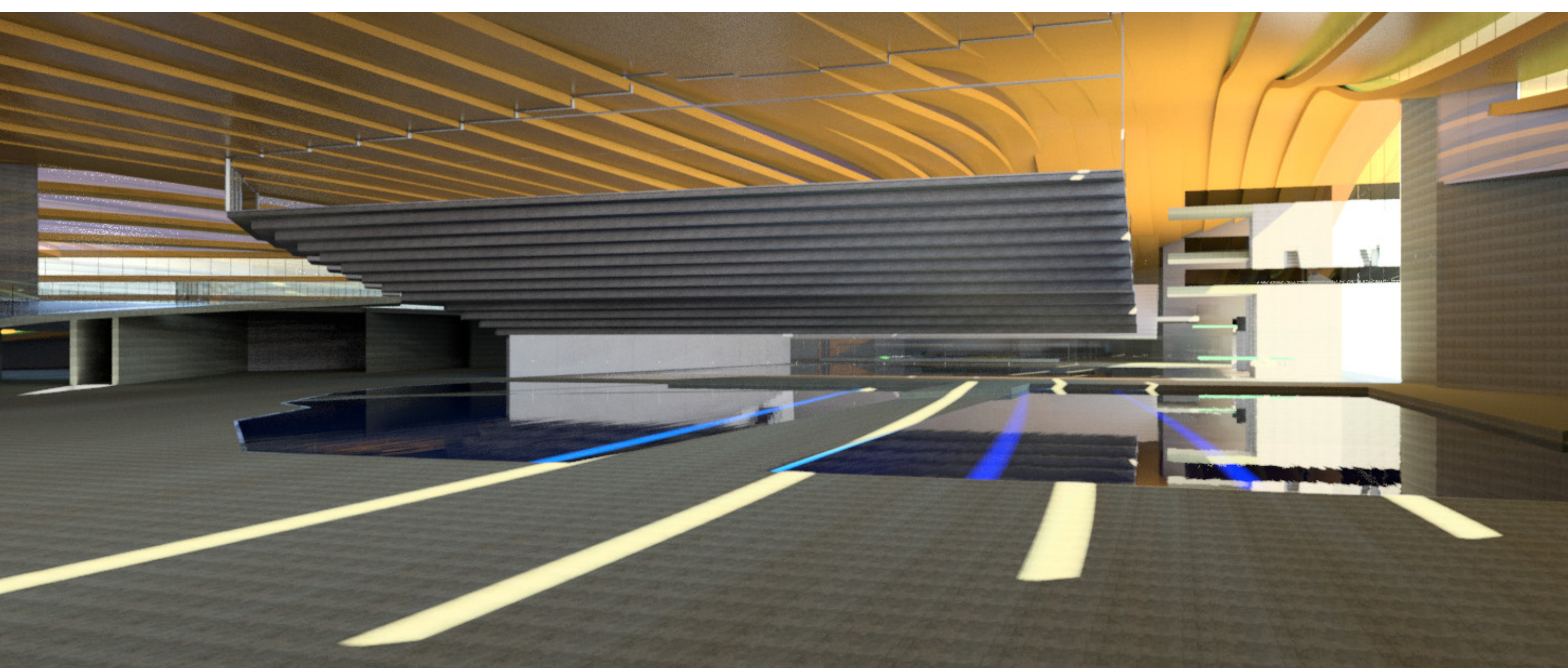




\section{Childrens Pools}

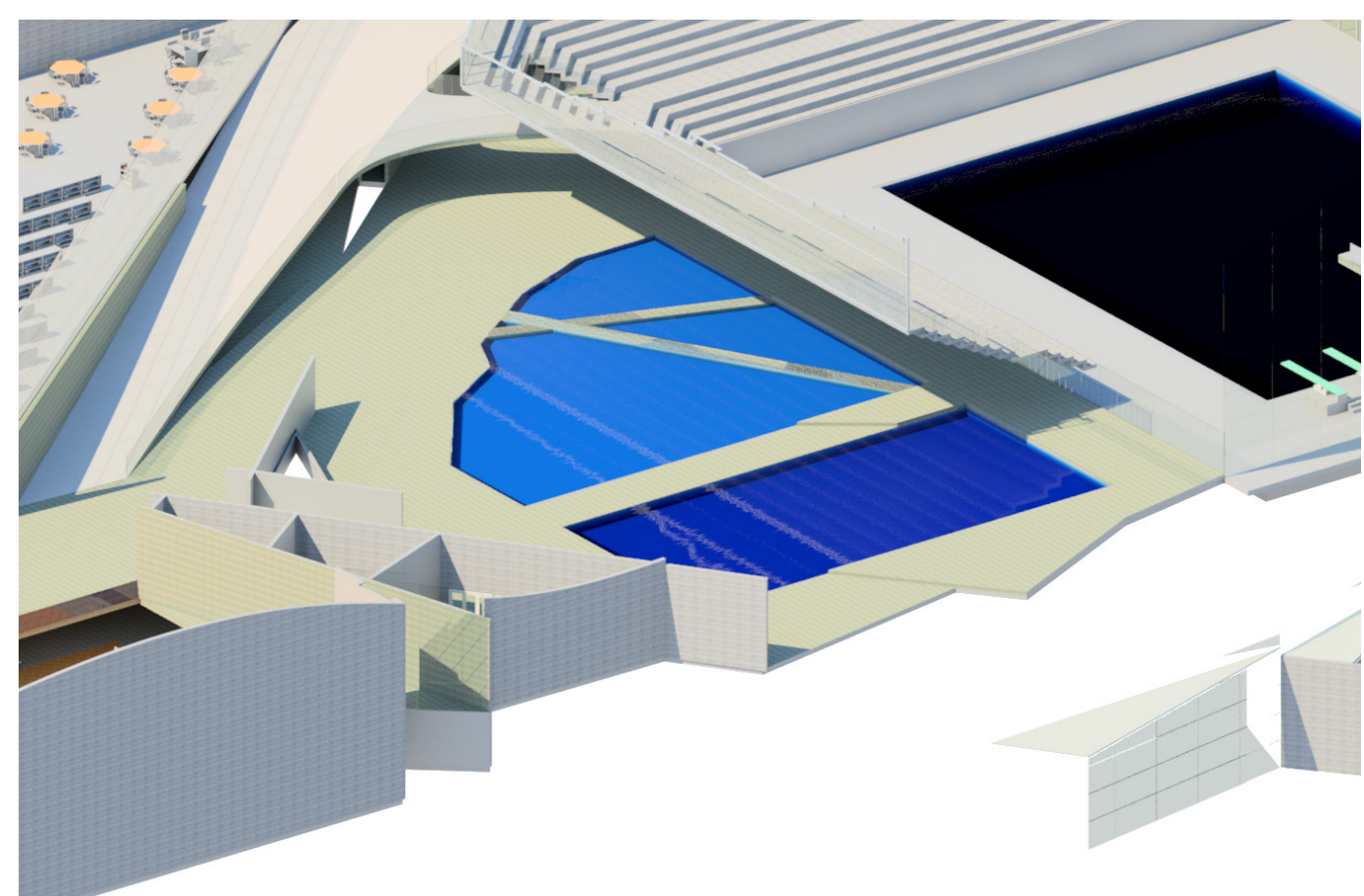

Fig. 121 Above: Axo of Children's Pool.

The Children's Pool Space is a key area in the design. It is the entry

point of the design and creates a link between the athlete program and

community program. The majority of users to the facility will pass through

this space allowing them to be inspired to try new activities.

Fig. 124 Left: Rendered view of Children's Pool looking towards the Dive Pool
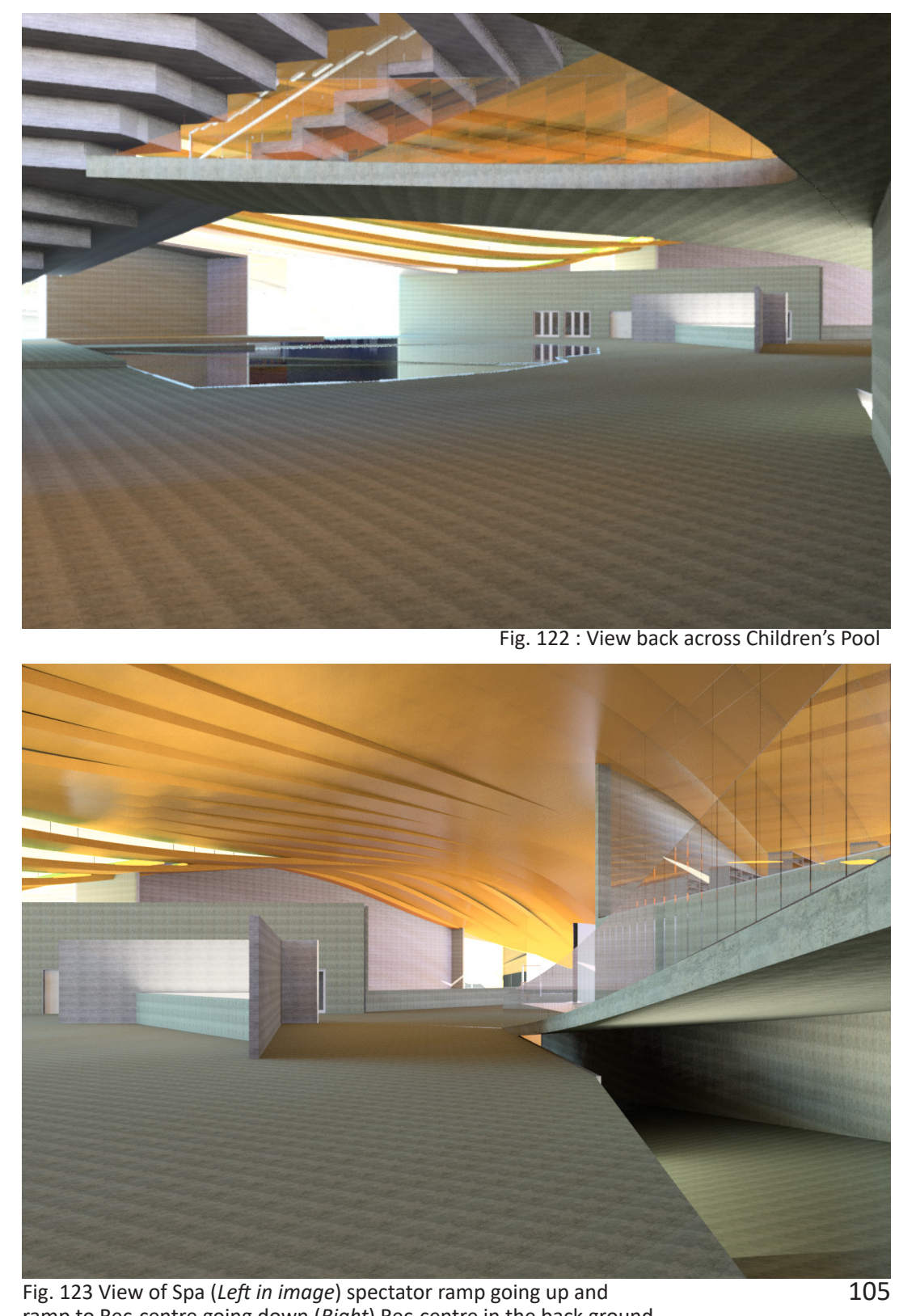


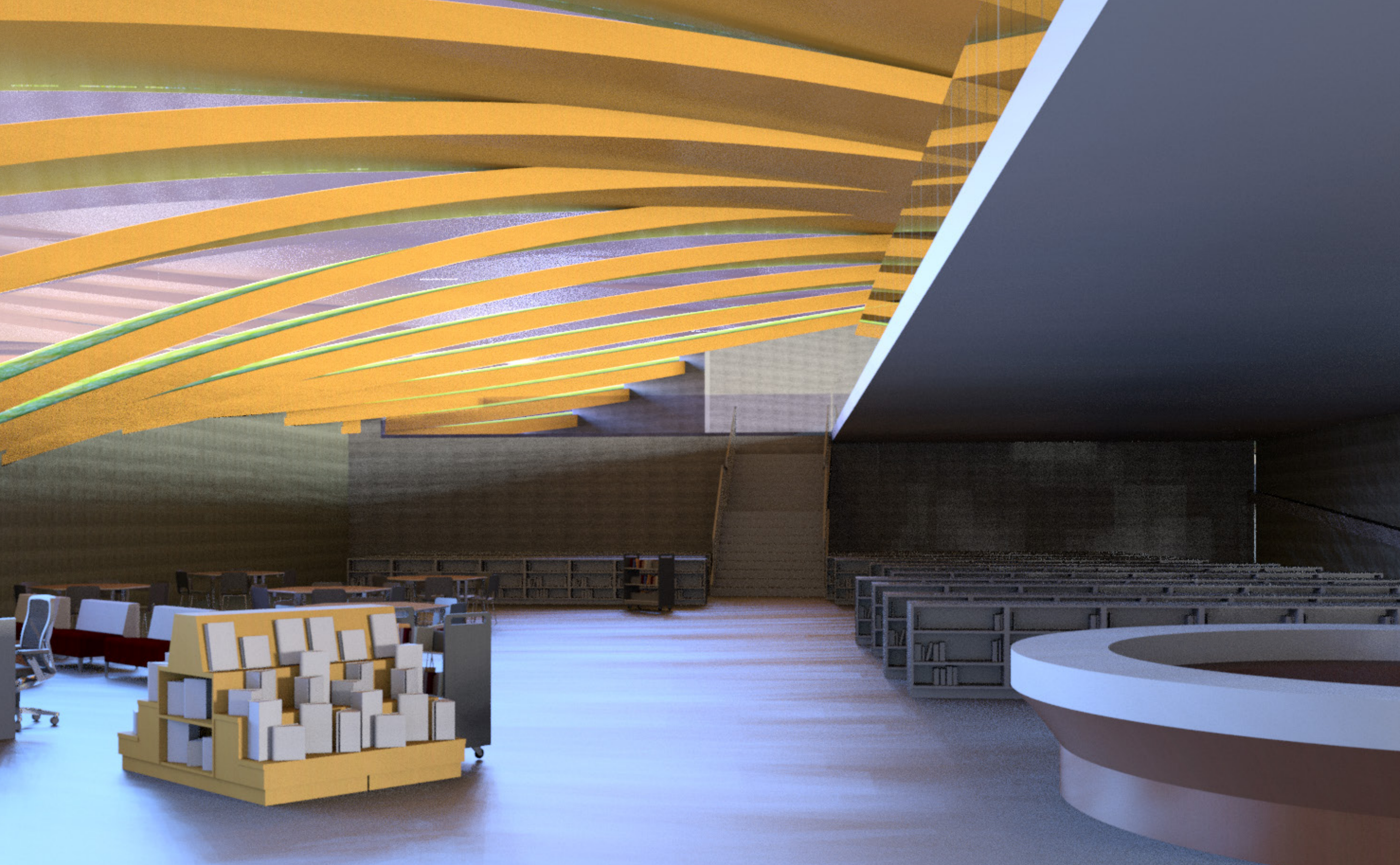




\section{Library}

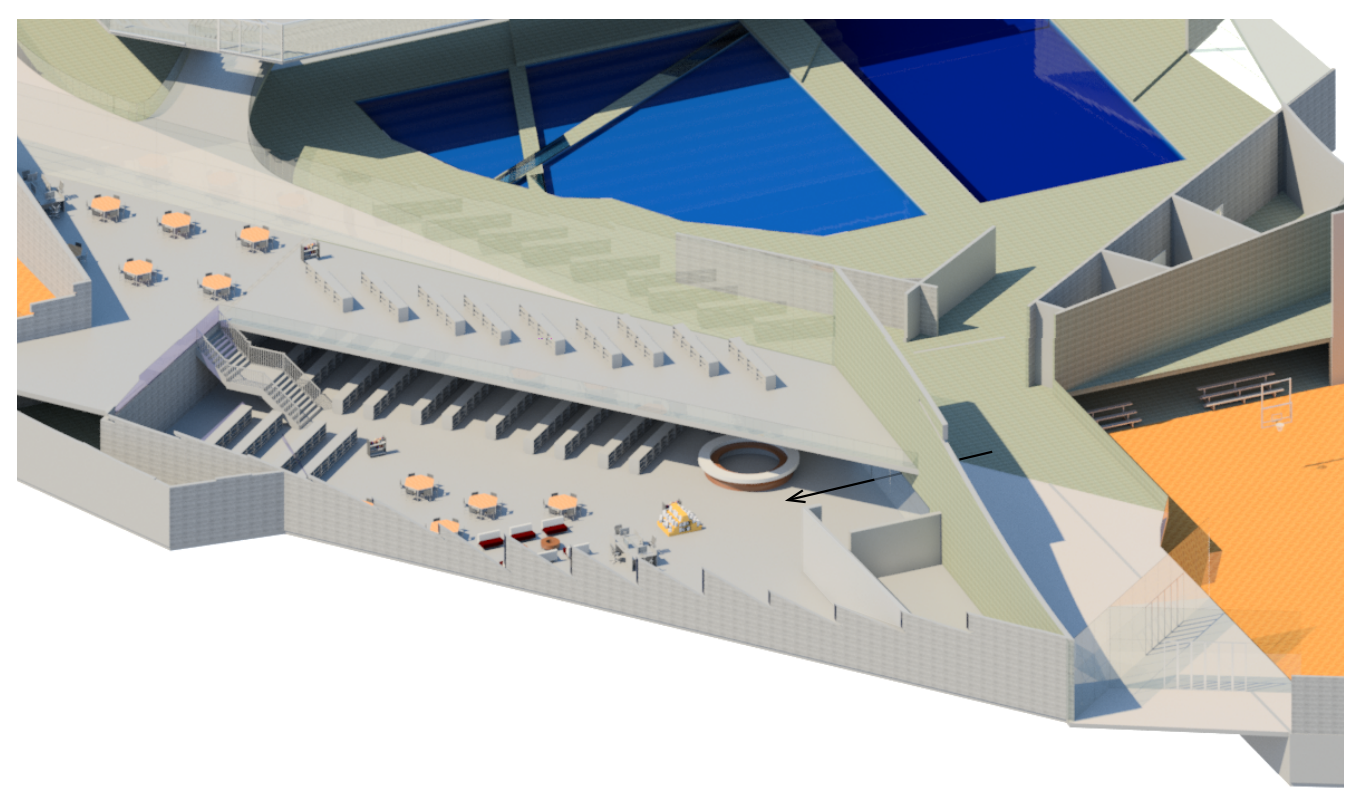

Fig. 125 Above: Axo of the Library

Fig. 126 Left: Rendered view of the bottom floor of the Library.

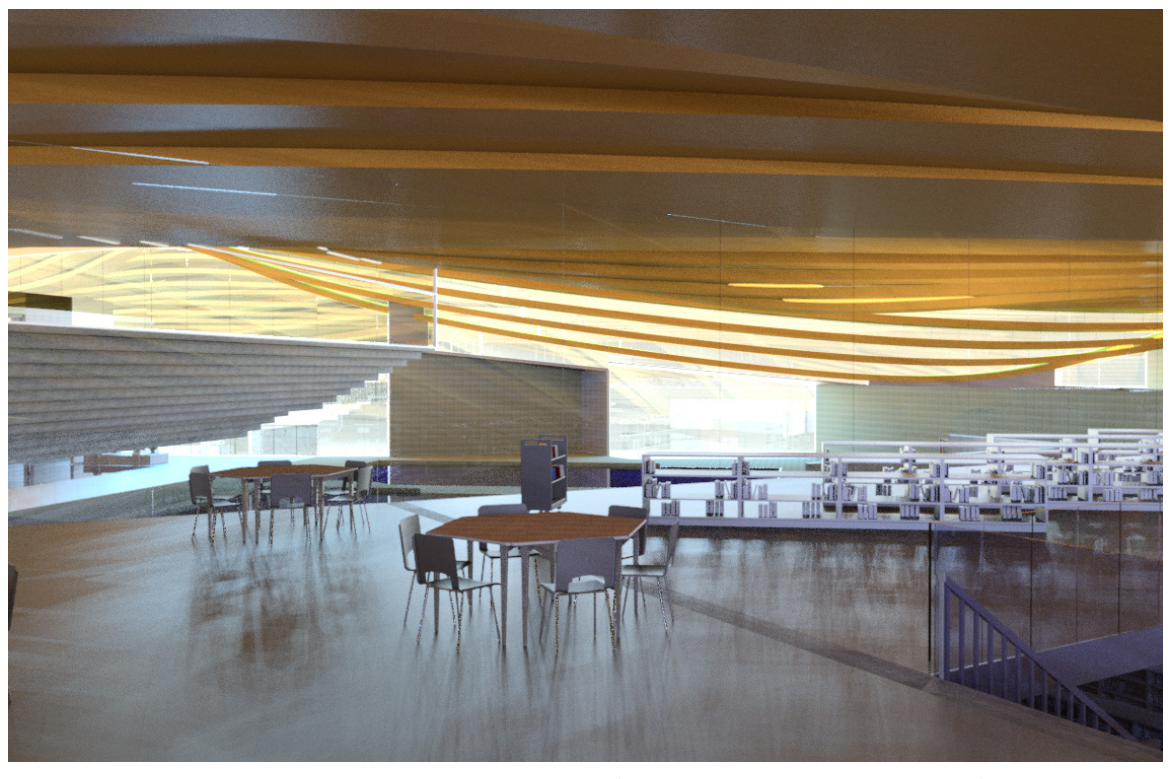

Fig. 127 :Level 2 of Library looking toward Children's and Dive Pools

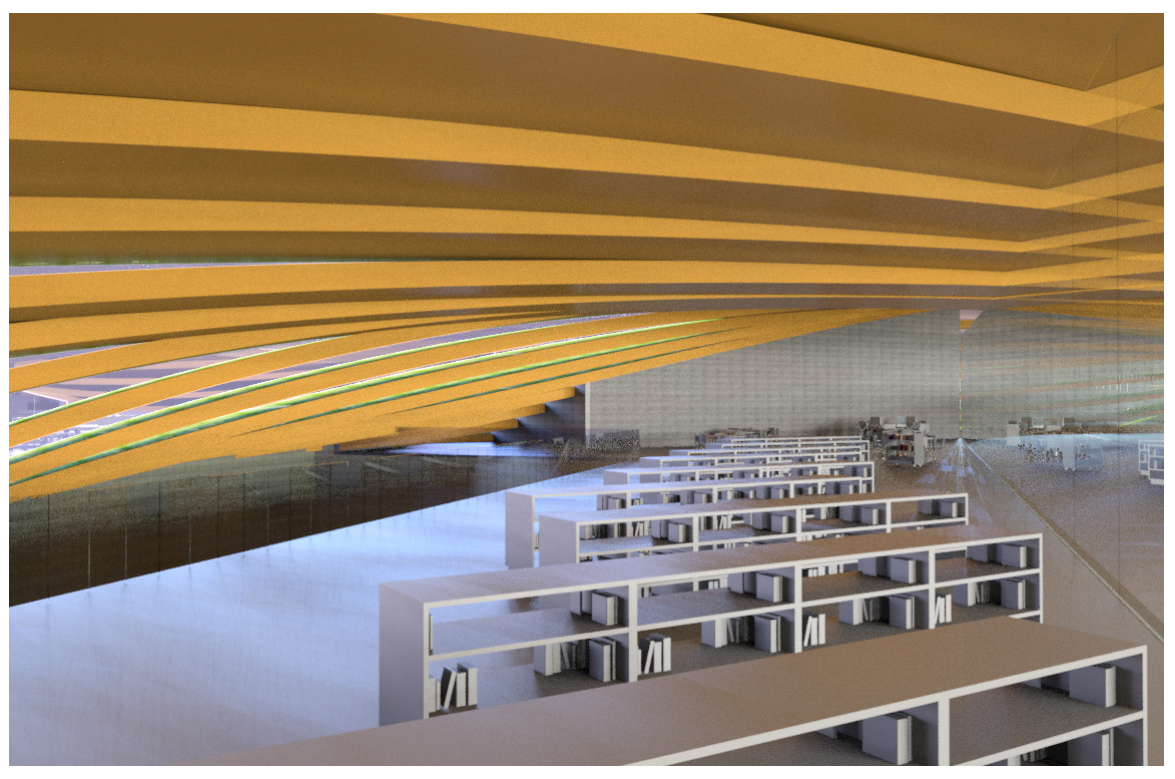

Fig. 128 :Level 2 of Library looking toward the Library stairs 



\section{Rec-centre}

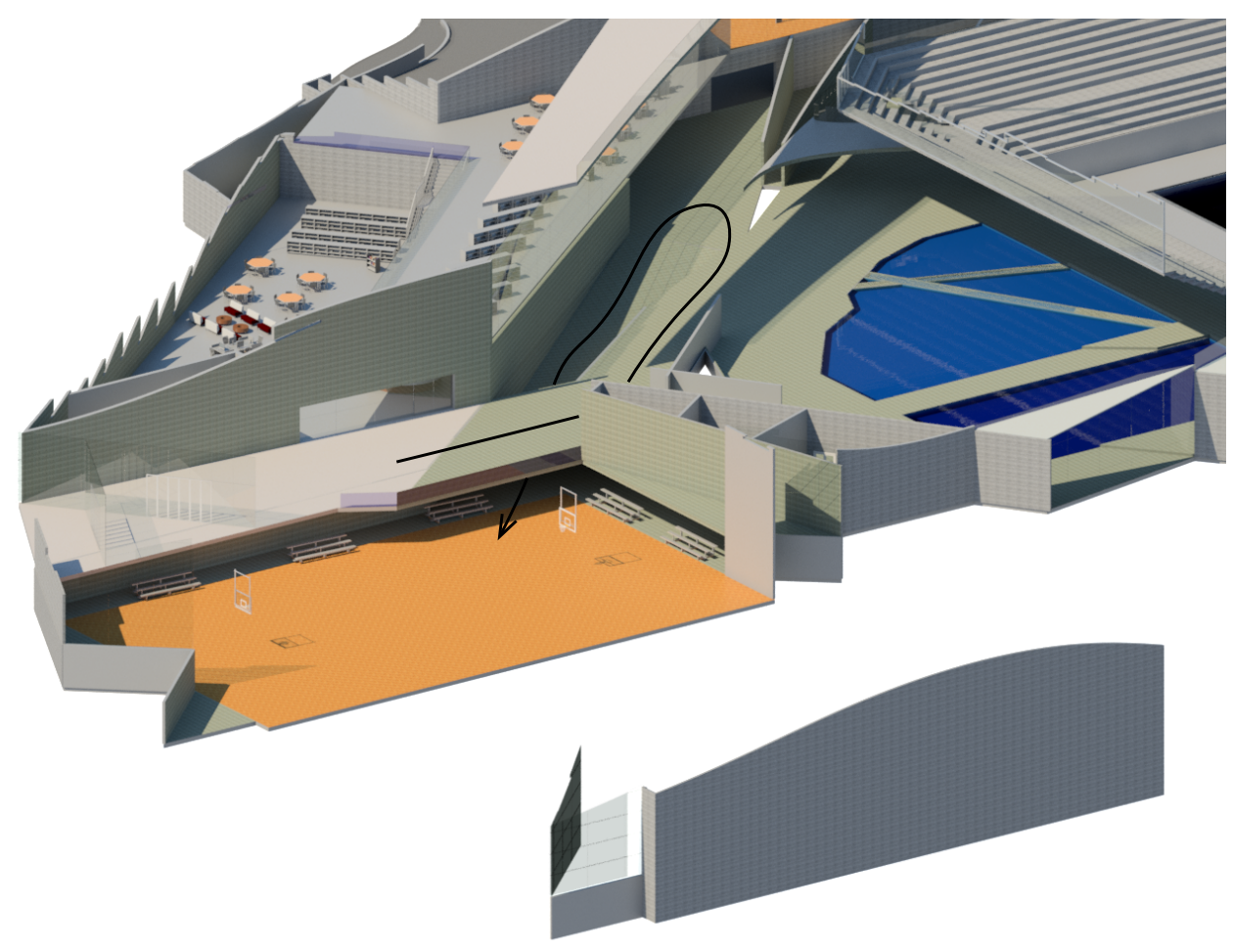

Above: Axo of the Rec-centre

The entrance is from the Children's pool area under the public entry

Fig. 129 Left: Rendered View of the Rec-centre from entrance

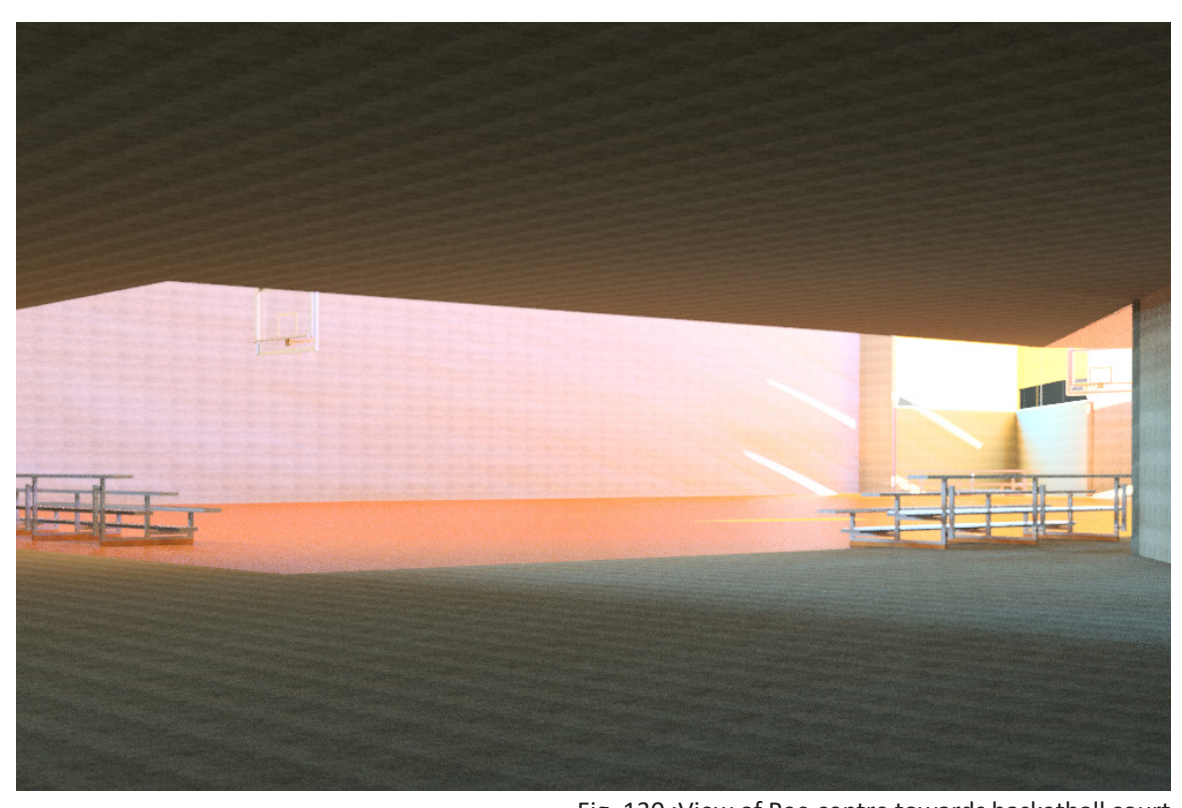

Fig. 130 :View of Rec-centre towards basketball court

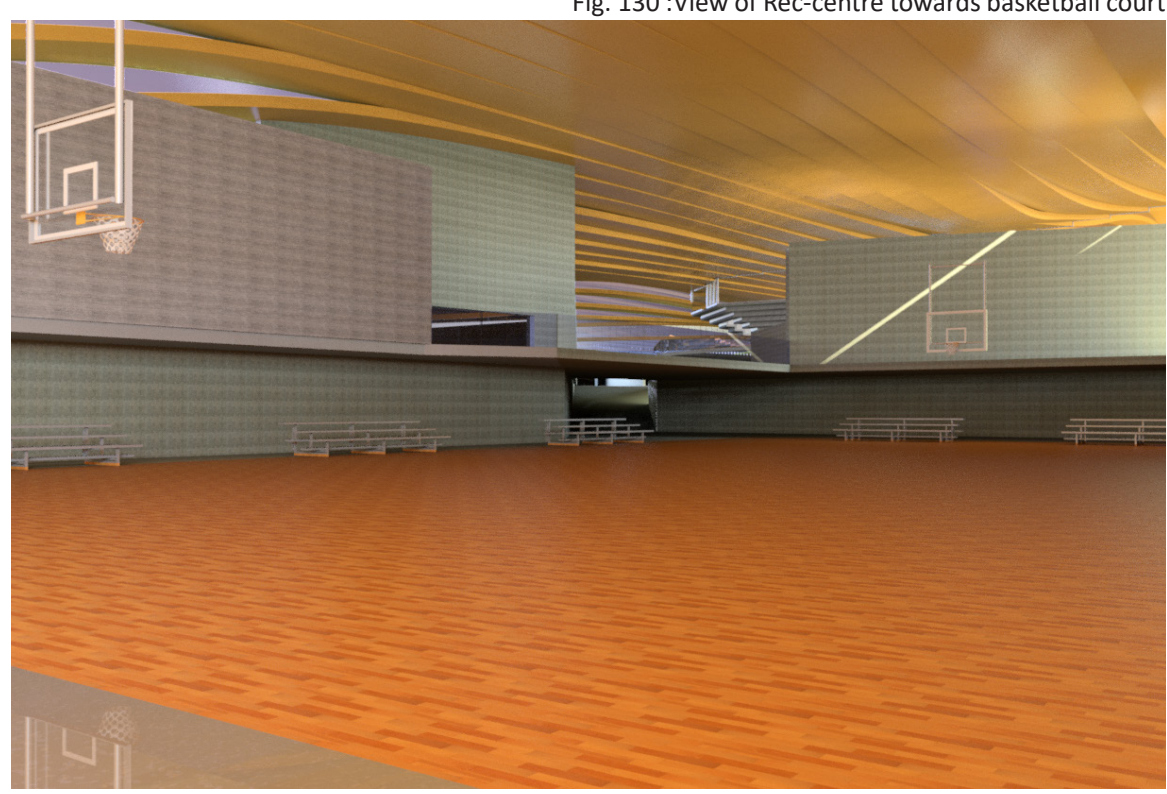

Fig. 131 :View towards public entry 


\section{Gym}

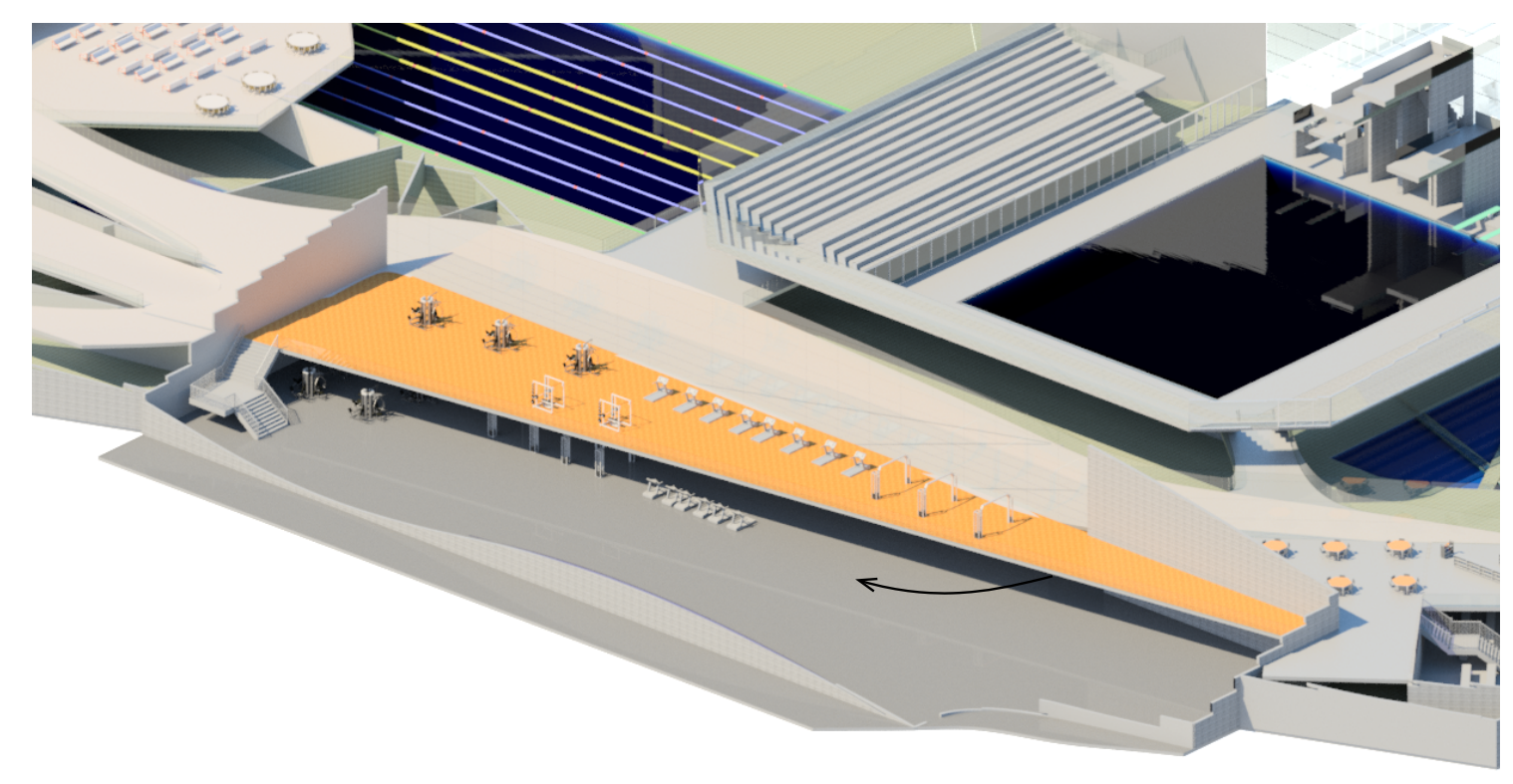

Fig. 132: Axo of the Gym
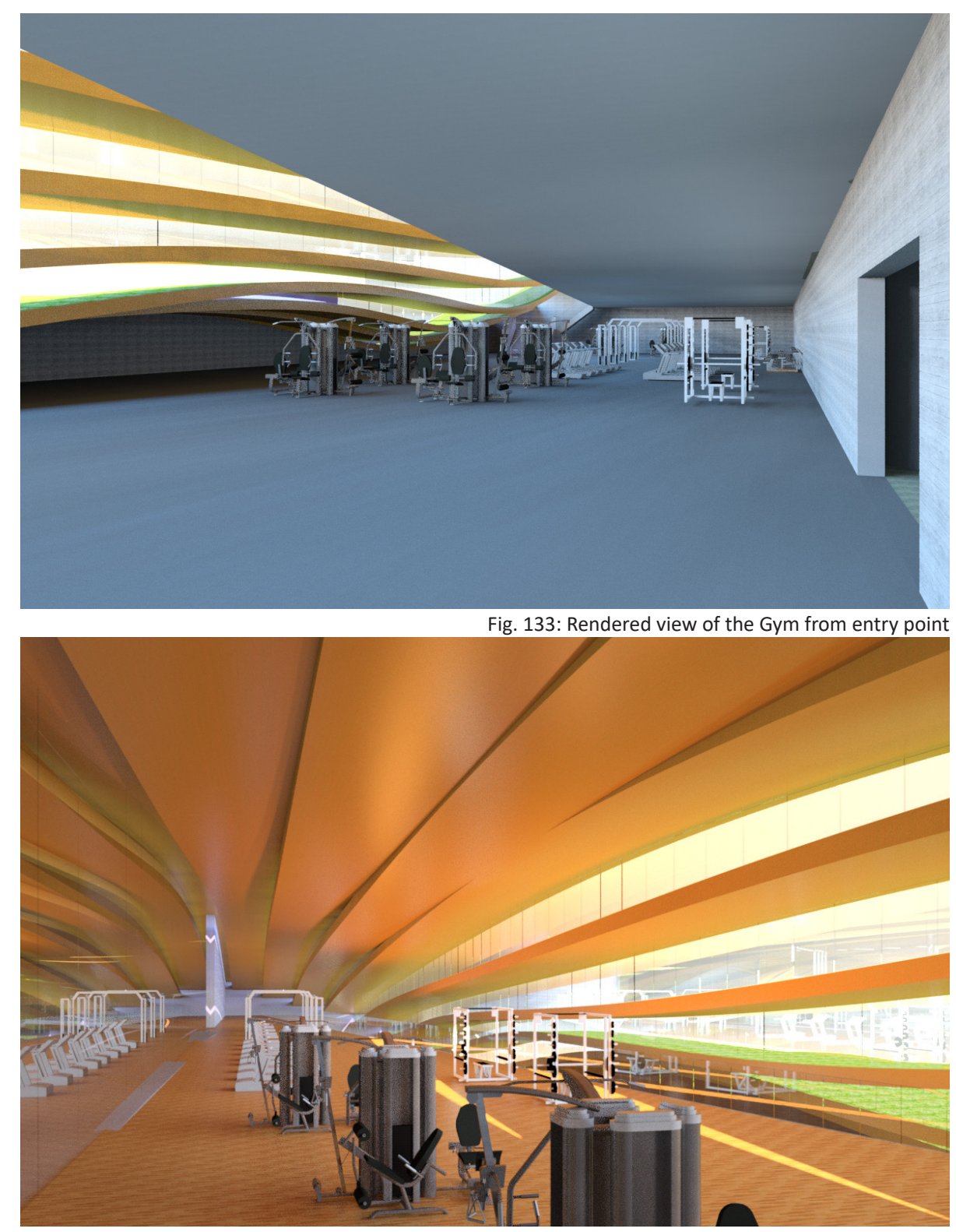

Fig. 134: Level 1 of Gym looking to the exterior 


\section{Hydrotherapy Pool}
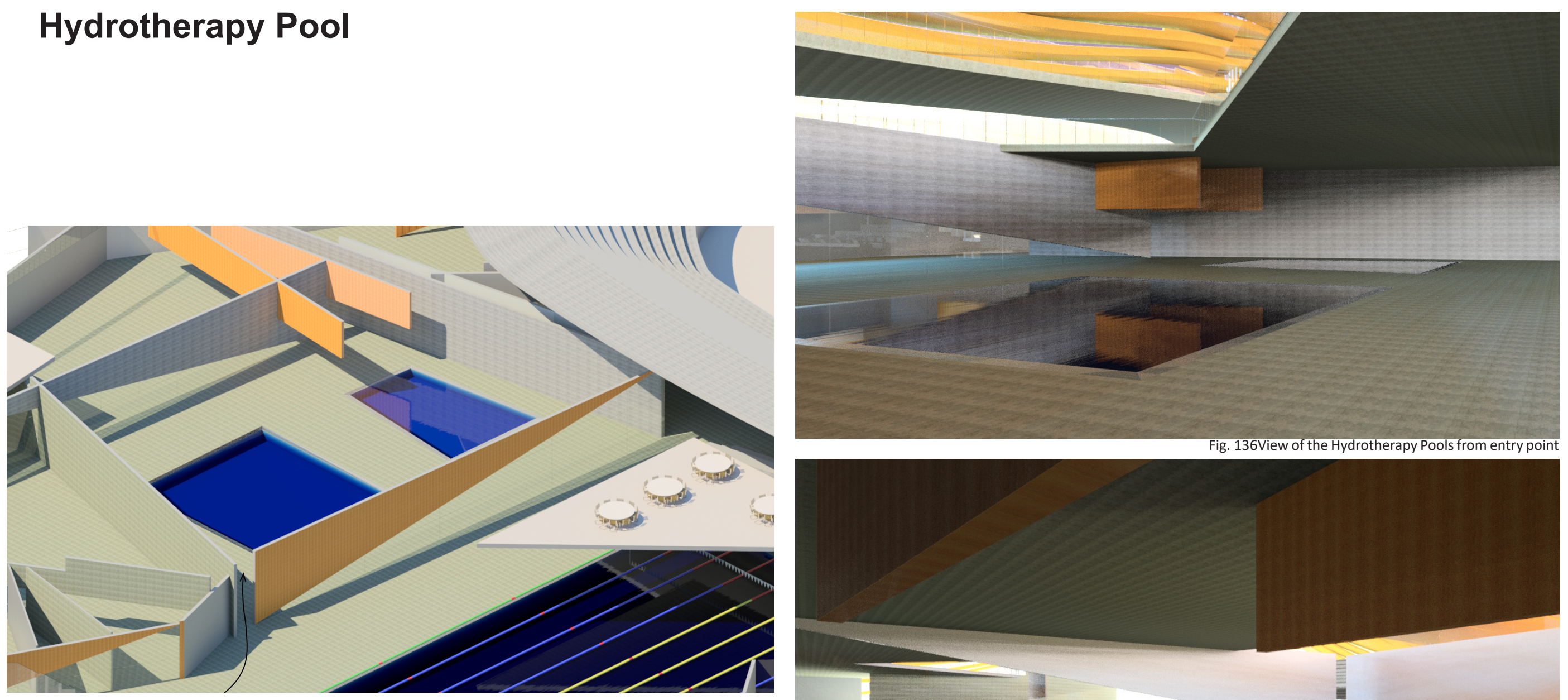

Fig. 135: Axo of the Hydrotherapy Pool

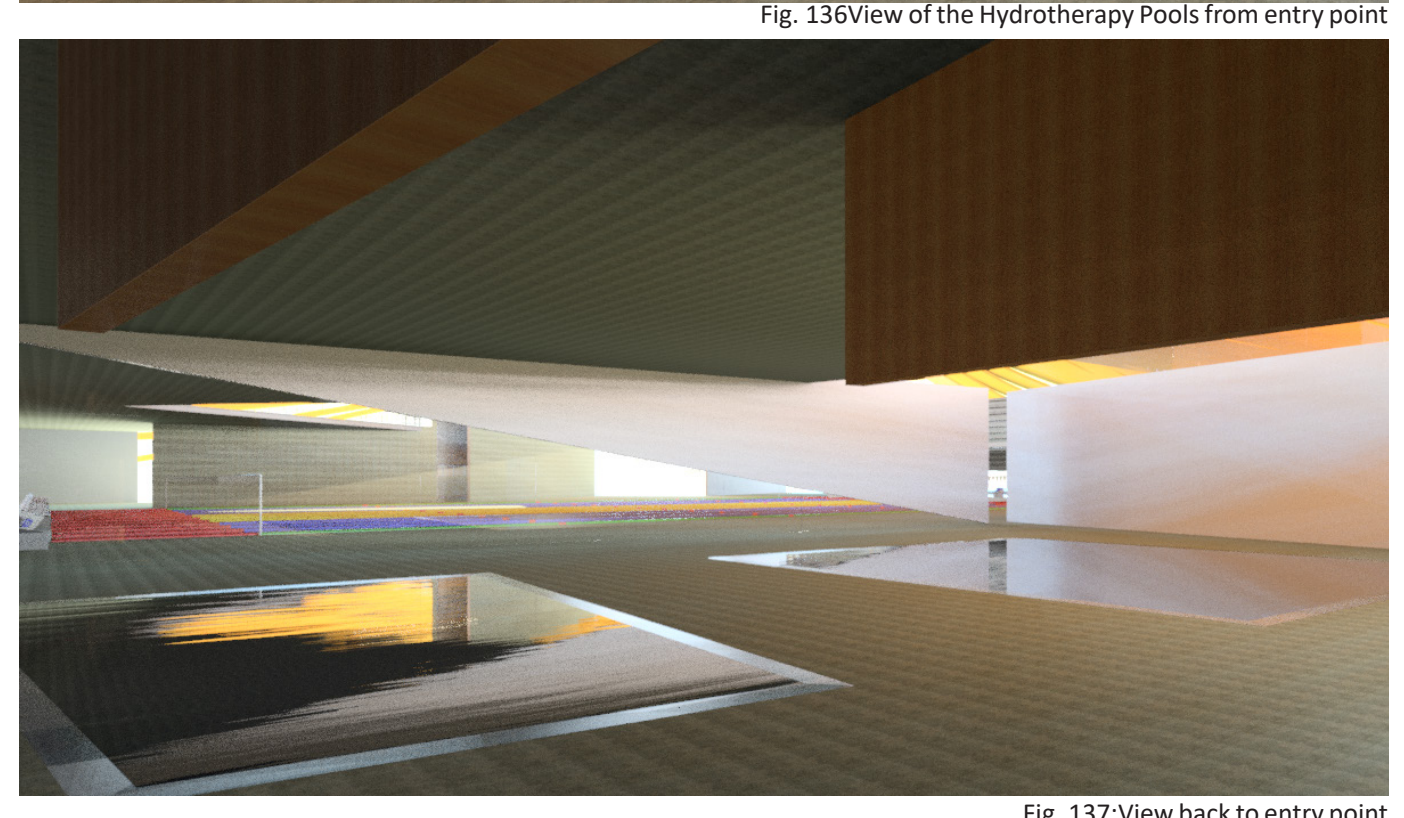




\section{Athlete Program}

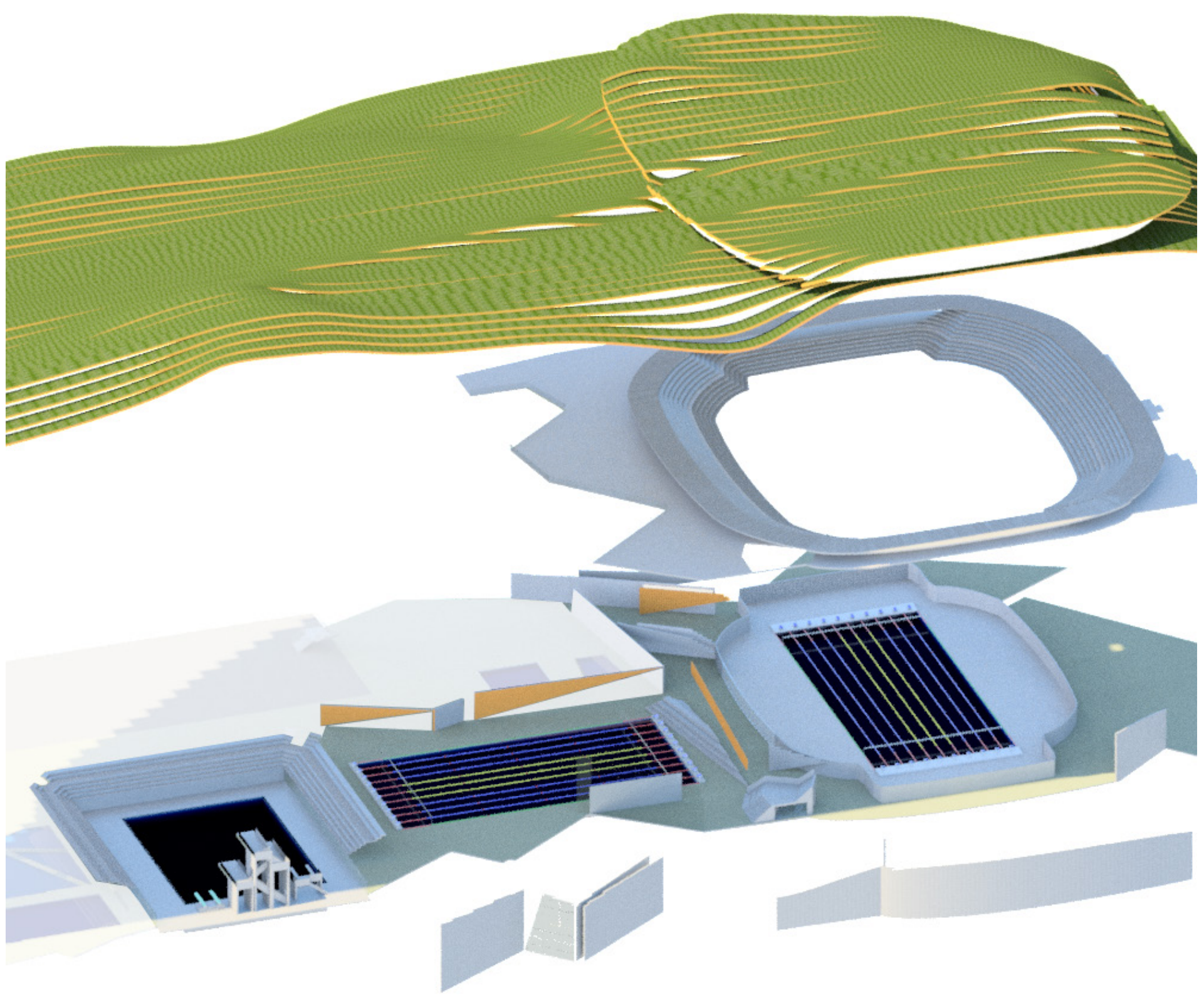




\section{Athlete's Lounge}
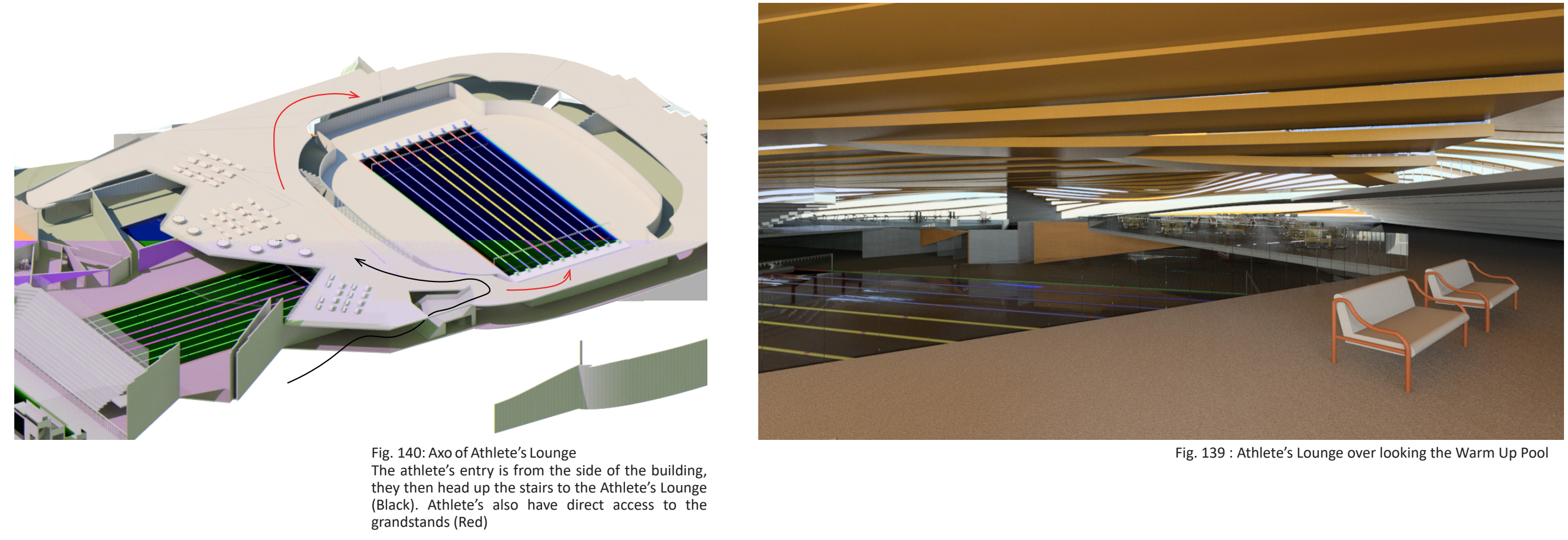

Fig. 139 : Athlete's Lounge over looking the Warm Up Pool grandstands (Red) 


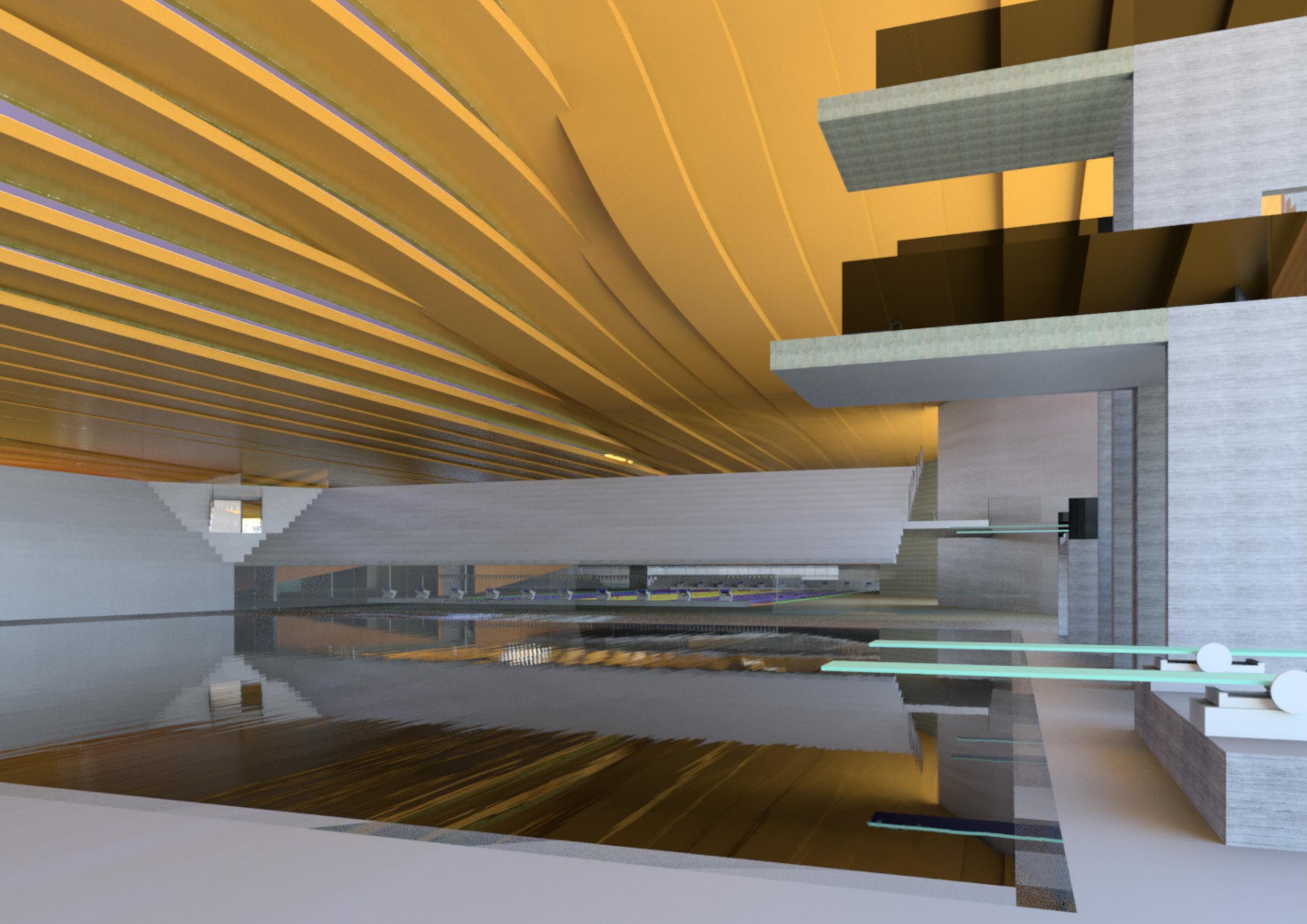




\section{Diving Pool}
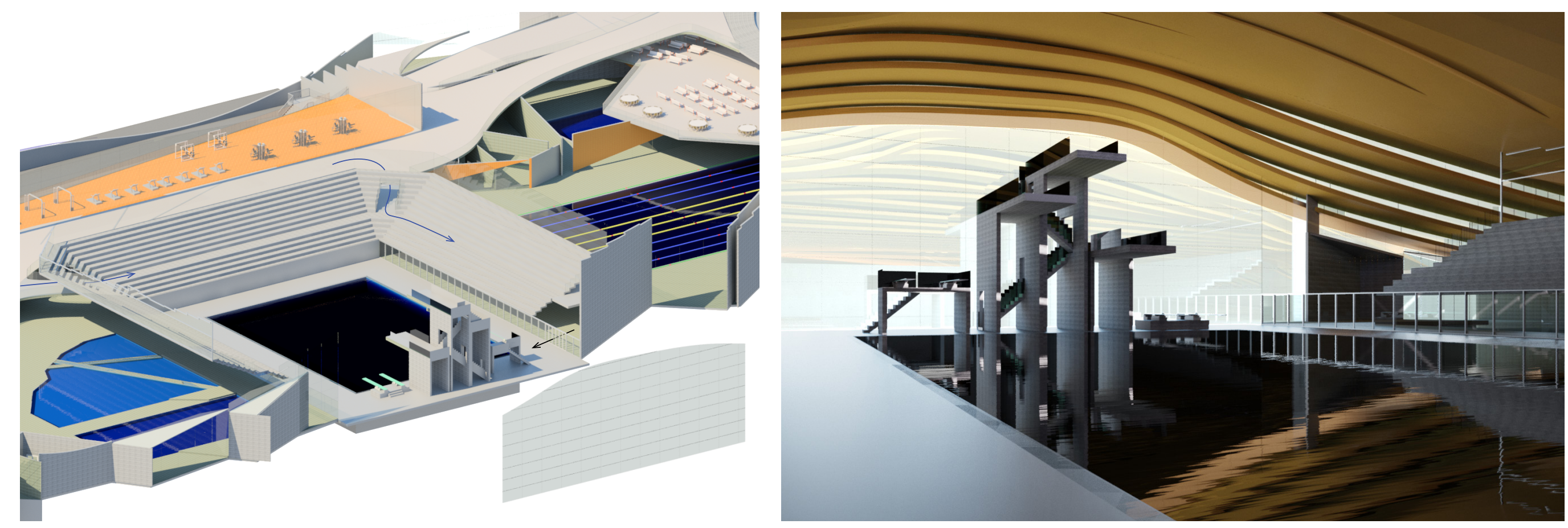

Fig. 141 Above: Axo of the Diving Pool

Fig. 143 : View towards diving platforms

Fig. 142 Left: Rendered View of the Diving Pool view from Children's Pool.

This pool can also be used for Water Polo competitions 


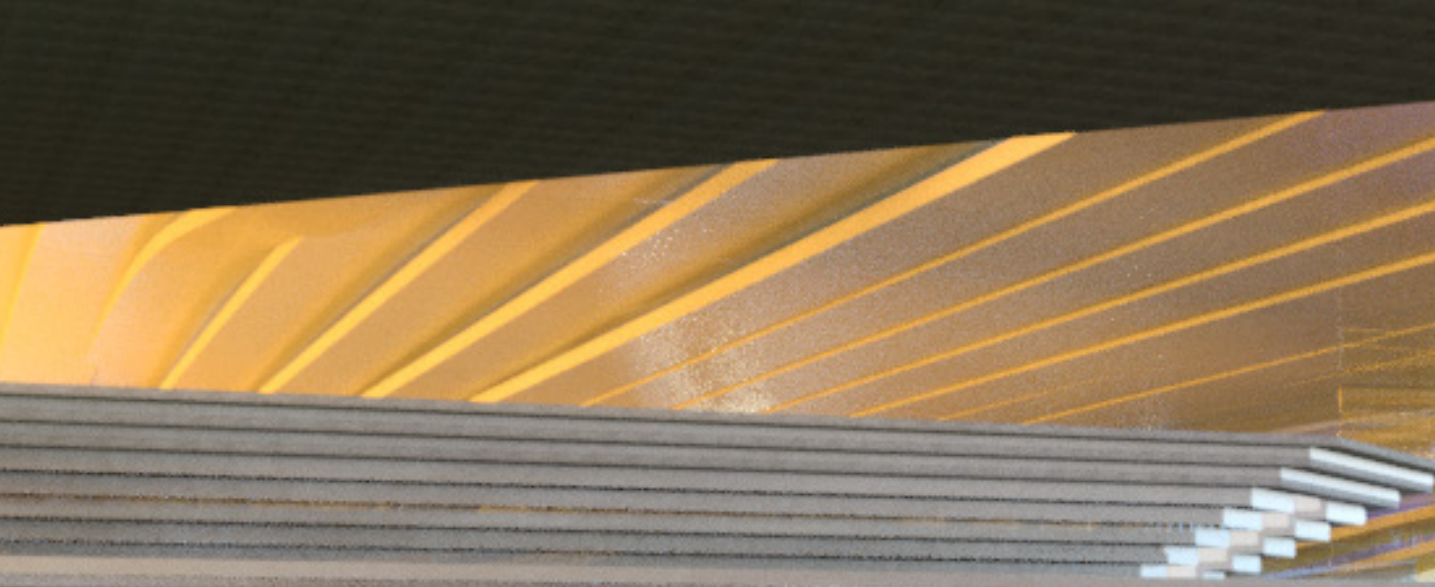

Wrav

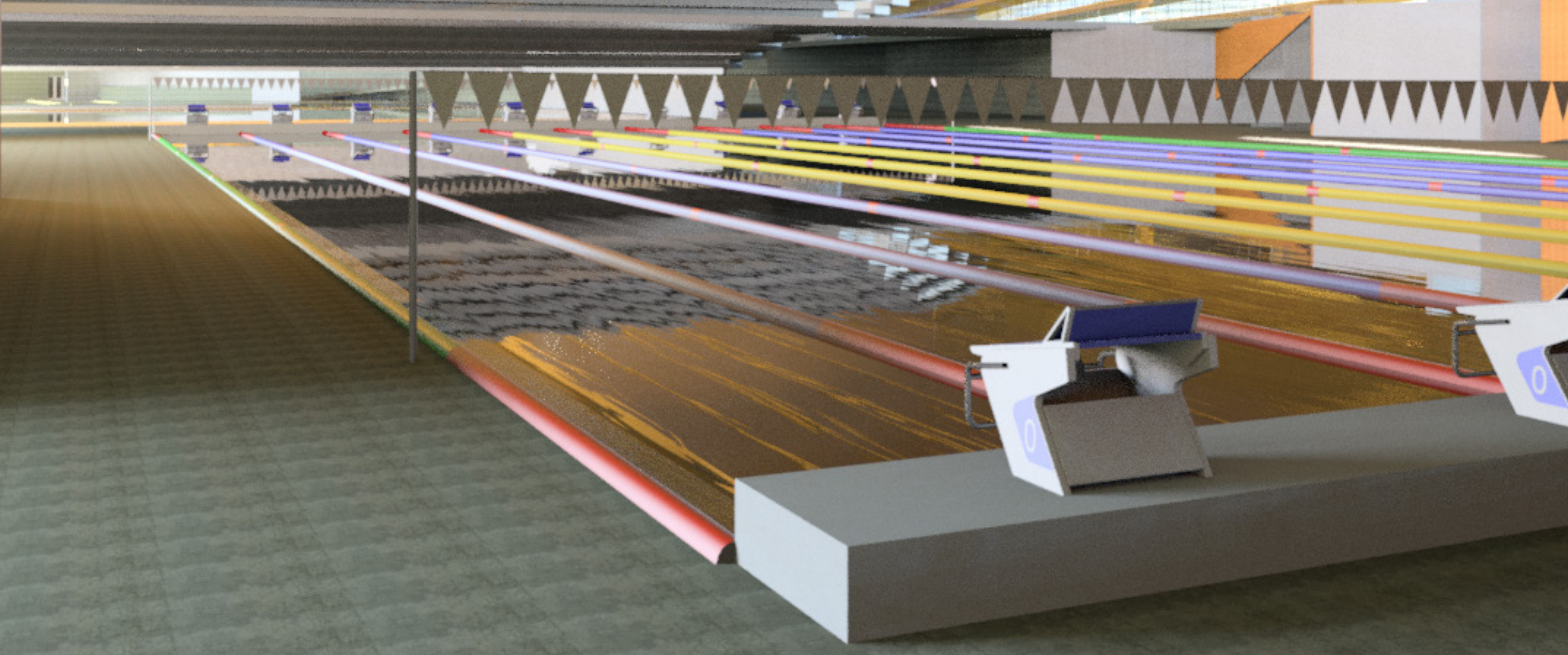




\section{Warm Up/Cool Down Pool}
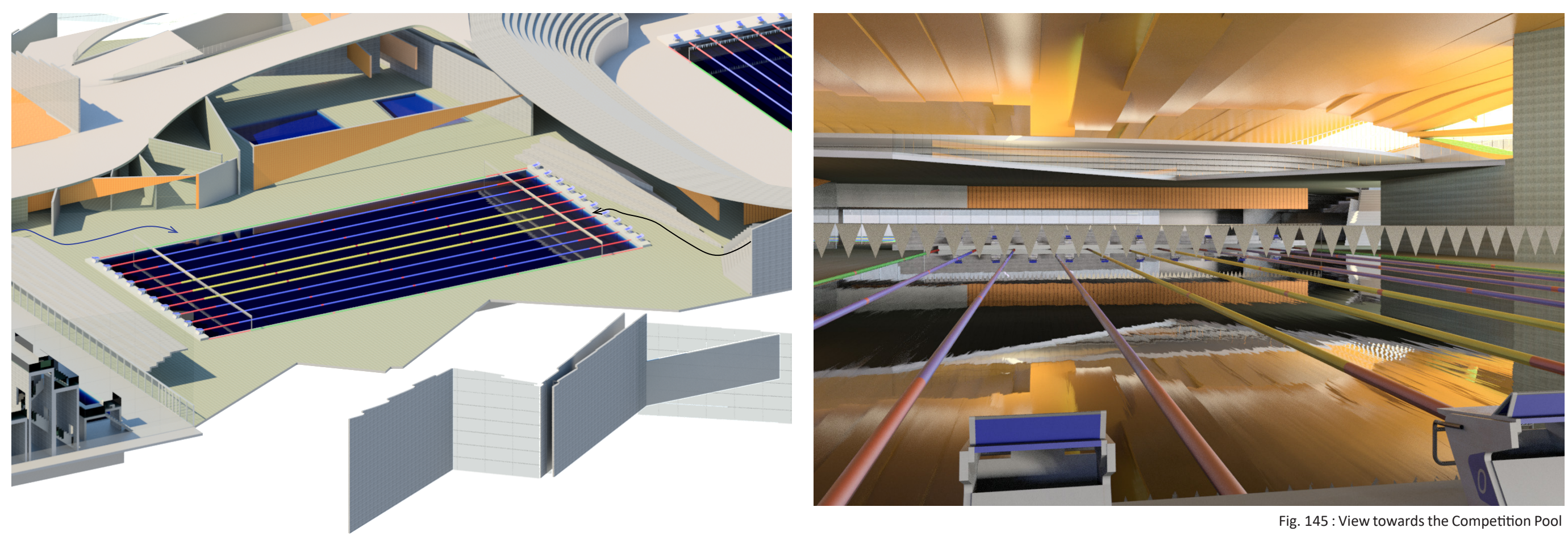

Fig. 145 : View towards the Competition Pool

Fig. 144: Axo of the Warm Up Pool.

This pool is designed to be community orientated with

variable pool depth to allow for a range of activities. Public

access during non-competition times from behind Dive

Pool (blue), Athlete access from athlete lounge (Black)

Fig. 146 Left: Rendered view of the Warm Up Pool towards 


\section{Marshalling and Last Words Area}

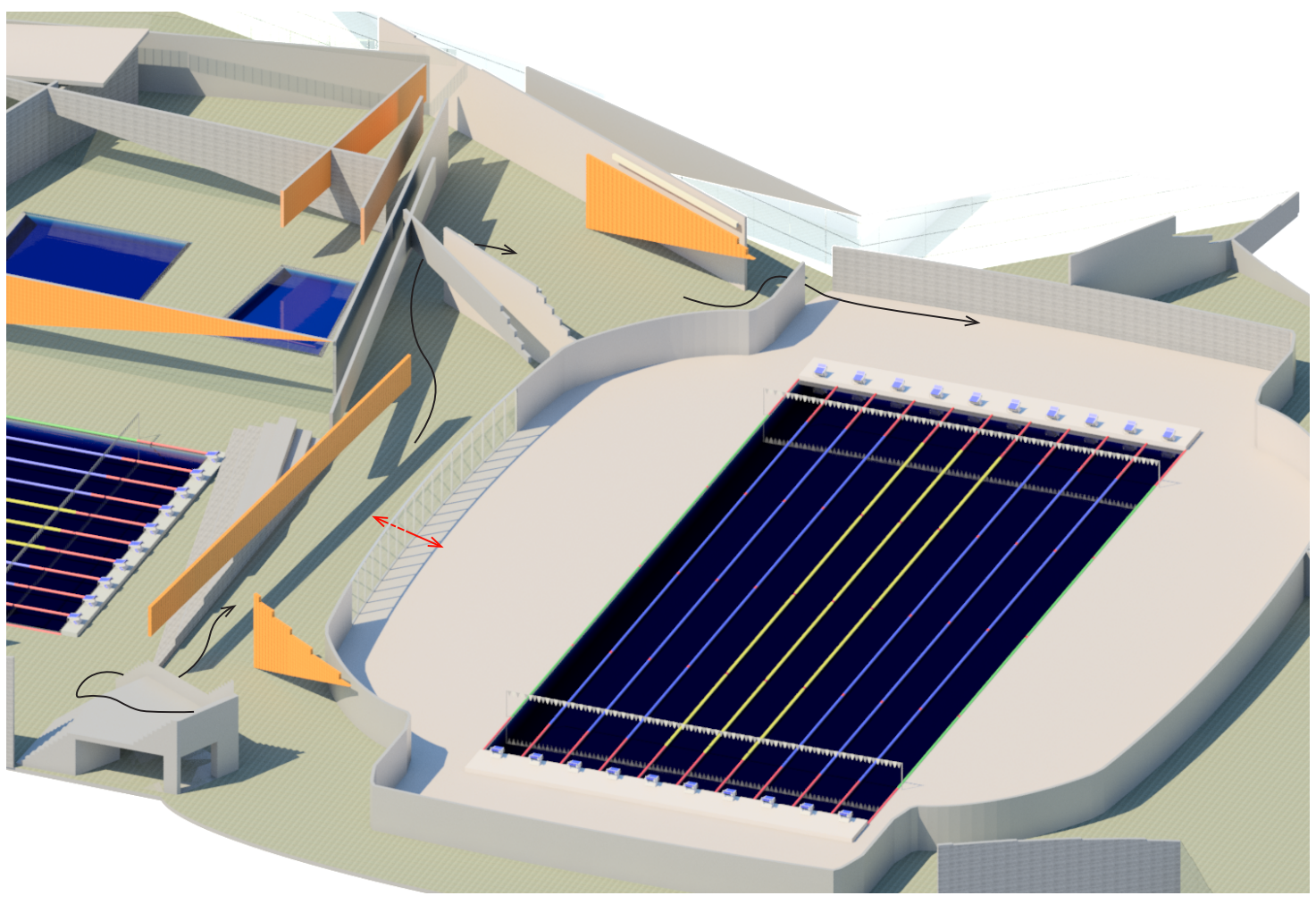

Fig. 147 Above: Axo of the areas.

Athlete movement from warm up through to approach the start blocks (Black). Coaches and general access to the Competition Pool (Red).

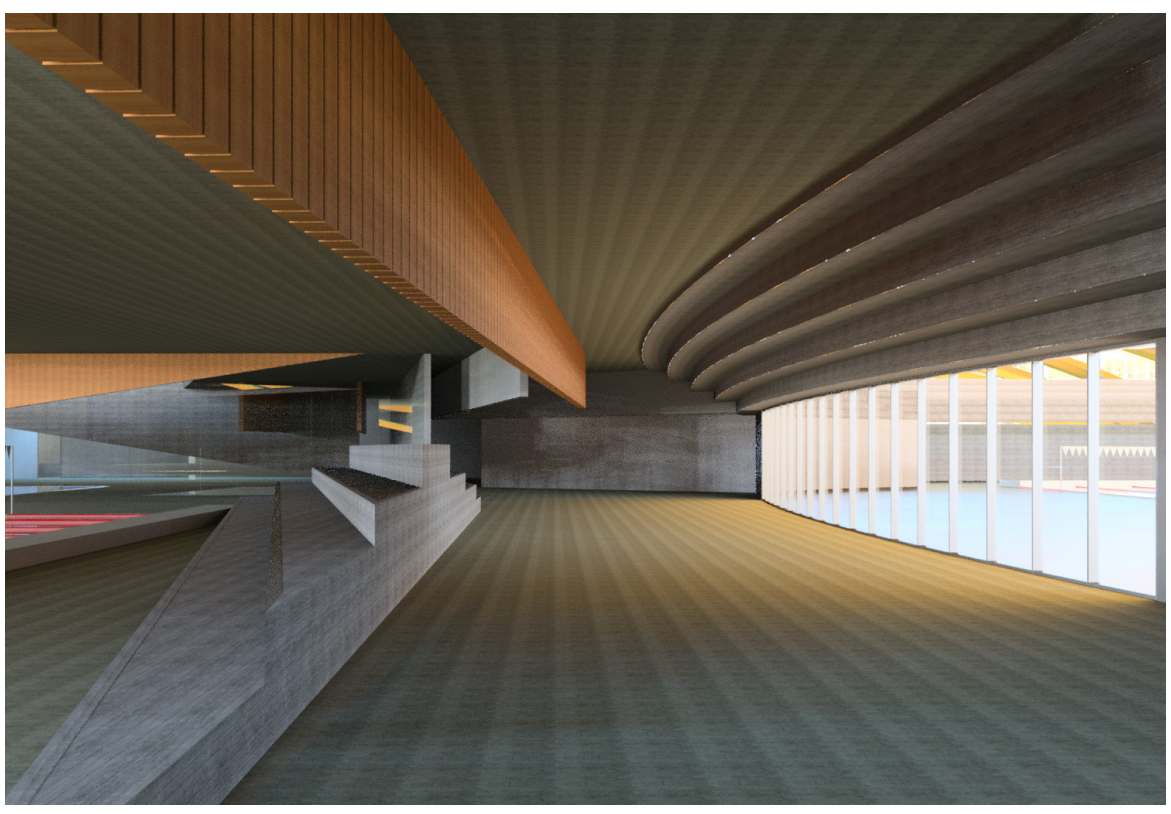

Fig. 148 Right Top: Rendered view of the Last words (Coaches area)

Fig. 149 Right Bottom: View of the Marshalling area

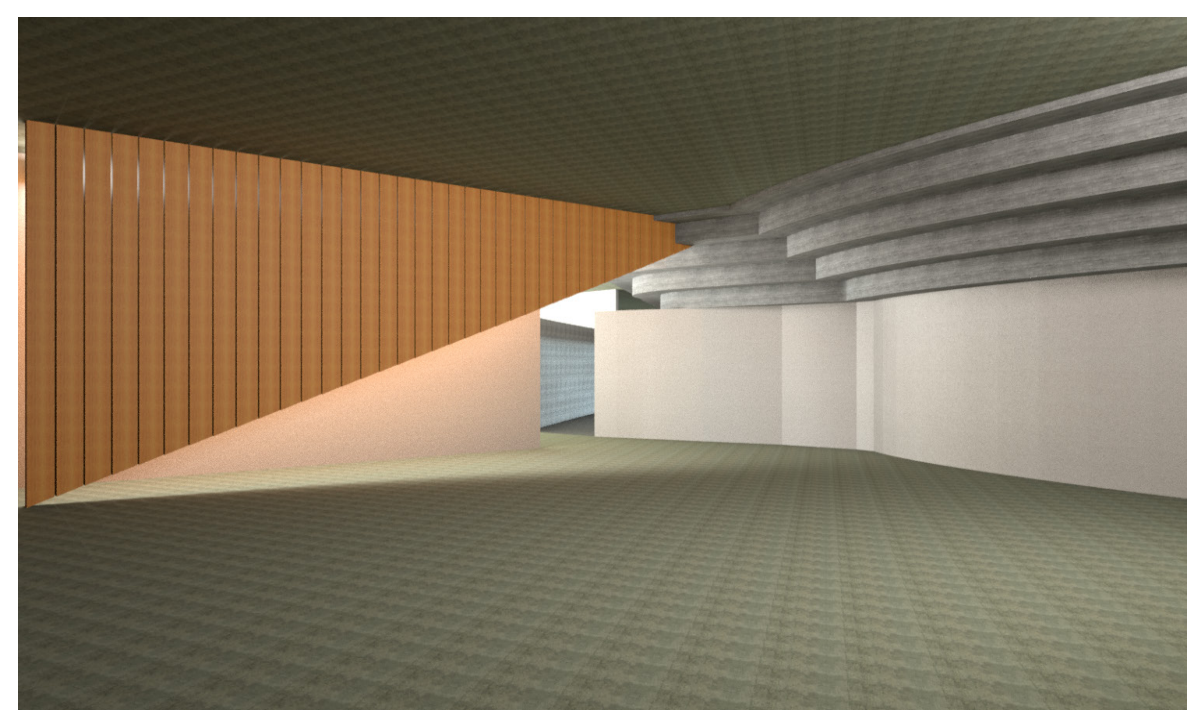




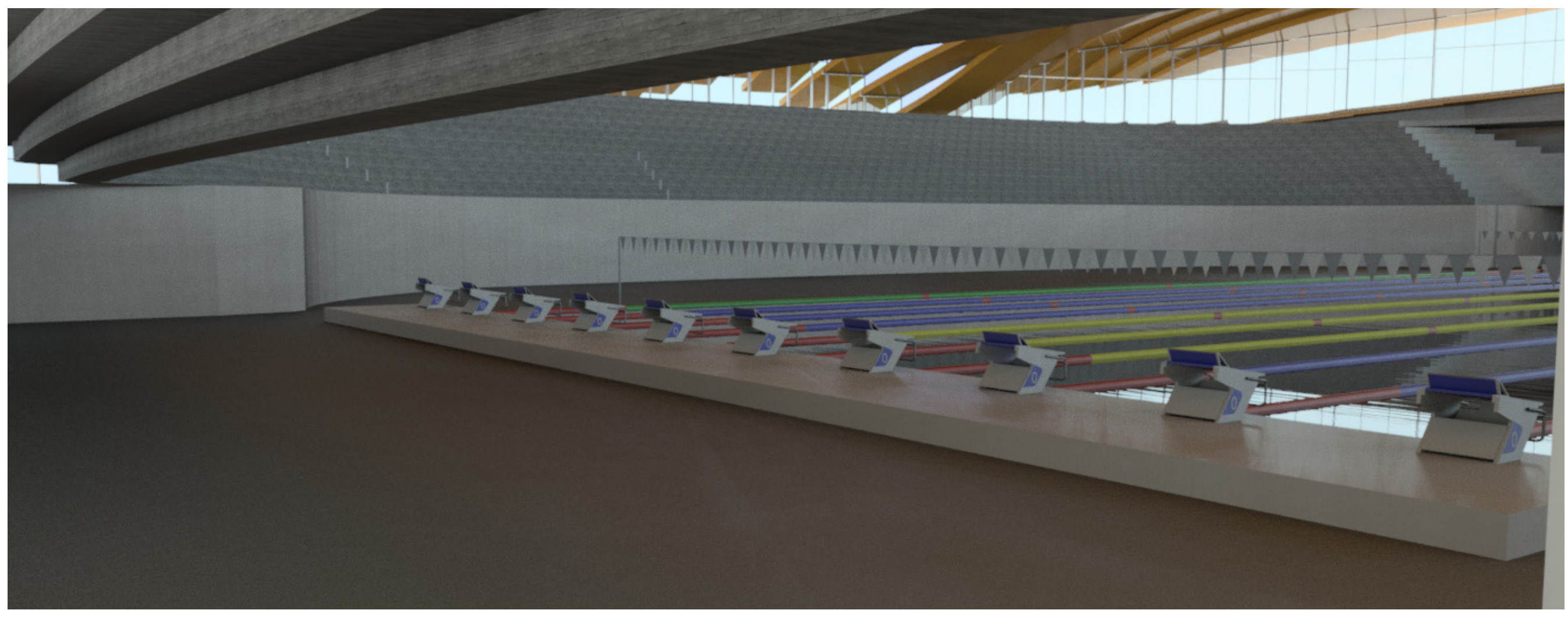

Fig. 150 : Approach to start blocks from Marshalling area 


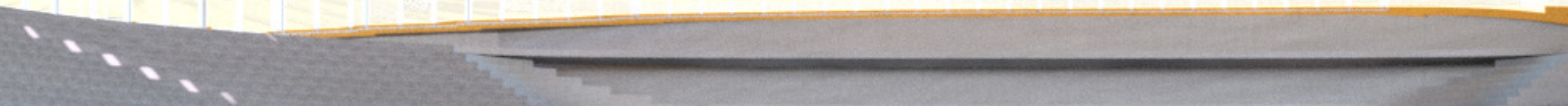

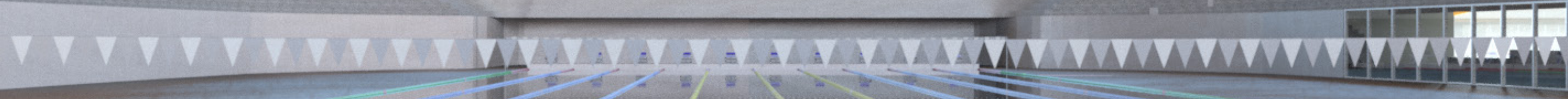
Ein 


\section{Main Competition Pool}
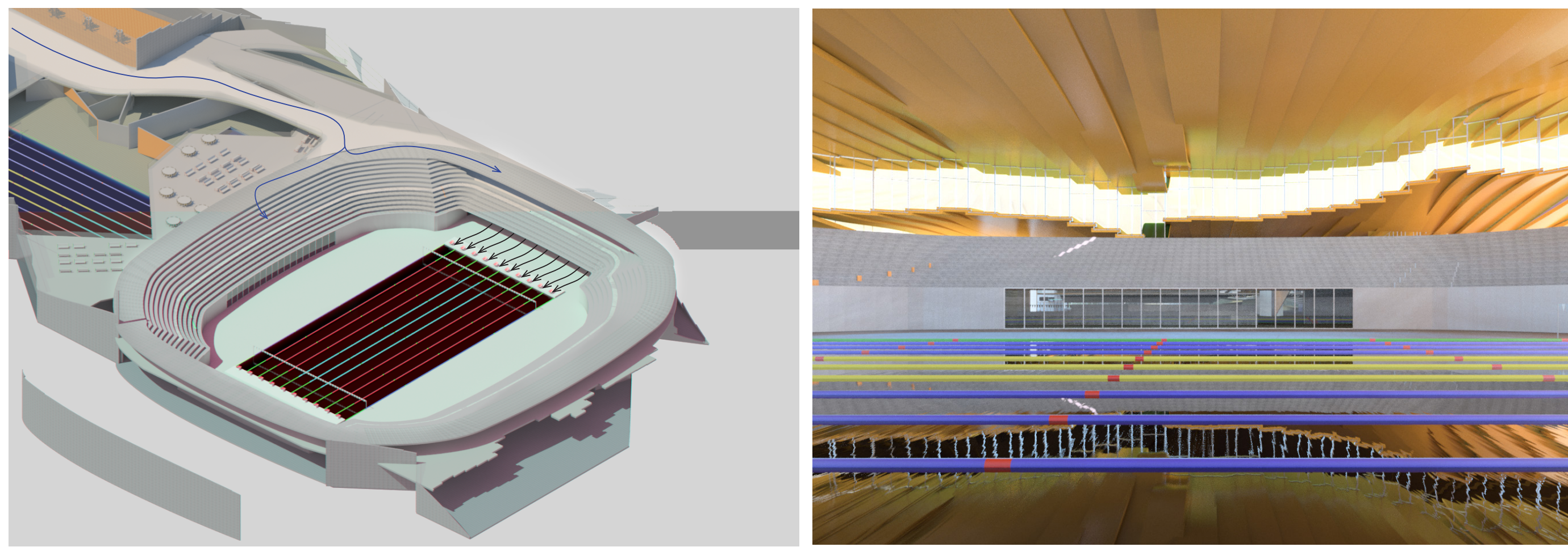

Fig. 151 Above: Axo of the Competition Pool.

Fig. 152 : View towards the Last Words area

Athlete's approach the start blocks from behind the start blocks

(Black). Spectators enter from the ramp and move around the

perimeter and down into the stands.

Fig. 153 Left: Rendered view of the Competition Pool from behind the start blocks 


\section{Spectator Movements}

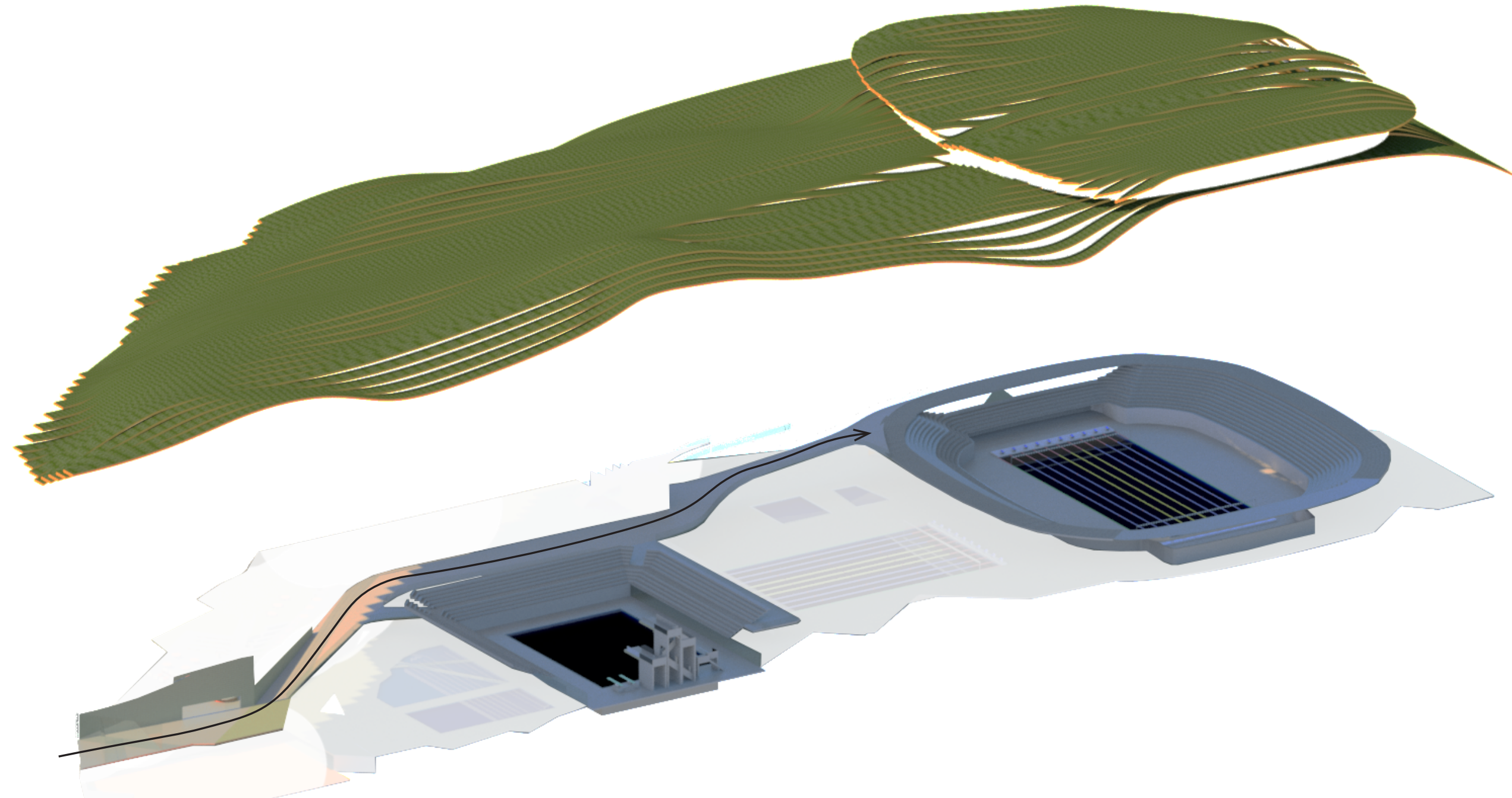



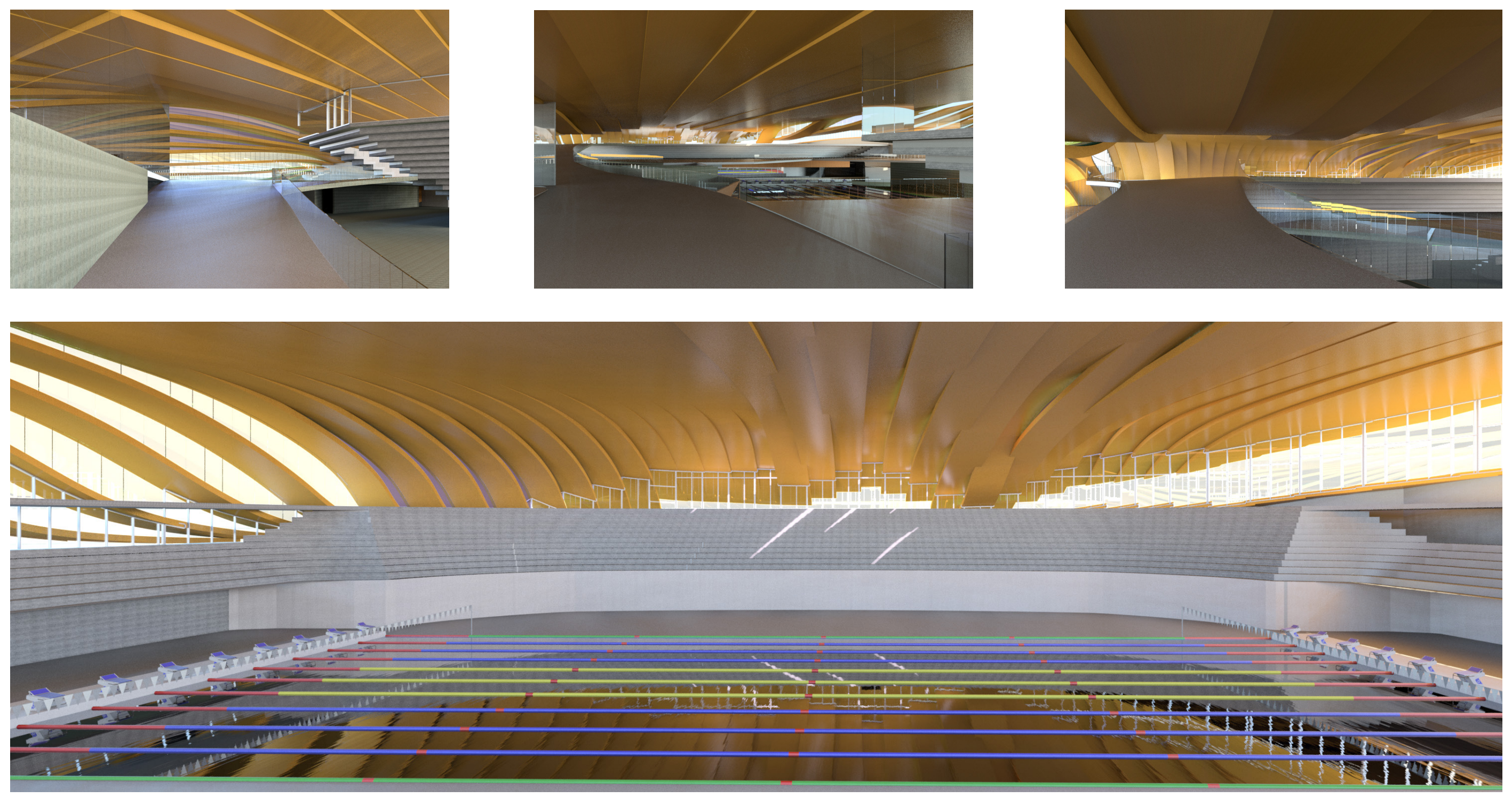

Fig. 155 : Series of images describing the ramp up to the spectator seating for the Competition Pool.

Top Left: Looking up the begging of the ramp, Top Centre: Look over the Warm Up Pool, Top Right looking up to the spectator seating, Above: Spectator view of the Competition Pool. 


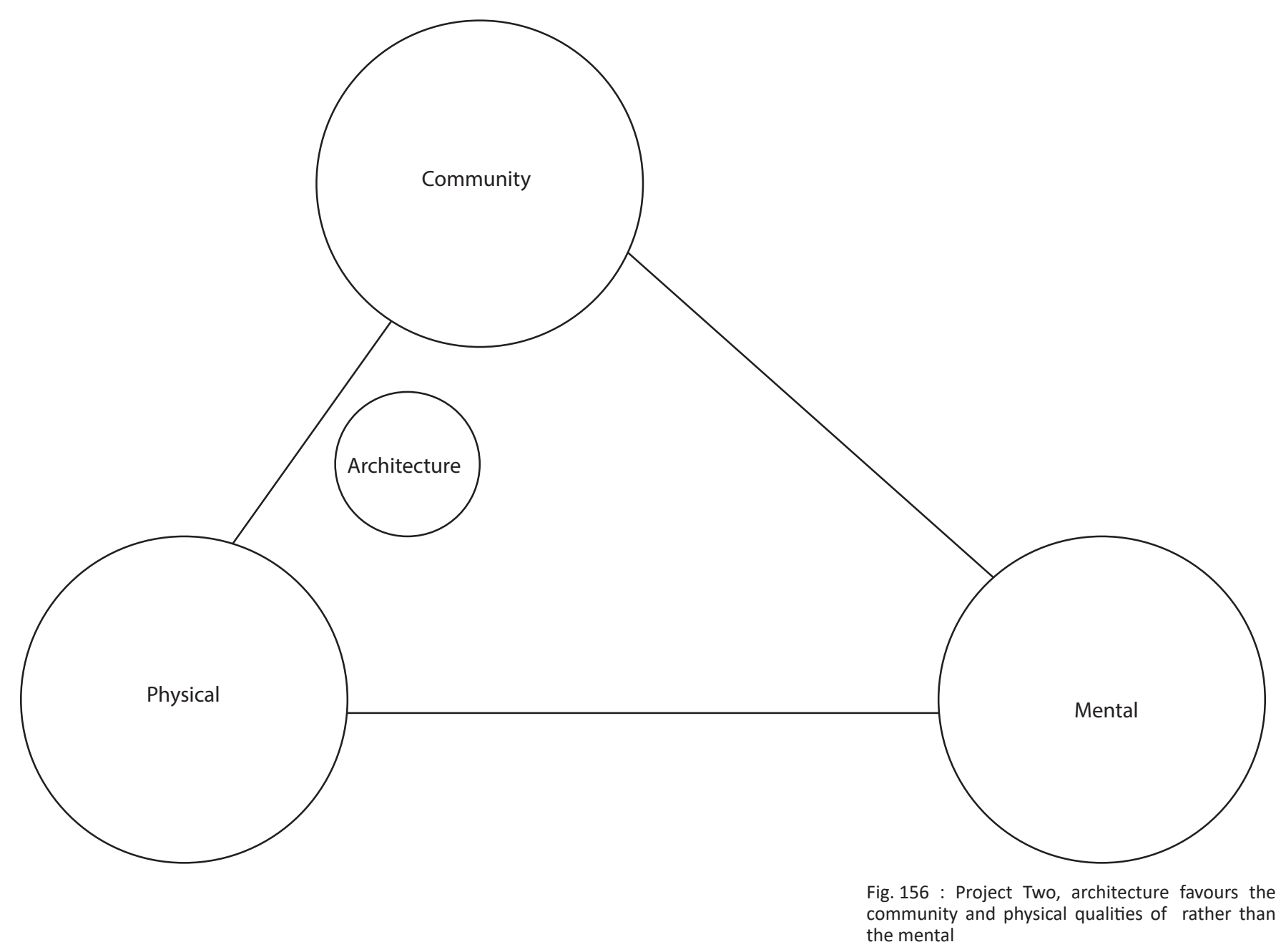




\section{PROJECT 2 DESIGN CONCLUSIONS}

My investigation into how the aquatic facility will respond to designing it in relation to a site has shown that a bias towards the community programs develops. The design of Project Two has a greater focus on the community program. This is where this project diverts away from the focus of the thesis. It has allowed me to re-think how the building works in relation an athlete. It creates a third factor that I didn't take into consideration when starting this process. Rather than just physical and mental aspects, a facility can also be community orientated. So, I have added a third aspect to my diagram: 'The Community'. This building positions itself towards the physical and community points in the diagram.

The building has been positioned here because as I concluded from the first project, for a facility to be athlete focused, the requirements would not be fully met in this design.

Where the building doesn't meet these key moments:

- The vertical travel between levels based on the stage of their process

- They see but don't travel the length of the building

- No complete separation between the public and the athletes

- The spaces do not create enough atmosphere to allow an athlete to enter the IZOP
What this building does do well is incorporate the community. It creates a community hub of recreation and social interactions. This hub creates a situation where people can gather and be inspired to try activities. It allows for different communities to interact with one another, and to learn from each other. The building also makes the space usable for a wider audience than just people who like to swim.

Aesthetically, the building is quite pleasing from the outside. It creates an interesting and dynamic form. There is opportunity here for the language created to influence other areas of the building. 


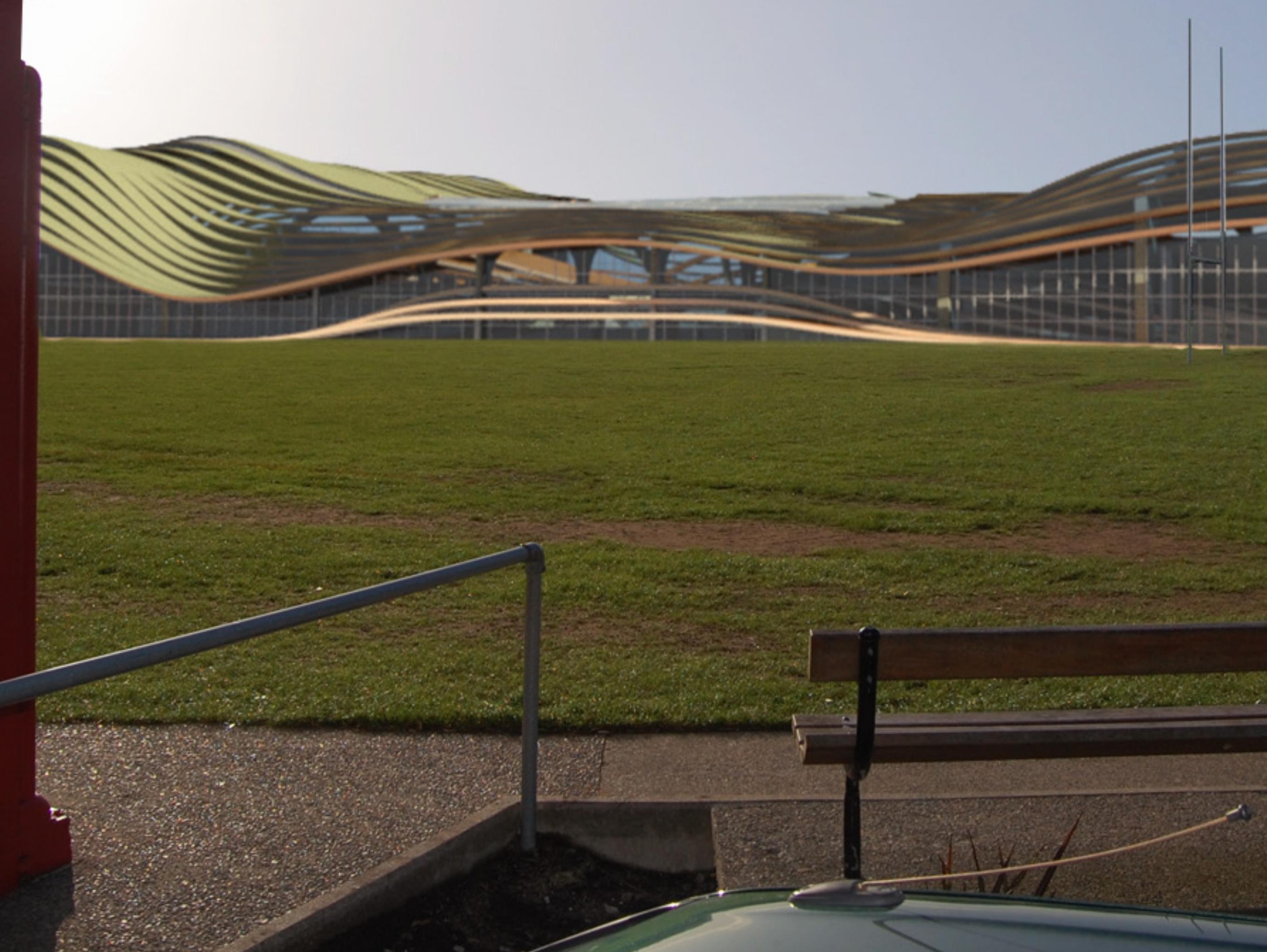




\section{PROJECT 3}

THE HIGH PERFORMANCE CENTRE 


\section{My Motivation}

The Project - The problem -

Research on problem-

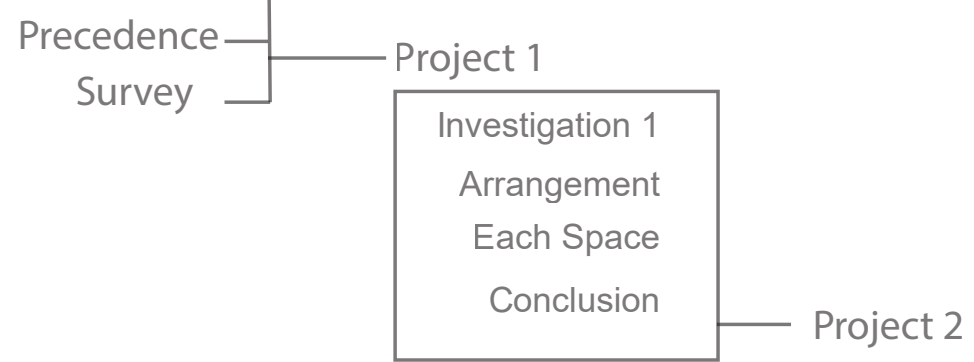

Problem Generated from Project 1 and 2 My Motivation

nvestigation 3

Arrangement

Each Space

Conclusion 


\section{PROJECT 3 INTRODUCTION}

Through the investigation in the second project, the conclusion made was that It focused too much on the community influence. Because of this I resorted back to looking at sport through architecture and lost the athlete focus for the design.

Due to the outcome of Project Two, I re-evaluated the influences the programs have on each other and how the space can be created. To do this, I will revisit my motivation and change my approach to the design so that I can investigate new approaches to these problems.

Aim - to apply findings from Project One and Two and approach the design outcome with new insight based on my underlying motivation

Method of design

- Re-interpretation of my motivation

- Re-evaluate arrangement of program

- Investigate how the spaces are connected and the atmosphere that they create

- Overall design conclusions 



\section{MOTIVATION RE-EVALUATION}

The motivation for this project has been to look at the architecture through the lens of an athlete and design accordingly. This project is to link back to my initial motivation and my experiences of training for and competing in a high-level event overseas.

I will be approaching it from two main challenges; training and education.

Wellington's climate is not conducive for all year-round training, which is required to perform well in international competitions. The harsh conditions not only make it harder to train outside, but the chance of injury increases which can set and athlete back in their training program.

Education in the sporting world is becoming more important as sport becomes more professional. The sporting career of an athlete is limited in the scheme of an entire lifetime. Therefore, education is an important aspect to modern sport. Personally, managing time between my education, training, and recovery is challenging. Unlike the American and Australian Sports Academies, which are based around University Education systems and opportunities, these approaches to sport and developing athletes at the same time as receiving an education are very limited in New Zealand. The role of architect can be to explore how facilities in New Zealand can allow the two programs to more effectively work together. 


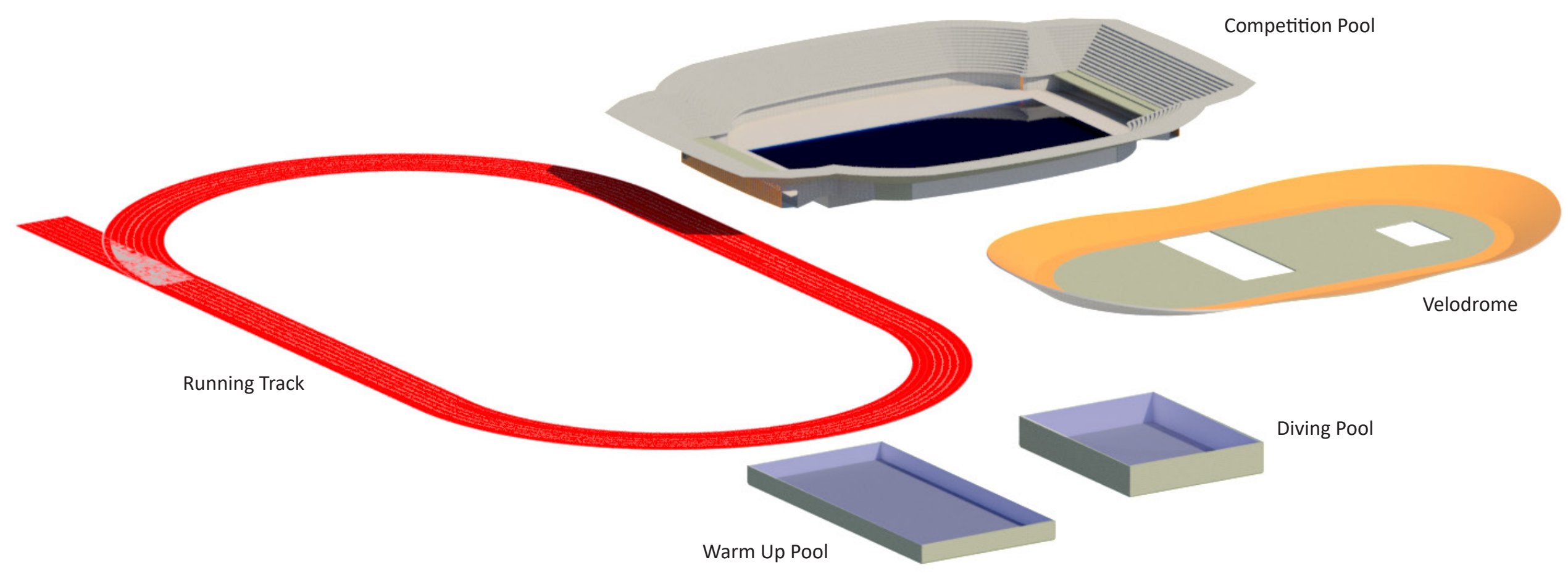

Fig. 159 : Individual program forms 


\section{DESIGN RESPONSE}

Building from the successful aspects of Project 2, Project 3 looks to extend these and allows them to influence the design.

The key aspects:

- How the building sits on the site

- The 'split and lift' language

- The integration of the community aspects into the building

There are two new features incorporated in the facility; a Velodrome and Running Track, so a High Performance Centre can be designed and developed in Wellington. All of the aspects of high performance sport can come together, and continue to develop with one another. 

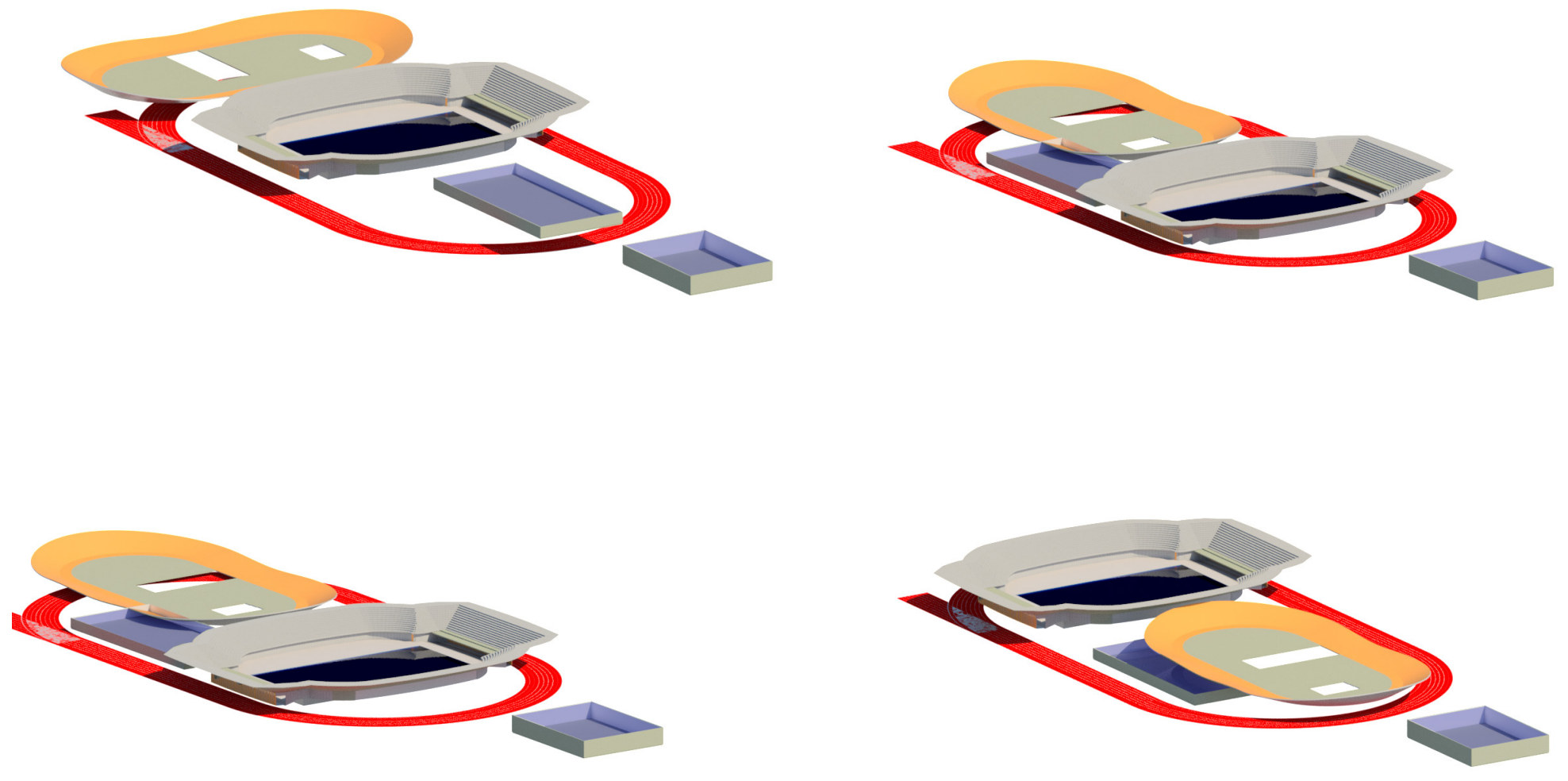

Fig. 160 : Experimenting with the arrangement of program forms 


\section{Arrangement of Forms}

The key to this building is how all the programs interact with each other because each has its own set of requirements.

The five main components are the Competition Pool, Warm Up Pool, Dive Pool, Running Track and the Velodrome.

To understand how the five components of the building will work together, an experiment of arrangement was done to understand and figure out the best relationship. Because each component has a unique form, this will influence the arrangement of the program.

Brasilia by Oscar Niemeyer has a strong influence on the relationship and arrangement of these forms. The podium and two geometric forms placed on top and that oppose each other, is the effect I am looking to generate. 

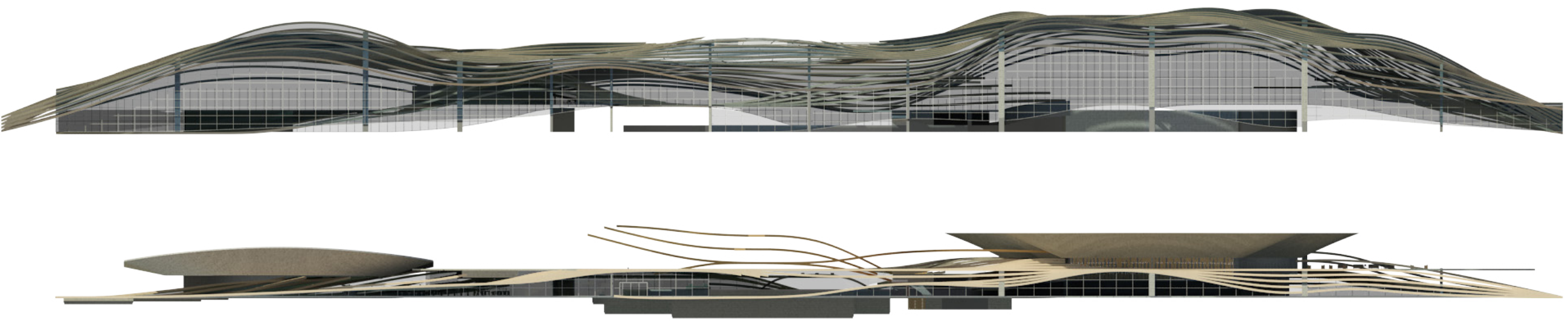

Fig. 163 : East view showing the form

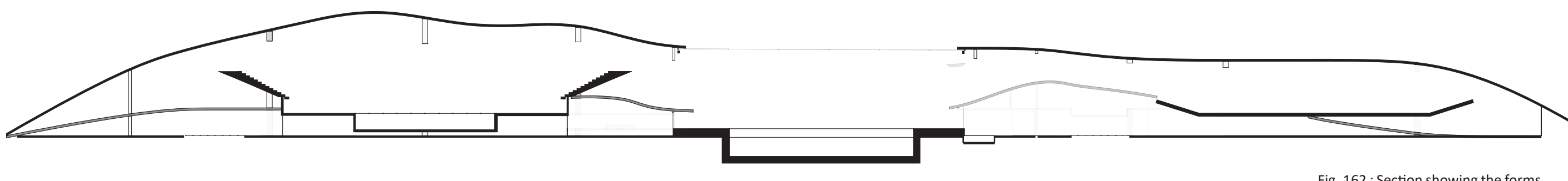




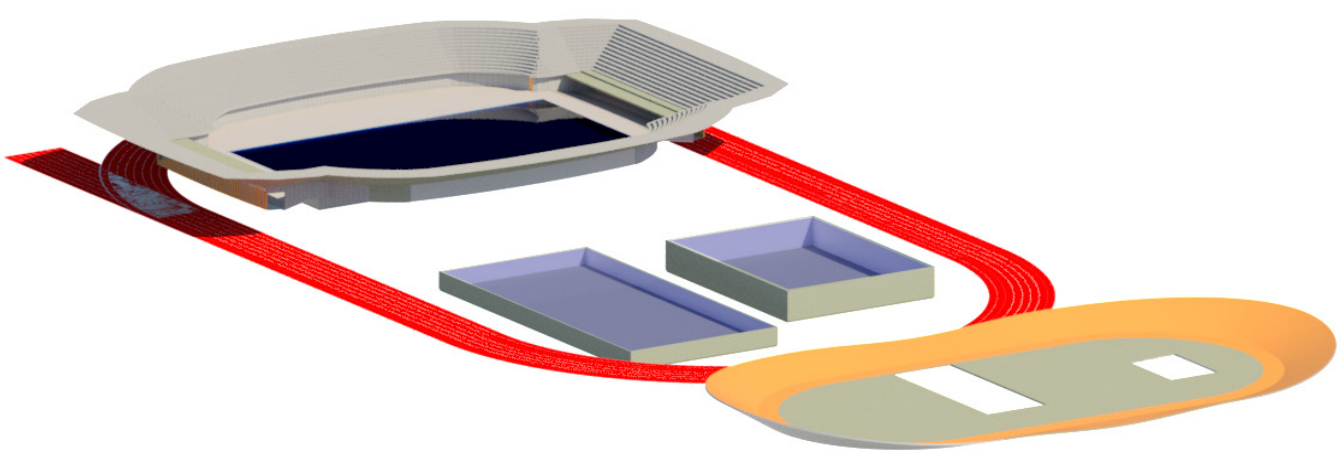

Fig. 164 : Arrangement of Form
The experimentation concluded that the three pools are to be placed in the centre of the Running Track with the Competition Pool raised above the others, allowing the findings from the first project to be used.

A similar method to Neimyer will be used. The Velodrome will be placed with the same orientation as the Competition Pool and raised. An undulating floor will create the Podium. As these forms are similar, the Dive Pool will create the tension by cutting a hole in the Podium.

The 'split and lift' language from Project Two will be adopted to create the roof that provides cover for the program and the undulating floor plane that connects each program. The reaming program can fit in spaces generated through this arrangement, and create their own interesting spaces. 


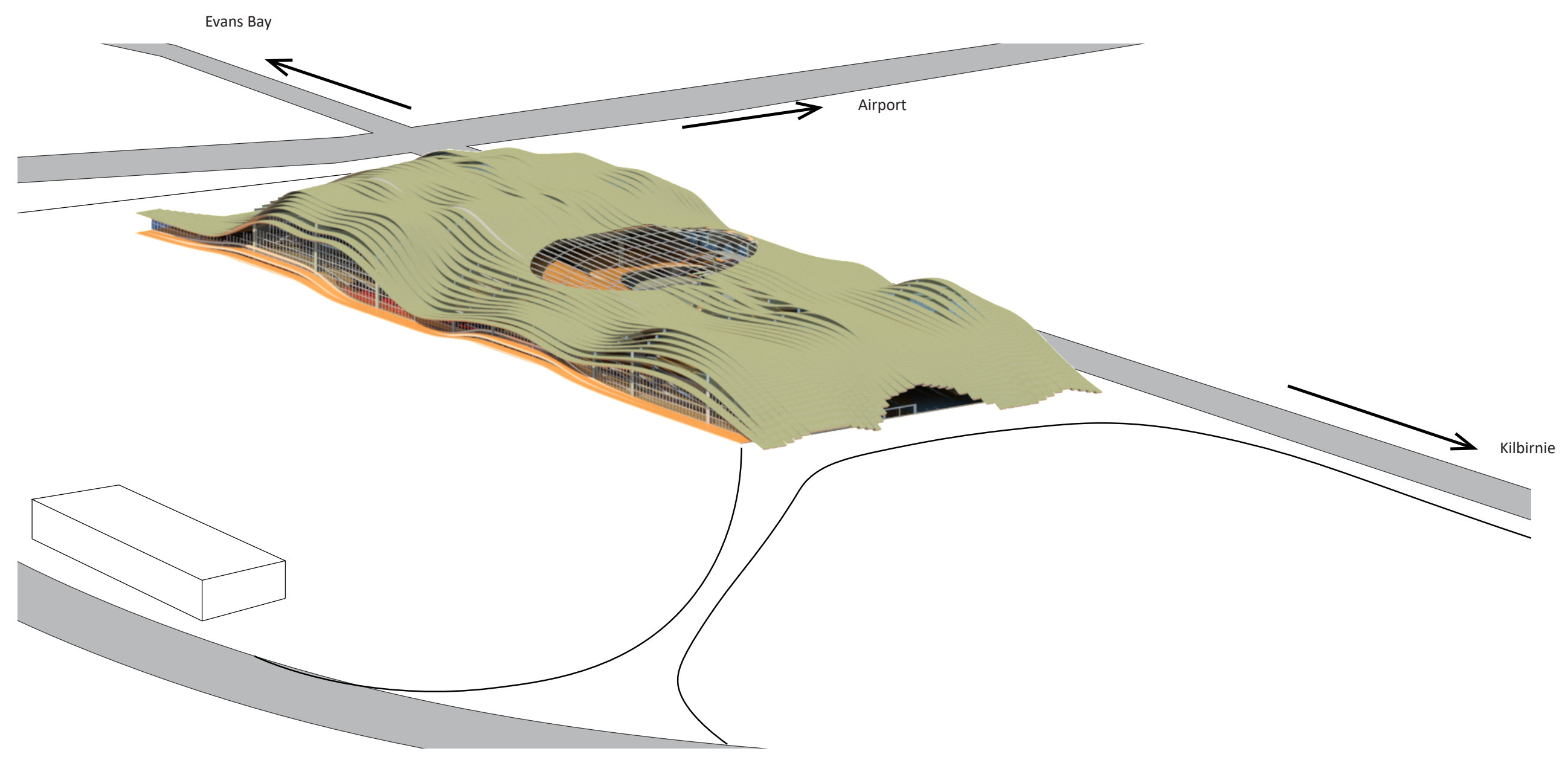

Fig. 165 Above: Overall building form on site

Fig. 166 Left: Approach from North-West corner of Kilbirnie Park 


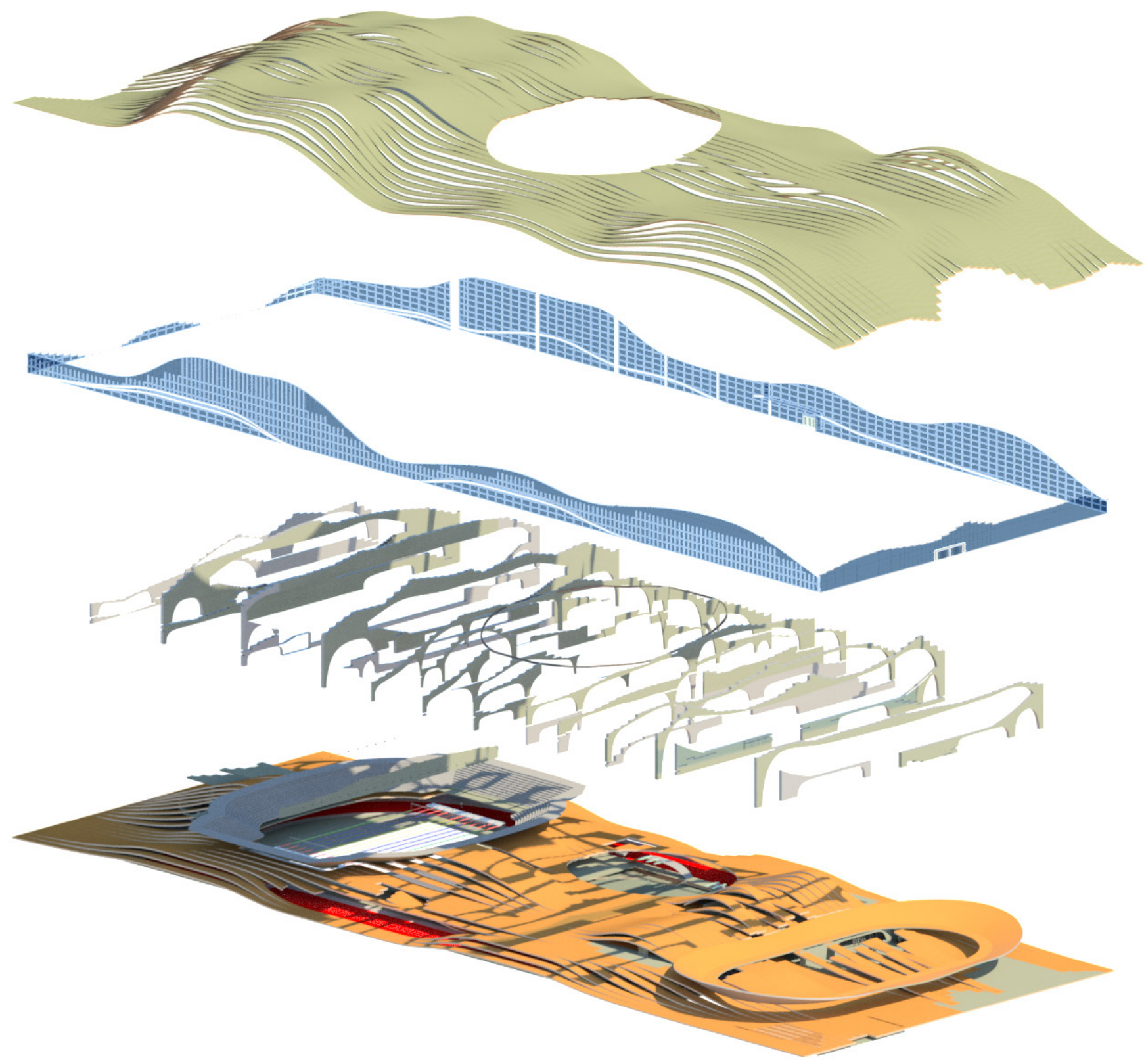




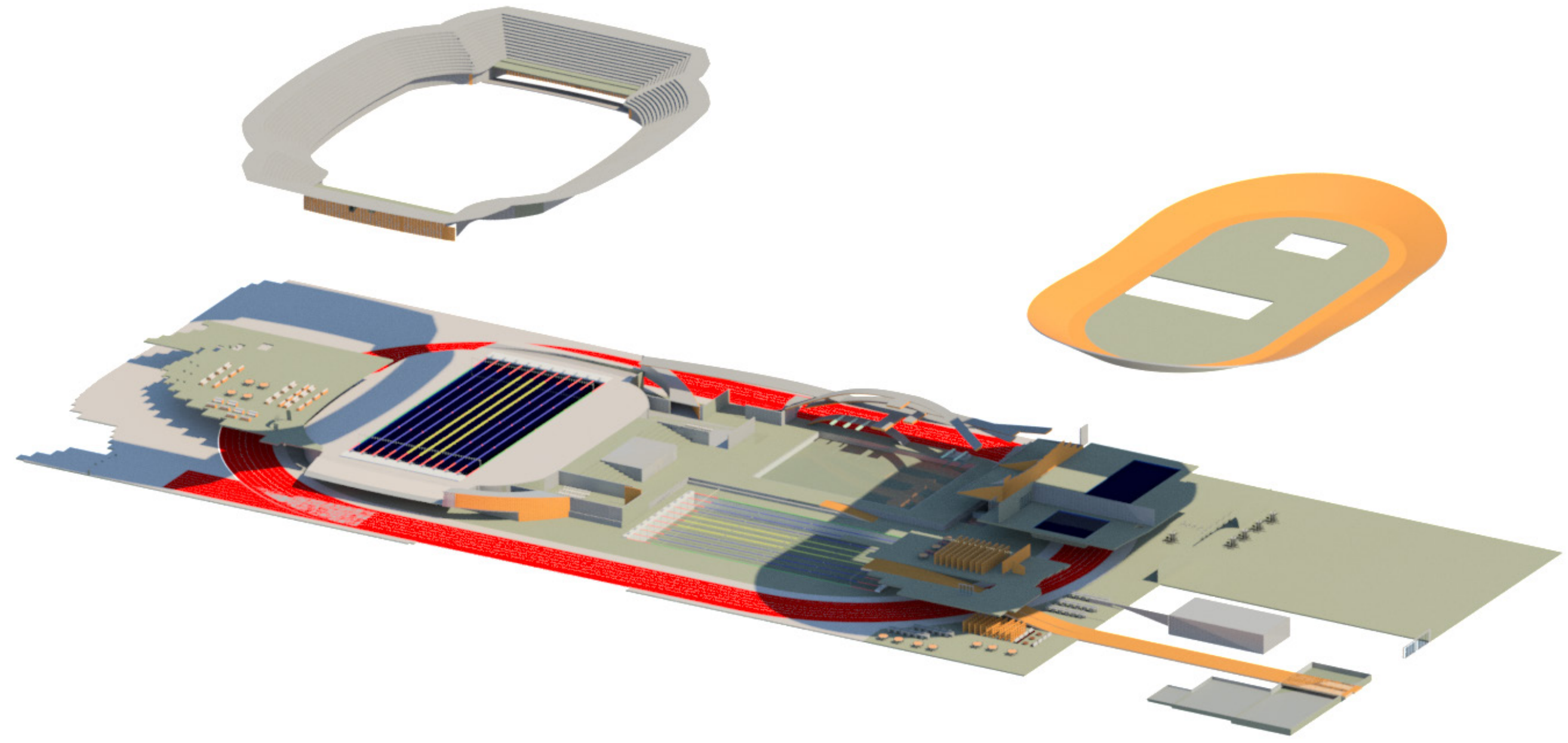




\title{
Layout of Facility
}

\author{
1 - Entry \\ 2 - Children's Pool \\ 3 - Gym \\ 5 - Ramp to Atrium \\ 6 - Recovery Area \\ 7 - Warm Up Pool \\ 8 - Dive Pool \\ 9 - Last Words \\ 11- Marshalling \\ 12- Up to Dive platform \\ 13- Competition Pool (below pool deck) \\ 14- Pool Services Space \\ 15- Running Track \\ 16- Extra Training Space \\ 17- Athlete's Entry \\ 18- Ramp to and from Athlete's Lounge
}

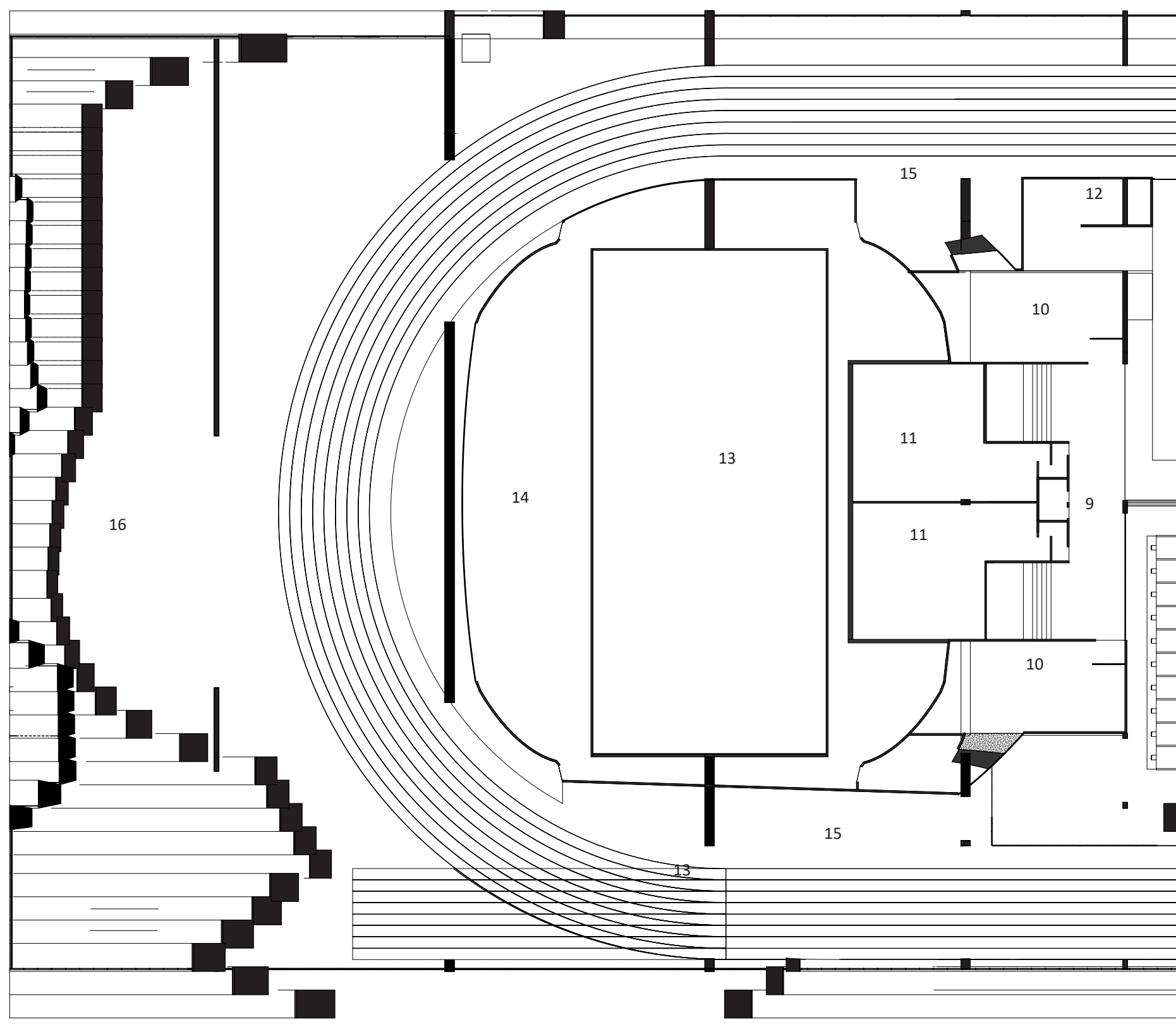




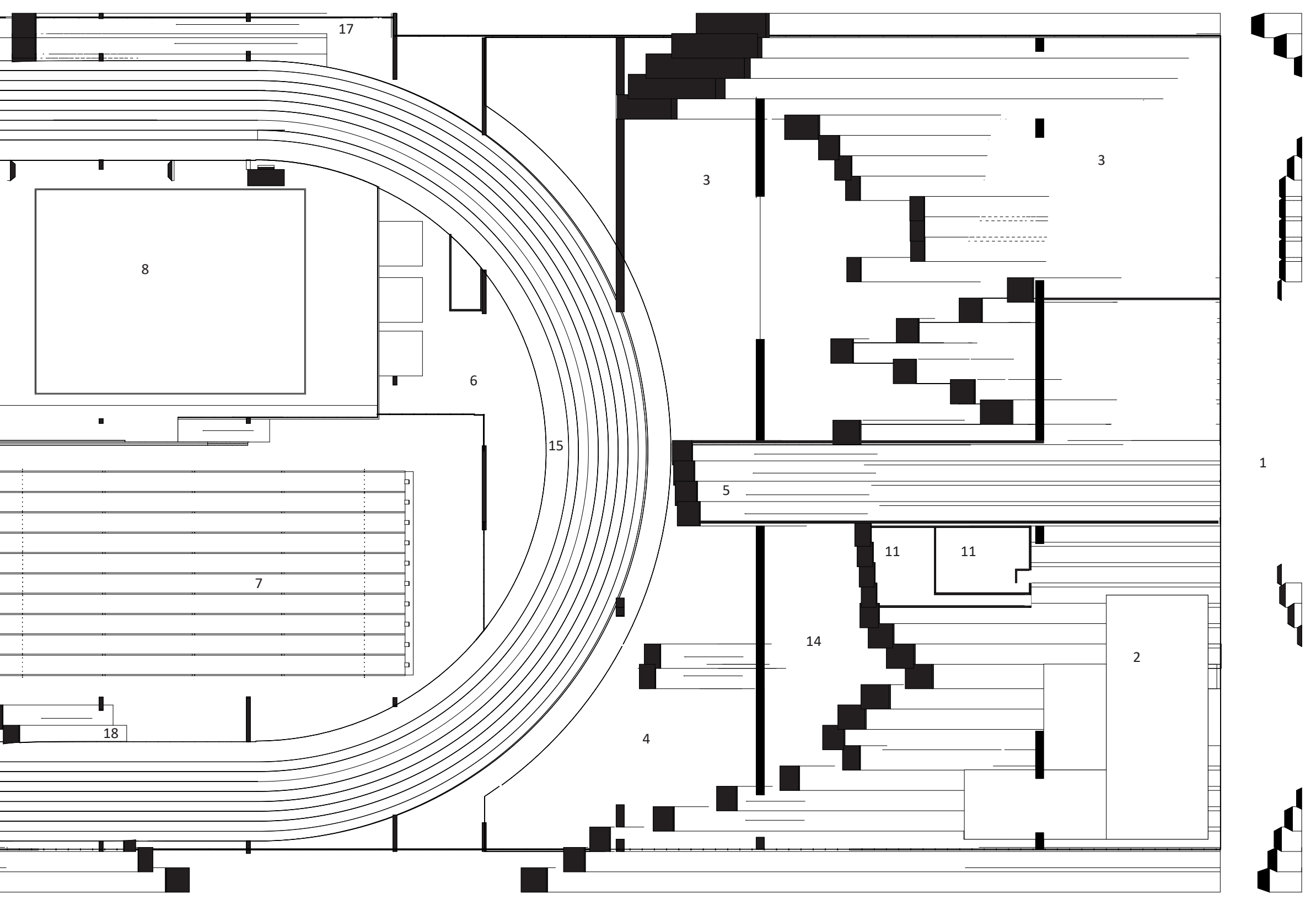




\section{Layout of Facility}

1 - Entry
2 - Velodrom

3 - Entry to Velodrome

4 - Library

5-Ramp to Atrium

6 - Hydrotherapy Pool

7 - Atrium

8 - Dive Pool void

9 - Last Words

10- Stairs from Competition Pool to Warm Up Poo

11 - Entry to last words from atrium

12- Up to dive platforms

13- Approach to Start Block

14- Competition Pool

15- Athlete access to grand stand

16- Athlete's Lounge

18- Ramp to and from Warm Up Pool

19- Changing rooms

20- Learn to Swim Poo

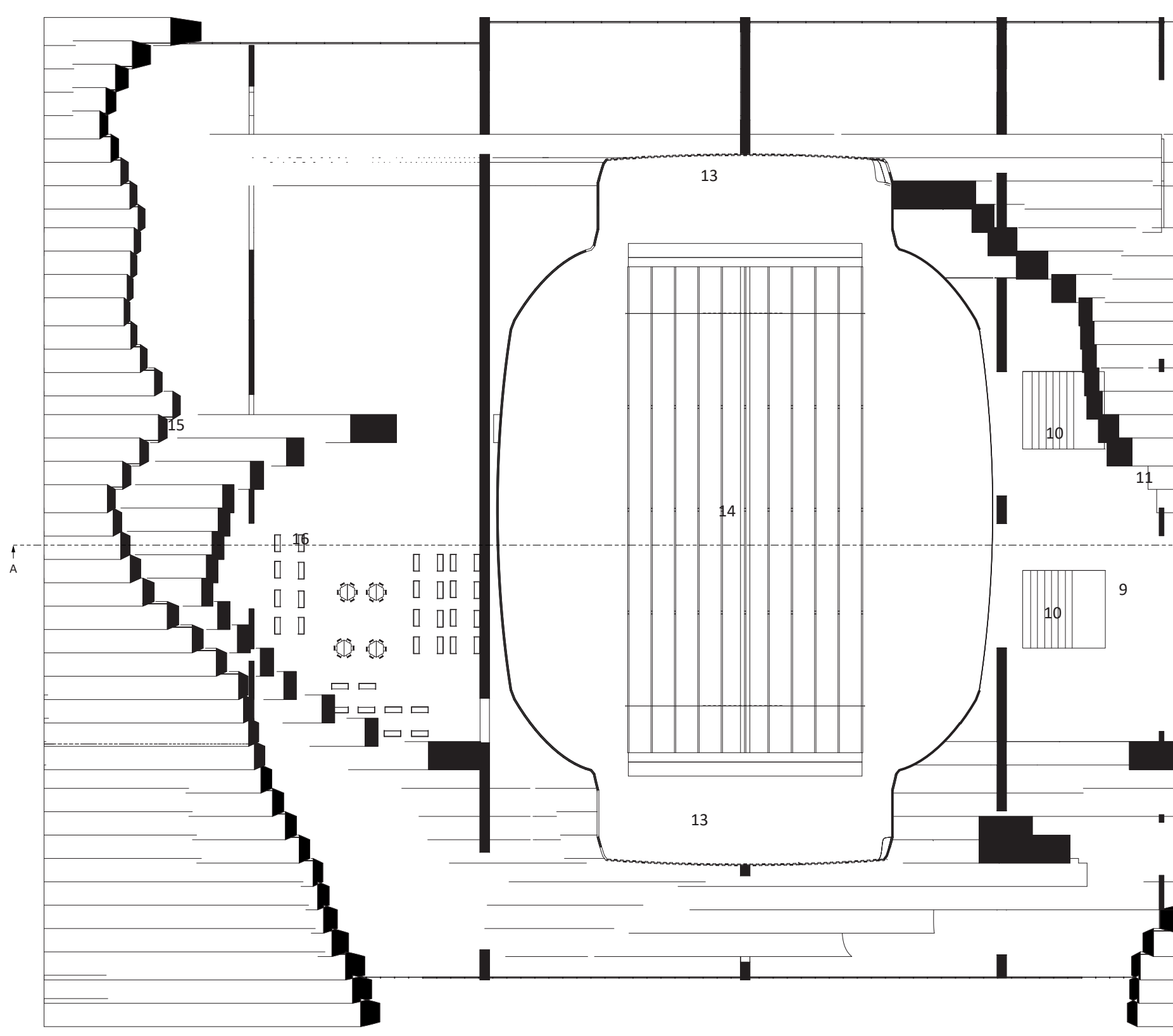




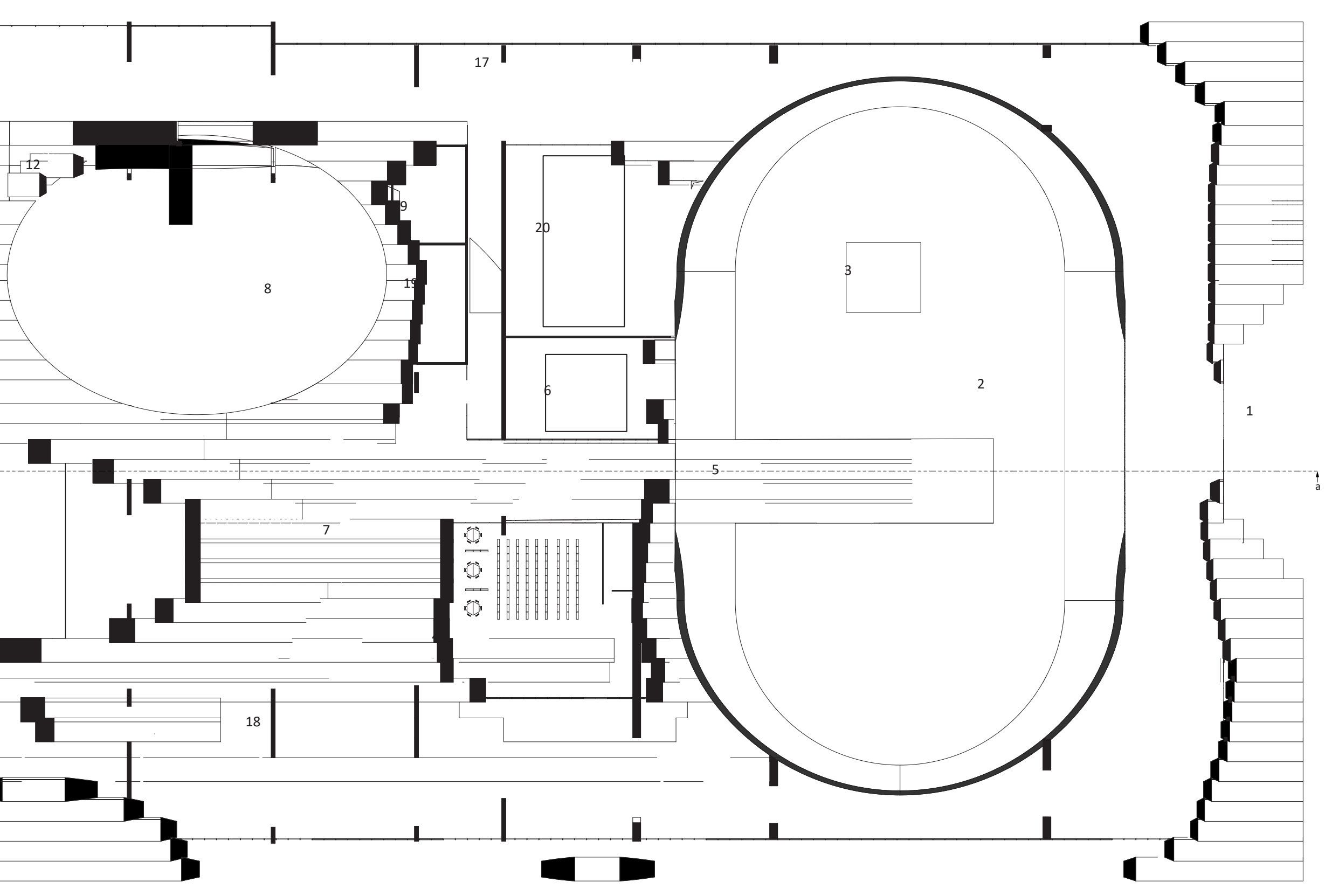




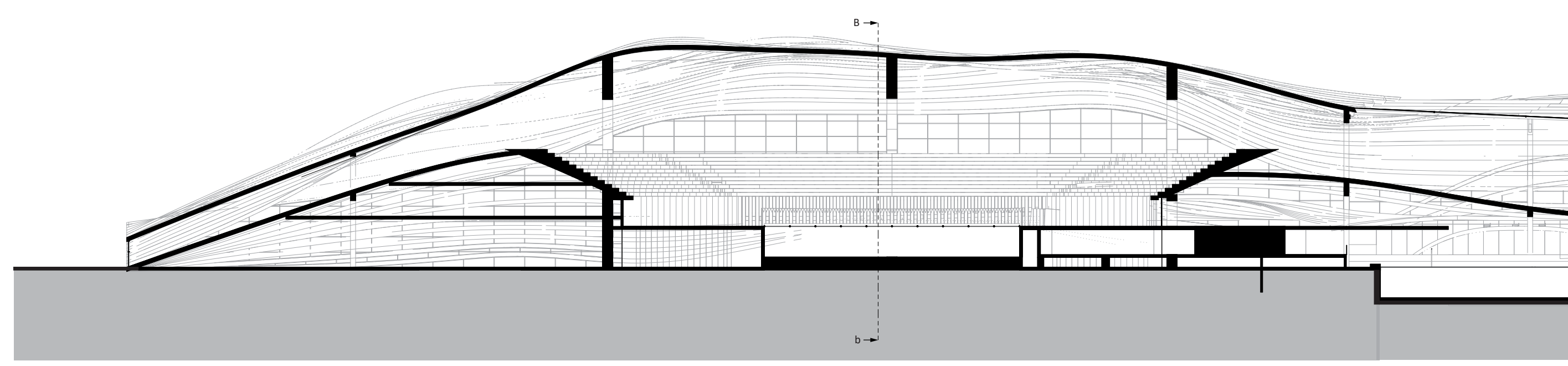



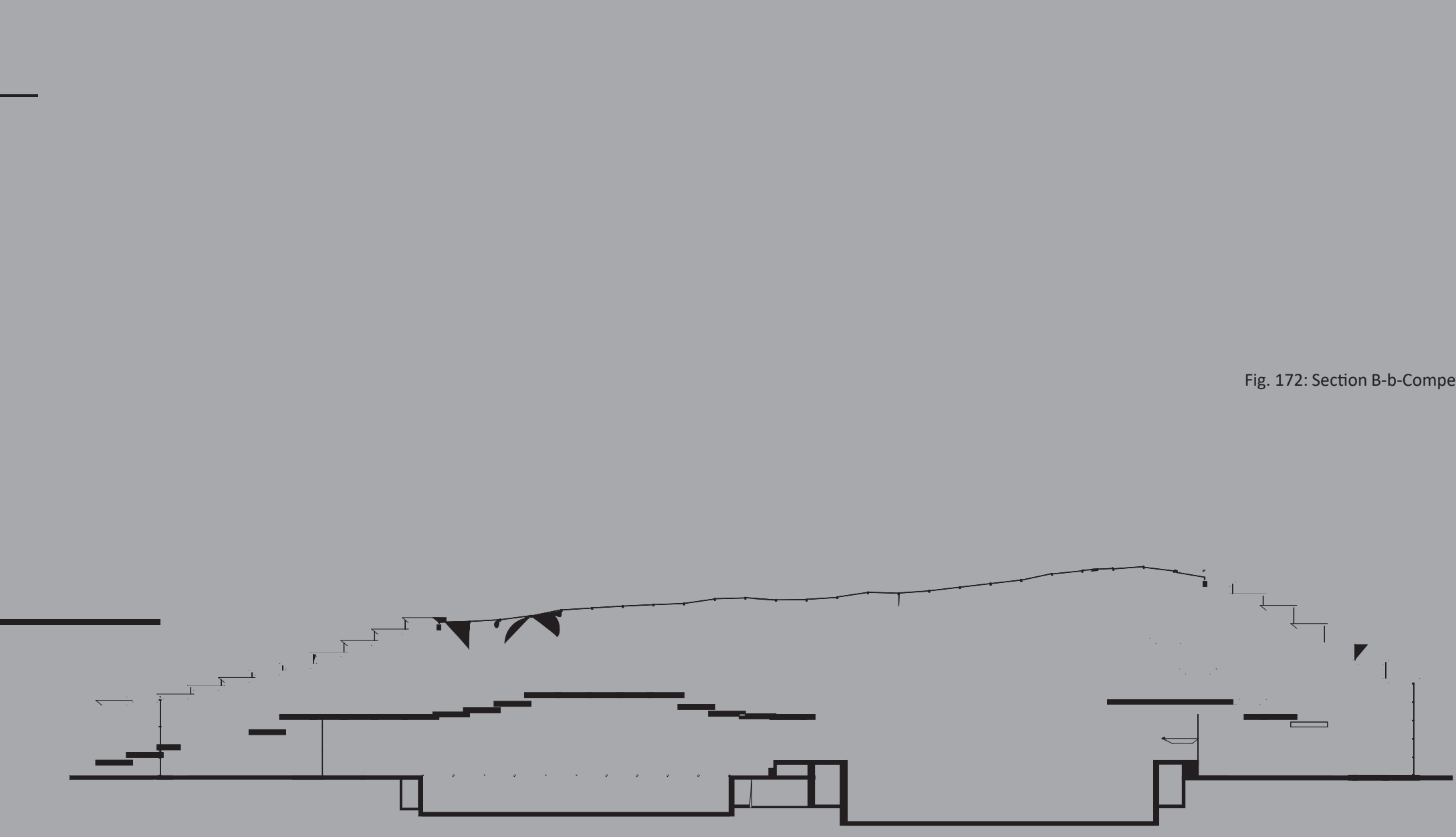


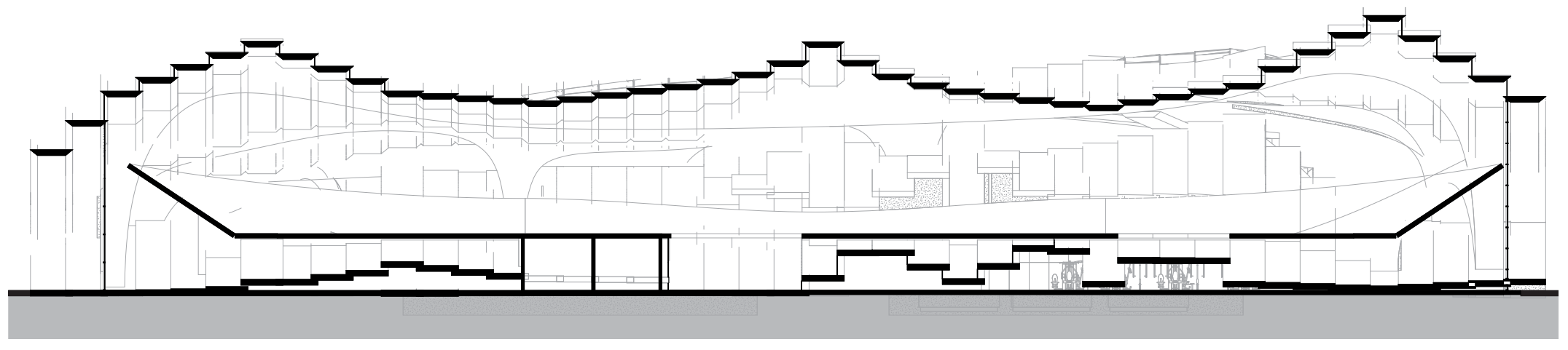

Fig. 174: Section D-d- Dive Pool 


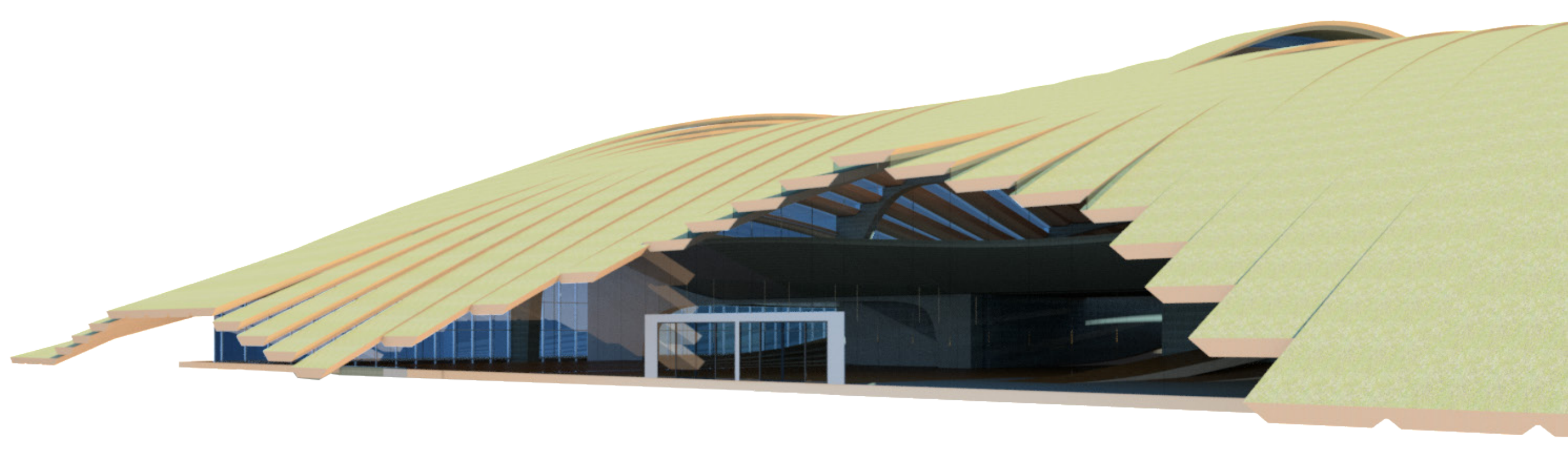




\section{Public Entry}

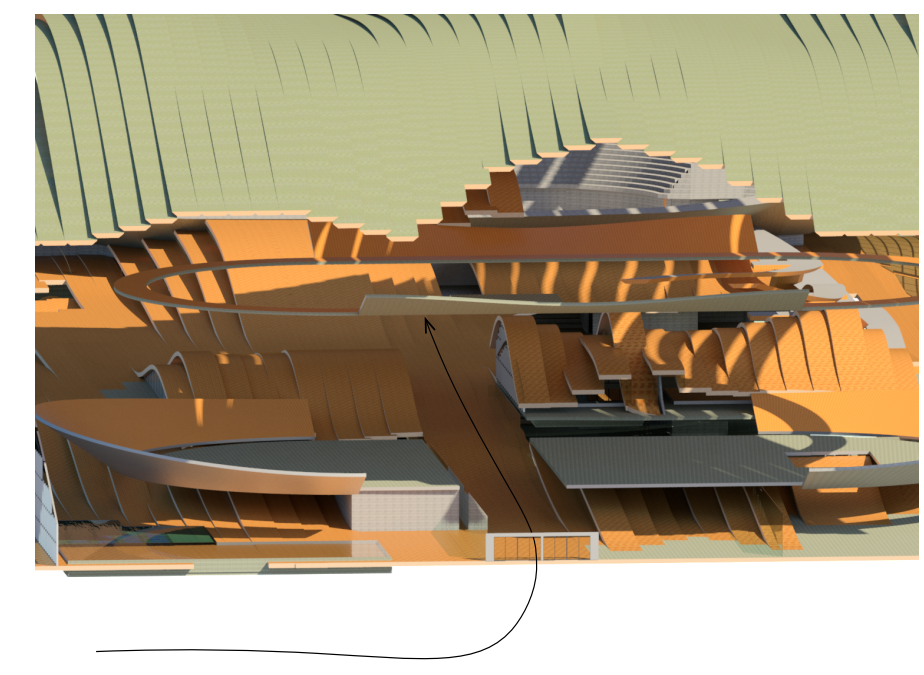

Fig. 175 Above: Axo of the public entry Fig. 176 Left: Rendered exterior view of entry

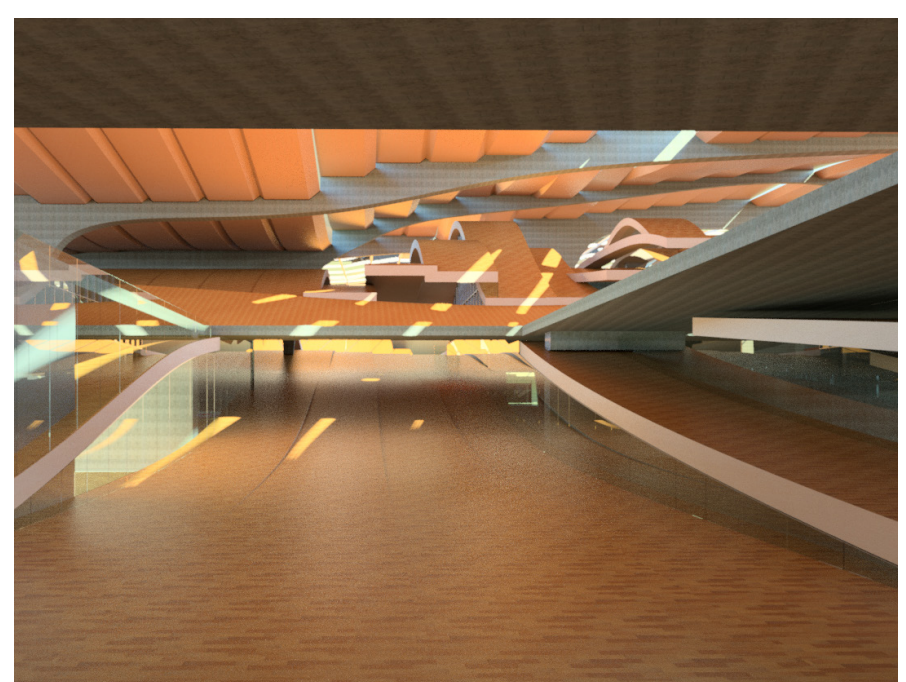

Fig. 177 : View up the access ramp towards the atrium.

This creates a confined dramatic space with glimpses

to programs the facility offers like passing under the

Velodrome as shown.

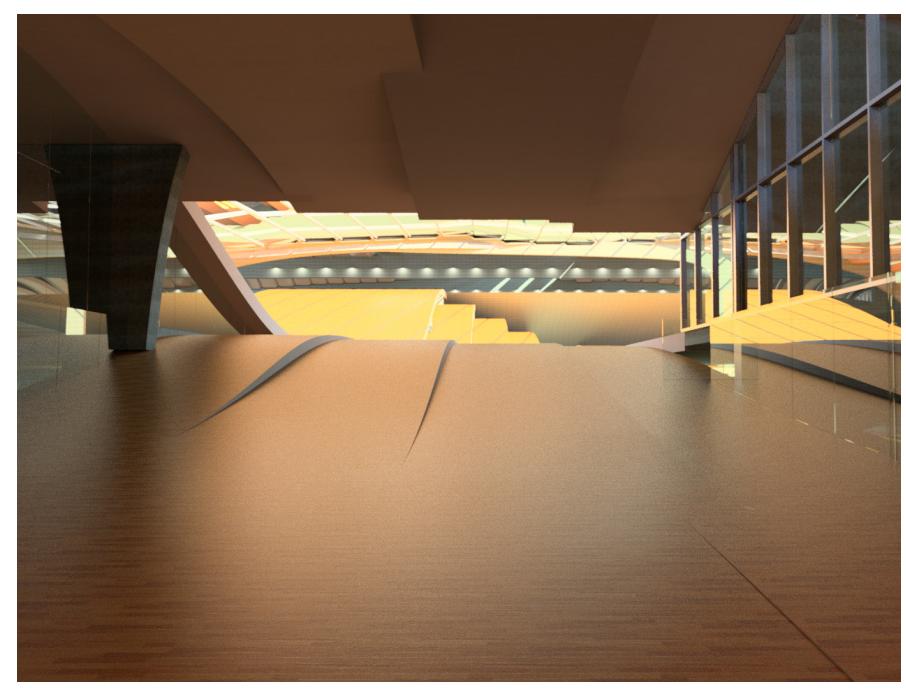

Fig. 178 : View of the entry into the atrium from the access ramp 
- hetate

1

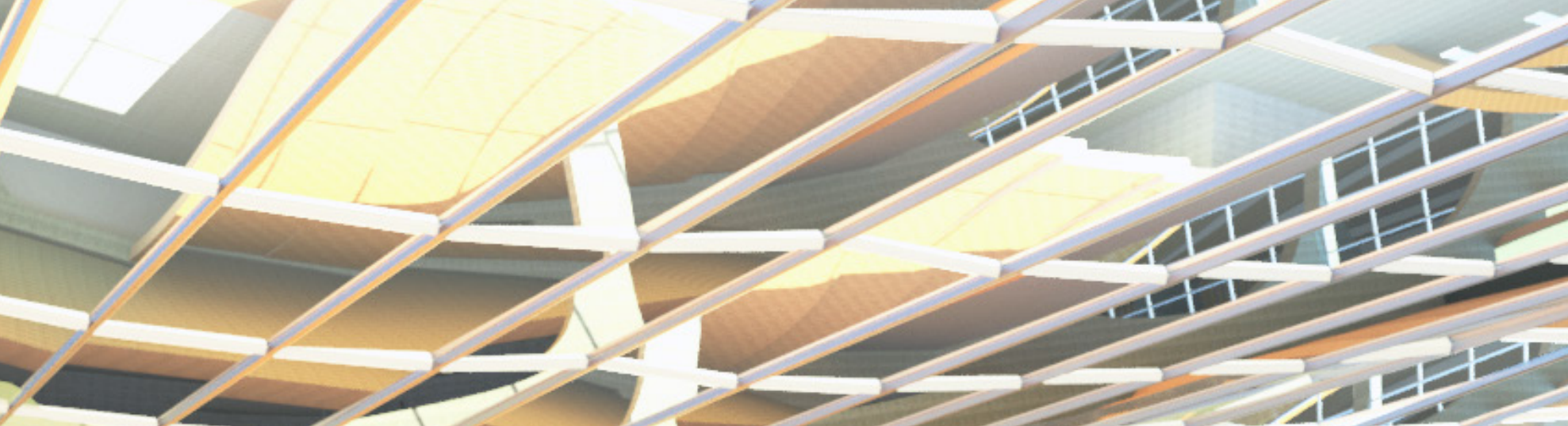

$-1$
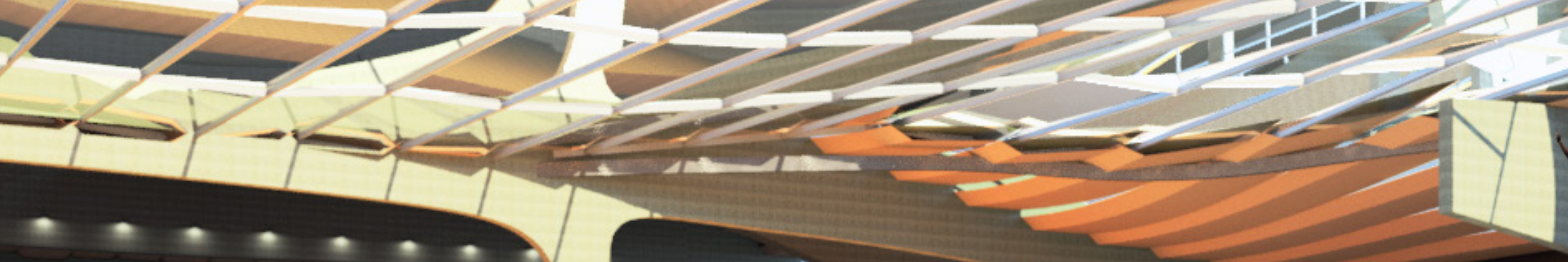

\section{$\frac{1}{2}$}

12
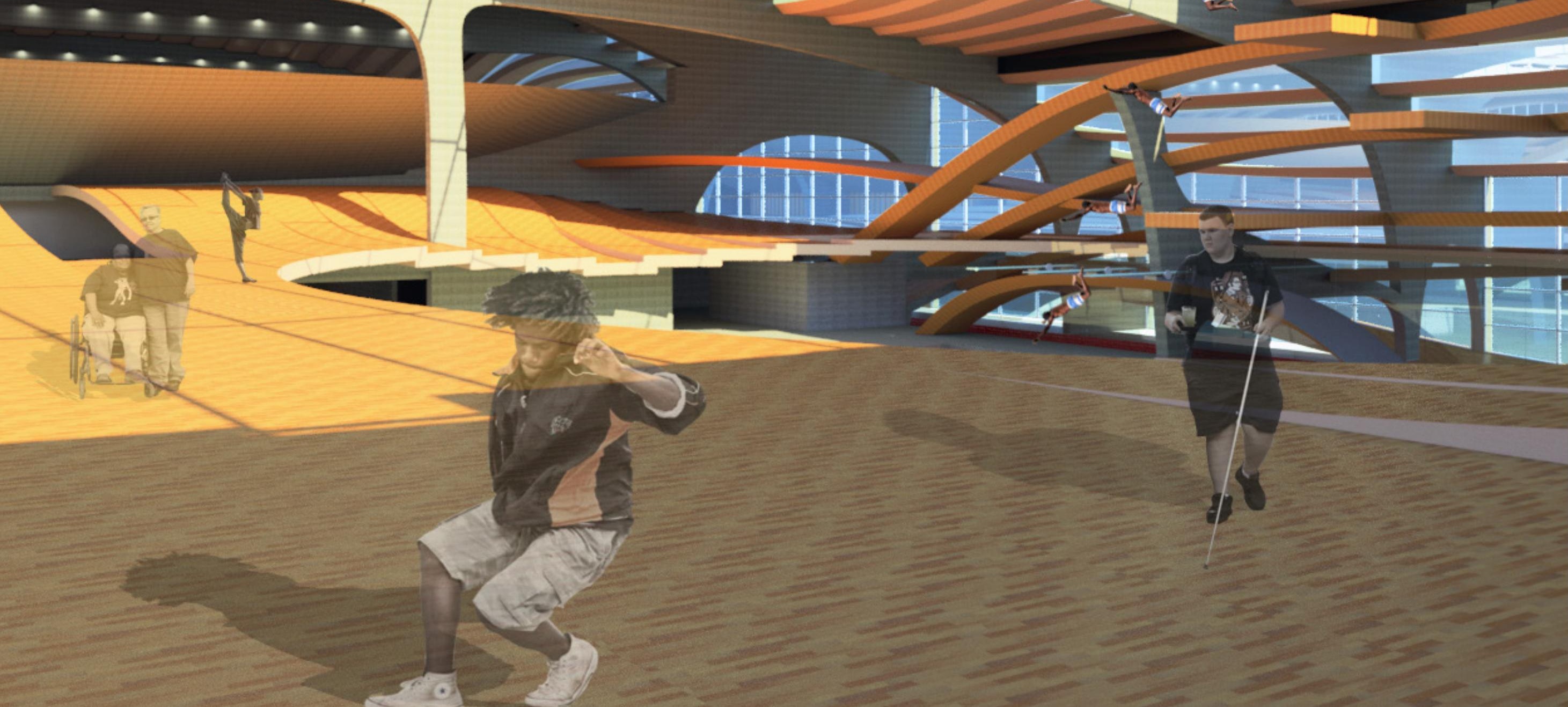


\section{The Atrium}

The Atrium is the most important part of the design that allows the public and athlete programs to mix. The approach to, and the space itself allows glimpses of program and activity happening within the facility. The dramatic entrance of compression and opening up create a sense of grandeur. This makes the space special and inspires people to investigate different programs.

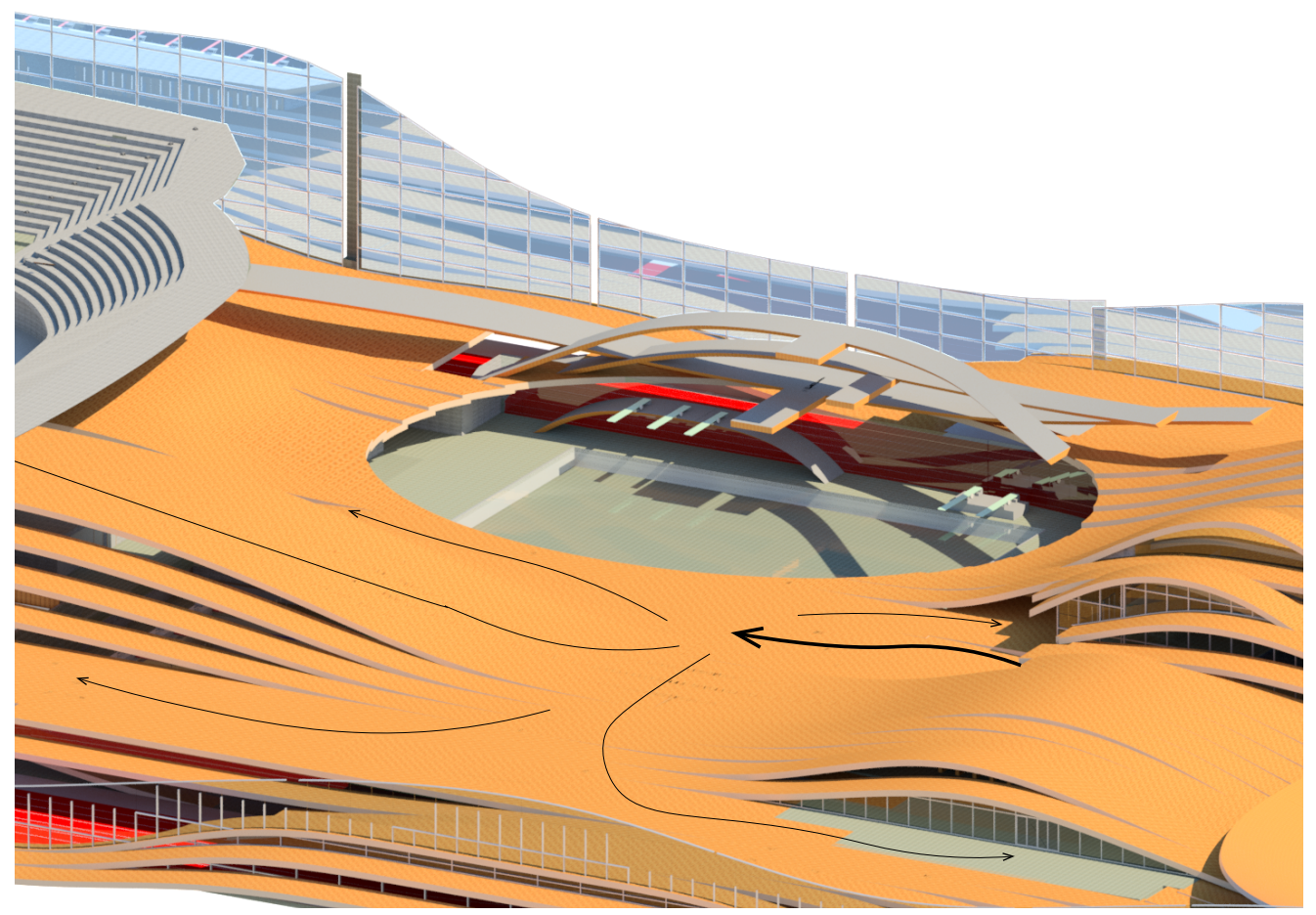

Fig. 179 Above: Axo of the Atrium

Fig. 180 Left: View of the Atrium towards the dive boards

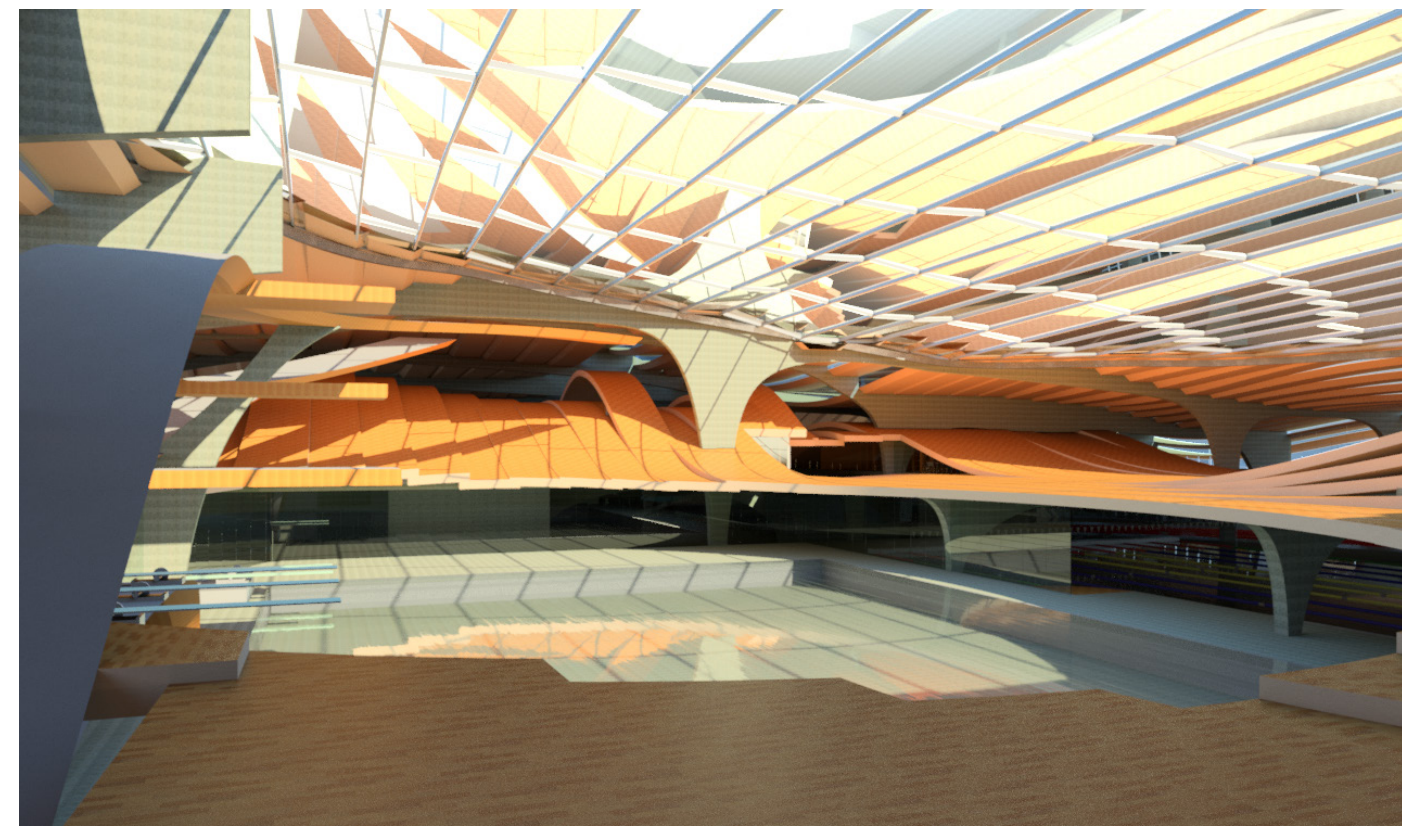

Fig. 181 : View back towards the entry over the Dive Pool

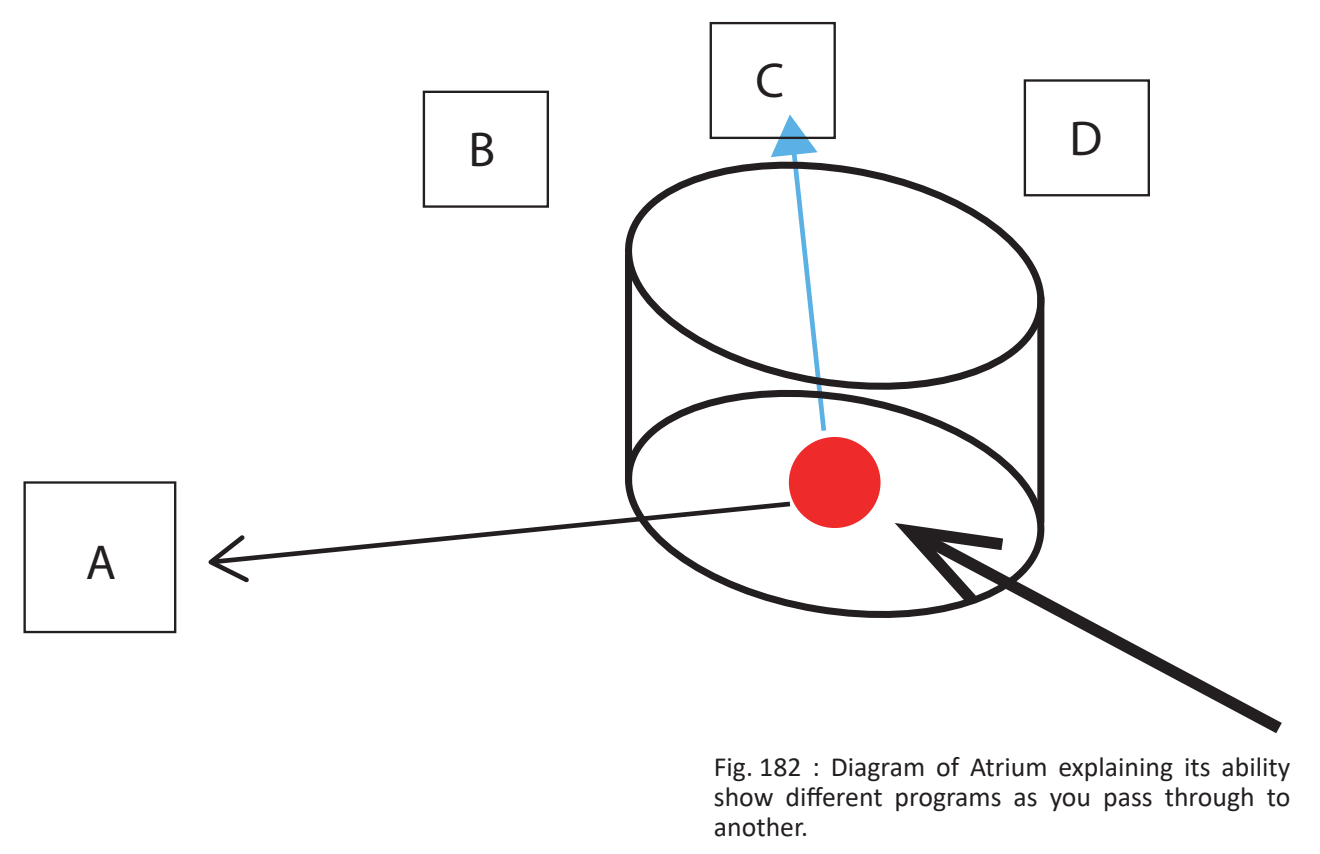


Hydrotherapy Pool
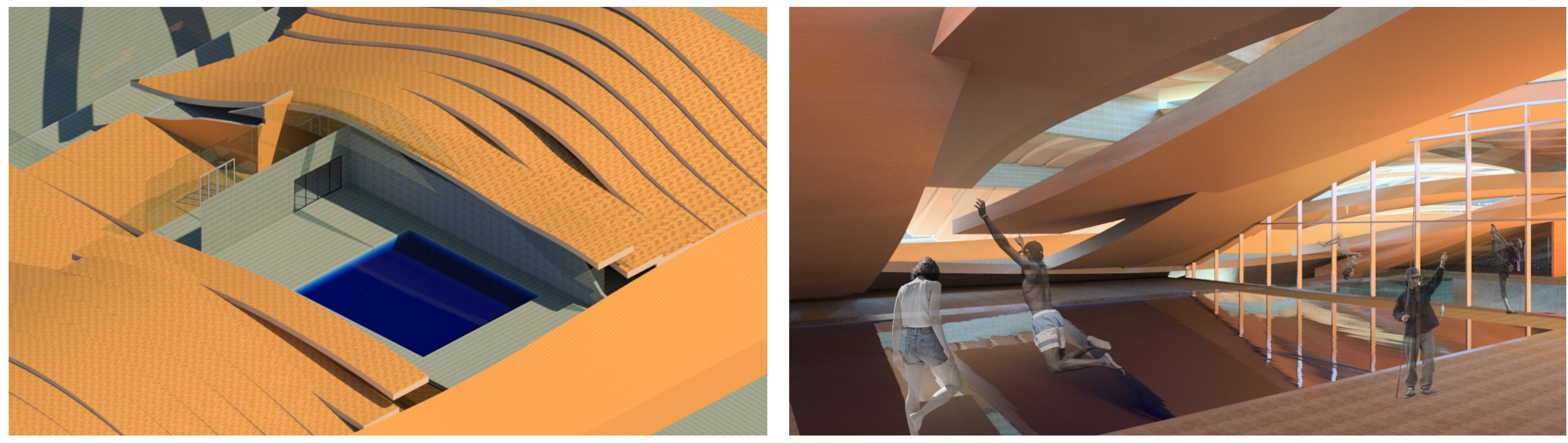

Fig. 183 : Axo of Hydrotherapy Pool

Fig. 184:View of Hydrotherapy Pool 


\section{Learn To Swim Pool}
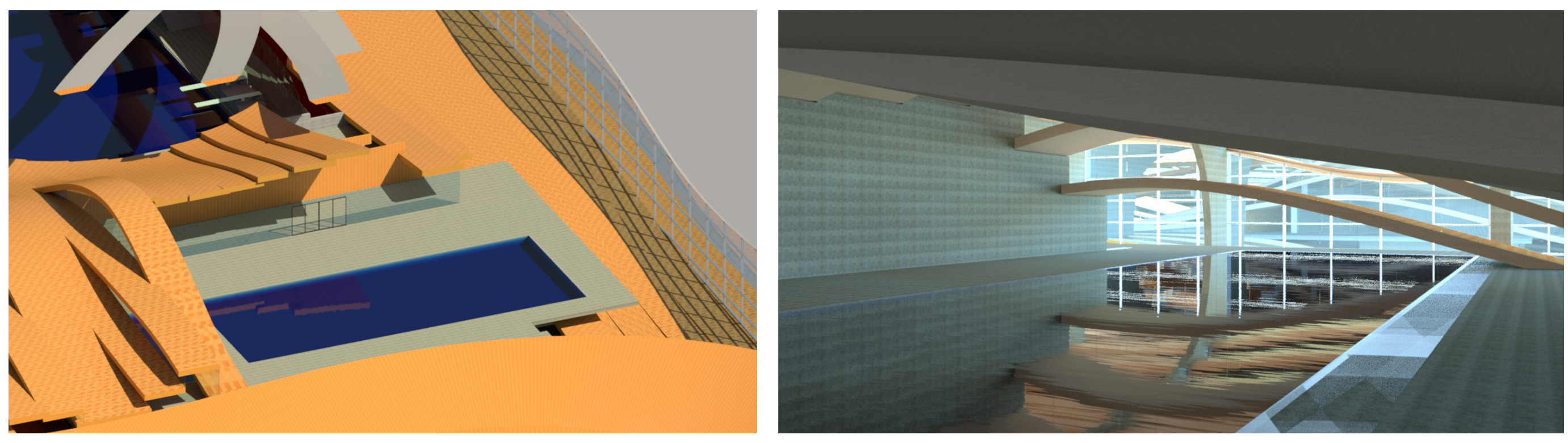

Fig. 185 : Axo of the Learn to Swim Pool

Fig. 186:View of the Learn to Swim 


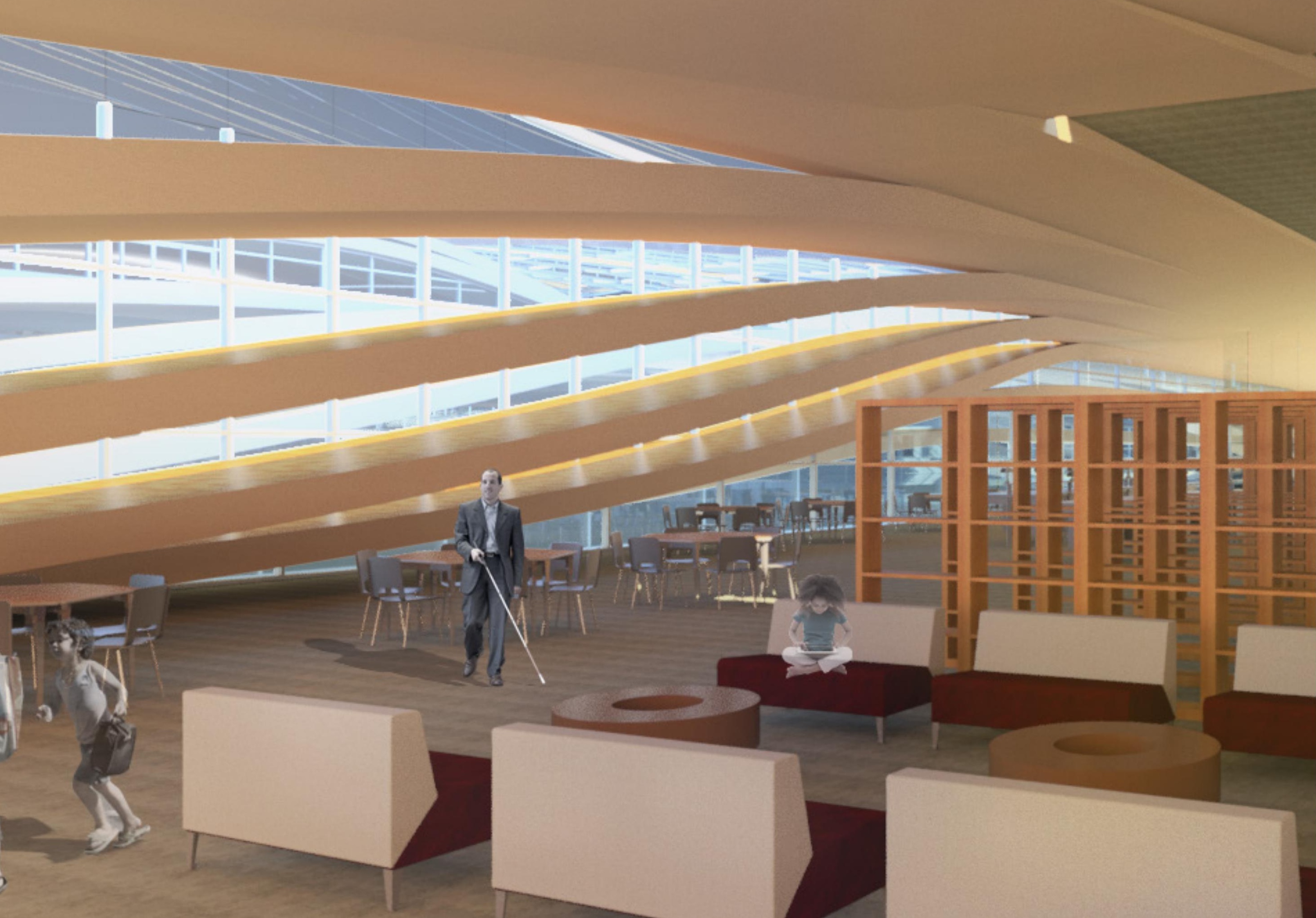




\section{Library}
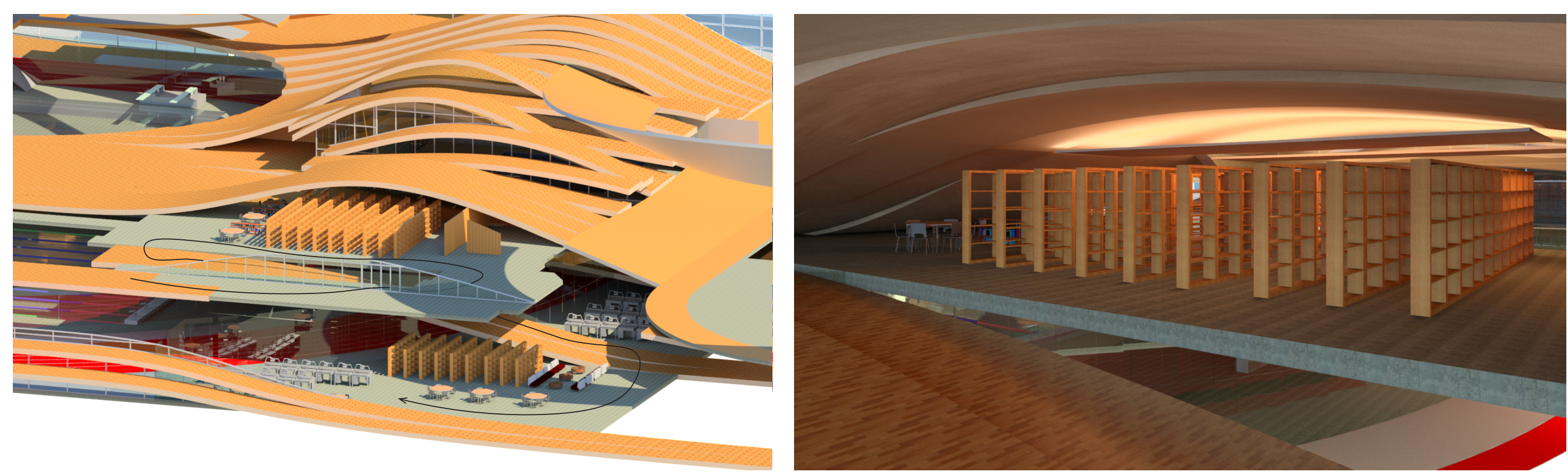

Fig. 187 Above: Axo of the Library, access is from level 1 and is extended

Fig. 189 : View of level 1 of the Library down to the ground level through its own ramps.

Fig. 188 Left: Rendered view of the ground floor of the Library. 



\section{The Gym}
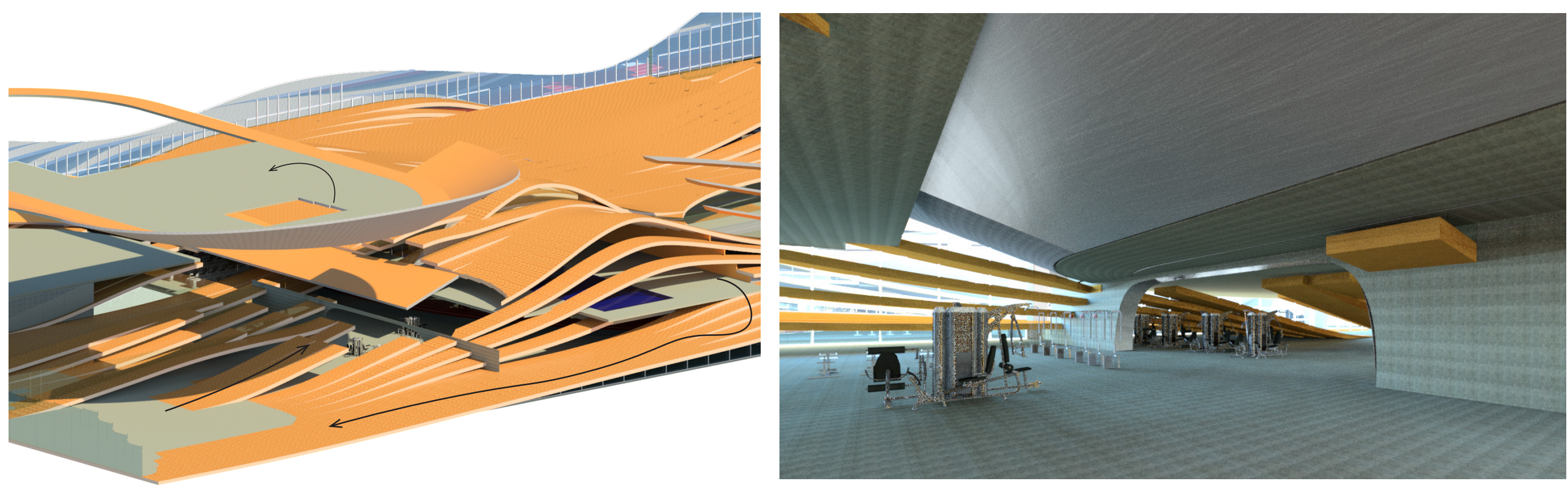

Fig. 190 Above: Axo of the gym.

Access to the gym is past the Hydrotherapy and Learn to Swim

Pools. This is also access through to the Velodrome and can be

used as support space when competitions are on.

Fig. 192 Left: View up to the Velodrome 


\section{Athlete Entry}
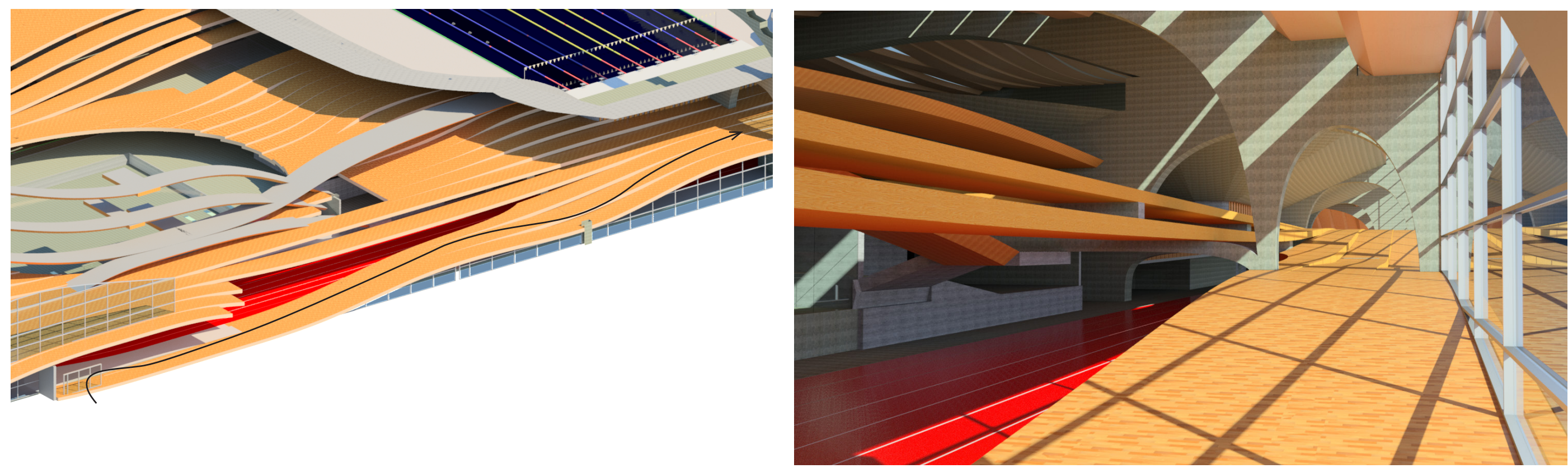

Fig. 194 : View towards the Athlete's Lounge

Fig. 193 Above: Axo of the Athlete Entry.

They enter from the East side and travel behind the Competition Pool. This

is to give them a sense of the length of the building and experience the

atrium space, while keeping separated from the public.

Fig. 195 Left: Exterior view of the Athlete Entrance 



\section{The Velodrome}

Fig. 196 Left: View of the Velodrome from the track

Fig. 197 Right: Axo of the Velodrome

Fig. 198 Below: View of the Velodrome from a spectators view.
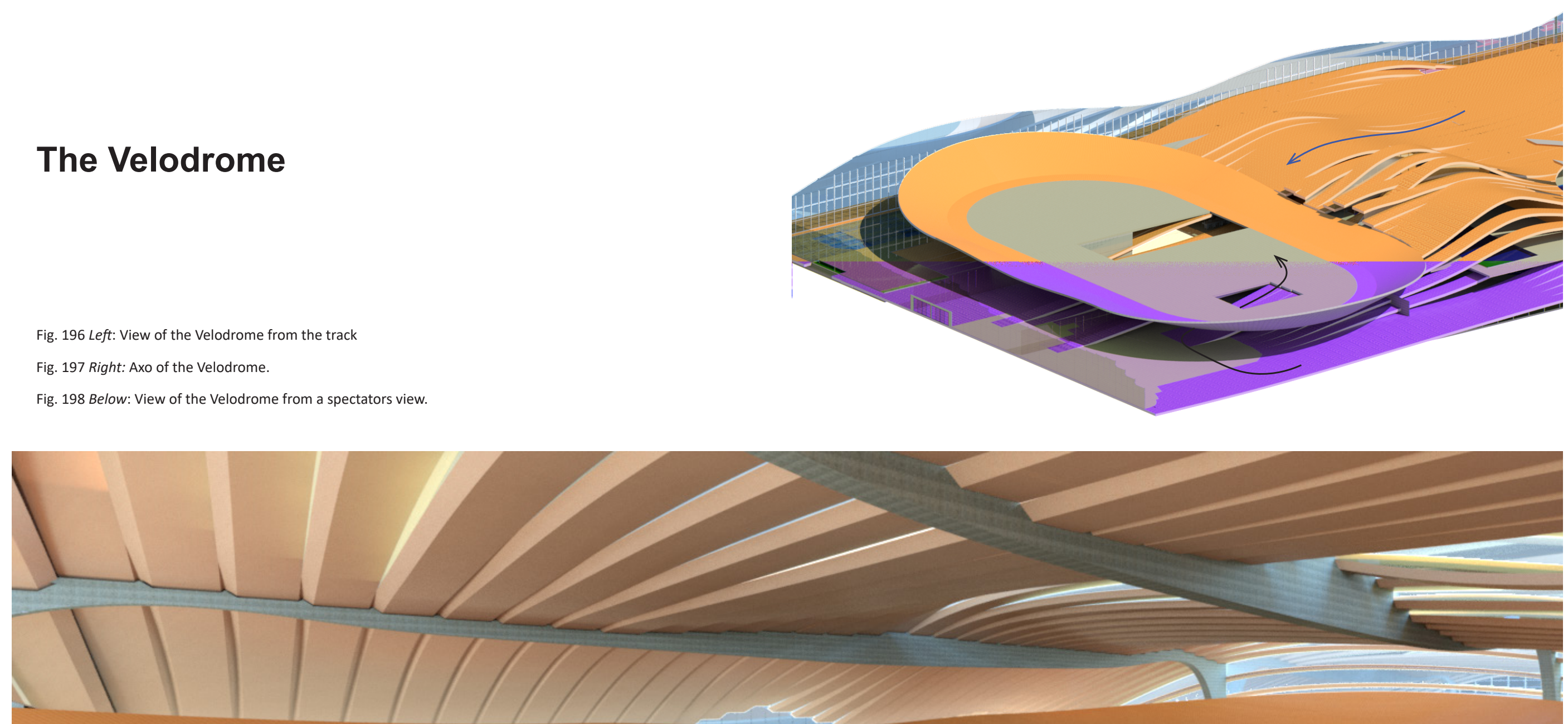


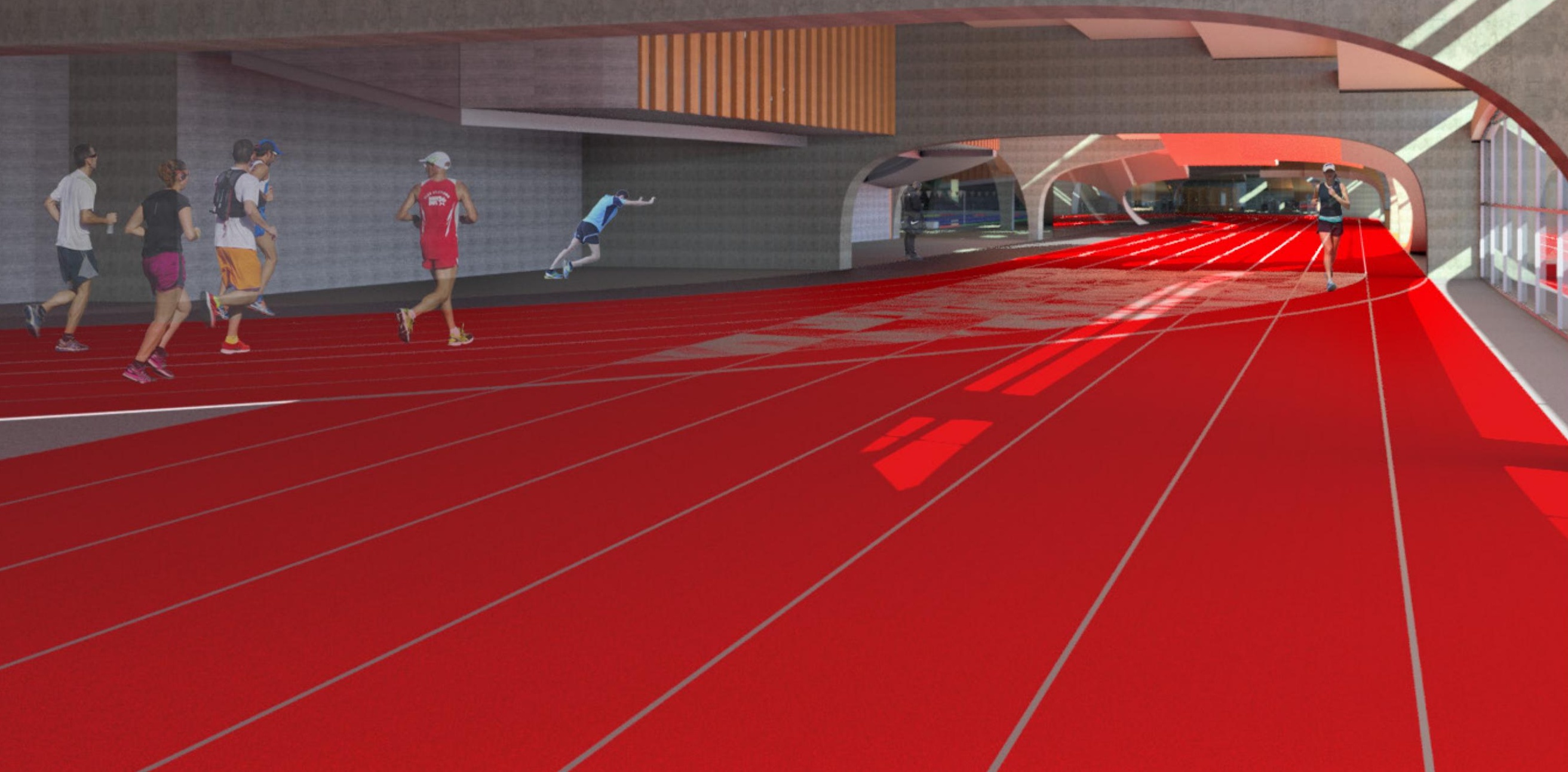




\section{The Running Track}

Fig. 199 Left: View from the 100m start-line towards the Library

Fig. 200 Right Top: View as the track bends around with view of the Library and Recovery Area

Fig. 201 Below: Axo of the Running Track, access is from the Warm Up Pool and Gym facilities.

Fig. 202.Bottom Right: View behind the Dive Pool and past the Athlete's Entrance
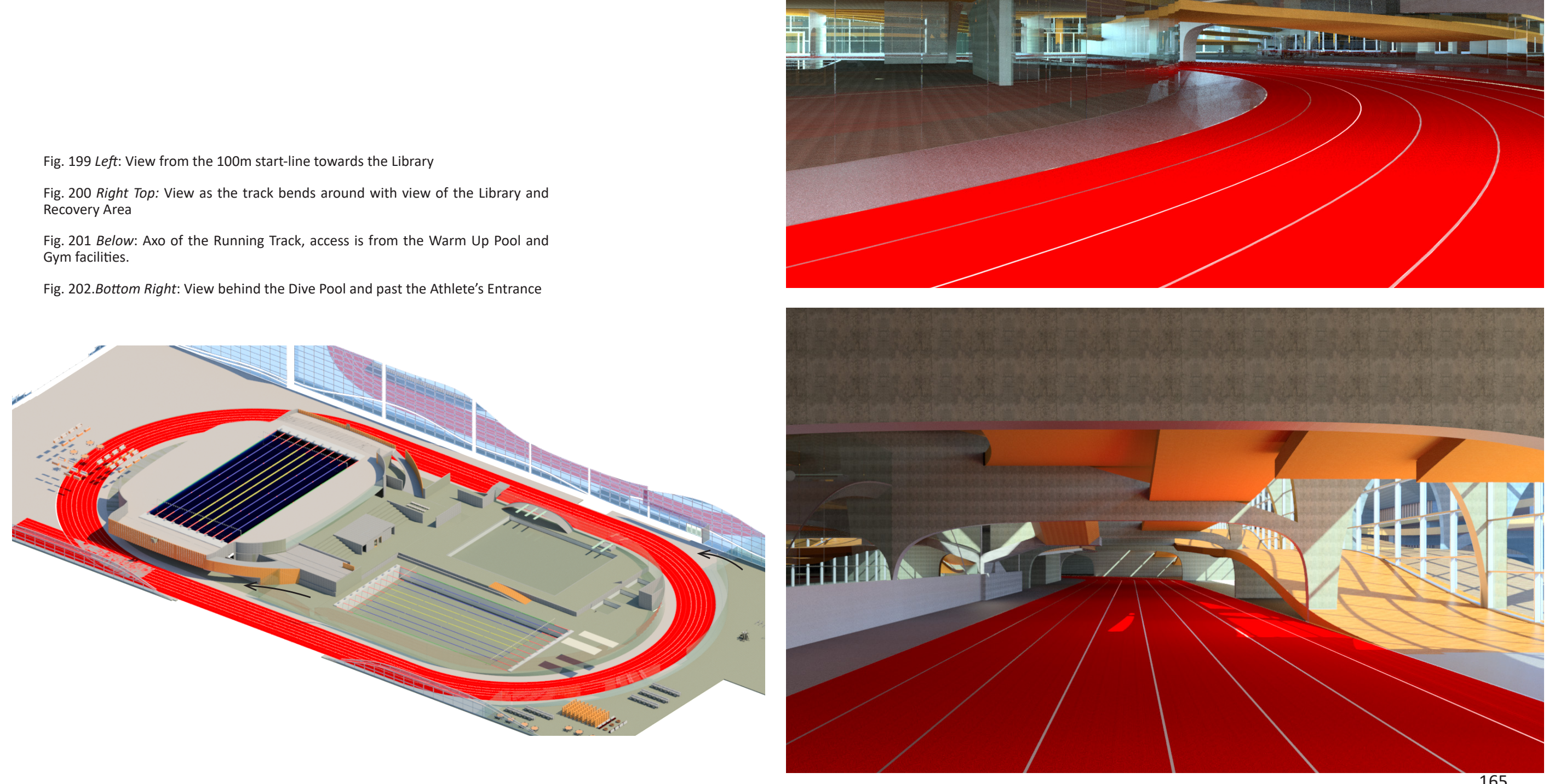


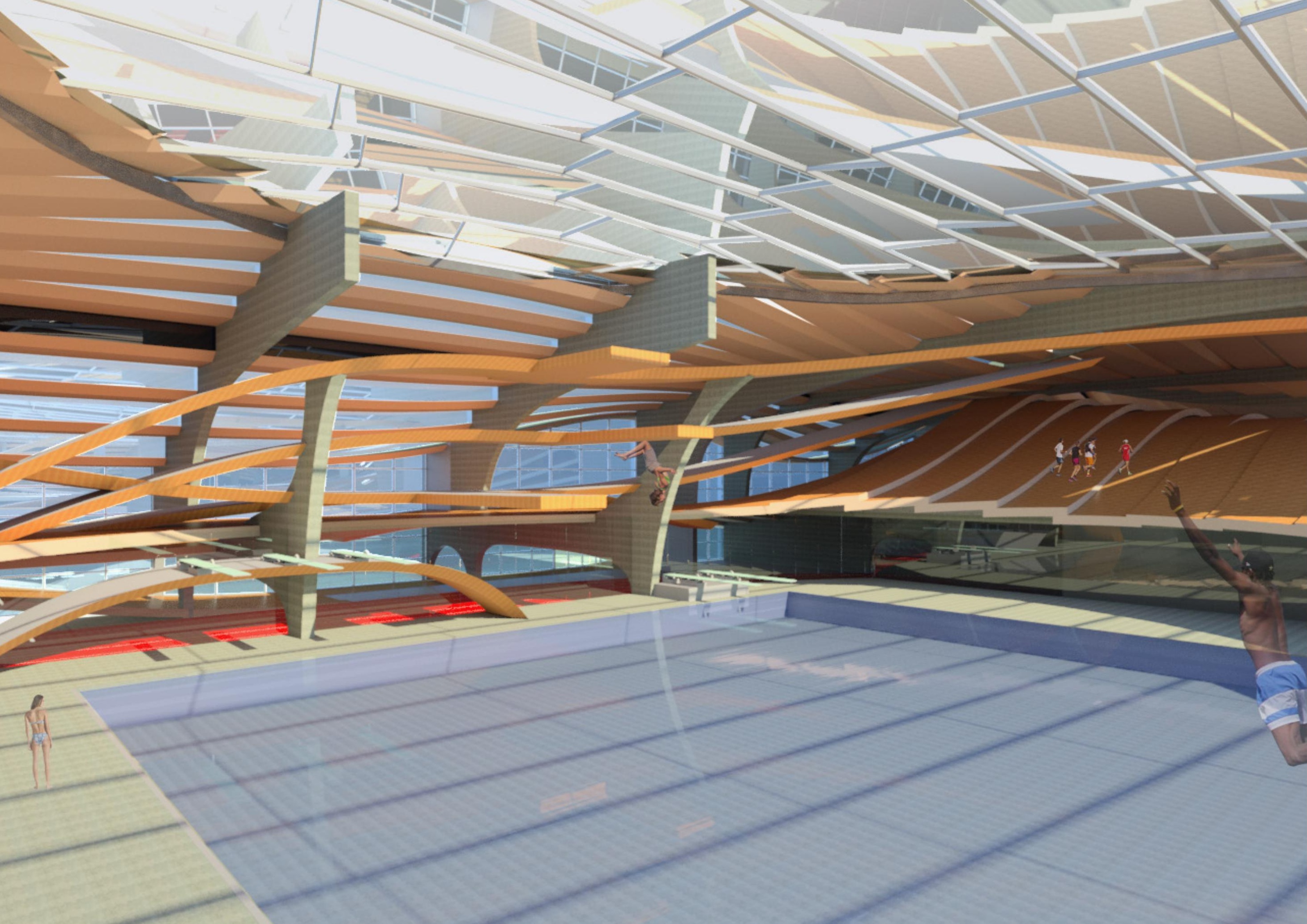




\section{Diving Pool}

Fig. 204 Left: View of the Diving Boards

Fig. 205 Right Top: View from the 10m Diving Platform across to the Atrium area

Fig. 206 Below: Axo of the Diving Pool

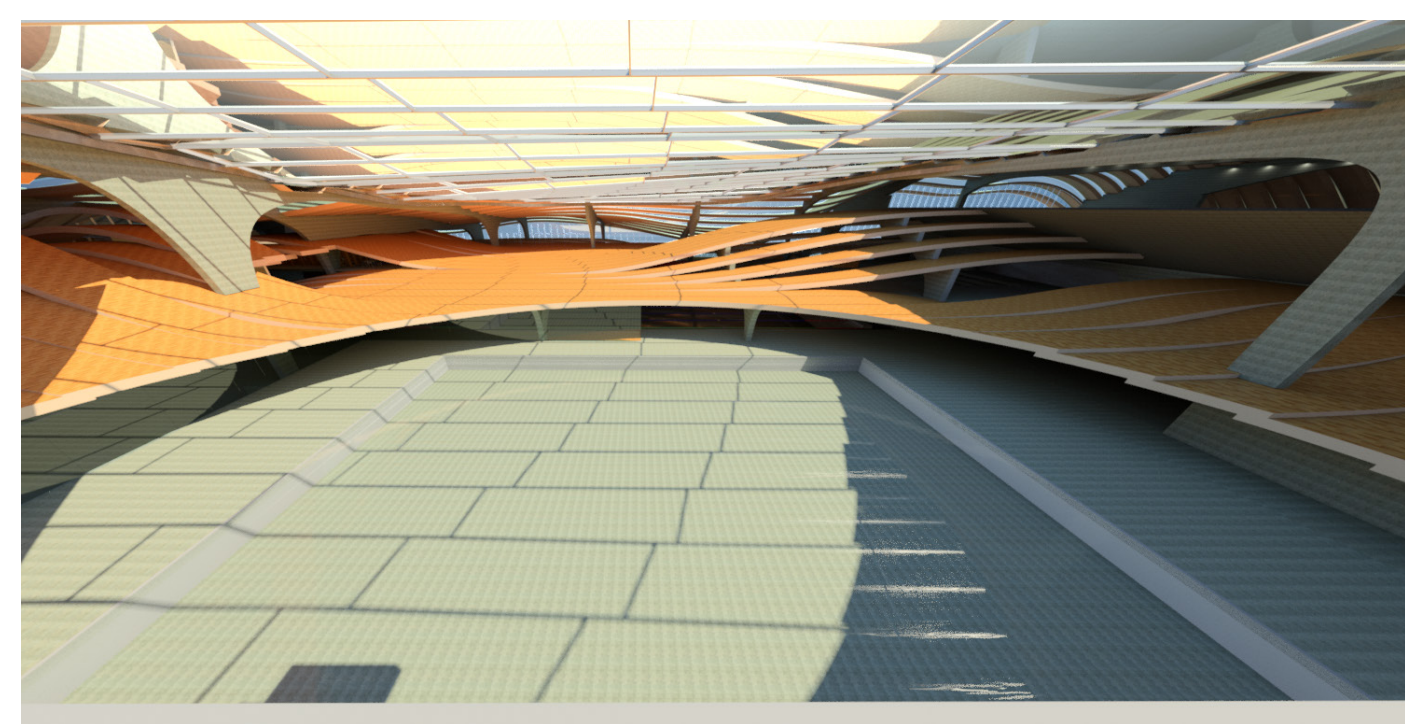

Fig. 207.Bottom Right: View below Diving Boards across the Dive Pool
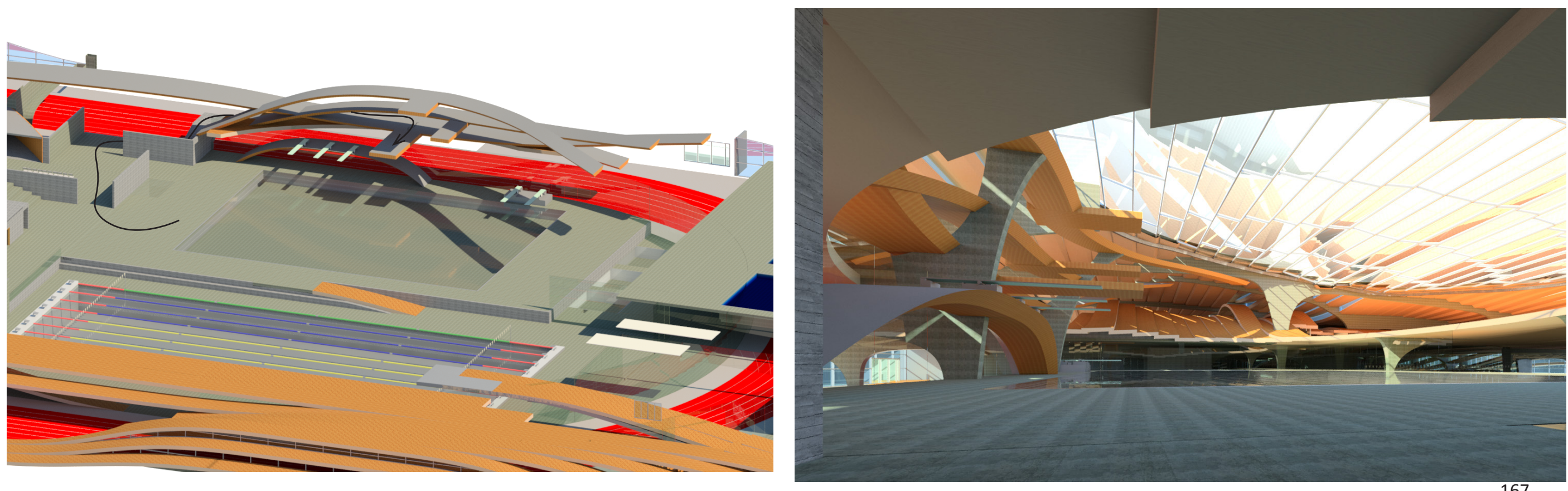


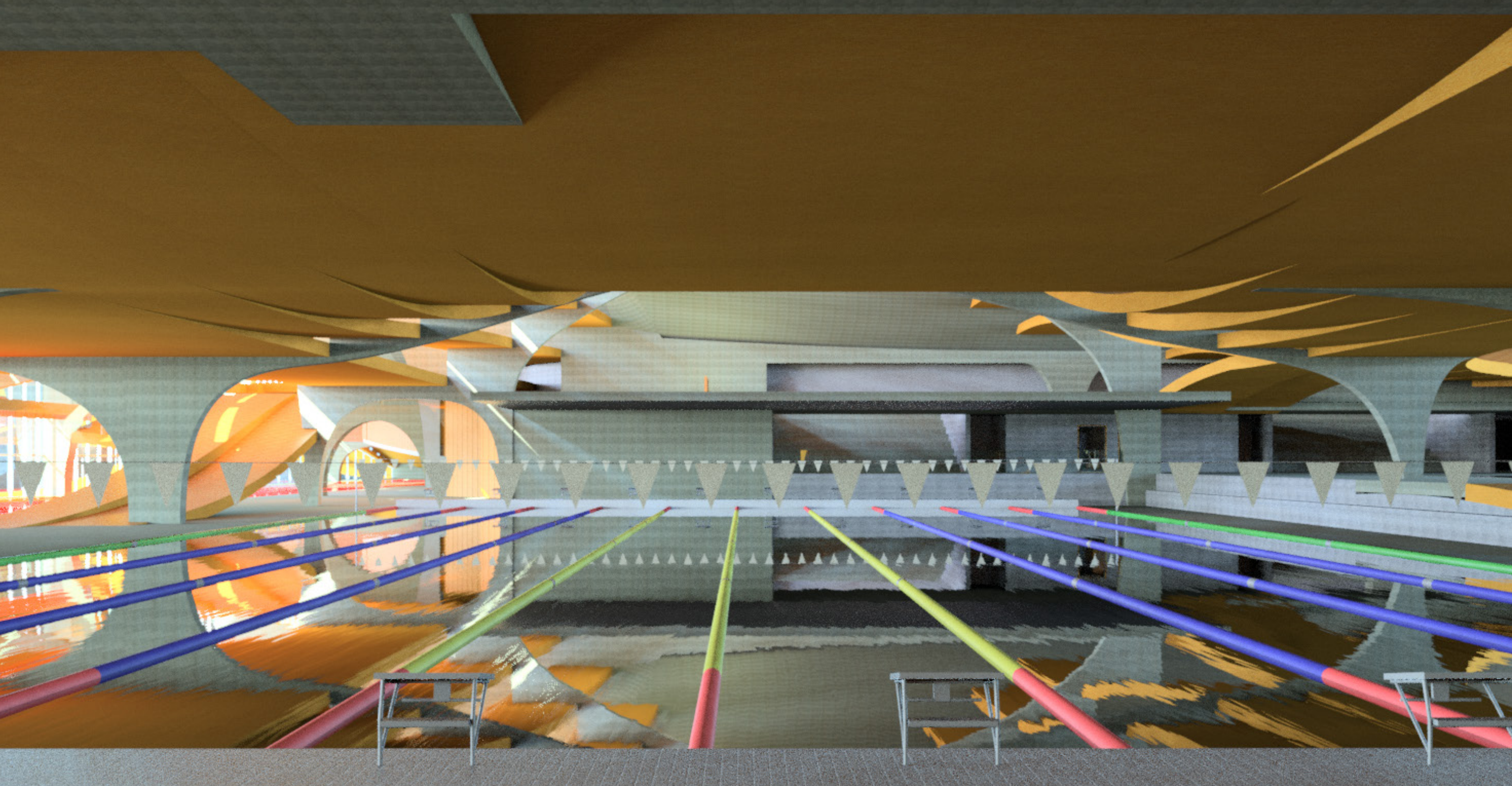




\section{Warm Up/Cool Down Pool}
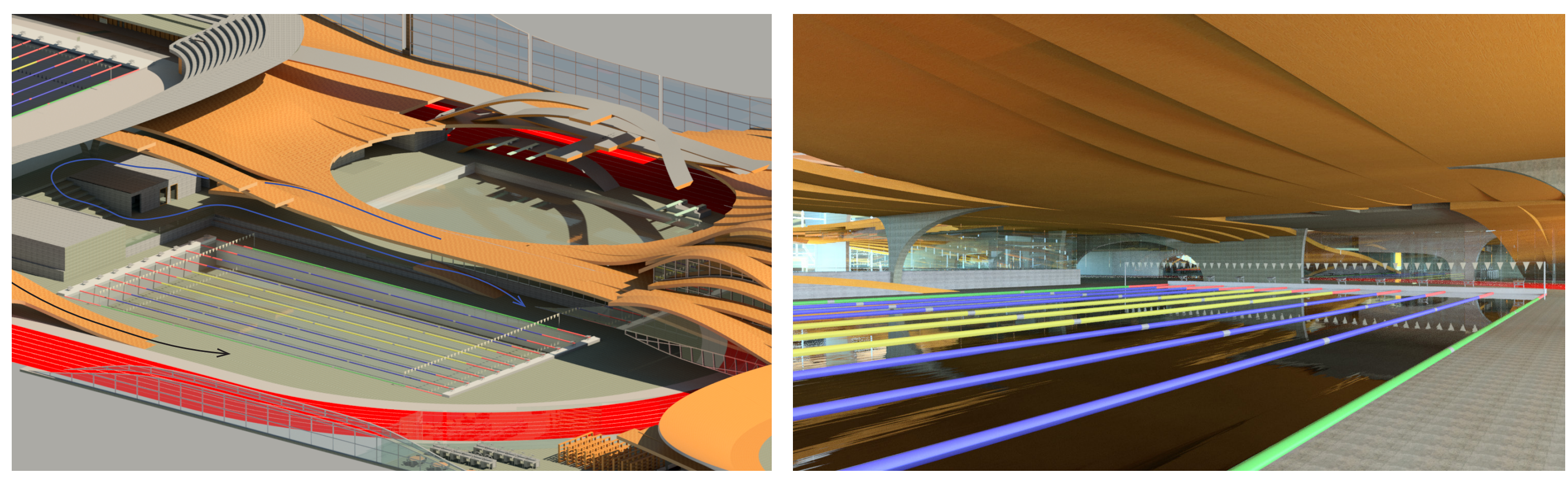

Fig. 208 Above: Axo of the Warm Up Pool.

This pool has also got a community focus when

competitions are not on. This dramatic space entices

people to swim and just like the athletes, it offers the

ability to relax and allows users to fully focus on their

swimming. Athlete's access(black) Public Access (Blue)

Fig. 210 Left: View looking towards the Last Words

Fig. 209 : View towards Recovery Area 


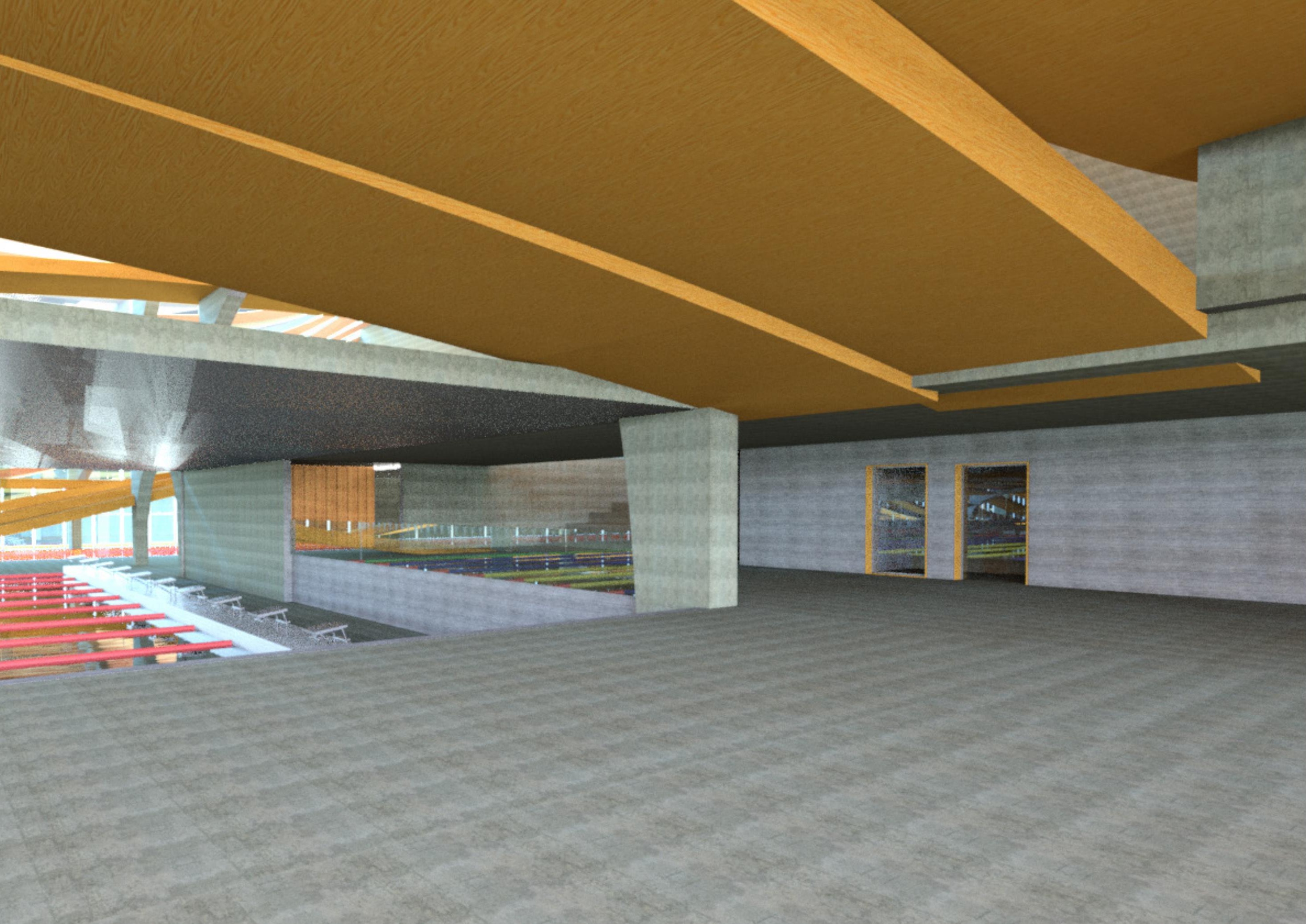




\section{Last Words (Coaches' Area) and Marshalling}

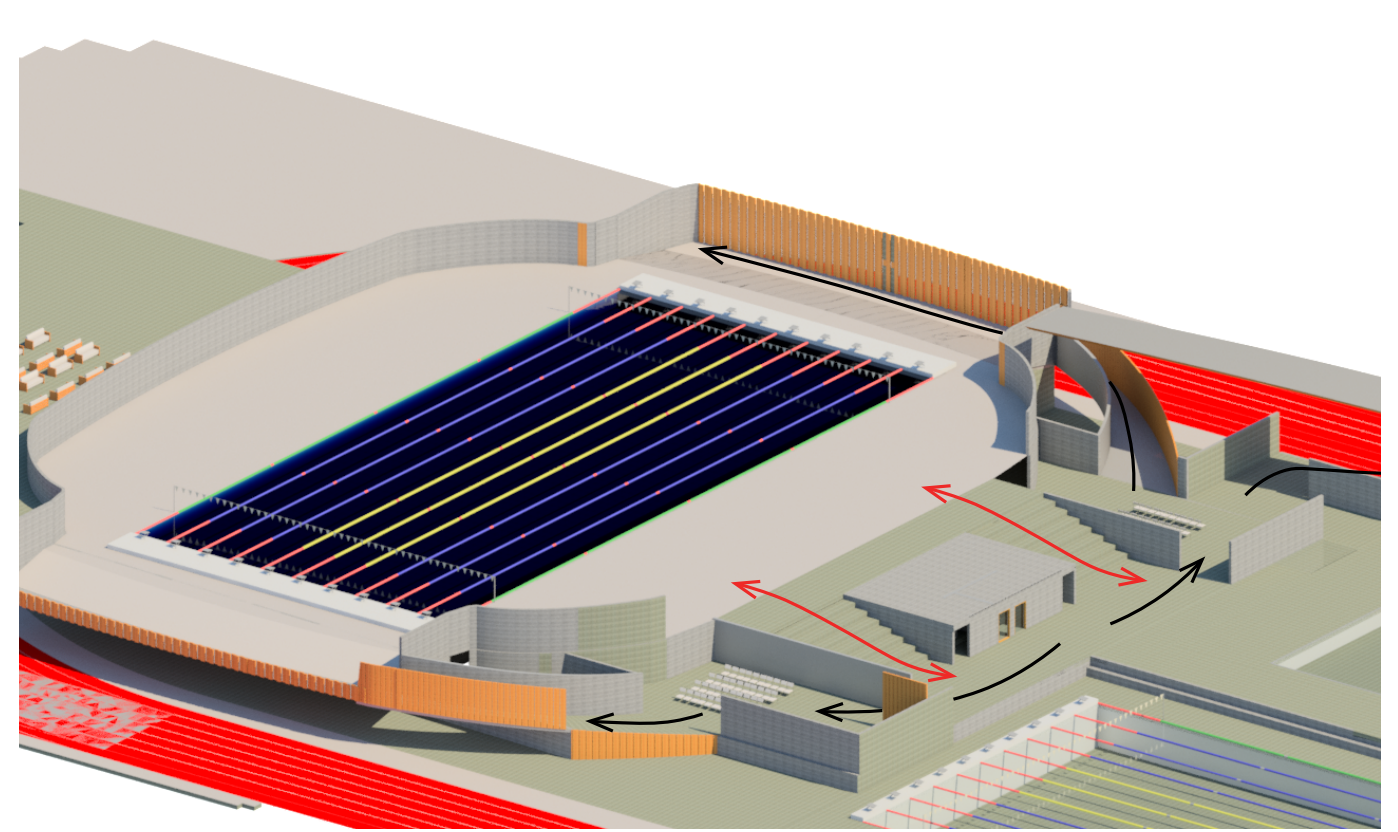

Fig. 211 Above: Axo of the Last Words and Marshalling area.

Coaches access between the spaces (Red), Athlete Movements (Black). There are two marshalling rooms one serves the East diving athletes to use the same atmospheric qualitions the swimmers. The other room seres the West end. This allows flexibility in the facility. Unlike the other projects, these rooms poll to enphas being deep in the individua zone of optimal performance.

Fig. 213 Left: View of the Last Words area

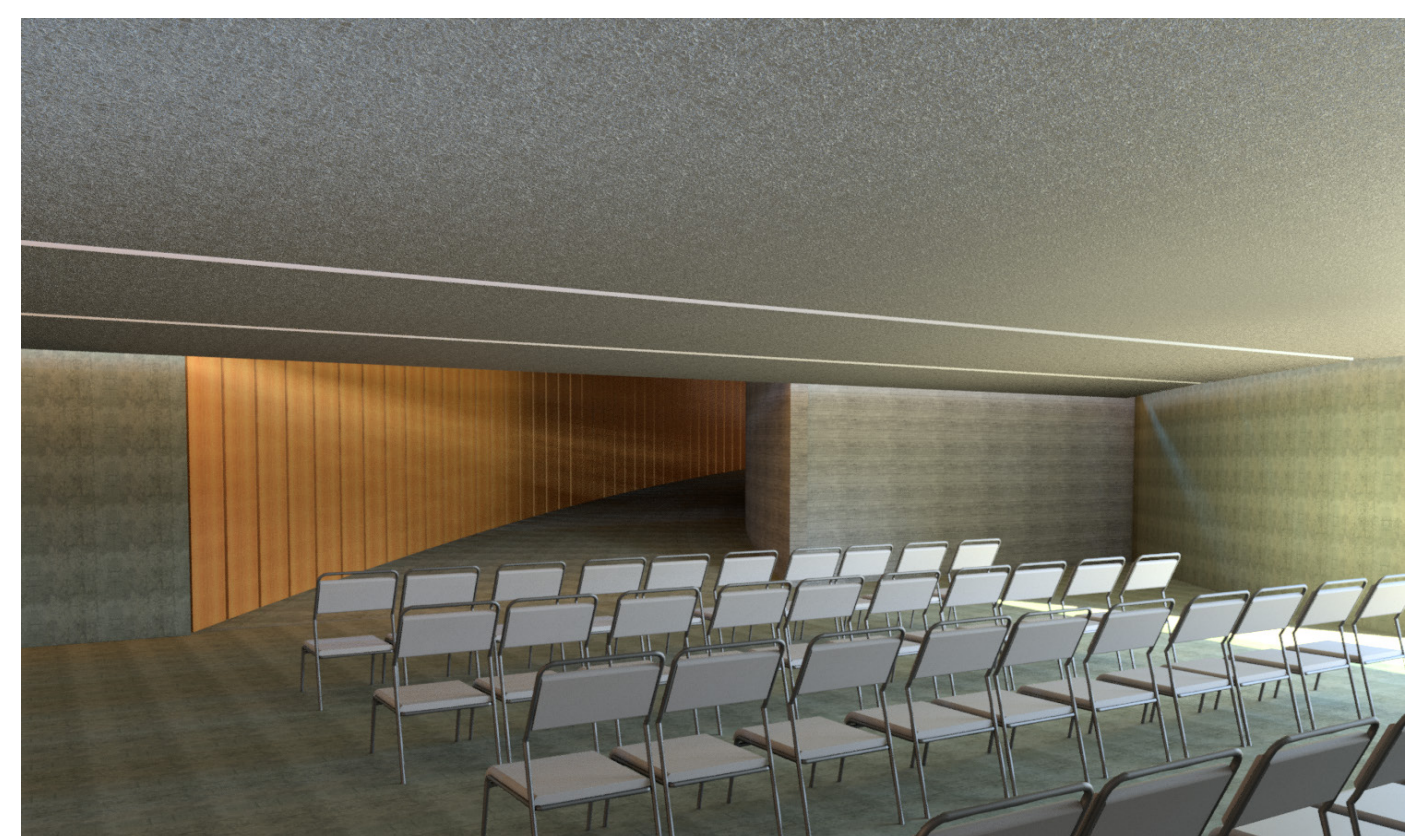

Fig. 212 : View of the West marshalling room towards the tunnel to the competition pool. Unlike Project One slopes up to celebrate the physical symbolic move of 'step up to the challenge' more. 


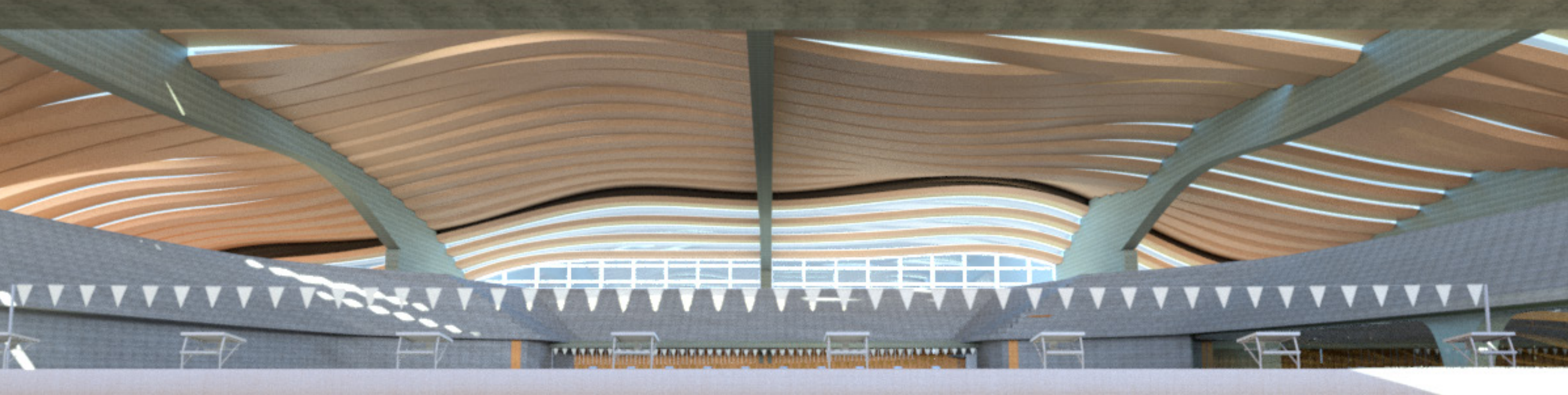




\section{Competition Pool}

Fig. 214 Left: View from behind the start blocks with the step up like Project One

Fig. 215 Right Top: View from the start blocks highlights the many lines across the pool and the wall edges meeting at the end of the pool

Fig. 216 Below: Axo of the Competition Pool

Fig. 217.Bottom Right: View behind the Dive Pool and past the Athlete's Entrance
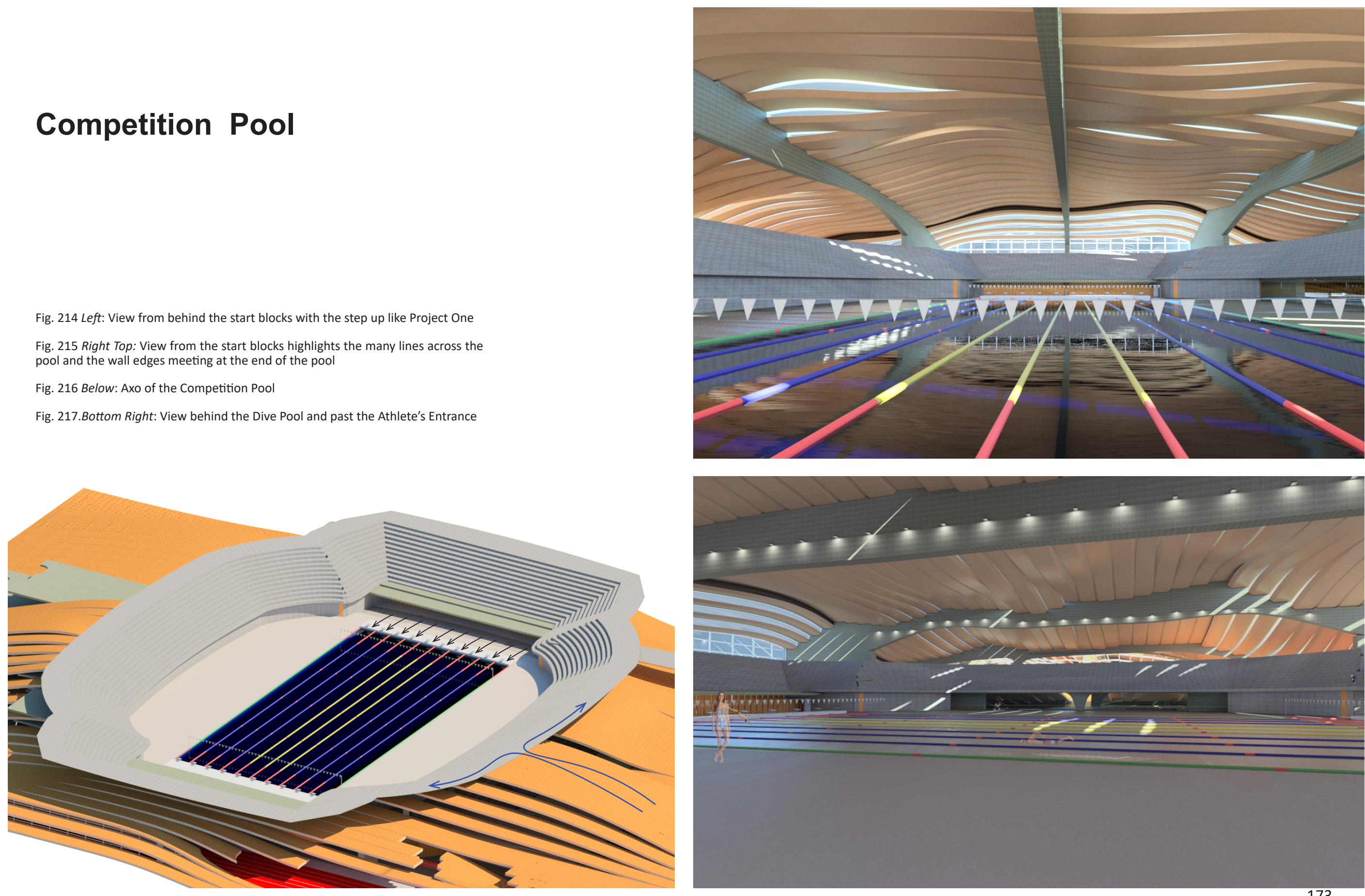


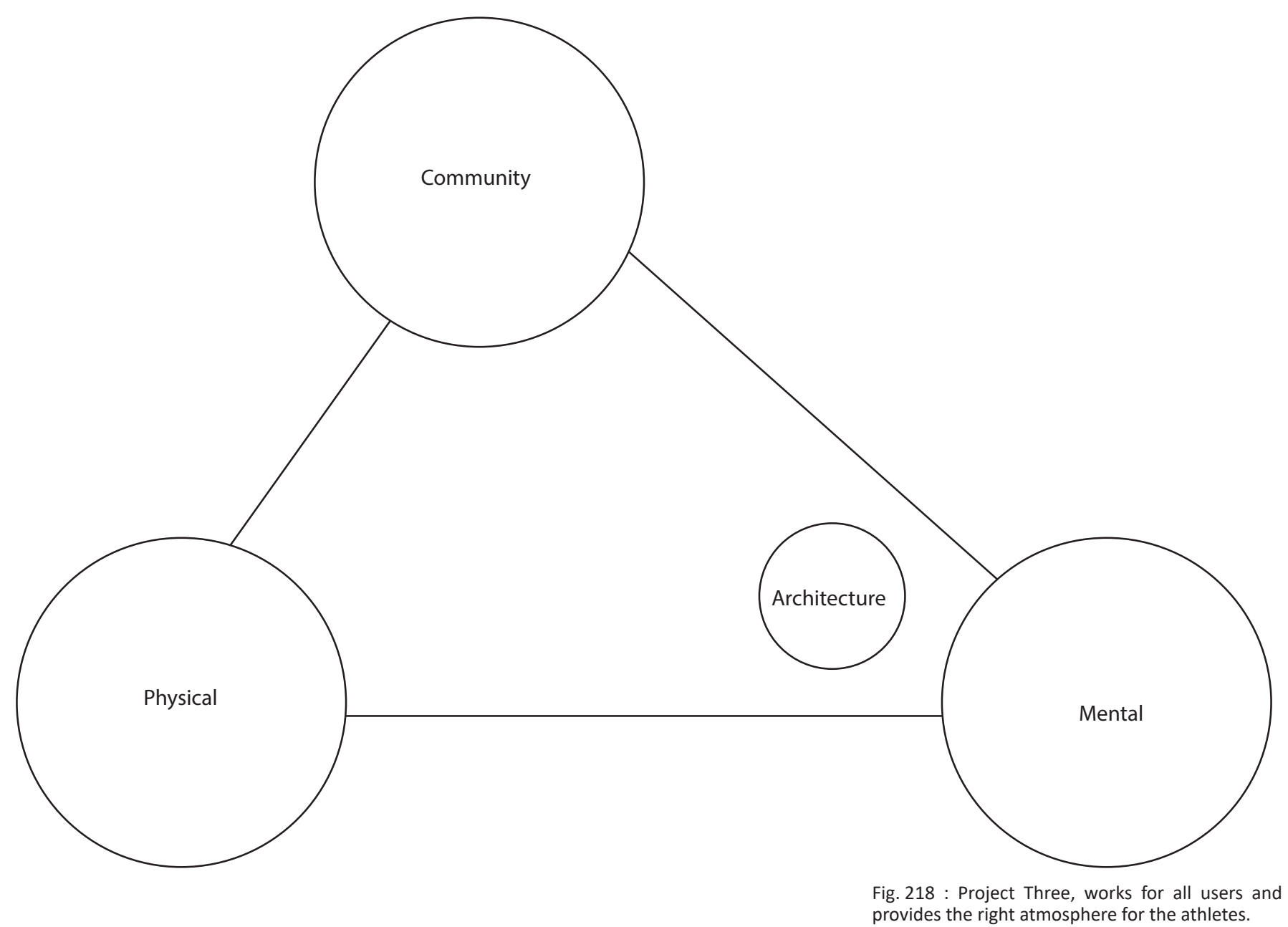




\section{PROJECT 3 DESIGN CONCLUSIONS}

The design of the building allows the community to inhabit the space as well as the High-Performance Athlete's to use the space without interruption by the public. The facility operates the right amount of interaction between spaces that not only allows athletes to train, but inspires future generations to be involved in the sport.

On the diagram of the connections between physical, mental and community attributes of the facility, the 'architecture,' I have located in the middle with a bias towards the mental aspect, as it works for all users during and out of competition.

Through this design investigation, the key finding is the use of the Atrium and the glimpses be-tween programs that occur, which make you curious as to what else is going on. The building's layout of a long approach ramp that walks you underneath the Velodrome and opening you up into a bright Atrium allows for investigation and research of each of the program.

The building is a success as it has taken the results of both Project One and Two, and added new insight into how each space could be arranged to optimise not only space, but the advantages that each program offers. This improves and increases not only the athlete's ability to train and schooling, but allows the community to be involved in the facility as well. 


\section{My Motivation}

The Project - The problem -

Research on problem-

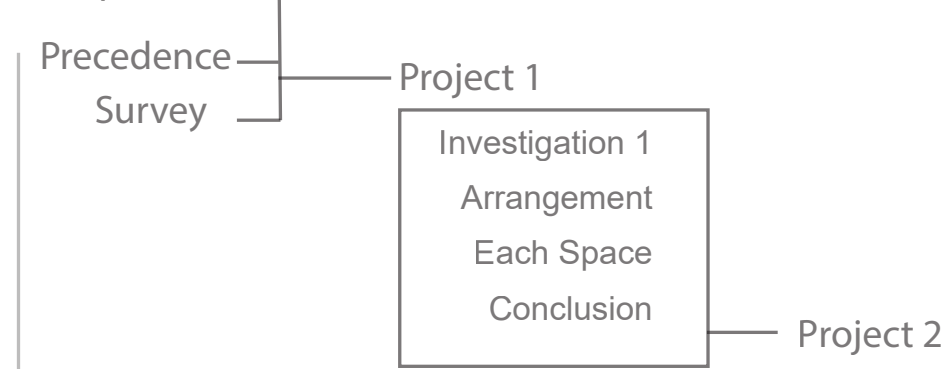

\section{Project 3}

Problem Generated from Project 1 and 2

My Motivation

Investigation 3

Arrangement

Each Space

Conclusion 


\section{FinAL CONCLUSION}




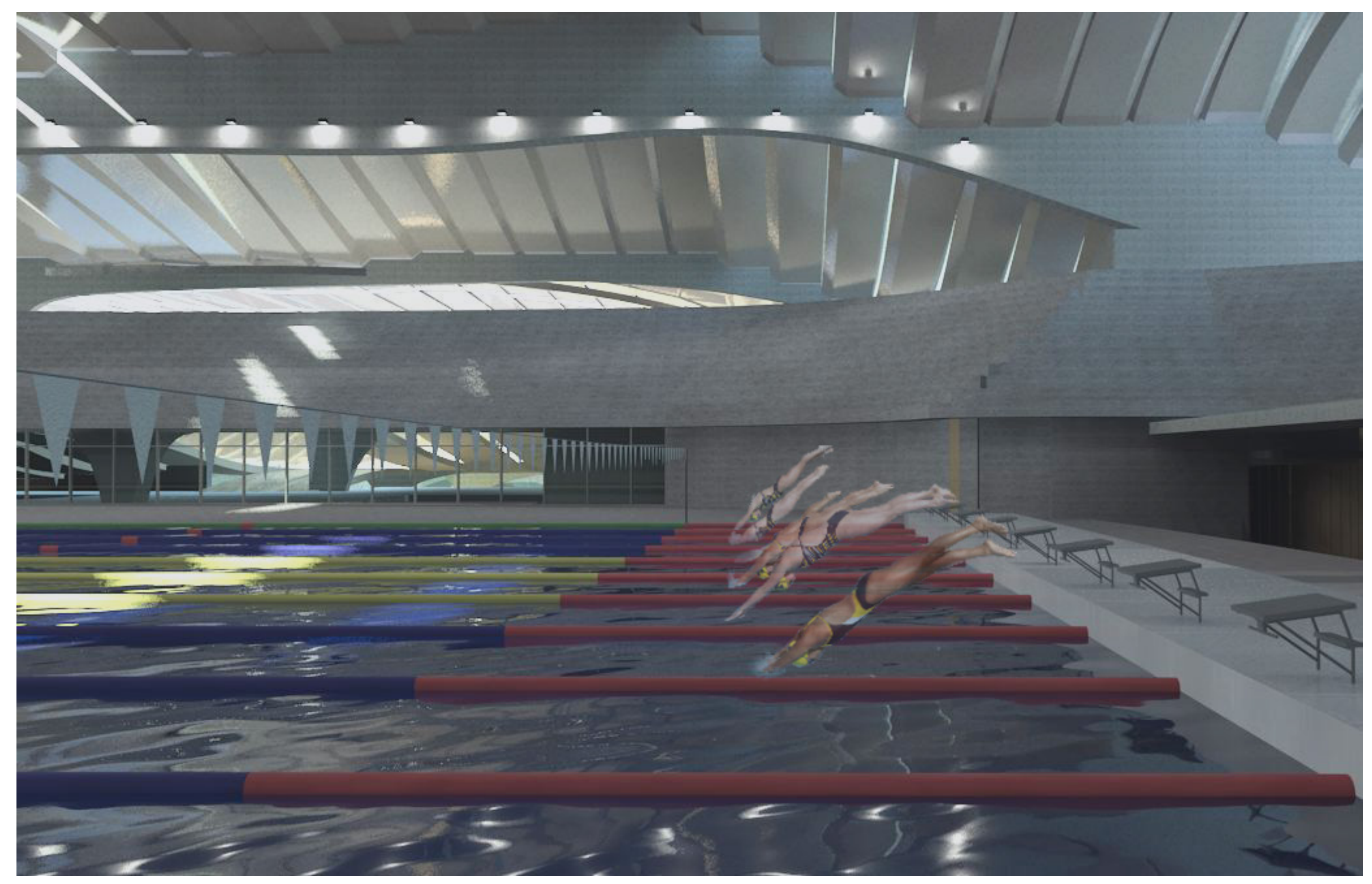




\section{Final Research Conclusions}

Architecture and sport both use emotions, but in different ways. Architecture creates emotion and sport uses it. As Ben Anderson states, architecture creates emotion through form, light and materiality. Hamin Yuri explains the effects that emotion can have on an athlete's performance and how it can be used to improve performance. These two factors have allowed the exploration of natatoriums and sports facilities to understand how architecture could be used to improve an athlete's mental state going into a race and therefore, having a higher chance of a successfu performance.

To design a facility based on an athlete's needs, the optimal way is with a simplistic and systematic approach which allows the processes of the athlete to be the hierarchy of design. Although athlete's have individual needs, a facility can't have individual routes for all. Spaces need to create an atmosphere that wil allow for the right emotions to be created at certain points in their build up. A series of interconnected spaces are required rather than one long journey. Through the three projects, this has been explored with different approaches and has allowed for different outcomes.

Solely designing for an athlete cannot be done. Consideration of other factors, like the needs of the spectators and the community needs to be carried out as these affect the usability of the space. To design these facilities with a response to site has meant allowances for public use outside of competition.

Though the community and spectators were not the focus of the projects, the outcomes have acknowledged them and due to this, an interesting relationship has occurred between the two programs. The atmospheres created have also allowed the public to experience the atmosphere, which has the potential to inspire them to try or investigate new activities. This therefore grows the sport at the amateur level.

Further investigation into the link between atmosphere and the athlete is needed, as this will allow for the development of better spaces and connections, resulting in the athlete entering their IZOP easier. As well as improving the outcomes of the facility's design, the athlete will also benefit from more consistent and successful performances.

There is potential for this type of facility, but a re-think of design process and program hierarchy will allow for these facilities to provide more than what they are intended to. Though these projects are on a large scale, there is potential for these conditions to occur in smaller facilities, or be adapted to current facilities, which will improve the overall quality of Aquatic Facility design.

Further consideration into these types of facilities would open pathways for the local community, spectators, and amateur athletes, as well as allowing the swimming to continue to grow and benefit athletes at an elite level of the sport to be better versions of what they already are. 


\section{BIBLIOGRAPHY}

Akihito Kamata, G. T. (2002). Individual Zone of Optimal Functioning (IZOF): A Probabilistic Estimation. Journal of Sport and Exercise Psycology, 189-208.

Anderson, B. (2009). Affective Atmospheres. Emotion Space and Society, 77-81.

ArchDaily. (2012, September 20). Clayton Community Centre / Jackson Architecture. Retrieved July 17, 2015, from ArchDaily: <http://www.archdaily. com/272354/clayton-community-centre-jackson-architecture/>

Bohme, G. (2006). Atmosphere as a subject matter. In Herzog and Meuron: Natural History (pp. 398 - 407). London: Lars Muller Publishers.

Broto, C. (2005). Architecture on Sports Facilities. Barcelona: 2005.

Claudio Robazza, M. P. (2004). Emotion self-regulation and athletic performance: An. Psychology of Sport and Exercise, 379-404.

COX Architecture. (2014). Gold Coast Aquatic Centre. Retrieved from Cox Architecture: http://www.coxarchitecture.com.au/project/gold-coast-aquatic centre/?discipline=architecture

DUFF, M. (2011, June 16). Critics throw cold water on pool study. Retrieved October 26, 2015, from Stuff - Dominion Post: http://www.stuff.co.nz/dominionpost/news/5149969/Critics-throw-cold-water-on-pool-study

Eichberg, H. (1993, June). New Spatial Configurations of Sport? Experiences from Dannish Alternative Planning. International Review for the Sociology of Sport, 28 245-262.

Federation Internationale De Natation. (2015). FINA Rules and Regulations. Retrieved May 16, 2015, from FINA (Federation Internationale De Natation): http://www.fina.org/sites/default/files/rules-print-pdf/8458.pdf

Hanin, Y. L. (2007). Emotions in Sport. In R. C. Gershon Tenenbaum, Handbook of Sport Psycology (pp. 38-57). Hoboken: John Wiley and Son Inc.

Lynette L. Craft, T. M. (2003). The Relationship Between the Competitive State Anxiety. Journal of Sport and Exercise Psycology, 44-65.
Michael. (2016, March 4). "If it isn't broke, don't fix it" - Tell that to Dick Fosbury. Retrieved from Mindmills Insights: https://blog.mindmill.co.uk/MindmillBlog/ post/if-ain-t-broke-don-t-fix-it-tell-that-to-dick-fosbury

PALLASMAA, J. (2014, July 1). Space, place and atmosphere. Emotion and peripherical perception in architectural experience. Lebenswelt: Aesthetics and Philosophy of Experience, 4, 230-245.

Queensland Government: Department of Housing and Public Works. (2014, July). Initial Assessment Report: Sleemans Sports Complex. Retrieved from State Development Queensland: http://www.statedevelopment.qld.gov.au/resources/ project/gc2018/ssc/gc2018-ssc-initial-assessment-report\%20for-publicnotification.pdf

Tom Dyckhoff, C. B. (2012). The Architecture of London 21012, Vission, Design Legacy. Chichester, West Sussex: John Wiley and Sons.

Yee, R. (2006). Sports and Recreational Facilities. New York: Visual Reference Publications, Inc. 


\section{LIST OF FIGURES}

All figures not attributed are authors own

Figure1: Right Yin Fu

Figure2: Left: Al Milligan Images

Figure3: Left: Reuters

Figure4: Left: The Author In Competition (Marathon Photos)

Figure5: Left: Dick Fosbury, (Getty Images)

Figure6: Intended Design Result, diagram of Physical focus vs Mental Focus of a facility

Figure7: Current Facilities, diagram of Physical focus vs Mental Focus of a facility

Figure8: Map of Thesis

Figure9: Crematorium Baumschulenweg by Shultes Frank Architeckten. Mattias Hamren

Figure10: Bath De Vaals by Peter Zumthor. Helene Binet

Figure11: Interactive effects of enhancing and harmful emotions. Adapted from:

Hanin, Y. L. (2007). Emotions in Sport. In R. C. Gershon Tenenbaum,

Handbook of Sport Psycology (pp. 38-57). Hoboken: John Wiley and Son Inc. 14

Figure12: Athlete's Process Timeline

Figure13: Left: Grant Faint Via Getty Images

Figure14: Left: Wellington Regional Aquatic Centre

Figure15: Top: WRAC Ground Floor Plan

Figure16: Left top: WRAC Entrance

Figure17: Right Top: WRAC Main Pool

Figure18: Left Bottom: Rear Entrance

Figure19: Right Bottom: Hydrotherapy Pool (HDT Architecture)

Figure20: Left: The London Aquatic Centre during its unveiling in July 2011 (Ben Sutherland - Flickr)

Figure21: Top: Ground Floor Plan(Zaha Hadid Architects)

Figure22: Left Top: Outside South (Red Dater)

Figure23: Right Top: Under Diving Boards (Hélène Binet)

Figure24: Left Bottom: Noth Plaza (Red Dater)

Figure25: Right Bottom: Warm Up Pool (Hélène Binet)

Figure26: Left: Sleemans Brisbane Aquatic Centre (Sleeman Sports Complex)
Figure27: Top: Ground Floor Plan (adapted from CaSSSA Diagram) 27

Figure28: Left Top: Main Entry

Figure29: Right Top: External Main Approach

Figure30: Left Bottom: Warm Up Pool

Figure31: Right Bottom: Main Pool Hall

Figure32: Main Competition Pool without temporary Stands (Ceramic Solutions)

Figure33: Gold Aquatic Centre during an event (Swimming Australia Ltd)

Figure34: Aquatic Centre From above (Cox Architecture)

Figure35: View Across Lap pool to Dive Platforms (Christopher Frederick Jones)

Figure36: Left: External render of project

Figure37: Thesis map, Project One

Figure38: Athlete's process and focus of design

Figure39: Connections of space through the athlete movements

Figure40: Athlete's progression through facility mapped against intensity of emotions

Figure41: An exploration of an athlete's progression mapped vertically and spatially.

Figure42: Pool arrangement exploration vs axis and form of the facility

Figure43: Axis analysis of precedents, from Left: London Aquatic Centre, Brisbane Aquatic Centre, WRAC

Figure44: Aerial view

Figure45: Approach from the Competition Pool end

Figure46: Approach from the Entrance end

Figure47: Top: Earth Race Boat has a streamlined design (Pam-Flickr)

Figure48: Bottom: Wally Power Boat is wider and heavier looking (Walley Design)

Figure49: Left: Entrance render with view towards the Competition Pool

Figure50: Right: Axo of Entrance pathway

Figure51: Left: Athlete's Lounge looking from Entrance

Figure52: Right: Athlete's Lounge looking towards Warm Up Pool.

Figure53: Axo of Athlete's Lounge. 
Figure54: Left: Axo of the Warm Up Pool, arrows describing the athlete's path

Figure55: Right: Warm Up Pool render looking towards back in the direction of the Athlete's Lounge

Figure56: Left: Axo of the Last Words area, black arrows describing athlete's path and red describing the coaches.

Figure57: Right: Warm Up Pool render looking towards the direction of the Athlete's Lounge

Figure58: Axo of the Marshalling rooms, black arrows describe athlete's path

Figure59: Marshalling room looking towards the path to the Competition Pool

Figure60: Marshalling room looking down the path to the Competition Pool

Figure61: Top: Tunnel from Marshalling to behind Start Blocks

Figure62: Bottom: Diagram of precedents

Figure63: Right: Approach to Start Block

Figure64: Left: Axo of the Competition Pool

Figure65: Right: Rendered image of the Competition Pool

Figure66: Left: Rendered image of Competition Pool Hall from spectator's view

Figure67: Right: Experimentation with pool hall forms

Figure68: Project One Ground Floor Plan

Figure69: Project One First Floor Plan

Figure70: Section A-a - Long Section

Figure71: Section B-b - Warm Up Pool

Figure72: Section C-c - Competition Pool

Figure73: Project One architecture favours the mental qualities rather than the physical

Figure74: Left: Project Two building exterior looking towards Evans Bay

Figure75: Thesis map, Project Two

Figure76: Left: View across Kilbirnie Park to WRAC and Poneke Rugby Club Rooms.

Figure77: Top Right: WRAC rear entrance

Figure78: Right: Rec-centre and Library

Figure79: Bottom Right: View of access to Kilbirnie township

Figure80: Site(Green) in relation to the Airport (Dark Blue) and the City (Light Blue)

Figure81: Key site approaches

Figure82: Key cycle and walkway

Figure83: Key elements on Site

Figure84: Movement through site
Figure85: Sports facilities (Orange), Sports fields(Green)

Figure86: Community Facilities-Yellow

Figure87: First floor plan of the initial response

Figure88: Top: Initial design building foot print

Figure89: Bottom: Space the addition would take up

Figure90: Above: Cayton Community Centre (Jackson Architecture)

Figure91: Top Left: Exterior View (Archiphoto Pty Ltd)

Figure92: Left: Library (Archiphoto Pty Ltd)

Figure93: Bottom Left: Fitness club over looking the swimming facilities (Archiphoto Pty Ltd)

Figure94: Finding the axis

Figure95: Responding to the local

Figure96: Building program arrangement

Figure97: Vertical arrangement of program

Figure98: Split and Lift of the ground diagram

Figure99: Section of the terraced roof

Figure100: (Satoru Mishima / FOA)

Figure101: (Cristiano Mascaro)

Figure102: (Author 2015)

Figure103: Section of the roof cut out

Figure104: Roof Cut Out Diagram

Figure105: From Kilbirnie

Figure106: From Evans Bay

Figure107: From the City

Figure108: Approaching the facility

Figure109: Axo of the exterior form

Figure110: Exploded Axo of the design showing the interior layout.

Figure111: Ground Floor Plan

Figure112: Long Section A-a

Figure113: Section B-b-Competition Pool

Figure114: Section C-c- Warm Up Pool

Figure115: Section E-e - Rec-Centre and Library

Figure116: Section D-d- Dive Pool 
Figure117: Exploded Axo - Community Programs

Figure118: Entry Axo

Figure119: Interior view of entry looking toward Children's Poo

Figure120: Exterior view of entry

Figure121: Above: Axo of Children's Pool.

Figure122: Left: Rendered view of Children's Pool looking towards the Dive Pool

Figure123: View of Spa (Left in image) spectator ramp going up and ramp to Rec-centre going down (Right) Rec-centre in the back ground

Figure124: View back across Children's Pool

Figure125: Above: Axo of the Library

Figure126: Left: Rendered view of the bottom floor of the Library.

Figure127: Level 2 of Library looking toward Children's and Dive Pools

Figure128: Level 2 of Library looking toward the Library stairs

Figure129: Left: Rendered View of the Rec-centre from entrance

Figure130: View of Rec-centre towards basketball court

Figure131: View towards public entry

Figure132: Axo of the Gym

Figure133: Rendered view of the Gym from entry point

Figure134: Level 1 of Gym looking to the exterior

Figure135: Axo of the Hydrotherapy Pools

Figure136: View of the Hydrotherapy Pools from entry point

Figure137: View back to entry point

Figure138: Exploded Axo- Athlete Programs

Figure139: Axo of Athlete's Lounge

Figure140: Athlete's Lounge over looking the Warm Up Pool

Figure141: Above: Axo of the Diving Pool

Figure142: Left: Rendered View of the Diving Pool view from Children's Pool. This pool can also be used for Water Polo competitions

Figure143: View towards diving platforms

Figure144: Axo of the Warm Up Pool.

Figure145: Left: Rendered view of the Warm Up Pool towards the Dive Pool

Figure146: View towards the Competition Pool

Figure147: Above: Axo of the areas.

Figure148: Right Top: Rendered view of the Last words (Coaches area)

Figure149: Right Bottom: View of the Marshalling area

Figure150: Approach to start blocks from Marshalling area

Figure151: Above: Axo of the Competition Pool.

Figure152: Left: Rendered view of the Competition Pool from behind the start blocks

Figure153: View towards the Last Words area

Figure154: Exploded axo of spectator movements

Figure155: Series of images describing the ramp up to the spectator seating for the Competition Pool.

Figure156: Project Two, architecture favours the community and physical qualities of rather than the mental

Figure157: Left: View of Project 3 from Poneke Rugby Club Rooms 127

Figure158: Thesis map, Project $3 \quad 128$

Figure159: Individual program forms 132

Figure160: Experimenting with the arrangement of program forms 134

Figure161: Brazilia By Osaczr Niemeyer (gary yim) 135

Figure162: East view showing the forms 136

Figure163: Section showing the forms 136

Figure164: Arrangement of Form 137

Figure165: Above: Overall building form on site 139

Figure166: Left: Approach from North-West corner of Kilbirnie Park 139

$\begin{array}{ll}\text { Figure167: Exploded Axo of structure } & 140\end{array}$

Figure168: Exploded Axo of program 141

Figure169: Ground Floor Plan 143

Figure170: First Floor Plan 145

Figure171: Section A-a - Long 147

Figure172: Section B-b-Competition Pool 148

Figure173: Section C-c- Warm Up Pool 148

Figure174: Section D-d- Dive Pool 149

Figure175: Above: Axo of the public entry 151

Figure176: Left: Rendered exterior view of entry 151

Figure177: View up the access ramp towards the atrium. 151

Figure178: View of the entry into the atrium from the access ramp 151 
Figure180: Left: View of the Atrium towards the dive boards

Figure181: View back towards the entry over the Dive Pool

Figure182: Diagram of Atrium explaining its ability show different programs as you pass

$$
\text { through to another. }
$$

Figure183: Axo of Hydrotherapy Pool

Figure184: View of Hydrotherapy Poo

Figure185: Axo of the Learn to Swim Pool

Figure186: View of the Learn to Swim

Figure187: Above: Axo of the Library, access is from level 1 and is extended down to the ground level through its own ramps.

Figure188: Left: Rendered view of the ground floor of the Library.

Figure189: View of level 1 of the Library

Figure190: Above: Axo of the gym.

Figure191: Left: View up to the Velodrome

Figure192: View of the gym under the Velodrome

Figure193: Above: Axo of the Athlete Entry.

Figure194: Left: Exterior view of the Athlete Entrance

Figure195: View towards the Athlete's Lounge

Figure196: Left: View of the Velodrome from the track

Figure197: Right: Axo of the Velodrome.

Figure198: Below: View of the Velodrome from a spectators view.

Figure199: Left: View from the 100m start-line towards the Library 165

Figure200: Right Top: View as the track bends around with view of the Library and Recovery Area 165

Figure201: Below: Axo of the Running Track, access is from the Warm Up Pool and Gym facilities. 165 Figure202: . Bottom Right: View behind the Dive Pool and past the Athlete's Entrance 165 Figure203: Left: View of the Diving Boards

Figure204: Right Top: View from the 10m Diving Platf

Figure206: .Bottom Right: View below Diving Boards across the Dive Pool 167

Figure207: View towards the Last words area 167

Figure208: Above: Axo of the Warm Up Pool. 169

Figure209: Left: View looking towards the Last Words area 169
Figure210: View towards Recovery Area 169

Figure211: Above: Axo of the Last Words and Marshalling area.

Figure212: Left: View of the Last Words area

Figure213: View of the West marshalling room towards the tunnel to the competition pool. Unlike Project One slopes up to celebrate the physical symbolic move of 'step up to the challenge' more.

Figure214: Left: View from behind the start blocks with the step up like Project One

Figure215: Right Top: View from the start blocks highlights the many lines across the pool and the wall edges meeting at the end of the pool

Figure216: Below: Axo of the Competition Pool

Figure217: . Bottom Right: View behind the Dive Pool and past the Athlete's Entrance

Figure218: Project Three, works for all users and provides the right atmosphere for the athletes. 174

Figure219: Left: Swimmers diving into Project 3 Competition Pool 179

Figure220: Sir Owen Glen National Aquatic Centre Pool Hall (Mark Scowen, Intense Photography)

Figure221: Exterior of Faclity (INTENSE PHOTOGRAPHY)

Figure222: Pool Hall (North Harbour Synchronised Swimming Club)

Figure223: Pool Hall from Grandstand (Unex Systems)

Figure224: Beijing Aquatics Centre Competition Pool Hall (Daily Mail Australia)

Figure225: Floor Plans and Sections (moreAEdesign)

Figure226: Water Cube at Night (PTW Architects) 
APPENDICES 


\section{APPENDIX 1}

\section{Sir Owen Glenn National Aquatic Centre}

This is the premiere aquatic facility in New Zealand. Completion of the project was in late 2015. It was originally built for a bid for the 2018 Commonwealth Games. This facility is the home of Swimming New Zealand and their high-performance swimming squads.

The facility has a deep-water pool that is consistent in depth. It is designed to the Olympic standard which New Zealand was lacking in a facility. It portrays a classic layout with one Pool Hall that houses both the Warm-Up Pool and Main Competition Pool.

In relation to other buildings analysed in this thesis, this building does not have what is required to develop swimming in New Zealand on a global stage. It is believed that swimming is going to continue to develop as a sport in New Zealand, and as a nation, there is no current facility that inspires future generations to take on the sport or attract high-profile swimming competitions in New Zealand.

Fig. 220 : Sir Owen Glen National Aquatic Centre Pool Hall (Mark Scowen, Intense Photography) 


\section{APPENDIX 2}

\section{BEIJING Aquatic Centre - "WATER CUBE"}

The Beijing Aquatic Centre hosted the 2008 Olympic games where it created interest around its architectural form. This is where the design of the Olympic aquatic facility had to make a statement alongside the Iconic Bird's Nest Stadium. The building was influential in design through the revolutionary use of EFT as the main facade and the honey comb structure engulfing it. This building is a true testament to how the design of a facility can attract people to use it.

Fig. 224 : Beijing Aquatics Centre Competition Pool Hall (Daily Mail Australia) 


\section{APPENDIX 3}

\section{Survey Results Summarised}

I conducted anonymous survey of swimmers that race in national events and higher.

The results concluded what was my research had been saying about atmosphere and the way an athlete will look at it. I found that it was individual preferences that would have the biggest impact.

The results

What kind of environment will help you mentally prepare for a race the best, When:

Waiting to race and warm up? E.g. quiet and calm or loud and excited

The majority of respondents wanted a loud and excited space to warm up

There were a few that wanted a space that is loud but calm

"Loud and exciting atmosphere, to get you pumped up and ready to race"

“before warm up i don't mind if it is a bit loud as it helps me relax a bit and not feel so much pressure but before the race it is best when it is calm as that enables me to focus on what ineed to do during my race properly."

During marshalling up to start blocks?

Most people wanted a quiet and calm space in marshalling but walking up to the start blocks They wanted it to get more excited

"Quiet and calm so its easy to focus"

"Quite in marshalling but loud and exciting walking up to the blocks"

"In marshalling i prefer it when there is not so much noise as it enables me to focus properly. The temperature of the room is also very important, not to hot or cold!"

Interesting comment: "in marshalling i prefer it when there is not so much noise as it enables me to focus properly. The temperature of the room is also very important, not to hot or cold!"

During a race?

The majority of people wanted an atmosphere that was loud bright and exciting

Some commented on physical qualities of the pool.
Where would you feel you would race faster out of these two facilities below? Based on visual appeal I showed them to Images of two different facilities. Facility A was Wellington regional Aquatic Centre B was London Olympic Aquatic Centre. The majority ( $88.5 \%$ ) of respondents chose the Aquatic Centre, B was London
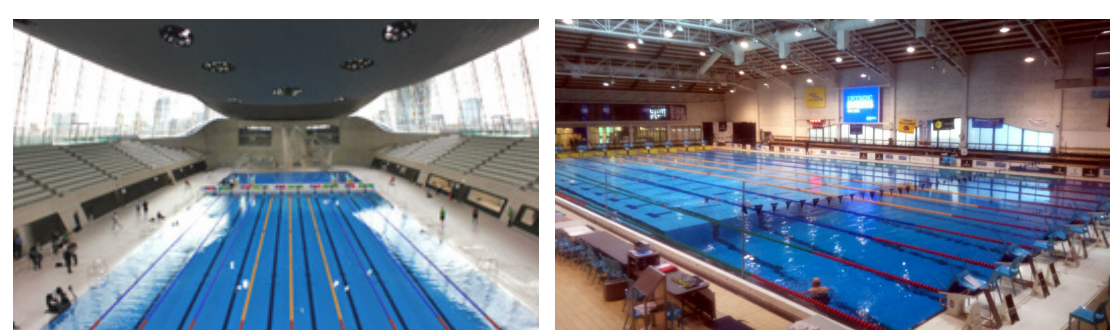

Besides the standard visual cues like end of lane $T$ and the $5 \mathrm{~m}$ flags. What aspects of a pool design help you to feel like you will swim faster before a race? i.e. long or short perspective of the pool, layout, where you enter the pool hall

Most people wanted a short perspective of the pool but a large pool hall. "Short perspective of the pool. Large pool hall, feels less enclosing"

Short perspective of the pool, less colours and objects taking my attention away from the

\section{A lower roof so it doesn't seem so long and big}

Short perspective of pool, large blocks, short entry to blocks from marshalling

Short looking pool, good view from entrance

Besides the standard visual cues like end of lane $\mathrm{T}$ and the $5 \mathrm{~m}$ flags. What aspects of a pool design help you feel like you are swimming faster? i.e change in pool depths, horizontal lines, intensity of ligh down a bit

The pool depth makes a difference, as the pool gets deeper $i$ feel as though $i$ am slowing

A consistently deep pool and when doing backstroke, it is always nice for there to be a line/ beam on the roof to follow to make sure you go in a straight line 
Changing depth! It's awesome! I have goals to work towards. Also, shiny dark tiles mean that I can see my silhouette while racing and if its a long race that can help me motivate myself and correct my stroke as necessary. Lighting should be bright so as to not feel sleepy

more

Change in pool depths breaks up a 50m lane which is nice. Bright lights also help me focus

Black on white tiles are easier to see while you are racing. The roof of a swimming pool can't be too complex as it makes it hard to swim in a straight line while doing backstroke (it's hard to do good backstroke at a pool like the new one at Raumati). fewer lines on the bottom of the pool are better

Do you have any comments you would like to share, that may help me design an optimal facility?

- $\quad$ Please make sure the vibe is still friendly... the thing I LOVE about wrac at the moment is that when you're there with your team, you're all together supporting each other so when designin "an optimal facility" please make sure that crowds are still involved with the race so that you still get that team atmosphere... I also love how the seats are quite close together because that also keeps that team spirit

ceilings! They make or break the building! If it is a cool design that has lines you can follow when swimming backstroke that would be ideal.

- consistent pool depth, built for a specific purpose (racing) not a multi purpose facility trying to cater to too many groups, ie no ramps into the pool, proper jet placement to avoid a current or disadvantage/effect certain lanes

\section{Findings}

The majority of respondent aligned to the research and the way I analysed the precedents. The keys aspects are:

Warm up and support area are team focused

The ability to go to a quite space to warm up

The marshalling area is where swimmers want peace to allow them to get into their zone

At start blocks to be loud for warm ups

Ceiling has to be interesting but simple

Pool same depth but changing

Consistent temperature

A quality designed facility 